DOC.20041108.0002

QA: QA

ANL-WIS-MD-000005 REV 02

November 2004

\title{
Features, Events, and Processes: Disruptive Events
}

Prepared for:

U.S. Department of Energy

Office of Civilian Radioactive Waste Management

Office of Repository Development

1551 Hillshire Drive

Las Vegas, Nevada 89134-6321

Prepared by:

Bechtel SAIC Company, LLC

1180 Town Center Drive

Las Vegas, Nevada 89144

Under Contract Number

DE-AC28-01RW12101 


\section{DISCLAIMER}

This report was prepared as an account of work sponsored by an agency of the United States Government. Neither the United States Government nor any agency thereof, nor any of their employees, nor any of their contractors, subcontractors or their employees, makes any warranty, express or implied, or assumes any legal liability or responsibility for the accuracy, completeness, or any third party's use or the results of such use of any information, apparatus, product, or process disclosed, or represents that its use would not infringe privately owned rights. Reference herein to any specific commercial product, process, or service by trade name, trademark, manufacturer, or otherwise, does not necessarily constitute or imply its endorsement, recommendation, or favoring by the United States Government or any agency thereof or its contractors or subcontractors. The views and opinions of authors expressed herein do not necessarily state or reflect those of the United States Government or any agency thereof. 
Features, Events, and Processes: Disruptive Events ANL-WIS-MD-000005 REV 02

November 2004 


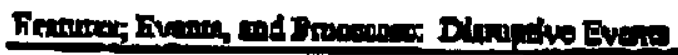

\begin{tabular}{|c|c|c|}
\hline \multirow{2}{*}{ OORWM } & \multirow{2}{*}{ 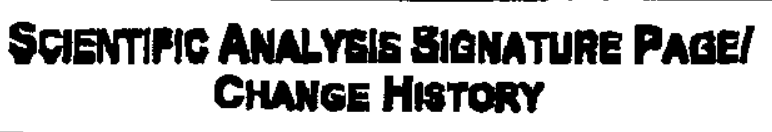 } & Page II \\
\hline & & 1.Total Peses: 190 \\
\hline
\end{tabular}

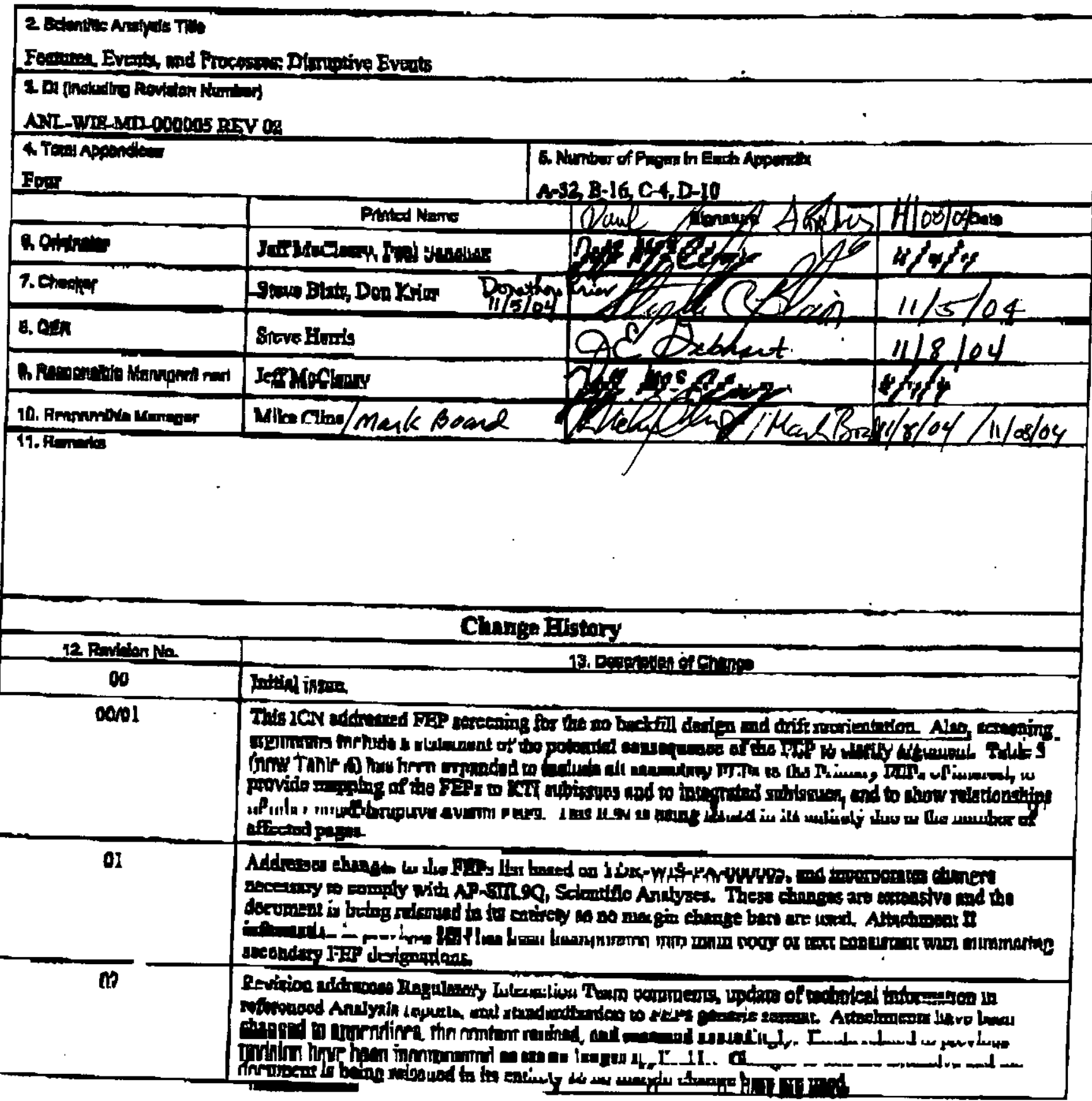




\section{INTENTIONALLY LEFT BLANK}




\section{CONTENTS}

ACRONYMS AND ABBREVIATIONS ix

1. PURPOSE $1-1$

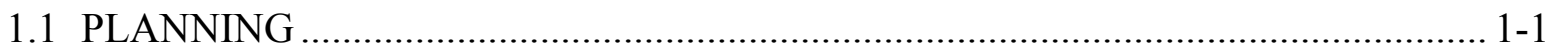

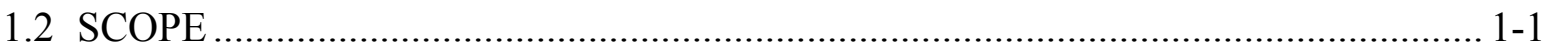

1.3 SCIENTIFIC ANALYSIS LIMITATIONS AND USE ............................................. 1-2

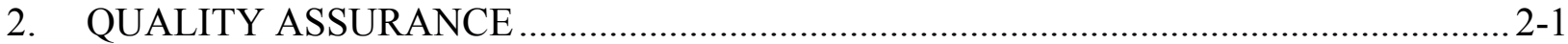

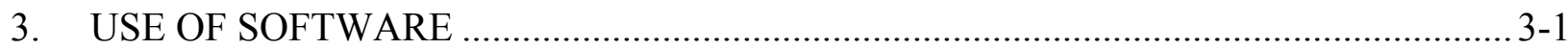

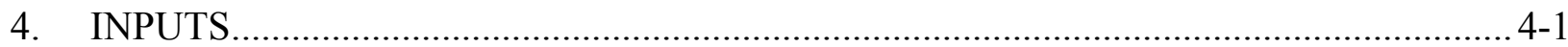

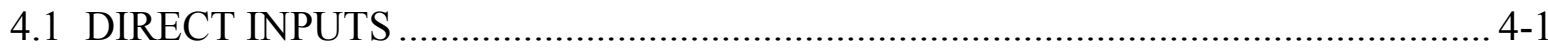

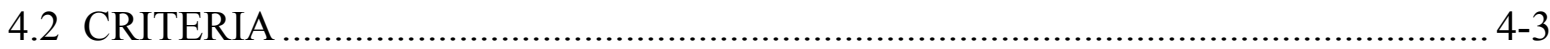

4.2.1 Projects Requirements Document............................................................. 4-3

4.2.2 Yucca Mountain Review Plan .................................................................. 4-4

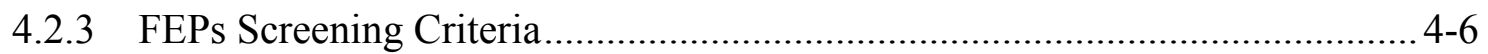

4.3 CODES, STANDARDS, AND REGULATIONS ……………................................ 4-8

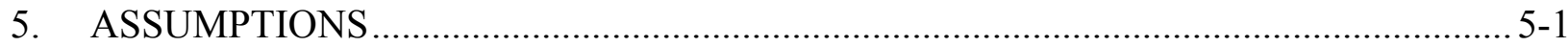

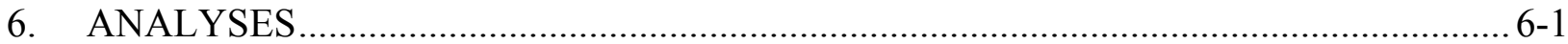

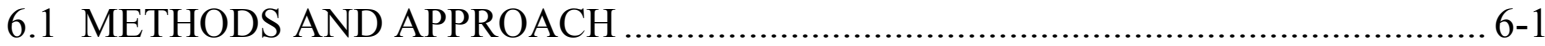

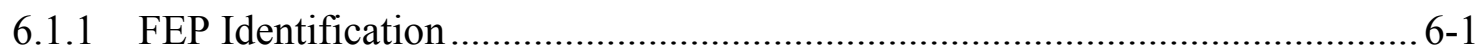

6.1.2 Feature, Event, and Process Screening Process ................................................. 6-2

6.1.3 Supporting Analysis Reports and Indirect Inputs ........................................... 6-3

6.1.4 Qualification of Unqualified Direct Inputs ................................................. 6-4

6.1.5 Assumptions and Simplifications ……………............................................ 6-5

6.1.6 Intended Use and Limitations ................................................................... 6-5

6.2 DISRUPTIVE EVENTS FEATURE, EVENT, AND PROCESS SCREENING

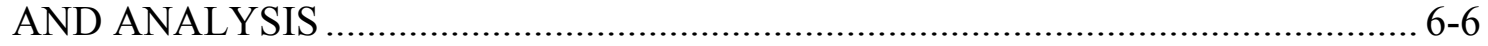

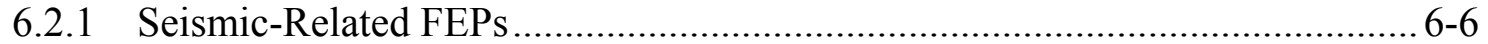

6.2.1.1 Tectonic Activity-Large Scale (1.2.01.01.0A) ............................... 6-7

6.2.1.2 Fault Displacement Damages EBS Components (1.2.02.03.0A) .... 6-13

6.2.1.3 Seismic Ground Motion Damages EBS Components

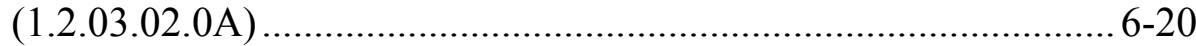

6.2.1.4 Seismic-Induced Rockfall Damages EBS Components

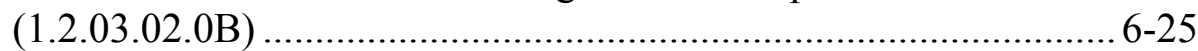

6.2.1.5 Seismic-induced Drift Collapse Damages EBS Components

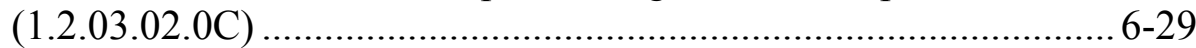

6.2.1.6 Seismic-Induced Drift Collapse Alters In-Drift Thermohydrology (1.2.03.02.0D) ............................................... 6-31

6.2.1.7 Seismicity Associated with Igneous Activity (1.2.03.03.0A).......... 6-35 


\section{CONTENTS (Continued)}

6.2.1.8 Hydrologic Response to Seismic Activity (1.2.10.01.0A). 6-37

6.2.1.9 Seismic Activity Changes Porosity and Permeability of Rock (2.2.06.01.0A)

6.2.1.10 Seismic Activity Changes Porosity and Permeability of Faults (2.2.06.02.0A)

6.2.1.11 Seismic Activity Changes Porosity and Permeability of Fractures (2.2.06.02.0B) $6-45$

6.2.1.12 Seismic Activity Alters Perched Water Zones (2.2.06.03.0A) ........ 6-48

6.2.2 Igneous-Related FEPs $6-49$

6.2.2.1 Igneous Activity Changes Rock Properties (1.2.04.02.0A)............. 6-50

6.2.2.2 Igneous Intrusion into Repository $(1.2 .04 .03 .0 \mathrm{~A}) \ldots \ldots \ldots \ldots \ldots \ldots \ldots \ldots \ldots . . . .6-54$

6.2.2.3 Igneous Intrusion Interacts with EBS Components (1.2.04.04.0A) 6-56

6.2.2.4 Chemical Effects of Magma and Magmatic Volatiles (1.2.04.04.0B) 6-63

6.2.2.5 Magma or Pyroclastic Base Surge Transports Waste (1.2.04.05.0A) 6-65

6.2.2.6 Eruptive Conduit to Surface Intersects Repository (1.2.04.06.0A) 6-68

6.2.2.7 Ashfall (1.2.04.07.0A) 6-72

6.2.2.8 Ash Redistribution via Soil and Sediment Transport (1.2.04.07.0C) 6-76

6.2.2.9 Hydrologic Response to Igneous Activity (1.2.10.02.0A)............... 6-80

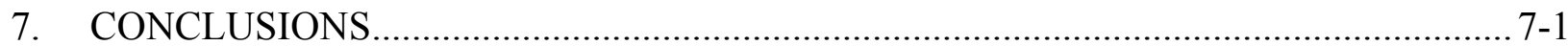

8. INPUTS AND REFERENCES ................................................................................ 8-

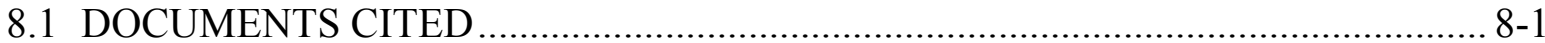

8.2 CODES, STANDARDS, REGULATIONS, AND PROCEDURES ………………..... 8-9

8.3 SOURCE DATA, LISTED BY DATA TRACKING NUMBER ……………........... 8-10

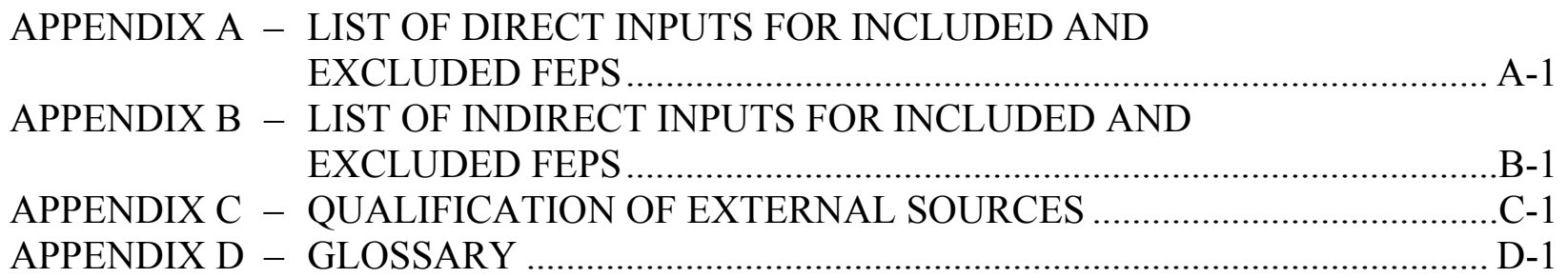




\section{TABLES}

Page

1-1. Disruptive Events FEPs for TSPA-LA …........................................................... 1-3

4-1. Direct Input from Regulations Used for the Disruptive Events FEP Screening............. 4-2

4-2. Relationships of Regulations to the YMRP Acceptance Criteria ............................... 4-3

4-3. Relevant YMRP Acceptance Criteria .................................................................. 4-5

6-1. Supporting Reports for Included FEPs ................................................................... 6-4

6-2. Annualized Frequency of Exceedance and Displacements for Various Locations within the TSPA-LA Repository Footprint............................................................ 6-14

6-3. Ash Redistribution Factors for the TSPA Model....................................................... 6-78

7-1. Summary of Disruptive Events FEP Screening Decisions ...................................... 7-1

7-2. YMRP Acceptance Criteria Addressed in AMR ................................................ 7-2

A-1. Table of Direct Inputs for Included and Excluded Features, Events, and Processes...... A-1

B-1. Table of Indirect Inputs for Included and Excluded Features, Events, and Processes ....B-1 


\section{INTENTIONALLY LEFT BLANK}




\section{ACRONYMS AND ABBREVIATIONS}

BWR boiling water reactor

CDF cumulative distribution function

$\mathrm{cm} \quad$ centimeter

DOE U.S. Department of Energy

DTN Data Tracking Number

EBS engineered barrier system

ECRB Enhanced Characterization of the Repository Block

FEPs features, events, and processes

$\mathrm{km} \quad$ kilometers

LA license application

m meters

Ma million years (before present)

MT metric ton

Mw moment magnitude (a measure of earthquake magnitude)

NRC U.S. Nuclear Regulatory Commission

PGV peak ground velocity

PRD Project Requirements Document

PSHA Probabilistic Seismic Hazard Analyses for Fault Displacement and Vibratory Ground Motion at Yucca Mountain, Nevada

PWR pressurized water reactor

PVHA Probabilistic Volcanic Hazard Analysis for Yucca Mountain, Nevada

QA quality assurance

RMEI reasonably maximally exposed individual

SZ saturated zone

TBV to be verified

TSPA total system performance assessment

TSPA-LA total system performance assessment for license application

TSPA-VA total system performance assessment for viability assessment

TWP technical work plan

UZ unsaturated zone

YMP Yucca Mountain Project

YMRP Yucca Mountain Review Plan, Final Report 
INTENTIONALLY LEFT BLANK 


\section{PURPOSE}

The purpose of this analysis report is to evaluate and document the inclusion or exclusion of the disruptive events features, events, and processes (FEPs) with respect to modeling used to support the total system performance assessment for license application (TSPA-LA). A screening decision, either "Included" or "Excluded," is given for each FEP, along with the technical basis for screening decisions. This information is required by the U.S. Nuclear Regulatory Commission (NRC) at 10 CFR 63.114 (d), (e), and (f) [DIRS 156605].

The FEPs addressed in this report deal with both seismic and igneous disruptive events, such as fault displacements through the repository and an igneous intrusion into the repository. For included FEPs, this analysis summarizes the implementation of the FEP in TSPA-LA (i.e., how the FEP is included). For excluded FEPs, this analysis provides the technical basis for exclusion from TSPA-LA (i.e., why the FEP is excluded). Previous versions of this report were developed to support the total system performance assessments (TSPA) for various prior repository designs. This revision addresses the repository design for the license application (LA).

\subsection{PLANNING}

Documentation requirements for this analysis report are described in the technical work plan (TWP) titled Development of Seismic Design Inputs, Preparation of Seismic Topical Reports, and Evaluation of Disruptive Events Features, Events, and Processes (BSC 2004 [DIRS 169886]). The only deviations from the work plan are that 10 CFR 63.114 (c) [DIRS 156605] (consideration of alternative conceptual models) and YMRP (NRC 2003 [DIRS 163274]) acceptance criteria 2.2.1.2.2.3 (3) and (4) (probability model support and parameters) were found to be not applicable to this document. Consideration of alternative conceptual models and probability model support and parameters are appropriately described in the supporting models and other inputs to this report. Any changes in the assigned disruptive events FEP list for TSPA-LA that result in proposed additions or deletions to the FEP list are further described in Section 6.1.1.

\subsection{SCOPE}

The scope of this report is to describe, evaluate, and document screening decisions and technical bases for the disruptive events FEPs for TSPA-LA. For FEPs that are included in the TSPA-LA, this analysis report provides a TSPA-LA disposition, which is a consolidated summary of how the FEP has been included and addressed in the TSPA-LA model, based on the various supporting technical analysis reports and model reports that describe the inclusion of the FEP. This report also provides references to the specific supporting technical analysis reports that provide more detailed discussions of the included FEPs. For FEPs that are excluded from the TSPA-LA, this analysis report provides a screening argument that identifies the basis for the screening decision (i.e., low probability, low consequence, or by regulation) and discusses the technical basis that supports that decision. This report also provides appropriate references to project and non-project information that supports the exclusion. 
In cases where a FEP covers multiple technical areas and is shared with other FEP reports, this analysis report provides only a partial technical basis for the screening decision as it relates to disruptive events concerns. The full technical basis for these shared FEPs is addressed, collectively, by all of the sharing FEP analysis reports. This information is provided in Section 6.2 and subsequent sections and subsections.

An overview of the Yucca Mountain Project (YMP) FEP analysis and scenario development process is available in The Development of the Total System Performance Assessment License Application Features, Events, and Processes (BSC 2004 [DIRS 168706]), which describes the TSPA-LA FEP identification and screening process. As part of that process, the TSPA-LA FEP list (DTN: MO0407SEPFEPLA.000 [DIRS 170760]) was developed. This DTN was used as an initial input to the disruptive events FEP analysis. The list of disruptive events TSPA-LA FEPs, presented in Table 1-1, was derived from DTN: MO0407SEPFEPLA.000 [DIRS 170760] with subsequent modifications to the FEP list, FEP names, and/or FEP descriptions. These modifications are documented in the FEP History File in the FEP database (BSC 2004 [DIRS 168706], Table 6-2) and will be incorporated into a subsequent revision of the TSPA-LA FEP List (see Section 7). Table 1-1 also includes the designation of shared FEPs.

Direct inputs supporting the screening decisions are listed in Section 4. Indirect inputs supporting the screening decisions are provided in Section 6.1. The individual FEP discussions providing identification (FEP number, name, and description) and screening (screening decision, screening argument or TSPA disposition) information are in Section 6.2.

\subsection{SCIENTIFIC ANALYSIS LIMITATIONS AND USE}

The intended use of this analysis report is to provide FEP screening information for a project-specific FEP database, and to promote traceability and transparency for both included and excluded disruptive events FEPs. This analysis report is intended for use as the documentation for inclusion or exclusion of disruptive events FEPs within or from the TSPA-LA model. The following limitations apply to this analysis report:

- Because this analysis report cites other reports and controlled documents as direct input, the limitations of this analysis report inherently include any limitations or constraints described in the cited reports or controlled documents.

- In cases where FEPs are shared, the scope of this analysis report is limited to the disruptive events aspect of the FEP. The full technical basis for these shared FEPs is addressed, collectively, by all of the sharing FEP analysis reports.

- For screening purposes, this analysis report generally uses mean values of probabilities, mean amplitude of events, or mean value of consequences (e.g., mean time to waste package degradation) as a basis for reaching an include/exclude decision. Mean values are determined based on the range of possible values. 
- The results of the FEP screening presented in this report are specific to the repository design and processes for the YMP available at the time of the TSPA-LA. Changes in direct inputs listed in Section 4.1, in baseline conditions used for this evaluation or in other subsurface conditions, will need to be evaluated to determine whether the changes are within the limits stated in the FEP evaluations. Engineering and design changes are subject to evaluation to determine whether there are any adverse impacts to safety, as codified at 10 CFR 63.73 and in Subparts F and G [DIRS 156605] (see also the requirements at 10 CFR 63.44).

Table 1-1. Disruptive Events FEPs for TSPA-LA

\begin{tabular}{|c|c|c|c|}
\hline FEP Number & FEP Name & $\begin{array}{l}\text { Addressed in } \\
\text { Section }\end{array}$ & $\begin{array}{c}\text { Sharing FEP } \\
\text { Analysis Model } \\
\text { Report }\end{array}$ \\
\hline \multicolumn{4}{|c|}{ Seismic - Related FEPs: } \\
\hline 1.2.01.01.0A & Tectonic activity-large scale & 6.2.1.1 & (None) \\
\hline 1.2.02.03.0A & Fault displacement damages EBS components & 6.2.1.2 & (EBS) \\
\hline 1.2.03.02.0A & Seismic ground motion damages EBS components & 6.2.1.3 & (EBS) \\
\hline 1.2.03.02.0B & Seismic-induced rockfall damages EBS components & 6.2.1.4 & (EBS) \\
\hline 1.2.03.02.0C & $\begin{array}{l}\text { Seismic-induced drift collapse damages EBS } \\
\text { components }\end{array}$ & 6.2.1.5 & (EBS) \\
\hline 1.2.03.02.0D & $\begin{array}{l}\text { Seismic-induced drift collapse alters in-drift } \\
\text { thermohydrology }\end{array}$ & 6.2.1.6 & (EBS) \\
\hline 1.2.03.03.0A & Seismicity associated with igneous activity & 6.2.1.7 & (None) \\
\hline 1.2.10.01.0A & Hydrologic response to seismic activity & 6.2.1.8 & $(\mathrm{UZ}, \mathrm{SZ})$ \\
\hline 2.2.06.01.0A & $\begin{array}{l}\text { Seismic activity changes porosity and permeability } \\
\text { of rock }\end{array}$ & 6.2.1.9 & $(\mathrm{UZ}, \mathrm{SZ})$ \\
\hline 2.2.06.02.0A & $\begin{array}{l}\text { Seismic activity changes porosity and permeability } \\
\text { of faults }\end{array}$ & 6.2 .1 .10 & $(U Z, S Z)$ \\
\hline 2.2.06.02.0B & $\begin{array}{l}\text { Seismic activity changes porosity and permeability of } \\
\text { fractures }\end{array}$ & 6.2.1.11 & $(\mathrm{UZ}, \mathrm{SZ})$ \\
\hline 2.2.06.03.0A & Seismic activity alters perched water zones & 6.2.1.12 & $(U Z)$ \\
\hline \multicolumn{4}{|c|}{ Igneous-Related FEPs: } \\
\hline 1.2.04.02.0A & Igneous activity changes rock properties & 6.2 .2 .1 & $(\mathrm{UZ}, \mathrm{SZ})$ \\
\hline 1.2.04.03.0A & Igneous intrusion into repository & 6.2.2.2 & (None) \\
\hline 1.2.04.04.0A & Igneous intrusion interacts with EBS components & 6.2.2.3 & (None) \\
\hline 1.2.04.04.0B* & Chemical effects of magma and magmatic volatiles & 6.2 .2 .4 & (None) \\
\hline 1.2.04.05.0A & Magma or pyroclastic base surge transports waste & 6.2.2.5 & (None) \\
\hline 1.2.04.06.0A & Eruptive conduit to surface intersects repository & 6.2 .2 .6 & (None) \\
\hline 1.2.04.07.0A & Ashfall & 6.2.2.7 & $(\mathrm{BIO})$ \\
\hline 1.2.04.07.0C & Ash redistribution via soil and sediment transport & 6.2.2.8 & (None) \\
\hline 1.2.10.02.0A & Hydrologic response to igneous activity & 6.2.2.9 & $(\mathrm{UZ}, \mathrm{SZ})$ \\
\hline
\end{tabular}

NOTE: FEPs = features, events, and processes; $\mathrm{BIO}=$ Biosphere; $\mathrm{SZ}$ = Saturated Zone; $U Z=$ Unsaturated Zone; EBS = Engineered Barrier System.

* New FEP described in this report. 


\section{INTENTIONALLY LEFT BLANK}




\section{QUALITY ASSURANCE}

Development of this analysis report and the supporting analyses are subject to the Office of Civilian Radioactive Waste Management quality assurance program as identified in the Development of Seismic Design Inputs, Preparation of Seismic Topical Reports, and Evaluation of Disruptive Events Features, Events, and Processes (BSC 2004 [DIRS 169886], Section 8.1).

This report contributes to the analysis and modeling used to support performance assessment. The disruptive events FEPs documented in this report involve the investigations of items or barriers on the Q-List (BSC 2004 [DIRS 168361]), and have the potential to affect the calculation of the performance of the natural barriers and various engineered barrier system (EBS) components included on the Q-List. However, the disruptive events FEPs themselves do not qualify as $Q$-List items. The evaluations and conclusions do not directly impact engineered features important to safety, as defined in AP-2.22Q, Classification Analyses and Maintenance of the Q-List.

Approved QA procedures identified in the TWP (BSC 2004 [DIRS 169886], Section 4.1) have been used to conduct and document the activities described in this analysis report, and the documentation has been prepared according to AP-SIII.9Q, Scientific Analyses, and in accordance with related procedures and guidance documents as outlined in the TWP. The TWP also identifies applicable controls for the electronic management of data (BSC 2004 [DIRS 169886], Section 8.1) during the analysis and documentation activities. 


\section{INTENTIONALLY LEFT BLANK}




\section{USE OF SOFTWARE}

This analysis report uses no computational software; therefore, this analysis is not subject to software controls. The analyses and arguments presented in this report are based on guidance and regulatory requirements, on results of analyses presented and documented in other analysis reports, or on other technical literature. Software and models used in the supporting documents are cited in this analysis report for traceability and transparency purposes, but were not used in its development.

This analysis report was developed using only commercial, off-the-shelf software. Microsoft ${ }^{\circledR}$ Word 2000, used for word processing, is exempt from qualification requirements in accordance with LP-SI.11Q, Software Management. 


\section{INTENTIONALLY LEFT BLANK}




\section{INPUTS}

AP-3.15Q, Managing Technical Product Inputs categorizes technical product input usage as either direct or indirect input. Direct input is used to develop the results or conclusions in a technical product. Indirect input is used to provide additional information that is not used in the development of results or conclusions. Direct inputs are addressed in this Section. Indirect inputs are addressed in Section 6.1.3.

Section 4.1 identifies all direct inputs used in this FEP analysis report. The direct inputs were obtained from controlled source documents and other appropriate sources in accordance with AP-3.15Q, Managing Technical Product Inputs. Section 4.2 identifies the FEP screening criteria described in 10 CFR Part 63 [DIRS 156605], along with the regulatory-derived FEP screening criteria. Section 4.3 identifies applicable codes and standards.

\subsection{DIRECT INPUTS}

The LA FEP List (DTN: MO0407SEPFEPLA.000 [DIRS 170760]) was used as a direct input to provide the initial list of disruptive events FEPs for screening in this analysis report. The LA FEP List identifies a FEP or a set of sharing FEP analysis reports for each FEP. Subsequent additions to or changes from that FEP list (numbers, names, or descriptions) are reflected in the information provided in Section 6.2 and can be traced through the FEP History File in the FEP database (BSC 2004 [DIRS 168706], Table 6-2). Appendix A lists direct inputs used for the FEP screening analysis for both included and excluded FEPs. Non-project direct inputs have been qualified for intended use in Appendix $\mathrm{C}$ and in a data qualification report prepared per AP-S.III.2Q, as described in Section 6.1.4.

The regulations at 10 CFR Part 63 [DIRS 156605] also provide direct inputs to the FEP screening process. By specifying characteristics, concepts, and definitions, the regulations serve as de facto inputs used for screening FEPs. For additional information on regulatory definitions, and an elucidation of the regulatory concepts pertaining to the reference biosphere, geologic setting, reasonably maximally exposed individual (RMEI), and human intrusion, the reader is referred to The Development of the Total System Performance Assessment-License Application Features, Events, and Processes (BSC 2004 [DIRS 168706], Section 4.1.3), which is an indirect input to this document. For the disruptive events FEPs, the inputs of particular interest include the relationship of the geologic setting to the reference biosphere, and the location of the reasonably maximally exposed individual (RMEI). Specific direct inputs from the regulations addressing these concepts are listed in Table 4-1. 
Table 4-1. Direct Input from Regulations Used for the Disruptive Events FEP Screening

\begin{tabular}{|l|l|c|l|}
\hline \multicolumn{1}{|c|}{ Source } & $\begin{array}{c}\text { Input } \\
\text { Category }\end{array}$ & Direct Use In & \multicolumn{1}{c|}{ Description } \\
\hline 10 CFR 63.2 & Established & 6.2 .2 .9 & Regulatory definition for reference biosphere \\
& Fact & & \\
\hline 10 CFR 63.302 & Established & 6.2 .2 .2 & Regulatory definitions for accessible \\
& Fact & 6.2 .2 .3 & environment and controlled area \\
& & 6.2 .2 .5 & \\
& & 6.2 .2 .6 & \\
& & 6.2 .2 .7 & \\
\hline \multirow{2}{*}{ 10 CFR 63.312 } & Established & 6.2 .2 .2 & Regulatory characteristics of the RMEl \\
& Fact & 6.2 .2 .3 & \\
& & 6.2 .2 .5 & \\
& & 6.2 .2 .6 & \\
& & 6.2 .2 .7 & \\
& & 6.2 .2 .8 & \\
\hline
\end{tabular}

Source: 10 CFR Part 63 [DIRS 156605].

$\mathrm{DOE}=\mathrm{U} . \mathrm{S}$. Department of Energy.

The definitions and concepts discussed in The Development of the Total System Performance Assessment-License Application Features, Events, and Processes (BSC 2004 [DIRS 168706], Section 4.1.3.3) indicate that the RMEI is located no closer than $18 \mathrm{~km}$ to the south in the direction of groundwater flow and above the highest concentration of radionuclides in the plume of contamination (in accordance with 10 CFR 63.312 (a), (b), (c), (d), and (e) [DIRS 156605]), and that the limit of the controlled area is no greater than $5 \mathrm{~km}$ from the repository in any other direction (as specified at 10 CFR 63.302 [DIRS 156605]). The location of the RMEI and the associated distance from the repository are of primary interest in evaluating potential exposure risk due to potential releases at the repository. The location of the RMEI is also important for determining exposure and is part of the technical basis for included FEPs. The location and characteristics of the RMEI for the nominal scenario class are also used for the disruptive scenario classes.

The reference biosphere must be consistent with present knowledge of conditions in the region, and changes in the biosphere (other than climate) from conditions at the time of license application submittal should not be projected (BSC 2004 [DIRS 168706], Section 4.1.3.2; 10 CFR 63.305(a), (b) [DIRS 156605]). The geologic setting (geology, hydrology, and climate) may evolve based upon cautious but reasonable assumptions, consistent with present knowledge of factors that could affect the system in the next 10,000 years (BSC 2004 [DIRS 168706], Section 4.1.3.2).

By NRC's juxtaposition of the geologic and hydrologic factors within the subsection addressing required characteristics of the reference biosphere, it is inferred that the listed regulatory constraint of changes in the reference biosphere may also be applicable to conditions that may 
occur at Yucca Mountain. This approach agrees with the statement at 10 CFR 63.102(i) [DIRS 156605] that:

Characteristics of the reference biosphere and the reasonably maximally exposed individual are to be based on current human behavior and biospheric conditions in the region, as described in $\S 63.305$ and $\S 63.312$ [DIRS 156605].

\subsection{CRITERIA}

This section addresses the criteria relevant to the FEP screening process. These criteria stem from the applicable regulations at 10 CFR Part 63 [DIRS 156605], as identified in the Project Requirements Document (PRD) (Canori and Leitner 2003 [DIRS 166275]). These criteria find expression as specific acceptance criteria presented by the NRC in the Yucca Mountain Review Plan, Final Report (YMRP) (NRC 2003 [DIRS 163274], Sections 2.2.1.2.1.3 and 2.2.1.2.2.3). The correlation of the regulations and YMRP acceptance criteria are shown in Table 4-2. These criteria are also listed in section 3 of the TWP (BSC 2004 [DIRS 169886]). Readers should note that since this analysis report summarizes and reports the results of supporting analysis reports and other information, discussions of representativeness of results are not appropriate here, and are not included.

\subsubsection{Projects Requirements Document}

The PRD (Canori and Leitner 2003 [DIRS 166275]) documents and categorizes the regulatory requirements and other project requirements and provides a cross-reference to the various YMP organizations that are responsible for ensuring that the criteria have been addressed in the license application. The regulatory requirements include criteria relevant to performance assessment activities, in general, and to FEP-related activities as they pertain to performance assessment, in particular. Table 4-2 provides a crosswalk between the regulatory requirements, the PRD, and the acceptance criteria provided in the YMRP (NUREG-1804, NRC 2003 [DIRS 163274], Sections 2.2.1.2.1.3 and 2.2.1.2.2.3).

Table 4-2. Relationships of Regulations to the YMRP Acceptance Criteria

\begin{tabular}{|c|c|c|c|}
\hline \multirow{2}{*}{$\begin{array}{c}\text { Description of the } \\
\text { Applicable Regulatory } \\
\text { Requirement or } \\
\text { Acceptance Criterion }\end{array}$} & $\begin{array}{l}10 \text { CFR Part } 63 \\
\text { [DIRS 156605] }\end{array}$ & $\begin{array}{c}\text { Canori and Leitner } 2003 \\
\text { [DIRS 166275] }\end{array}$ & \multirow{2}{*}{$\begin{array}{c}\text { Associated } \\
\text { Criteria } \\
\text { in the YMRP } \\
\text { [DIRS 163274 }\end{array}$} \\
\hline & Regulatory Citation & $\begin{array}{l}\text { Associated } \\
\text { PRD }\end{array}$ & \\
\hline \multicolumn{4}{|c|}{ General Requirements and Scope Pertinent to FEP Screening } \\
\hline $\begin{array}{l}\text { Include data related to } \\
\text { geology, hydrology, and } \\
\text { geochemistry (including } \\
\text { disruptive processes and } \\
\text { events). }\end{array}$ & $63.114(a)$ & $\begin{array}{l}\text { PRD-002/ } \\
\text { T-015 }\end{array}$ & $\begin{array}{l}\text { 2.2.1.2.1.3 } \\
\text { Acceptance } \\
\text { Criterion } 1\end{array}$ \\
\hline $\begin{array}{l}\text { Include information on the } \\
\text { design of the engineered } \\
\text { barrier system used to } \\
\text { define parameters and } \\
\text { conceptual models. }\end{array}$ & $63.114(a)$ & $\begin{array}{l}\text { PRD-002/ } \\
\text { T-015 }\end{array}$ & $\begin{array}{l}\text { 2.2.1.2.1.3 } \\
\text { Acceptance } \\
\text { Criterion } 1\end{array}$ \\
\hline
\end{tabular}


Table 4-2. Relationships of Regulations to the YMRP Acceptance Criteria (Continued)

\begin{tabular}{|c|c|c|c|}
\hline \multirow{2}{*}{$\begin{array}{l}\text { Description of the } \\
\text { Applicable Regulatory } \\
\text { Requirement or } \\
\text { Acceptance Criterion }\end{array}$} & $\begin{array}{l}10 \text { CFR Part } 63 \\
\text { [DIRS 156605] }\end{array}$ & $\begin{array}{c}\text { Canori and Leitner } 2003 \\
\text { [DIRS 166275] }\end{array}$ & \multirow{2}{*}{$\begin{array}{c}\text { Associated } \\
\text { Criteria } \\
\text { in the YMRP } \\
\text { [DIRS 163274] }\end{array}$} \\
\hline & Regulatory Citation & $\begin{array}{l}\text { Associated } \\
\text { PRD }\end{array}$ & \\
\hline \multicolumn{4}{|c|}{ General Requirements and Scope Pertinent to FEP Screening } \\
\hline $\begin{array}{l}\text { Account for uncertainties } \\
\text { and variabilities in } \\
\text { parameter values and } \\
\text { provide the technical basis } \\
\text { for parameter ranges, } \\
\text { probability distributions, or } \\
\text { bounding values. }\end{array}$ & $63.114(b)$ & $\begin{array}{l}\text { PRD-002/ } \\
\text { T-015 }\end{array}$ & $\begin{array}{l}2.2 .1 .2 .2 .3 \\
\text { Acceptance } \\
\text { Criteria } \\
2 \text { and } 5\end{array}$ \\
\hline \multicolumn{4}{|c|}{ FEP Screening Criteria } \\
\hline $\begin{array}{l}\text { Provide the justification } \\
\text { and technical basis for } \\
\text { excluding FEPs } \\
\text { specifically excluded by } \\
\text { regulation. }\end{array}$ & Not Applicable & Not Applicable & $\begin{array}{l}2.2 .1 .2 .1 .3 \\
\text { Acceptance } \\
\text { Criterion } 2\end{array}$ \\
\hline $\begin{array}{l}\text { Provide the technical basis } \\
\text { for either inclusion or } \\
\text { exclusion of FEPs. } \\
\text { Provide the justification } \\
\text { and technical basis for } \\
\text { those excluded based on } \\
\text { probability. }\end{array}$ & $\begin{array}{l}63.114(d) \\
63.342\end{array}$ & $\begin{array}{l}\text { PRD-002/ } \\
\text { T-015 } \\
\text { PRD-002/ } \\
\text { T-034 }\end{array}$ & $\begin{array}{l}\text { 2.2.1.2.1.3 } \\
\text { Acceptance } \\
\text { Criterion } 2 \\
\text { 2.2.1.2.2.3 } \\
\text { Acceptance } \\
\text { Criteria } \\
1 \text { and } 2 \\
\end{array}$ \\
\hline $\begin{array}{l}\text { Provide the technical basis } \\
\text { for either inclusion or } \\
\text { exclusion of FEPs. } \\
\text { Provide the justification } \\
\text { and the technical basis for } \\
\text { FEPs excluded based on } \\
\text { lack of significant change } \\
\text { in resulting radiological } \\
\text { exposure or release to the } \\
\text { accessible environment. }\end{array}$ & $\begin{array}{l}63.114 \\
\text { (e and f) } \\
63.342\end{array}$ & $\begin{array}{l}\text { PRD-002/ } \\
\text { T-015 } \\
\text { PRD-002/ } \\
\text { T-034 }\end{array}$ & $\begin{array}{l}\text { 2.2.1.2.1.3 } \\
\text { Acceptance } \\
\text { Criterion } 2 \\
\text { 2.2.1.2.2.3 } \\
\text { Acceptance } \\
\text { Criteria } \\
1 \text { and } 2\end{array}$ \\
\hline
\end{tabular}

\subsubsection{Yucca Mountain Review Plan}

The NRC will be reviewing the license application. The basis of the review is described in the YMRP (NRC 2003 [DIRS 163274], Section 2.2.1.2), and the bases for acceptance are stated as acceptance criteria. In Table 4-2, YMRP acceptance criteria are correlated to the corresponding regulations as they pertain to FEP-related criteria.

The cited YMRP (NRC 2003 [DIRS 163274]) criteria are provided in Table 4-3. The YMRP acceptance criteria for FEP screening echo the regulatory screening criteria of low probability and low consequence, but also allow for exclusion of a FEP if the process is specifically excluded by the regulations (see Section 4.2.3). 
Table 4-3. Relevant YMRP Acceptance Criteria

\begin{tabular}{|c|c|c|}
\hline YMRP Section & $\begin{array}{l}\text { Acceptance } \\
\text { Criterion }\end{array}$ & Description \\
\hline \multirow{4}{*}{$\begin{array}{l}\text { Scenario Analysis } \\
\text { and Event } \\
\text { Probability: }\end{array}$} & $\begin{array}{l}\text { 1. The Identification } \\
\text { of a List of FEPs Is } \\
\text { Adequate }\end{array}$ & $\begin{array}{l}\text { The safety analysis report contains a complete list of FEPs related to } \\
\text { the geologic setting or the degradation, deterioration, or alteration of } \\
\text { engineered barriers (including those processes that would affect the } \\
\text { performance of natural barriers) that have the potential to influence } \\
\text { repository performance. The list is consistent with the site } \\
\text { characterization data. The comprehensive features, events, and } \\
\text { processes list includes, but is not limited to, potentially disruptive } \\
\text { events related to igneous activity (extrusive and intrusive); seismic } \\
\text { shaking (high-frequency-low magnitude, and rare large-magnitude } \\
\text { events); tectonic evolution (slip on existing faults and formation of } \\
\text { new faults); climatic change (change to pluvial conditions); and } \\
\text { criticality. }\end{array}$ \\
\hline & \multirow[t]{3}{*}{$\begin{array}{l}\text { 2. Screening of the } \\
\text { Initial List of FEPs Is } \\
\text { Appropriate }\end{array}$} & $\begin{array}{l}\text { The DOE has identified all FEPs related to either the geologic setting } \\
\text { or to the degradation, deterioration, or alteration of engineered } \\
\text { barriers (including those processes that would affect the performance } \\
\text { of natural barriers) that have been excluded. }\end{array}$ \\
\hline & & $\begin{array}{l}\text { The DOE has provided justification for those FEPs that have been } \\
\text { excluded. An acceptable justification for excluding FEPs is that either } \\
\text { the FEP is specifically excluded by regulation; probability of the FEP } \\
\text { (generally an event) falls below the regulatory criterion; or omission of } \\
\text { the feature, and process does not significantly change the magnitude } \\
\text { and time of the resulting radiological exposures to the reasonably } \\
\text { maximally exposed individual, or radionuclide releases to the } \\
\text { accessible environment. }\end{array}$ \\
\hline & & $\begin{array}{l}\text { The DOE has provided an adequate technical basis for each FEP, } \\
\text { excluded from the performance assessment, to support the } \\
\text { conclusion that either the FEP is specifically excluded by regulation; } \\
\text { the probability of the FEP falls below the regulatory criterion; or } \\
\text { omission of the FEP does not significantly change the magnitude and } \\
\text { time of the resulting radiological exposures to the reasonably } \\
\text { maximally exposed individual, or radionuclide releases to the } \\
\text { accessible environment. }\end{array}$ \\
\hline \multirow{4}{*}{$\begin{array}{l}\text { Scenario Analysis } \\
\text { and Event } \\
\text { Probability: } \\
\text { Identification of } \\
\text { Events with } \\
\text { Probability Greater } \\
\text { than } 10^{-8} \text { per Year } \\
\text { (from Section } \\
2.2 .1 .2 .2 .3 \\
\text { NUREG-1804 } \\
\text { [DIRS 163274]) }\end{array}$} & \multirow[t]{2}{*}{$\begin{array}{l}\text { 1. Events are } \\
\text { Adequately Defined }\end{array}$} & $\begin{array}{l}\text { Events or event classes are defined without ambiguity and used } \\
\text { consistently in probability models, such that probabilities for each } \\
\text { event or event class are estimated separately. }\end{array}$ \\
\hline & & $\begin{array}{l}\text { Probabilities of intrusive and extrusive igneous events are calculated } \\
\text { separately. Definitions of faulting and earthquakes are derived from } \\
\text { the historical record, paleoseismic studies, or geological analyses. } \\
\text { Criticality events are calculated separately by location. }\end{array}$ \\
\hline & $\begin{array}{l}\text { 2. Probability } \\
\text { Estimates for Future } \\
\text { Events Are Supported } \\
\text { by Appropriate } \\
\text { Technical Bases }\end{array}$ & $\begin{array}{l}\text { Probabilities for future natural events are based on past patterns of } \\
\text { the natural events in the Yucca Mountain region, considering the } \\
\text { likely future conditions and interactions of the natural and engineered } \\
\text { repository system. These probability estimates have specifically } \\
\text { included igneous events, faulting and seismic events, and criticality } \\
\text { events. }\end{array}$ \\
\hline & $\begin{array}{l}\text { 5. Uncertainty in } \\
\text { Event Probability is } \\
\text { Adequately Evaluated }\end{array}$ & $\begin{array}{l}\text { Probability values appropriately reflect uncertainties. Specifically: } \\
\text { a. The DOE provides a technical basis for probability values used, } \\
\text { and the values account for the uncertainty in the probability } \\
\text { estimates. } \\
\text { b. The uncertainty for reported probability values adequately reflects } \\
\text { the influence of parameter uncertainty on the range of model results } \\
\text { (i.e., precision) and the model uncertainty, as it affects the timing and } \\
\text { magnitude of past events (i.e., accuracy). }\end{array}$ \\
\hline
\end{tabular}




\subsubsection{FEPs Screening Criteria}

The criteria for determining low probability, low consequence, or regulation exclusions are described below.

\section{Low Probability}

The low-probability criterion is stated in 10 CFR 63.114(d) [DIRS 156605]:

Consider only events that have at least one chance in 10,000 of occurring over 10,000 years.

And low-probability criterion is supported by 10 CFR 63.342 [DIRS 156605]:

The U.S. Department of Energy's (DOE) performance assessments shall not include consideration of very unlikely features, events, or processes, i.e., those that are estimated to have less than one chance in 10,000 of occurring within 10,000 years of disposal. The DOE assessments for the human-intrusion and groundwater protection standards shall not include consideration of unlikely features, events, and processes, or sequences of events and processes, i.e., those that are estimated to have less than one chance in 10 and at least one chance in 10,000 of occurring within 10,000 years of disposal.

As noted in Assumption 5.1, the low-probability criterion for very unlikely events corresponds to an annual-exceedance probability of $10^{-8}$. The criterion for unlikely events corresponds to an annual-exceedance probability of $10^{-5}$ to $10^{-8}$.

\section{Low Consequence}

The low consequence criterion is stated in 10 CFR 63.114 (e) and (f) [DIRS 156605]:

(e) Provide the technical basis for either inclusion or exclusion of specific features, events, and processes in the performance assessment. Specific features, events, and processes must be evaluated in detail if the magnitude and time of the resulting radiological exposures to the reasonably maximally exposed individual, or radionuclide releases to the accessible environment, would be significantly changed by their omission.

(f) Provide the technical basis for either inclusion or exclusion of degradation, deterioration, or alteration processes of engineered barriers in the performance assessment, including those processes that would adversely affect the performance of natural barriers. Degradation, deterioration, or alteration processes of engineered barriers must be evaluated in detail if the magnitude and time of the resulting radiological exposures to the reasonably maximally exposed individual, or radionuclide releases to the accessible environment, would be significantly changed by their omission. 
And low consequence criterion is supported by 10 CFR 63.342 [DIRS 156605]:

DOE performance assessments need not evaluate the impacts resulting from any features, events, and processes or sequences of events and processes with a higher chance of occurrence if the results of the performance assessments would not be changed significantly.

Some FEPs have a beneficial effect on the TSPA, as opposed to an adverse effect. As identified in 10 CFR 63.102(j) [DIRS 156605], the concept of a performance assessment includes that:

The features, events, and processes considered in the performance assessment should represent a wide range of both beneficial and potentially adverse effects on performance (e.g., beneficial effects of radionuclide sorption; potentially adverse effects of fracture flow or a criticality event). Those features, events, and processes expected to materially affect compliance with 10 CFR 63.113(b) or be potentially adverse to performance are included, while events (event classes or scenario classes) that are very unlikely (less than one chance in 10,000 over 10,000 years) can be excluded from the analysis. ...

The Yucca Mountain Review Plan, Final Report (NRC 2003 [DIRS 163274], Section 2.2.1), states that:

In many regulatory applications, a conservative approach can be used to decrease the need to collect additional information or to justify a simplified modeling approach. Conservative estimates for the dose to the reasonably maximally exposed individual may be used to demonstrate that the proposed repository meets U.S. Nuclear Regulatory Commission regulations and provides adequate protection of public health and safety. The total system performance assessment is a complex analysis with many parameters, and the U.S. Department of Energy may use conservative assumptions to simplify its approaches and data collection needs. However, a technical basis that supports the selection of models and parameter ranges or distributions must be provided.

On the basis of these statements, those FEPs that are demonstrated to have only beneficial effects on the radiological exposures to the reasonably maximally exposed individual or radionuclide releases to the accessible environment can be excluded on the basis of low consequence because they have no adverse effects on performance.

\section{By Regulation}

The Yucca Mountain Review Plan, Final Report (NRC 2003 [DIRS 163274], Section 2.2.1.2.1.3, Acceptance Criterion 2) allows for exclusion of a FEP if the process is specifically excluded by the regulations. The report states:

The DOE has provided justification for those FEPs that have been excluded. An acceptable justification for excluding FEPs is that either the FEP is specifically excluded by regulation; probability of the FEP (generally an event) falls below the regulatory criterion; or omission of the feature and process does not significantly 
change the magnitude and time of the resulting radiological exposures to the reasonably maximally exposed individual, or radionuclide releases to the accessible environment.

\subsection{CODES, STANDARDS, AND REGULATIONS}

No standards, regulations, or code requirements other than those cited in Sections 4.1 and 4.2 apply to this document. 


\section{ASSUMPTIONS}

This section addresses assumptions used in the FEP screening for the disruptive events FEPs.

Assumption 5.1: For naturally occurring FEPs, it is assumed that regulations expressed as a probability criterion can also be expressed as an annual-exceedance probability, which is defined as the probability that a specified value (such as for ground motions or fault displacement) will be exceeded during one year. More specifically, a stated probability-screening criterion of one chance in 10,000 in 10,000 years $\left(10^{-4} / 10^{4} \mathrm{yr}\right)$ is assumed equivalent to a $10^{-8}$ annual-exceedance probability. Likewise, the probability criterion of one chance in 10 in 10,000 years $\left(10^{-1} / 10^{4} \mathrm{yr}\right)$, as used in assessments of human intrusion and groundwater protection standards, is assumed equivalent to a $10^{-5}$ annual-exceedance probability.

Justification-The definition of annual exceedance probability and the following justification for this assumption is taken from Characterize Framework for Seismicity and Structural Deformation at Yucca Mountain, Nevada (BSC 2004 [DIRS 168030], Glossary).

The assumption of equivalence of annual-exceedance probability is appropriate. This assumption satisfies the definition of a Poisson distribution as "...a mathematical model of the number of outcomes obtained in a suitable interval of time and space, that has its mean equal to its variance..." This definition is inferred to mean that naturally occurring, infrequent, and independent events can be represented as stochastic processes in which distinct events occur in such a way that the number of events occurring in a given period of time depends only on the length of the time period. The use of this assumption is justified in Characterize Framework for Seismicity and Structural Deformation at Yucca Mountain, Nevada (BSC 2004 [DIRS 168030], Section 6.4.2), which indicates that the underlying assumption in all probabilistic hazard analyses is that the behavior of the earth is generally Poissonian or random.

Although there may be cases where sufficient data and information exist to depart from this assumption, the Poissonian model is generally an effective representation of nature and it represents a compromise between the complexity of natural processes, availability of information, and the sensitivity of results of engineering relevance. Consequently, for geologic processes that occur over long time spans, assuming annual equivalence over a 10,000-year period (a relatively short time span for geologic-related events) is reasonable and consistent with the basis of probabilistic hazard analyses. Therefore, no further confirmation is required.

Use-This assumption is used throughout Section 6.2 of this report, either implicitly or explicitly, for each of the disruptive events FEPs that cite to an annualized probability or annual-exceedance frequency.

Assumption 5.2: It is assumed that potential naturally occurring events, but perhaps of different magnitude, have occurred at least once in the past within the geologic record. This assumption is the basis for determining the factors that could affect the Yucca Mountain disposal system over the next 10,000 years.

\footnotetext{
${ }^{1}$ Merriam-Webster's Collegiate Dictionary, 10th ed., s.v. "Poisson distribution."
} 
Justification-This assumption is justified because it is consistent with the regulations used as direct input. At 10 CFR 63.305(c) [DIRS 156605], DOE is directed to "vary factors related to the geology, hydrology, and climate based upon cautious, but reasonable assumptions consistent with present knowledge of factors that could affect the Yucca Mountain disposal system over the next 10,000 years."

The implication of this assumption is that any discernible impacts or processes related to past events on the site setting are reflected in the present knowledge of natural processes that form the basis of the TSPA. If the subject FEP phenomena are not reflected or discernible in the data used to describe past settings, then they are either of low consequence or of low probability and can be excluded from consideration. Because it is consistent with the regulations, no further confirmation is necessary.

Use-This assumption is used throughout. It is particularly germane to FEPs related to processes or phenomena that, speculatively, could affect future states of the system, but for which the magnitude and/or coupling to the effect on the repository is not well defined, or for which consequences in present time are known to be minor.

These types of events are known to occur. However, the effects of the phenomenon or the effects associated with varying magnitudes of the event type and probabilities are not well documented (e.g., effects of a supernova); the form of the coupling process is not well defined (e.g., changes in the earth's magnetic field), or the phenomenon has been shown to have no impact or insignificant impact at the present time (e.g., earth tides).

Assumption 5.3-It is assumed that the repository will be constructed, operated, and closed according to the regulatory requirements applicable to the construction operation and closure period. Deviations from design will be detected and corrected.

Justification: Inherent in the FEPs evaluation approach is the assumption that the repository will be constructed, operated, and closed according to the design used as the basis for the FEP screening and in accordance with NRC license requirements. This assumption is inherent in performance evaluation of any engineering project, and design verification and performance confirmation are required as part of the construction and operation processes. Therefore, no further confirmation of the assumption is required.

Engineering and design changes are subject to evaluation to determine if there are any adverse impacts to safety as codified at 10 CFR 63.73 and in Subparts F and G [DIRS 156605]. See also the requirements at 10 CFR 63.32, 10 CFR 63.44, and 10 CFR 63.131 [DIRS 156605].

These requirements call for periodic updates and special reports regarding:

- Progress of construction

- Any data about the site obtained during construction and not within the predicted limits on which the facility design was based 
- Any deficiencies in design and construction that could adversely affect safety at any future time if uncorrected

- Results of research and development programs being conducted to resolve safety questions.

Use: Any changes in direct inputs listed in Section 4.1, in baseline conditions used for this evaluation, or in other subsurface conditions will need to be evaluated to determine if the changes are within the limits stated in the FEP evaluations. This assumption is used in all FEPs that depend on the size of the repository footprint, orientation of the drifts, or other design features such as backfilled connecting drifts, for example 1.2.02.03.0A (Fault displacement damages EBS components) and 1.2.04.04.0A (Igneous intrusion interacts with EBS components). 


\section{INTENTIONALLY LEFT BLANK}




\section{ANALYSES}

The following sections discuss the disruptive events FEP analyses. Section 6.1 of this analysis report discusses the methods and approach used for the FEP screening. Section 6.2 provides the screening documentation.

\subsection{METHODS AND APPROACH}

The identification and screening of a comprehensive list of FEPs potentially relevant to the postclosure performance of the Yucca Mountain repository is an ongoing, iterative process based on site-specific information, design, and regulations. FEP analysis uses the following definitions, as taken from the Yucca Mountain Review Plan, Final Report (NRC 2003 [DIRS 163274], Glossary):

feature An object, structure, or condition that has a potential to affect disposal system performance.

event A natural or human-caused phenomenon that has a potential to affect disposal system performance and that occurs during an interval that is short compared to the period of performance.

process A natural or human-caused phenomenon that has a potential to affect disposal system performance and that operates during all or a significant part of the period of performance.

FEP analysis for TSPA-LA is described in The Development of the Total System Performance Assessment-License Application Features, Events, and Processes (BSC 2004 [DIRS 168706]). It is also summarized in the following subsections.

\subsubsection{FEP Identification}

The first step of FEP analysis is FEP identification and classification, which addresses Acceptance Criterion 1 of the Yucca Mountain Review Plan, Final Report (NRC 2003 [DIRS 163274], Section 2.2.1.2.1.3). The TSPA-LA FEP identification and classification process is described in The Development of the Total System Performance Assessment-License Application Features, Events, and Processes (BSC 2004 [DIRS 168706], Section 3). This process produced a version of the LA FEP List (DTN: MO0407SEPFEPLA.000 [DIRS 170760]), which is used as initial input in this disruptive events FEP analysis. Subsequent modifications to the FEP list from the information shown in DTN: MO0407SEPFEPLA.000 [DIRS 170760], aside from editorial corrections to FEP descriptions, are discussed later in this section. All subsequent modifications are also documented in the FEP History File in the FEP database (BSC 2004 [DIRS 168706], Table 6-2).

As part of the TSPA-LA FEP identification process, a new FEP to evaluate the chemical effects of magma and magmatic volatiles is described in this report for the igneous scenario. The new FEP (1.2.04.04.0B) titled "Chemical effects of magma and magmatic volatiles," is evaluated in Section 6.2.2.4 of this report. Consequently, this analysis report addresses 21 FEPs that are identified as disruptive events FEPs for TSPA-LA. 


\subsubsection{Feature, Event, and Process Screening Process}

The second step of FEP analysis is FEP screening, which addresses Acceptance Criterion 2 of the Yucca Mountain Review Plan, Final Report (NRC 2003 [DIRS 163274], Section 2.2.1.2.1.3). The TSPA-LA FEP screening process is described in The Development of the Total System Performance Assessment-License Application Features, Events, and Processes (BSC 2004 [DIRS 168706], Section 4).

For FEP screening, each FEP is screened against the specified exclusion criteria (see Section 4.2.3) summarized in the three following FEP screening statements:

- FEPs having less than one chance in 10,000 of occurring over 10,000 years may be excluded (screened out) from the TSPA on the basis of low probability (as per 10 CFR 63.114(d) and 63.342 [DIRS 156605]).

- FEPs, whose omission would not significantly change the magnitude and time of the resulting radiological exposures to the RMEI, or radionuclide releases to the accessible environment, may be excluded (screened out) from the TSPA on the basis of low consequence (as per 10 CFR 63.114 (e) and (f) [DIRS 156605]).

- FEPs that are inconsistent with the characteristics, concepts, and definitions specified in 10 CFR Part 63 [DIRS 156605] may be excluded (screened out) from the TSPA by regulation.

A FEP need only satisfy one of the exclusion screening criteria to be excluded from TSPA. A FEP that does not satisfy any of the exclusion screening criteria must be included (screened in) in the TSPA-LA model.

This analysis report documents the screening decisions for the disruptive events FEPs. In cases where a FEP covers multiple technical areas and is shared with other FEP analysis reports, this analysis report provides only a partial technical basis for the screening decision as it relates to disruptive events issues. The full technical basis for these shared FEPs is addressed, collectively, by all of the sharing FEP analysis reports.

For postclosure evaluation of fault-displacement (Section 6.2.1.2; FEP 1.2.02.03.0A) and seismic FEPs requiring ground motion inputs (e.g., Section 6.2.1.3; 1.2.03.02.0A), the FEP screening statements are applied based on the mean value of the event at an annual-exceedance probability of $10^{-8}$ (BSC 2004 [DIRS 169183], Table 4-1 and Table 6.1-1). For the total system performance assessment for site recommendation, the DOE elected to use median hazard curves to screen seismic FEPs, considering the median curve representative of the hazard's central tendency at an annual-exceedance frequency lower than approximately $10^{-6}$. However, NRC reviewers suggested that using the median hazard for FEP screening is inconsistent with established NRC practice for use of probabilistic seismic hazard analyses (PSHA) in risk assessment. Consequently, the DOE has implemented an alternative approach for TSPA-LA that uses the mean values. The decision to use this alternative approach is documented in Williams (2001 [DIRS 161728]). 
The use of the mean value from the hazard curve is particularly pertinent to the following FEPs:

1.2.02.03.0A Fault displacement damages EBS components (Section 6.2.1.2)

1.2.03.02.0A Seismic ground motion damages EBS components (Section 6.2.1.3)

1.2.03.02.0B Seismic-induced rockfall damages EBS components (Section 6.2.1.4)

1.2.03.02.0C Seismic-induced drift collapse damages EBS components (Section 6.2.1.5)

1.2.03.02.0D Seismic-induced drift collapse alters in-drift thermohydrology

(Section 6.2.1.6).

Documentation of the screening for each FEP is provided in Section 6.2. The following standardized format is used:

\section{Section 6.2.X.X FEP Name (FEP Number)}

FEP Description: This field describes the nature and scope of the FEP under consideration.

Screening Decision-Identifies the screening decision using one of the following descriptions:

- Included

- Excluded-Low Probability

- Excluded-Low Consequence

- Excluded-By Regulation

In a few cases, a FEP may be excluded by a combination of two criteria (e.g., low probability and low consequence).

Screening Argument-This field is used only for excluded FEPs. It provides the discussion for why a FEP has been excluded from TSPA-LA.

TSPA Disposition-This field is used only for included FEPs. It provides the consolidated discussion of how a FEP has been included in TSPA-LA, making reference to more detailed documentation in other supporting technical analysis reports, as applicable.

Supporting Reports-This field is only used for included FEPs. It provides the list of supporting technical analysis reports that identified the FEP as an included FEP and contain information relevant to the implementation of the FEP within the TSPA-LA model. This list of supporting technical analysis reports provides traceability of the FEP through the document hierarchy. For excluded FEPs it is indicated as "Not Applicable."

\subsubsection{Supporting Analysis Reports and Indirect Inputs}

Table 6-1 lists the supporting reports, defined in Section 6.1.2, that have been cited for all included igneous and seismic FEPs. The data sources, product outputs, and references used for the FEP evaluations are also cited within each of the individual FEP discussions. The direct inputs for each FEP are documented in Section 4, per YMP procedural requirements and guidance. 
Table 6-1. Supporting Reports for Included FEPs

\begin{tabular}{|l|l|}
\hline DIRS Number & \multicolumn{1}{|c|}{ Supporting Report } \\
\hline 169183 & Seismic Consequence Abstraction \\
\hline 168030 & Characterize Framework for Seismicity and Structural Deformation at Yucca Mountain, Nevada \\
\hline 170027 & $\begin{array}{l}\text { Development of Earthquake Ground Motion Input for Preclosure Seismic Design and } \\
\text { Postclosure Performance Assessment of a Geologic Repository at Yucca Mountain, Nevada }\end{array}$ \\
\hline 169753 & $\begin{array}{l}\text { Mechanical Assessment of the Drip Shield Subject to Vibratory Motion and Dynamic and Static } \\
\text { Rock Loading }\end{array}$ \\
\hline 170063 & Mechanical Assessment of the Waste Package Subject to Vibratory Ground Motion \\
\hline 166107 & Drift Degradation Analysis \\
\hline 169565 & Multiscale Thermohydrologic Model \\
\hline 169131 & Abstraction of Drift Seepage \\
\hline 169980 & Characterize Eruptive Processes at Yucca Mountain, Nevada \\
\hline 169989 & Characterize Framework for Igneous Activity at Yucca Mountain, Nevada \\
\hline 170028 & Dike/Drift Interactions \\
\hline 170001 & Number of Waste Packages Hit by Igneous Intrusion \\
\hline 170026 & $\begin{array}{l}\text { Atmospheric Dispersal and Deposition of Tephra from a Potential Volcanic Eruption at Yucca } \\
\text { Mountain, Nevada }\end{array}$ \\
\hline
\end{tabular}

Other project and external source documents are cited as needed in individual FEPs to amplify the discussions, but are corroborative or referential in nature. Appendix B provides the list of supporting document sources that are cited as indirect sources to seismic and igneous related FEPs.

\subsubsection{Qualification of Unqualified Direct Inputs}

Direct Inputs are listed in Appendix A and any unqualified data are identified by footnotes to the direct inputs table or otherwise identified as being qualified by procedure. These inputs are qualified for use in a separate report "Qualification of Igneous Inputs to Disruptive Events Features, Events, and Processes" (BSC 2004 [DIRS 171999]), qualified per AP-SIII.2Q, Qualification of Unqualified Data. The data are from Crowe et al. 1986 ([DIRS 101532]), which is used as direct input in Section 6.2.2.5, FEP 1.2.04.05.0A (Magma or pyroclastic base surge transports waste). Some of the data summarized in Crowe et al. 1986 ([DIRS 101532]) were collected under the Nevada Nuclear Waste Storage Investigation project in the early 1980s. These data were not subject to a quality assurance program that was compliant with 10 CFR 60, Subpart G. The qualification status of Crowe et al. 1986 ([DIRS 101532]) is indicated in the DIRS database and Appendix A, Table A-1. Appendix C documents justification of additional unqualified data obtained from an outside source for intended use per the requirements of AP-SIII.9Q. 


\subsubsection{Assumptions and Simplifications}

For included FEPs, the TSPA-LA dispositions may include statements regarding assumptions made to implement the FEP within the TSPA-LA model. Such statements are descriptive of the manner in which the FEP has been included and are not used as the basis of the screening decision to include the FEP with the TSPA-LA model.

Because the individual FEPs are specific in nature, any discussion of applicable mathematical formulations, equations, algorithms, numerical methods, or idealizations or simplifications are provided within the individual FEP discussions in Section 6.2.

\subsubsection{Intended Use and Limitations}

The intended use of this analysis report is to provide FEP screening information for a Project-specific FEP database and to promote traceability and transparency regarding FEP screening. This analysis report is intended to be used as the documentation for the FEP database described in The Development of the Total System Performance Assessment-License Application Features, Events, and Processes (BSC 2004 [DIRS 168706]). For included FEPs, this document summarizes and consolidates the method of implementation of the FEP in TSPA-LA in the form of TSPA-LA disposition statements, based on more detailed implementation information in the listed supporting technical analysis reports. For excluded FEPs, this document provides the technical basis for exclusion in the form of screening arguments.

Inherent in this evaluation approach is the limitation that the repository will be constructed, operated, and closed according to the design used as the basis for the FEP screening and in accordance with NRC license requirements. This limitation is inherent in performance evaluation of any engineering project, and design verification and performance confirmation are required as part of the construction and operation processes. The results of the FEP screening presented in this report are specific to the repository design evaluated in this analysis report for TSPA-LA.

Any changes in direct inputs listed in Section 4.1, in baseline conditions used for this evaluation, or in other subsurface conditions will need to be evaluated to determine if the changes are within the limits stated in the FEP evaluations. Engineering and design changes are subject to evaluation to determine if there are any adverse impacts to safety as codified at 10 CFR 63.73 and in 10 CFR 63 Subparts F and G [DIRS 156605]. See also the requirements at 10 CFR 63.44 and 10 CFR 63.131 ([DIRS 156605]).

As discussed in sections 1.3, 4.2, and 7, this report summarizes the results of supporting analysis reports and other information. There is no testing or modeling associated with the development of this report, no new information is developed or presented, and no calculations or analyses are preformed within this document. Therefore, consistent with Section 2.3 of the TWP (BSC 2004 [DIRS 169886]), the procedural requirements of AP-SIII.9Q, Attachment 2, Section 6, concerning items such as uncertainties, alternate scientific approaches, and alternate software/computational methods are not applicable to this document. They have been addressed in the input documents. 


\subsection{DISRUPTIVE EVENTS FEATURE, EVENT, AND PROCESS SCREENING AND ANALYSIS}

This report addresses the 21 disruptive events FEPs that are identified for TSPA-LA consideration. Section 6.2.1 addresses the FEPs classified and assigned as seismic-related FEPs, and Section 6.2.2 addresses the FEPs classified and assigned as igneous-related FEPs. For all FEPs that have been evaluated as included, the discussion of the FEP will provide a brief summary of the basis for inclusion and a description of the manner by which the included FEP is incorporated in the TSPA-LA. For all FEPs that have been evaluated as excluded, the discussion of the FEP will provide the basis for exclusion. In those cases where a FEP is shared with another discipline, a cross-reference will be made to the appropriate FEP subsystem where all the discussions for each FEP will be collected. These subsystems include the engineered barrier system (EBS), unsaturated zone (UZ), and saturated zone (SZ).

\subsubsection{Seismic-Related FEPs}

The following subsections provide the screening decision and related discussions for the seismic-related FEPs:

1.2.01.01.0A Tectonic activity-large scale (Section 6.2.1.1)

1.2.02.03.0A Fault displacement damages EBS components (Section 6.2.1.2)

1.2.03.02.0A Seismic ground motion damages EBS components (Section 6.2.1.3)

1.2.03.02.0B Seismic-induced rockfall damages EBS components (Section 6.2.1.4)

1.2.03.02.0C Seismic-induced drift collapse damages EBS components (Section 6.2.1.5)

1.2.03.02.0D Seismic-induced drift collapse alters in-drift thermohydrology (Section 6.2.1.6)

1.2.03.03.0A Seismicity associated with igneous activity (Section 6.2.1.7)

1.2.10.01.0A Hydrologic response to seismic activity (Section 6.2.1.8)

2.2.06.01.0A Seismic activity changes porosity and permeability of rock (Section 6.2.1.9)

2.2.06.02.0A Seismic activity changes porosity and permeability of faults (Section 6.2.1.10)

2.2.06.02.0B Seismic activity changes porosity and permeability of fractures (Section 6.2.1.11)

2.2.06.03.0A Seismic activity alters perched water zones (Section 6.2.1.12). 


\subsubsection{Tectonic Activity-Large Scale (1.2.01.01.0A)}

FEP Description:

Large-scale tectonic activity, such as regional uplift, subsidence, folding, mountain building, or other processes related to plate movements, could affect repository performance by altering the physical and thermohydrologic properties of the geosphere.

Screening Decision: $\quad$ Excluded - Low Consequence.

Screening Argument: Global or plate-scale tectonics drives tectonism at the regional scale, and regional scale features, such as the Walker Lane, are expressed at the site scale as faults, folds, and similar features. Site scale features, events and processes related to tectonic activity, such as volcanism, faulting, seismicity, and fracturing, are evaluated as separate FEPs.

Large-scale tectonic activity is interpreted for this FEP to refer to tectonism that is expressed at a regional scale (1:250,000 to $1: 500,000$ or even less) and that has the potential to produce broad uplift, subsidence, folding, faulting, and geothermal effects. These changes, if they were to occur at a sufficient rate, could potentially impact UZ and SZ flow and transport properties during the repository performance period (10,000 years), thereby affecting dose and radionuclide release to the accessible environment. The basis for exclusion of large-scale tectonic activity is two-fold. First, rates of tectonic activity in the vicinity of Yucca Mountain are low, and if they were to occur uniformly across the region, no impacts are anticipated. For example, if all of the Southern Great Basin is gradually and uniformly uplifted a few meters over the next 10,000 years, there is no conceivable affect on radionuclide release from the repository. Second, it is explicitly recognized that large-scale tectonic activity can manifest itself locally, such as by displacement on a fault near the repository. These types of site-scale FEPs are treated as separate FEPs to ensure that their potential impacts are adequately evaluated. This two-fold approach ensures that all aspects of the large-scale tectonic activity FEP are appropriately addressed.

In the paragraphs that follow, documentation is provided for the low rate of tectonic activity in the vicinity of Yucca Mountain and several scenarios are discussed that support the screening decision for "Exclusion" of this FEP. In addition, cross-references are made to discussions of related FEPs, where appropriate.

Low Rates of Tectonic Activity-Yucca Mountain lies within the Southern Great Basin of the Basin and Range tectonic province and is located on the south flank of a large Miocene caldera complex. Structurally, the mountain is dominated by subparallel fault blocks that trend to the north and dip to the east. The blocks of ash-flow tuff are bounded by typical Basin and Range style, high-angle, generally west-dipping, normal and oblique faults that formed by rapid east-west extension during the waning phases of Miocene volcanism (BSC 2004 [DIRS 169989], Sections 6.1.1.1 and 6.4.1.1). The Miocene is defined as 23.8 Ma to 5.3 Ma. Secondary intrablock faults are common. Yucca Mountain is also within the Walker Lane, a 100-km-wide structural belt along the western edge of the Basin and Range province. The Walker Lane is characterized by long, northwest-striking and shorter, north-to-northeast-striking, strike-slip 
faults that accommodated much of the early extension in this region. At a more local scale, Yucca Mountain is within the Crater Flat Domain, and is located just east of the Crater Flat basin. The peak phase of tectonism took place during the middle Miocene, and the region has since experienced declining strain rates.

During the period of peak tectonism (approximately 11.6 to $12.7 \mathrm{Ma}$ ), the western part of Crater Flat basin subsided due to the basin extending from 18 to 40 percent in 1.1 million years or less. After 11.6 Ma, the rate of extension in the basin declined in a roughly exponential manner. The late Quaternary rate of extension is less than 1 percent of the initial rate (Fridrich et al. 1998 [DIRS 164051], pp. 1 and 13) and may be as low as 0.1 to 0.2 percent per million years (Fridrich et al. 1998 [DIRS 164051], pp. 19 and 20). The pattern of Quaternary deformation mimics the pattern of middle Miocene activity; however (as just discussed), at substantially lower rates (Fridrich et al. 1998 [DIRS 164051], pp. 1 and 2). Even during the Quaternary, the rate of subsidence appears to have diminished consistently over the last several million years and the locus of subsidence due to the waning extension has migrated west of Yucca Mountain (inferred from Fridrich 1999 [DIRS 118942], p. 189; Dixon et al. 1995 [DIRS 102793], p. 765). Although Crater Flat basin remains technically active, it is now in an advanced state of decline according to Fridrich et al. (1998 [DIRS 164051], p. 2).

As described in Characterize Framework for Seismicity and Structural Deformation at Yucca Mountain, Nevada (BSC 2004 [DIRS 168030], Section 6.3.1), tectonically, the Basin and Range is currently experiencing extensional strain at a low to moderate rate with low to moderate historical seismicity. Support for this statement comes from several sources. Fridrich (1999 [DIRS 118942], p. 190) indicates that across the southern part of the Crater Flat Basin, the northwest-southeast lengthening is approximately $0.1 \mathrm{~m}$ per thousand years. He also states that the late Quaternary extension rate is approximately one-half as great across central Yucca Mountain, and an order of magnitude lower across northern Yucca Mountain. Savage et al. (1999 [DIRS 118952]) present an evaluation of the rate of strain accumulation at Yucca Mountain, Nevada, for the period from 1983 to 1998. They also address alternative interpretations indicating higher strain-accumulation rates presented by Wernicke et al. (1998 [DIRS 103485]). The contemporary strain-accumulation rate in the Yucca Mountain area is very slow (less than $2 \mathrm{~mm} / \mathrm{yr}$ ) (Savage et al. 1999 [DIRS 118952], p. 17627). Reported as "principal strain accumulation rate" of $2+/-12$ nanostrain/year at $N 87^{\circ} \mathrm{W}+/-12^{\circ}$ and $-22+/-12$ nanostrain/year at $\mathrm{N} 03^{\circ} \mathrm{E}+/-12^{\circ}$, this strain accumulation is consistent with the paleoseismic slip rates calculated from Quaternary fault-displacement studies. Fault slip rates considered most probable at Yucca Mountain range from $0.001-0.03 \mathrm{~mm} / \mathrm{yr}$, excluding the Stagecoach fault, which may locally measure $0.05 \mathrm{~mm} / \mathrm{yr}$ (BSC 2004 [DIRS 168030], Table 6). The slip rate range represents the Solitario Canyon and Bow Ridge faults, which, as discussed in Section 6.2.1.2 (FEP 1.2.02.03.0A), are considered the block-bounding faults with the most potential to affect the repository.

Since uncertainties in strain rates are reflected at the site scale in uncertainties in recurrence and slip rates, uncertainty in the tectonic strain rate is implicitly evaluated through the consideration of multiple tectonic models and through uncertainties in the recurrence rates (CRWMS M\&O 1998 [DIRS 103731], Sections 7.1.1, 8.1.3, and Appendix E). The resulting hazard curves are used to evaluate FEPs specific to those issues. 
The present extensional-tectonic regime of the Yucca Mountain region does not promote significant tectonic uplift and mountain building. Based on the history of the Crater Flat Basin as presented in Characterize Framework for Seismicity and Structural Deformation at Yucca Mountain, Nevada (BSC 2004 [DIRS 168030]), and described briefly above, tectonic subsidence due to regional extension is a more likely scenario at Yucca Mountain than uplift. Subsidence will not perceptibly be advanced in the absence of significant slip along the block-bounding faults. Probable fault slip rates for block-bounding faults at Yucca Mountain (i.e., Solitario Canyon and Bow Ridge faults) are low, measuring at most $0.03 \mathrm{~mm} / \mathrm{yr}$ (BSC 2004 [DIRS 168030], Table 6). The probability of such movement is reflected in the hazard curves presented in the PSHA (CRWMS M\&O 1998 [DIRS 103731]) and used in the specific FEP evaluations for ground motion and faulting, which have been included. Thus, there is no mechanism not already considered (i.e., seismic ground motion and fault displacement) stemming from an extensional terrain that would lead to increased exposure or increased release of radionuclides to the accessible environment.

Physical Separation from Tectonically Active Areas-Tectonic activity at a regional scale typically is concentrated in zones or belts of ten, to hundreds of kilometers in width (Thatcher et al. 1999 [DIRS 119053], pp. 1714 to 1715) and persists for millions of years. The closest significant tectonic zones relevant to a discussion of Yucca Mountain include the eastern California shear zone, located west of the Funeral Mountains (west of Yucca Mountain), and the intermountain seismic belt, located generally north of $37^{\circ} \mathrm{N}$ latitude (north of Yucca Mountain) (Savage et al. 1995 [DIRS 104553], p. 20263). These zones and belts are characterized by relatively high geodetic strain rates and recurrent earthquakes (Thatcher et al. 1999 [DIRS 119053], pp. 1714 and 1715). In contrast, Yucca Mountain and its setting (i.e., the Crater Flat domain) have a lower geodetic strain rate (Savage et al. 1999 [DIRS 118952], p. 17627). The low geodetic strain rate (Savage et al. 1995 [DIRS 104553], p. 20263 and Figure 9), and low seismicity levels (e.g., Rogers et al. 1987 [DIRS 100176], p. 82) found in the Crater Flat domain suggest that the site area is located in a tectonic domain that may be isolated from the zones of high geodetic strain located to the west and to the north.

Possible Impacts on Infiltration Rates-Large-scale tectonic activity is reflected at the site as regional scale features such as faults and folds, as well as topography. Changes to such features resulting from large-scale tectonic activity may have an affect on infiltration. Day et al. (1996 [DIRS 124302], p. 2-7) observes deformation features in the hanging wall block associated with the Bow Ridge fault that suggest beds in the hanging wall block have been tilted and fractured associated with fault displacement. Future deformation in the hanging wall block will be low, not exceeding the strain associated with even the highest local fault slip rate (e.g., $0.05 \mathrm{~mm} / \mathrm{yr}$ for the Stage Coach Road fault, which would amount to $0.5 \mathrm{~m}$ in 10,000 years). Therefore, deformation within the hanging wall block is not expected to be significant. It follows that any impact on infiltration due to future hanging wall deformation is considered negligible.

Furthermore, the PSHA suggests the majority of future strain will be accommodated on block-bounding faults (see FEP 2.2.06.02.0B). This is corroborated by a critical tilting angle of approximately $25^{\circ}$ (Fridrich et al. 1996 [DIRS 105086], pp. 2-21 and 2-22). Block faulting will occur before an increase in fold-limb dip (and associated fracturing in the hangwall block) becomes a significant factor in determining local percolation. 
The effects of fractures on percolation flux have also been evaluated in a sensitivity study (BSC 2004 [DIRS 170012], Appendix D). Minor changes in fractured rock will not significantly affect infiltration or groundwater flow because increased fracturing will not occur to a degree greater than, or no more significant than, other uncertainties related to infiltration (BSC 2004 [DIRS 170012], Appendix D). That analysis also concluded that changes in fracture aperture confined to fault zones show virtually no effect on transport behavior. Furthermore, increased fracture aperture applied over the entire UZ domain results in effects that are no more significant than other uncertainties related to infiltration (BSC 2004 [DIRS 170012], Appendix D). Changes in porosity and permeability of faults, fractures, and the rock matrix are further addressed as specific FEPs.

The low rates of tectonic activity discussed previously related to uplift and subsidence; also apply to changes in topography. Given low and declining rates of tectonic activity, topographic changes will also not impact infiltration rates.

Possible Impacts on the Geothermal Regime-With regard to the geothermal regime, Yucca Mountain is now located in an area of moderate heat flow in the Southern Great Basin and lies south of the regions of higher crustal heat flow in the northern part of the Great Basin (Lachenbruch and Sass 1978 [DIRS 142990], pp. 212 and 246). The advent of basaltic volcanism at about $11 \mathrm{Ma}$, as described by Crowe et al. (1995 [DIRS 100110], pp. 4-1 and 4-2), signaled the end of crustal-level magmatism near Yucca Mountain. The description indicates generation of small, discrete batches of basaltic magma at upper-mantle depths (45 to $60 \mathrm{~km}$ (28 to $36 \mathrm{mi})$ ) that are capable of making their way quickly to the surface (Crowe et al. 1995 [DIRS 100110], pp. 5-2 and 5-6). Only small volumes (less than $0.5 \mathrm{~km}^{3}$ ) of basaltic magma have been generated in the Yucca Mountain region during the Quaternary (Crowe et al. 1995 [DIRS 100110], p. 5-5).

For the existing geothermal gradient to change significantly, there would have to be a major change in the present tectonic setting (see Low Rates of Tectonic Activity above). For example, a large volume of magma emplaced high in the mid-to-upper crust at approximately $5 \mathrm{~km}$ in depth (inferred from Lachenbruch and Sass 1978 [DIRS 142990], pp. 224 and 244) could bring the Yucca Mountain area to a pre-eruptive state with attendant hot-spring activity. However, this example would require great extension rates and crustal mobility, a rapidly evolving mantle, and subcrustal conditions that involve either a mantle plume hot spot (Parsons et al. 1994 [DIRS 106479], p. 83), or melting of a weakened subducting slab (inferred from Bohannon and Parsons 1995 [DIRS 101865], p. 957). A significant (i.e., potentially hazardous) increase in geothermal gradient associated with tectonic activity would probably require several million years of evolution of the tectonic setting.

The present tectonic state of Yucca Mountain and the present source of basaltic-magma generation at depths around 45 to $60 \mathrm{~km}$ (Crowe et al. 1995 [DIRS 100110], p. 5-2 and Figure 5-1) are consistent with the present geothermal gradient. By way of corroboration, after a two-year study, scientists at the University of Nevada Las Vegas (UNLV) concluded that hydrothermal water has not invaded the rocks of Yucca Mountain in at least two million years (Wilson and Cline 2001 [DIRS 155426]). The study indicates that fluid inclusions within minerals found in roughly half of the 155 rock samples collected throughout Yucca Mountain for the study were formed at temperatures ranging from $113^{\circ} \mathrm{F}$ to $141^{\circ} \mathrm{F}\left(45^{\circ} \mathrm{C}\right.$ to $\left.60^{\circ} \mathrm{C}\right)$. Moreover, 
calcite deposited in fractures and voids was not the result of deposition from the upwelling of geothermal water. The uranium-lead dating for the study indicates that the two-phase fluid inclusions are older than a minimum age of 1.9 million years. More precise age constraints on the two-phase fluid inclusions (based on associated dateable material) indicated that the two-phase fluid inclusions were older than 4.0 to 5.3 million years. The UNLV study concluded that mineral precipitation at the site has been stable for at least the last two to three million years and is consistent with formation from low temperature surficial fluids, rather than saturation of the site by upwelling hydrothermal fluids.

The existing geothermal regime is currently addressed, and conditions sufficient to create or allow a significant change in the regional geothermal regime within the 10,000-year performance period are absent. Consequently, there is no feasible and additional geothermal regime-related mechanism considered capable of leading to an increased exposure or an increased release of radionuclides into the accessible environment. This aspect of the FEP, therefore, is excluded based on low consequence.

Possible Impacts on Rates of Volcanism-A tectonic-related increase in volcanism could potentially impact the performance of the repository. Details of igneous events as they relate to a proposed repository at Yucca Mountain are specifically addressed in Characterize Framework for Igneous Activity at Yucca Mountain, Nevada (BSC 2004 [DIRS 169989]). Furthermore, the Probabilistic Volcanic Hazard Assessment (PVHA) (CRWMS M\&O 1996 [DIRS 100116]) documents the results of an expert elicitation project that provided the technical basis for assessing hazards related to volcanism. The use of tectonic models as they relate to volcanic hazard is summarized in the PVHA (CRWMS M\&O 1996 [DIRS 100116]). The PVHA serves as the basis for estimates of future igneous intrusion probability. The PVHA method incorporated the possibility that volcanic events are clustered in time. The PVHA also incorporated the possible waning or waxing of volcanic activity in the region during the period of time the experts believed was relevant to hazard analysis (BSC 2004 [DIRS 169989], Section 6.3.1.3). Thus, there is no igneous-related mechanism that has not already been considered (i.e., increased igneous activity related to tectonic changes) that would lead to an increased exposure or an increased release of radionuclides into the accessible environment.

Possible Impacts on Water Level-The evaluation of this FEP included consideration of the change in the spatial relationship of the repository and the current water table due to a tectonic-related mechanism. If a significant change (rise) in the water table were to occur, there could be potential impacts on repository performance. The mechanisms for such changes to occur could involve rising of the water level; lowering of the repository; or a combination of the effects of the first two. This consequence is excluded due to the factors described in conditions 1,2 , and 3 below.

(1) Rising of the water level. The vertical distance between the base of the repository and the saturated zone is approximately $300 \mathrm{~m}$. Stuckless (1996 [DIRS 119051], pp. 98 to 99) discusses excursions of the water table in Plio-Pleistocene time, and indicates that past water level elevations are estimated to have been a maximum of about $115 \mathrm{~m}$ higher than present levels. Stuckless further indicates that "neither geologic evidence for these past elevations nor hydrologic flow models suggest that the rises in the water 
table in response to climate changes, similar to those of the past 2 million years, would be sufficient to threaten the repository horizon in the future."

These past water level elevations reflect the effects of wetter climates and perhaps greater strain rates than currently exist. Climate changes have been considered and are included in the TSPA-LA models. Changes in strain rates could, hypothetically, also cause an increase in water levels. However, the horizontal geodetic strain-accumulation rate in the Yucca Mountain region is currently low, at approximately less than $2 \mathrm{~mm} / \mathrm{yr}$ (Savage et al. 1999 [DIRS 118952], p. 17627), with the strain reported as a nanostrain/yr rate. A change to a significantly higher rate would require major changes to the tectonic regime, which is a process requiring millions (not thousands) of years. Furthermore, regional strain patterns indicate waning effects of strain extension east of Death Valley (inferred from Fridrich 1999 [DIRS 118942], p. 191) with relatively minimal changes in strain conditions. A rise in water level, or change in head, could also be related to sudden changes in the strain conditions due to an earthquake and could result in seismic pumping as reported in Gauthier et al. (1996 [DIRS 100447], pp. 163 to 164). This corroborative analysis was performed for the total system performance assessment for viability assessment (TSPA-VA) to simulate the timing, amplitude, and duration of water-table rise, and indicated a maximum and temporary rise of $50 \mathrm{~m}$ within an hour of a simulated seismic event (Gauthier et al. 1996 [DIRS 100447], p. 164). This mechanism is described more fully for FEP 1.2.10.01.0A (Hydrologic response to seismic activity) and has been excluded. Therefore, neither regional changes in tectonic strain rates, nor seismic events have the potential to raise the water level at Yucca Mountain the $300 \mathrm{~m}$ needed to impact the repository during the 10,000-year performance period.

(2) Lowering the repository: Under long-term extension, normal faulting has caused the faulted blocks of Yucca Mountain to subside into Crater Flat basin. However, the rate of subsidence is proportional to the paleoseismic slip rate, amounting to no more than $0.3 \mathrm{~m}$ in 10,000 years or $30 \mathrm{~m}$ in a 1 million year period. As stated previously, probable fault slip rates for block-bounding faults are no more than $0.03 \mathrm{~mm} / \mathrm{yr}$ (BSC 2004 [DIRS 168030], Table 6). This cumulative displacement is small compared to the distance separating the repository and the water table. Therefore, cumulative fault offset alone is insufficient to cause the water table to approach the repository level given current rates of fault movement at Yucca Mountain.

(3) Combination of effects: Even if expected subsidence ( $0.3 \mathrm{~m}$ in 10,000 years) occurs, the accompanying water table rise would need to be on the order of $300 \mathrm{~m}$ for this FEP to be of any consequence. Based on geologic evidence as previously discussed, and as shown in the discussion regarding water table rise, the maximum increase in the water table (associated with climate change) would be no more than $115 \mathrm{~m}$. So, the distance between the water level and the repository would decrease by no more than approximately $115.3 \mathrm{~m}$. Therefore, the combined effects of a maximum water table rise and an expected subsidence of $0.3 \mathrm{~m}$ are insufficient to cause the water table to reach the repository level. Even if these two mechanisms were coupled with a seismic event (resulting in a temporary additional 50-m water table rise for a total of $165.3 \mathrm{~m}$ ), the water table would still remain approximately $134.7 \mathrm{~m}$ below the repository level. 


$\begin{array}{ll}\text { TSPA Disposition: } & \text { Not Applicable } \\ \text { Supporting Reports: } & \text { Not Applicable }\end{array}$

\subsubsection{Fault Displacement Damages EBS Components (1.2.02.03.0A)}

FEP Description:

Screening Decision: $\quad$ Included

Screening Argument:

TSPA Disposition:
Movement of a fault that intersects drifts within the repository may cause the EBS components to experience related movement or displacement. Repository performance may be degraded by such occurrences as tilting of components, component-to-component contact, or drip shield separation. Fault displacement could cause a failure as significant as shearing of drip shields and waste packages by virtue of the relative offset across the fault, or as extreme as exhumation of the waste to the surface.

\section{Not Applicable}

Faulting is considered to be a potentially disruptive process with effects that include sudden relative rock/soil displacements across a fault surface (i.e., fault displacement). These effects are potentially relevant to the integrity of the repository and are included in the TSPA-LA. The analysis model report supporting the Screening Decision contains a table of included FEPs with pointers to more detailed background information on this FEP (BSC 2004 [DIRS 169183], Table 6.2-1). Ground motions associated with fault displacements and rock fall are addressed under separate FEPs.

The following technical basis for inclusion involves a comparison of the potential fault displacement occurring at a $10^{-8}$ annual frequency (see Assumption 5.1 in Section 5) to various elements of the repository design (i.e., waste package-to-drift wall spacing and set-back requirements). As discussed in Seismic Consequence Abstraction (BSC 2004 [DIRS 169183], Section 6.7.2), the potential for fault displacement damage from block-bounding and intra-block faults and features likely to exist within the repository is included in the TSPA-LA. Block bounding faults are implicitly included, while other faulting within the repository block are explicitly included. Fault displacement could impact waste packages through mechanical damage caused directly by the fault displacement (BSC 2004 [DIRS 169183], Section 6.7).

The history of faulting and the nature of fault slip and its structural effects at Yucca Mountain are well known (CRWMS M\&O 1998 [DIRS 103731]; Whitney 1996 [DIRS 100188]). In situ stress measurements indicate that faults at Yucca Mountain are at the yield state (Stock and Healey 1988 [DIRS 101022], p. 92; Stock et al. 1985 [DIRS 101027], p. 8705). The PSHA considers these factors and provides the results of the expert-elicitation process as it applies to probable fault displacements at Yucca Mountain. 
The PSHA (CRWMS M\&O 1998 [DIRS 103731], Figures 8-2 to 8-14, p. 8-7) specifically examines displacements at specific points along block-bounding faults (Points 1 and 2), and intra-block faults (Points 3 through 6 and 9). The PSHA assessed features likely to be found within the repository (Points 7 and 8) with various preexisting conditions, including the occurrence of features within the intact rock (Points $7 \mathrm{~d}$ and $8 \mathrm{~d}$ ). These points were chosen to represent the range of conditions that may be encountered near or within the repository. Table 6-2 provides the median and mean fault displacements for the $10^{-8}$ annual-exceedance probability. The mean values for fault displacements at annual-exceedance probabilities of less than $10^{-6}$ are increasingly skewed toward larger displacements relative to median values. Therefore, the mean values shown in Table 6-2 represent a conservative projection of potential fault displacements and are used for the evaluations discussed below.

Table 6-2. Annualized Frequency of Exceedance and Displacements for Various Locations within the TSPA-LA Repository Footprint

\begin{tabular}{|c|c|c|}
\hline Location & $\begin{array}{c}\text { Median Displacement }(\mathrm{cm}) \text { for } \\
\text { Postclosure }\end{array}$ & $\begin{array}{c}\text { Mean Displacement }(\mathrm{cm}) \\
\text { for } \\
\text { Postclosure }\end{array}$ \\
\hline & \multicolumn{2}{|c|}{ Annual Frequency } \\
\hline & $10^{-8}$ & $10^{-8}$ \\
\hline 1. Bow Ridge fault & 200 & 600 \\
\hline 2. Solitario Canyon fault & 300 & $>1000$ \\
\hline 3. Drill Hole Wash fault & 30 & 240 \\
\hline 4. Ghost Dance fault & 59 & 160 \\
\hline 5. Sundance fault & 9.9 & $\sim 145$ \\
\hline 6. Unnamed fault west of Dune Wash & 20 & 210 \\
\hline $\begin{array}{l}\text { 7a. A hypothetical small fault with } 2 \mathrm{~m} \text { of offset, } \\
\text { located about } 100 \mathrm{~m} \text { east of Solitario } \\
\text { Canyon fault }\end{array}$ & 2.1 & $\sim 75$ \\
\hline $\begin{array}{l}\text { 7b. A hypothetical shear with } 10 \mathrm{~cm} \text { of offset, } \\
\text { located about } 100 \mathrm{~m} \text { east of Solitario } \\
\text { Canyon fault }\end{array}$ & $<0.1$ & 9 \\
\hline $\begin{array}{l}\text { 7c. A hypothetical fracture, located about } 100 \mathrm{~m} \\
\text { east of Solitario Canyon fault (no cumulative } \\
\text { displacement) }\end{array}$ & $<0.1$ & $<1$ \\
\hline $\begin{array}{l}\text { 7d. Intact rock, located about } 100 \mathrm{~m} \text { east of } \\
\text { Solitario Canyon fault }\end{array}$ & $<0.1$ & $<0.1$ \\
\hline $\begin{array}{l}\text { 8a. A hypothetical small fault with } 2 \mathrm{~m} \text { of offset, } \\
\text { located between the Solitario Canyon fault } \\
\text { and the Ghost Dance fault }\end{array}$ & 2.1 & $\sim 75$ \\
\hline $\begin{array}{l}\text { 8b. A hypothetical shear with } 10 \mathrm{~cm} \text { of offset, } \\
\text { located between the Solitario Canyon fault } \\
\text { and the Ghost Dance fault }\end{array}$ & $<0.1$ & 9 \\
\hline $\begin{array}{l}\text { 8c. A hypothetical fracture, located between the } \\
\text { Solitario Canyon fault and the Ghost Dance } \\
\text { fault }\end{array}$ & $<0.1$ & $<1$ \\
\hline
\end{tabular}


Table 6-2. Annualized Frequency of Exceedance and Displacements for Various Locations within the TSPA-LA Repository Footprint (Continued)

\begin{tabular}{|c|c|c|}
\hline Location & $\begin{array}{l}\text { Median Displacement (cm) for } \\
\text { Postclosure }\end{array}$ & $\begin{array}{c}\text { Mean Displacement }(\mathrm{cm}) \\
\text { for } \\
\text { Postclosure }\end{array}$ \\
\hline & \multicolumn{2}{|c|}{ Annual Frequency } \\
\hline & $10^{-8}$ & $10^{-8}$ \\
\hline $\begin{array}{l}\text { 8d. Intact rock, located between the Solitario } \\
\text { Canyon fault and the Ghost Dance fault }\end{array}$ & $<0.1$ & $<0.1$ \\
\hline $\begin{array}{l}\text { Midway Valley, fracture with no cumulative } \\
\text { displacement }\end{array}$ & 28 & 200 \\
\hline
\end{tabular}

Source: BSC 2004 [DIRS 169183], Table 6.7-5 and DTN: MO0401MWDRPSHA.000 [DIRS 166962], from files: /displ/tot_haz/s1.frac_mean.gz; /displ/tot_haz/s2.frac_mean.gz; ./displ/tot_haz/s3.frac_mean.gz; ./displ/tot_haz/s4.frac_mean.gz; ./displ/tot_haz/s5.frac_mean.gz;./displ/tot_haz/s6.frac_mean.gz; /displ/tot_haz/s7a.frac_mean.gz; /displ/tot_haz/s7b.frac_mean.gz; ./displ/tot_haz/s7c.frac_mean.gz; ./displ/tot_haz/s7d.frac_mean.g; ./displ/tot_haz/s8a.frac_mean.gz; ./displ/tot_haz/s8b.frac_mean.gz; ./displ/tot_haz/s8c.frac_mean.gz; ./displ/tot_haz/s8d.frac_mean.gz; ./displ/tot_haz/s9.frac_mean.gz.

NOTE: Zero displacement at Sites $7 \mathrm{~d}$ and $8 \mathrm{~d}$ at $>10^{-8}$ annual frequency is documented in DTN: MO0401MWDRPSHA.000 [DIRS 166962]. See also Probabilistic Seismic Hazard Analyses for Fault Displacement and Vibratory Ground Motion at Yucca Mountain, Nevada (CRWMS M\&O 1998 [DIRS 103731], Section 8.2.1). Some displacement information was scaled from figures presented in the PSHA (CRWMS M\&O 1998 [DIRS 103731], Figures 8-2 to 8-14 and p. 8-7) and may be approximate. Mean values for $10^{-8}$ annual frequency were extrapolated from Probabilistic Seismic Hazard Analyses for Fault Displacement and Vibratory Ground Motion at Yucca Mountain, Nevada (CRWMS M\&O 1998 [DIRS 103731], Figure 8-3) for Site 2.

Block-Bounding Faults-The block-bounding faults include the Bow Ridge fault (Point 1) and the Solitario Canyon fault (Point 2). The Bow Ridge fault is located to the east of the waste emplacement area, whereas the Solitario Canyon fault parallels the western repository footprint boundary. At a $10^{-8}$ annual-exceedance probability (see Assumption 5.1), the estimated mean displacements are $6 \mathrm{~m}$ and greater than $10 \mathrm{~m}$, respectively (Table 6-2). Both of these estimated mean displacements are greater than the nominal 5.5-m tunnel diameter planned for the emplacement drifts, so any engineered components present at the location of offset and displacement would be damaged. The Solitario Canyon fault and the Bow Ridge fault lie outside the emplacement area of the repository and require standoffs, as defined in the Underground Layout Configuration (BSC 2003 [DIRS 165572], Section 7.1.3).

Intrablock Faults and other Features Likely to Be Found in the Repository-The Drill Hole Wash fault, Pagany Wash fault, and Sever Wash fault are northwest-trending parallel intra-block faults that intersect the emplacement drifts in the northeast section of the repository (CRWMS M\&O 1998 [DIRS 103731], Figure 4-9). Referring to Table 6-2, the fault displacement hazard for the Drill Hole Wash fault is assumed (BSC 2004 [DIRS 169183], Section 5.2) to apply to the Pagany Wash fault and Sever Wash fault for purposes of determining consequences of their intersection with emplacement drifts. The Sundance fault is also considered in the fault displacement consequence model. Fault displacements range from $240 \mathrm{~cm}$ (Drill Hole Wash fault) to approximately $145 \mathrm{~cm}$ (Sundance fault) for the mean annual frequency $10^{-8}$ per year (Table 6-2). The disposition of the Ghost Dance fault in the TSPA-LA is discussed below.

Additionally, other displacement features that are likely to be found within the repository are represented in the PSHA using a fixed location within the repository, but with hypothetical 
existing characteristics (Points 7 and 8). The PSHA (CRWMS M\&O 1998 [DIRS 103731], Figures 8-8 to 8-13) addresses such features within the waste-emplacement area by assessing the probability of displacement along existing small faults, shears, and fractures, as represented in the PSHA for Points $7 \mathrm{a}, 7 \mathrm{~b}, 7 \mathrm{c}, 8 \mathrm{a}, 8 \mathrm{~b}$, and $8 \mathrm{c}$ as explained in Table 6-2. The mean $10^{-8}$ annual-exceedance probability for these small faults, shears, and fractures is $75 \mathrm{~cm}, 9 \mathrm{~cm}$, and less than $1 \mathrm{~cm}$, respectively. The PSHA (CRWMS M\&O 1998 [DIRS 103731], p. 8-7) also examines the probability of displacement in the intact rock (Points $7 \mathrm{~d}$ and $8 \mathrm{~d}$ ) at these hypothetical locations. The PSHA indicates that there is only a very unlikely probability (less than $10^{-8}$ annual-exceedance probability) that movement greater than $0.1 \mathrm{~cm}$ will occur in the intact rock. The potential for displacement in the intact rock is inferred to be analogous to the creation of new faults and fractures.

The fault displacement analysis considers a range of displacement, ranging from a maximum of $240 \mathrm{~cm}$ at the Drill Hole Wash fault and similarly oriented faults, down to less than $0.1 \mathrm{~cm}$ for intact rock (BSC 2004 [DIRS 169183], Table 6.7-5). To determine whether this range of displacements is significant to repository performance, the displacements are compared to the spatial gaps between various EBS components. This determination is dependent on whether the faulting occurs within a collapsed drift or an uncollapsed drift, which depends on the lithophysal or nonlithophysal character of the repository (BSC 2004 [DIRS 169183], Section 6.7.1 and 6.7.2.1).

The analysis concludes that no damage will occur to waste packages without tunnel collapse (BSC 2004 [DIRS 169183], Section 6.7.4 and 6.7.2.1). See FEPs 1.2.03.02.0B (Section 6.2.1.4) and 1.2.03.02.0C (Section 6.2.1.5) for a detailed discussion of seismic-induced drift degradation in lithophysal and nonlithophysal zones. For fault displacement, analyses find that known faults intersect emplacement drifts in lithophysal and nonlithophysal zones. For faulting at locations other than at known faults, analyses also conclude intersections occur in lithophysal and nonlithophysal zones (BSC 2004 [DIRS 169183], Section 6.7.2.2). Intersections are assumed to occur only in lithophysal zones because this is most restrictive in terms of clearance for the waste package and because the fraction of the overall repository in the lithophysal zone is 0.85 , compared to 0.15 for nonlithophysal zones (BSC 2004 [DIRS 169183], Sections 6.7.2.1 and 6.7.2.2).

Depending on the type of waste package, maximum allowable displacement within a collapsed drift (lithophysal zone) ranges from 671 to 1,079 mm (BSC 2004 [DIRS 169183], Section 6.7.1 and Table 6.7-8). Comparing these values to fault displacement from mean hazard curves (Table 6-2) provides the technical basis for the analysis. At the $10^{-6}$ annual exceedance frequency and less, the analysis concludes all boiling water reactor (BWR), pressurized water reactor (PWR), and naval spent nuclear fuel (naval) waste packages will survive a fault displacement event for Sites 7a and 8a in collapsed tunnels within lithophysal zones (BSC 2004 [DIRS 169183], Section 6.7.4). The maximum fault displacement for Sites 7 and 8 is $75 \mathrm{~cm}$ $(750 \mathrm{~mm})$, less than the allowable fault displacement of $852 \mathrm{~mm}$ for the naval waste package group with drift collapse. Again, the same conclusion is valid for the BWR and PWR waste package designs with even greater margin.

However, at mean annual exceedance frequencies between $10^{-7}$ per year and $10^{-8}$ per year, waste package failure may occur for any of the waste packages placed directly over four considered 
faults: the Drillhole Wash, Pagany, Sever, and Sundance faults. The same condition applies to the high-level radioactive waste package group placed over faults characterized by location $7 \mathrm{a}$ and 8a. In these cases, the fault displacement values in Table 6-2 exceed the maximum allowable displacements for the binned waste types PWR, BWR, naval and high-level radioactive waste (BSC 2004 [DIRS 169183], Section 6.7.4). The potential for fault displacement to impact waste packages through mechanical damage is explicitly included in the TSPA-LA, as described below (i.e., Block-bounding faults and Intrablock Faults and other Features Likely to Be Found in the Repository).

Consideration of Exhumation Due to Fault Displacement-The FEP description also mentions the extreme case of fault displacements leading to waste exhumation. The depth of the repository below the surface is on the order of $200 \mathrm{~m}$ or greater (BSC 2004 [DIRS 164519]; BSC 2003 [DIRS 165572]). The potential for exhumation due to fault movement is not credible given the low fault slip rates on block-bounding faults (i.e., Solitario Canyon and Bow Ridge). Likely fault slip rates for these faults are at most $0.03 \mathrm{~mm} / \mathrm{yr}$, or $0.3 \mathrm{~m}$ or less in 10,000 years (BSC 2004 [DIRS 168030], Table 6). Therefore, this aspect of the FEP is not considered further.

Implementation in the TSPA-LA-In the TSPA-LA model, the seismic scenario class evaluates the impact on EBS components from vibratory ground motion, fault displacement, and ground motion-induced post-seismic changes to the in-drift environment. The FEP is shared with Engineered Barrier System Features, Events, and Processes, where TSPA-LA disposition is also described with more emphasis on degradation effects (BSC 2004 [DIRS 169898]). Details on the manner of TSPA-LA disposition of included components of the seismic scenario class in the TSPA-LA are addressed in the model reports Seismic Consequence Abstraction (BSC 2004 [DIRS 169183]) and the Total System Performance Assessment (TSPA) Model for the License Application (BSC 2004 [DIRS 168504], Section 6.5).

Block-bounding faults-The Solitario Canyon and Bow Ridge block-bounding faults are not explicitly included in the TSPA-LA abstraction for mechanical disruption of EBS components from fault displacement. Standoffs are required for these faults and their location is outside the emplacement areas of the repository (BSC 2003 [DIRS 165572], Section 7.1.3). Potential displacements from these faults are implicitly included in the TSPA-LA because the repository design is the basis for the model configuration used in the TSPA-LA. For the Solitario Canyon and Bow Ridge block-bounding faults, the design basis for the TSPA-LA model configuration is based on project requirements, discussed below.

A Type 1 fault is a repository design term that refers to faults or fault zones that are subject to displacement and could have an effect on repository performance. Underground Layout Configuration (BSC 2003 [DIRS 165572], Section 7.1.3) states that a standoff must be maintained from the closest edge of a repository opening to the main trace of any Type I fault zones. Furthermore, the preferred location of the repository is the proposed repository block as defined by block bounding faults. For the above faults, waste packages will not be placed closer than the standoff $(60 \mathrm{~m})$ to the main fault trace unless a specific site impact analysis is performed (BSC 2003 [DIRS 165572], Sections 7.1.3 and 7.3.1). In the event that the standoff from repository openings to a Type I fault is waived following a site impact analysis, a standoff must be maintained between Type I faults and any waste package. In such cases, the standoff from the edge of the Type I fault or fault zone is defined as $15 \mathrm{~m}$ (49 feet). 
Intrablock Faults and other Features Likely to Be Found in the Repository-There are known faults that intersect the repository, including the traces of the Sever Wash fault, Drill Hole Wash fault, and Pagany Wash fault. Design requirements documents have not defined standoff requirements for these known intrablock faults or for small faults with less than $2 \mathrm{~m}$ of cumulative offset. For example, the Subsurface Facility Description Document (BSC 2004 [DIRS 171676], Section 3.1.1.4.8.6) refers only to "Standoff from Quaternary Faults with Potential for Significant Displacement." The document, Underground Layout Configuration (BSC 2003 [DIRS 165572], Section 7.1.3), only mentions the Solitario Canyon and Bow Ridge faults as Type I faults. Consequently, intrablock faults and features are explicitly implemented within the TSPA-LA as consequences from damage to waste packages from fault displacement (BSC 2004 [DIRS 169183], Sections 6.7.2.1 and 6.7.2.2).

Two intrablock faults not included in the TSPA-LA are the Ghost Dance fault and the western splay of the Ghost Dance fault. The Ghost Dance fault parallels the repository outside the eastern boundary of the repository layout. The fault is not considered in the TSPA-LA because no waste packages lie on these faults (BSC 2004 [DIRS 169183], Section 6.7.3). Although the western splay off the Ghost Dance fault intersects the repository, waste package placement in this contingency area is uncertain. Consequently, the splay is not considered in the TSPA-LA (BSC 2004 [DIRS 169183], Section 6.7.2.1).

As discussed previously in regard to faulting at locations other than at known faults, analyses have determined fault intersections occur within drifts in lithophysal zones and nonlithophysal zones. That analysis is based on a study that quantified the likelihood of such smaller faults to intersect the emplacement drifts (BSC 2004 [DIRS 169183], Section 6.7.2.2). The analysis assumed that the density of three known faults exposed in the underground can be extrapolated to the configuration of the emplacement drifts and repository footprint. The analyses concluded there are a total of 47 tunnels and 141 locations (47 times 3) where small faults intersect the emplacement drifts. Thus, faulting at locations other than known faults is explicitly considered within the fault displacement abstraction.

The probability of a fault displacement event severe enough to cause waste package failure is a function of both the specific fault (different fault displacements for a given probability) as well as the specific waste package design (different allowable displacements) (BSC 2004 [DIRS 169183], Section 6.7.4). To determine the probability associated with a fault displacement event severe enough to cause waste package damage, fault displacement hazard curves are used to tabulate the predicted fault displacement as a function of probability of the event and the resulting fault exceedance probabilities that would cause waste package failure (BSC 2004 [DIRS 169183], Section 6.7.4 and Table 6.7-9). As stated above, these results provide fault exceedance frequencies (per year) that also result in drift collapse in the lithophysal zone.

Within the TSPA-LA, fault displacement impacts EBS components through mechanical damage to the waste packages. In this case, the lid welds have the potential to fracture, separating the lid from the package and potentially exposing the entire waste form to seepage and release (BSC 2004 [DIRS 169183], Section 6.7). Once radionuclides are released from the EBS, flow and transport in the unsaturated zone and the saturated zone are based on the same models and algorithms as for the nominal scenario class. One exception is that changes occur in the in-drift 
environment, caused by drift collapse in the lithophysal zones of the repository (See FEP 1.2.03.02.0D, Section 6.2.1.6). Another exception is that if accelerated localized corrosion can occur, there is no flux splitting (diversion of seepage) on the drip shield. This determines the fraction of the liquid flux onto the waste package that can flow inside and contact the waste form. A sheared drip shield will allow all seepage to pass through it for TSPA-LA (BSC 2004 [DIRS 169183], Section 6.7.5). This FEP, shared with EBS, emphasizes details of the mechanical damage abstraction.

Consequences from fault displacement and vibratory ground motion are calculated simultaneously in each TSPA-LA realization as damage abstractions to the waste package and cladding (BSC 2004 [DIRS 168504], Section 6.5.2). The abstraction for fault displacement described within this FEP only considers impacts caused by displacement of the tunnel axis severe enough to cause shearing of a waste package at the location of the discontinuity (BSC 2004 [DIRS 169183], Section 6.7). Shearing is assumed to occur perpendicular to the tunnel axis with the displacement being purely vertical. The output of the fault displacement abstraction is the number of waste packages failed by fault displacement and the combined surface area from all waste packages exposed to waste form dissolution and release (BSC 2004 [DIRS 168504], Section 6.5). The number of waste packages failed is based on look-up tables correlating annual exceedance probabilities for displacement between $2 \times 10^{-7}$ and $2 \times 10^{-8}$ per year and the expected number of waste package failures for four representative waste package groups (BSC 2004 [DIRS 169183], Sections 6.7.4 and 6.7.5). The four representative waste package groups abstracted into the TSPA-LA include pressurized PWR, BWR, naval spent nuclear fuel (naval), and high-level radioactive waste.

The damaged area on a waste package caused by fault displacement is determined by sampling a uniform distribution with a lower bound of $0 \mathrm{~m}^{2}$ and an upper bound equal to the area of the waste package lid (BSC 2004 [DIRS 169183], Section 6.7.5). The upper limit of each waste package lid area uniform distribution is a reasonable estimate for a severely crimped waste package that loses its lid because of cracking in the welds holding the lid in place. The lower limit is a reasonable estimate for a waste package that is minimally damaged, either because fault displacement barely exceeds the available clearance, or because a minor shear occurs at a location that is far from the waste package lids. The resulting damage is assumed to allow advective flux into the waste package (if seepage is present) and allow advective and diffusive transport out of the waste package lid (BSC 2004 [DIRS 169183], Sections 6.7.5 and 6.9.2).

When a waste package fails from fault displacement, the associated EBS drip shield and fuel rod cladding are also assumed to fail as barriers to flow and transport. A sheared drip shield will allow all seepage to pass through it; that is, the damaged area is taken as the total surface area of the drip shield, so there is no flux splitting (diversion of seepage) on the drip shield. Similarly, cladding becomes 100 percent perforated in response to a fault displacement that can shear a waste package (BSC 2004 [DIRS 169183], Sections 6.9.2 and 6.7.5).

The fraction of the failed surface area as a function of waste package-type surface areas is used in the fault displacement abstraction (BSC 2004 [DIRS 169183], Section 6.9.2). The total failed area from a faulting event is the weighted sum of the damage to each waste package group (BSC 2004 [DIRS 168504], Section 6.5). Within TSPA-LA, fault-failed waste packages are further grouped into two bins: commercial spent nuclear fuel (CSNF), representing PWR, BWR, 
and naval waste packages; and co-disposal waste packages, representing high level waste packages. The surface area fraction is determined in a .DLL and is assigned to special CSNF and co-disposal waste packages TSPA-LA containers analogous to the groups used to account for early waste package failures. These groups combine the EBS damage fraction from ground motion and fault displacement and account for different environmental conditions (e.g., dripping or dry) (BSC 2004 [DIRS 168504], Sections 6.5.1 and 6.5.2).

Supporting Reports: $\quad$ Seismic Consequence Abstraction

MDL-WIS-PA-000003 (BSC 2004 [DIRS 169183])

Characterize Framework for Seismicity and Structural Deformation at Yucca Mountain, Nevada

ANL-CRW-GS-000003 (BSC 2004 [DIRS 168030])

\subsubsection{Seismic Ground Motion Damages EBS Components (1.2.03.02.0A)}

FEP Description:

Screening Decision: $\quad$ Included

Screening Argument:

TSPA Disposition:
Seismic activity that causes repeated vibration of the EBS components (drip shield, waste package, pallet, and invert) could result in severe disruption of the drip shields and waste packages, through vibration damage or through contact between EBS components. Such damaged mechanisms could lead to degraded performance.

\section{Not Applicable}

Ground motion associated with seismic activity has the potential to disrupt the integrity of components of the EBS or waste packages. These events could lead to impaired container performance and/or breaching, with subsequent radionuclide release. Seismic ground motion damage is included in the TSPA-LA using damage areas on EBS components based on vibratory ground motions at $5 \times 10^{-4}$, $10^{-4}, 10^{-5}, 10^{-6}$, and $10^{-7}$ per year levels. Analysis model reports supporting the Screening Decision contain tables of included FEPs with pointers to more detailed background information on this FEP (BSC $2004 \quad$ [DIRS 169183], Table 6.2-1; $\quad$ BSC 2004 [DIRS 166107], Table 6-50).

The technical basis for inclusion of this FEP includes the ground motion hazard curves developed for the PSHA that were extended to address ground motion during the postclosure period as documented in DTN: MO03061E9PSHA1.000 [DIRS 163721]. The seismic time histories were developed starting with the results of the PSHA (CRWMS M\&O 1998 [DIRS 103731]), but taking into account the effect of the upper $300 \mathrm{~m}$ of rock and soil at the site (the site response). These repository-level inputs for postclosure seismic evaluations are presented in Development of Earthquake Ground Motion Input for Preclosure Seismic Design 
and Postclosure Performance Assessment of a Geologic Repository at Yucca Mountain, Nevada (BSC 2004 [DIRS 170027]).

Site-specific ground motions for five levels of annual probability of exceedance, $5 \times 10^{-4}, 10^{-4}$, $10^{-5}, 10^{-6}$, and $10^{-7}$ per year, are used to assess the postclosure analyses of damage to EBS components from seismic ground motion, bounded by physically realistic limits (BSC 2004 [DIRS 169183], Sections 6.1.3 and 6.4.4). Horizontal peak ground velocity (PGV) is calculated for these mean annual exceedance frequencies at a Point B within the emplacement drifts, as described in the PSHA.

A horizontal PGV of $0.19 \mathrm{~m} / \mathrm{s}$ corresponds to the $5 \times 10^{-4}$ per year exceedance frequency, and a horizontal PGV of $0.384 \mathrm{~m} / \mathrm{s}$ corresponds to the $10^{-4}$ per year exceedance frequency. The horizontal PGV value corresponding to the $10^{-5}$ per year point on the hazard curve is $1.05 \mathrm{~m} / \mathrm{s}$. The horizontal PGV value for the $10^{-6}$ per year ground motions is $2.44 \mathrm{~m} / \mathrm{s}$. The horizontal PGV value for the $10^{-7}$ per year ground motions is $5.35 \mathrm{~m} / \mathrm{s}$ (BSC 2004 [DIRS 169183], Section 4.1). By way of explanation, the correspondence of $2.44 \mathrm{~m} / \mathrm{s}$ with $10^{-6}$ per year on the mean hazard curve means that all ground motion events with PGV greater than $2.44 \mathrm{~m} / \mathrm{s}$ occur with a mean annual frequency of $10^{-6}$ per year.

In the model report, Seismic Consequence Abstraction (BSC 2004 [DIRS 169183]), damage from ground motion is evaluated for the waste package and cladding. Calculations of the waste package and cladding damage resulting from vibratory motion are summarized in Mechanical Assessment of the Waste Package Subject to Vibratory Motion (BSC 2004 [DIRS 170063]). This document summarizes the results of a series of individual calculations that estimate damage to the waste package and cladding as well as present model sensitivity studies. These supporting calculations include analysis of the waste package vibratory motion (BSC 2004 [DIRS 167083]), damage assessment of the 21-PWR waste package (BSC 2003 [DIRS 162293]), determination of acceleration and damage to cladding (BSC 2003 [DIRS 162602]), sensitivity studies of the 21-PWR finite element model (BSC 2004 [DIRS 170844]), and additional sensitivity studies to variations in input ground motion parameters (BSC 2004 [DIRS 168385], and BSC 2004 [DIRS 170843]).

The model report, Seismic Consequences Abstraction (BSC 2004 [DIRS 169183]), also summarizes structural response calculations carried out to evaluate damage to drip shield from vibratory ground motion, which is documented in a separate calculation, Mechanical Assessment of the Drip Shield Subject to Vibratory Motion and Dynamic and Static Rock Loading (BSC 2004 [DIRS 169753]). This document summarizes the results of a series of individual calculations that address damage to the drip shield from vibratory motion (BSC 2003 [DIRS 163425]), from rockfall impact (BSC 2004 [DIRS 168993]), and quasi-static pressure from rockfall rubble (BSC 2004 [DIRS 170791]). Mechanical Assessment of the Drip Shield Subject to Vibratory Motion and Dynamic and Static Rock Loading (BSC 2004 [DIRS 169753]) presents kinematic analyses of drip shield separation not presented in the supporting calculations.

In general, the Seismic Consequence Abstraction model report (BSC 2004 [DIRS 169183]), Mechanical Assessment of the Waste Package Subject to Vibratory Motion (BSC 2004 [DIRS 170063]), and Mechanical Assessment of the Drip Shield Subject to Vibratory Motion and Dynamic and Static Rock Loading (BSC 2004 [DIRS 169753]) and their supporting calculations 
use structural response calculations for the waste package and drip shield as the basis for predicting failed areas for advective flow and transport. The criteria for failure are based on a residual stress threshold of between 80 percent and 90 percent of the yield strength for Alloy 22 and 50 percent of the yield strength for Titanium Grade 7.

Structural analyses for the waste package and drip shield performed at PGV values of $0.190 \mathrm{~m} / \mathrm{s}$ and $0.384 \mathrm{~m} / \mathrm{s}$ show no damage (BSC 2004 [DIRS 169183], Section 5.1). For less frequent ground motions $\left(10^{-6}\right.$ and $\left.10^{-7}\right)$ per year probabilities of annual recurrence), failed areas occur in response to impact of the waste package on the emplacement pallet and to end-to-end impacts of adjacent waste packages. Consequently, damage to the waste package is included in the seismic scenario class for TSPA-LA. Waste package damage results are fit to a uniform cumulative distribution function based on 15 structural response realizations at $2.44 \mathrm{~m} / \mathrm{s}$ and $5.35 \mathrm{~m} / \mathrm{s}$ PGV (BSC 2004 [DIRS 169183], Section 6.5.1.3). To address the potential for damage at $1.05 \mathrm{~m} / \mathrm{s}$ $\left(10^{-5}\right.$ probability of annual recurrence), the TSPA-LA conservatively assumes 100 percent cladding damage, as described in the abstraction below (BSC 2004 [DIRS 169183], Section 6.5.7.2).

Similar structural response calculations were also performed to assess response of the drip shield to ground motions (BSC 2004 [DIRS 169753]). The set of ground motion time histories used for these calculations is identical with that used for the analyses of seismic-induced rockfall and waste package structural response (BSC 2004 [DIRS 169183], Section 6.5.4.1).

Idealized dynamic kinematic analyses of a large number of interlocked drip shields (20 or 50) subjected to selected ground motion time histories with PGV of $2.44 \mathrm{~m} / \mathrm{s}$ and $5.35 \mathrm{~m} / \mathrm{sec}$ were completed. The results of these analyses are summarized as follows (BSC 2004 [DIRS 169753, Section 5.3.3):

- The drip shields do not separate in any of the analyzed cases, even assuming strong ground motion (i.e., $10^{-7}$ probability of annual recurrence), open emplacement-drifts, and small friction coefficients for the drip shield-invert contact.

- Adding the effect of rubble, resulting from drift degradation or seismic rockfall, either on the top of the drip shield or as a frictional restraint acting on the sides of the drip shield, results in stabilization of the chain of interlocked drip shields, reducing the magnitudes of displacements and forces in the contacts between them. In all of these cases, there is no predicted drip shield separation.

Although the analyses indicate drip shield separation is physically unlikely, even in an open drift, it is important to consider the timing and effects of seismic-induced drift collapse and rock fall and the potential for drip shield separation (BSC 2004 [DIRS 169753] and BSC 2004 [DIRS 166107] Section 6.3 and 6.4). As indicated in the following discussions involving FEPs 1.2.03.02.0B (Seismic-induced rockfall) and 1.2.03.02.0C (Seismic-induced drift collapse), partial or complete seismic-induced drift collapse and rockfall will occur in nonlithophysal and lithophysal zones, respectively. More importantly, partial or complete seismic-induced rockfall and drift collapse will occur at or below the $2.44 \mathrm{~m} / \mathrm{s}$ PGV level, associated with the $10^{-6}$ annual exceedance probability event. 
Therefore, drip shield separation is not further considered in TSPA-LA because:

- Interlocked drip shields move in synchronous motion to the large-period seismic ground motions, even in an open drift

- Ground motion amplitudes that are sufficient to cause drip shield separation are also large enough to partially or completely collapse drifts in the repository

- Drift collapse occurs within the first second or two of the arrival of these large amplitude ground motions (BSC 2004 [DIRS 166107], Sections 6.3.1.6.1 and 6.4.2.2.2).

In this situation, drift collapse provides restraints on the motion of the drip shields, preventing differential motion that could lead to separation (BSC 2004 [DIRS 169183], Section 6.5.5). See FEP 1.2.03.02.0C for a related discussion.

The drip shield will be surrounded by rock particles before significant differential displacement of the drip shields can occur (BSC 2004 [DIRS 169183], Section 6.5.5). Rock particles surrounding the drip shield provide a normal and shear confinement to the sidewalls and crown of the drip shield. Frictional forces existing between the footings and the invert, as well as the rubble and the drip shield plates, will also inhibit movement (BSC 2004 [DIRS 169183], Section 6.5.5; BSC 2004 [DIRS 166107], Section 6.3 and 6.4). Thus, the drip shield is partly surrounded by rockfall whenever separation could potentially occur, and this rockfall can occur near the start of the ground motions, rendering separation physically unlikely even for extreme ground motions. These drip shield calculations are documented in Mechanical Assessment of the Drip Shield Subject to Vibratory Motion and Dynamic and Static Rock Loading (BSC 2004 [DIRS 169753]).

Damage to the cladding has been evaluated using structural response calculations for end-to-end impacts of adjacent waste packages to define the axial loads on fuel assemblies. These loads are compared to fuel rod failure criteria based on buckling for various fuel pin designs. Comparison of axial loads with the failure criteria indicates that cladding will not fail from the vibratory ground motion at the $5 \times 10^{-4}$ per year level $(0.384 \mathrm{~m} / \mathrm{s})$; but (similar to the waste package itself) most, if not all, fuel pins will fail under vibratory ground motions at the $10^{-6}$ per year and the $10^{-7}$ per year levels. Since damage is predicted for strong vibratory ground motions, this FEP is included in the TSPA-LA (BSC 2004 [DIRS 169183], Section 6.5.7.2).

Implementation in the TSPA-LA-The TSPA-LA model explicitly abstracts damage to EBS components resulting from vibratory ground motion. This FEP is shared with Engineered Barrier System Features, Events, and Processes, where TSPA-LA disposition is also described with more emphasis on degradation effects (BSC 2004 [DIRS 169898]). Details on the manner of TSPA-LA disposition of included components of the seismic scenario class in the TSPA-LA can be found addressed in the model reports Seismic Consequence Abstraction (BSC 2004 [DIRS 169183]) and the Total System Performance Assessment (TSPA) Model for the License Application (BSC 2004 [DIRS 168504], Section 6.5).

Within the TSPA-LA, the damaged area on a waste package is abstracted as a uniform distribution with a lower bound of 0 and an upper bound that is a linear function of PGV 
(BSC 2004 [DIRS 169183], Section 6.9.2). The waste package damaged area is larger than the effective area susceptible to accelerated stress corrosion cracking (BSC 2004 [DIRS 169183], Section 6.3.2). The actual damaged area on the waste package is represented as a network of stress corrosion cracks.

In the abstraction, PGV values are first sampled from a hazard curve. The hazard curve is represented within TSPA-LA as a 1-D lookup table for PGV values associated with mean annual exceedance frequencies between $10^{-4}$ and $10^{-8}$ per year. This range spans the response of the system, from no damage at $10^{-4}$ annual exceedance probability to the regulatory limit at $10^{-8}$ annual exceedance probability per year (BSC 2004 [DIRS 169183], Section 6.9.1.1). The horizontal PGV value corresponding to the $10^{-4}$ annual exceedance probability point on the hazard curve is $0.384 \mathrm{~m} / \mathrm{s}$ (BSC 2004 [DIRS 169183], Section 5.1).

The value of PGV used for a particular realization results from applying a second uniform distribution used to bound unrealistic results, a uniform distribution defined as ranging from $1.5 \mathrm{~m} / \mathrm{s}$ and $5 \mathrm{~m} / \mathrm{s}$. The value of PGV is the minimum value obtained from a 1-D look-up table associated with mean annual exceedance frequencies between $10^{-4}$ and $10^{-8}$ per year or obtained using the bounding distribution (BSC 2004 [DIRS 169183], Section 6.9.1.2).

The damage abstraction for a waste package is defined by a uniform distribution with a lower bound of 0 percent damaged area and an upper bound that is a linear function of PGV (BSC 2004 [DIRS 169183], Section 6.9.2). The waste package damage abstraction is applied to all waste packages in the repository, excluding those packages that experience early time failures from manufacturing defects or from defects that occur during emplacement (BSC 2004 [DIRS 169183], Section 6.5.1.3). The sampled value of the uniform distribution (for each realization) is converted into an effective area for flow and transport.

Damage to cladding is explicitly implemented within the TSPA-LA. Cladding experiences complete failure (i.e., 100 percent of the cladding is perforated) at the time of the seismic event for ground motions with PGV amplitude of $1.05 \mathrm{~m} / \mathrm{s}$, or greater. As stated earlier, $1.05 \mathrm{~m} / \mathrm{s} \mathrm{PGV}$ corresponds to the $10^{-5}$ per year exceedance frequency (BSC 2004 [DIRS 169183], Section 4.1). The damage to the cladding is expressed as a percentage of perforated fuel rods (BSC 2004 [DIRS 169183], Section 6.9.2). The TSPA abstraction for damage to the cladding is represented in the TSPA-LA as 1-D table lookup as a function of the value of PGV for a particular realization.

Within the TSPA-LA, cladding damage is always zero for PGV values less than $0.55 \mathrm{~m} / \mathrm{s}$ and always 100 percent for PGV values greater than $1.05 \mathrm{~m} / \mathrm{s}$. For values between $0.55 \mathrm{~m} / \mathrm{s}$ and $1.05 \mathrm{~m} / \mathrm{s}$, percent damage is estimated by linear interpolation on PGV (BSC 2004 [DIRS 169183], Section 6.9.2). Within TSPA-LA, this damage is applied to all fuel assemblies, except for assemblies with initial clad damage or initial clad failures. There is no spatial variability in the damage because damage to the cladding occurs within all waste packages (BSC 2004 [DIRS 169183], Section 6.5.7.3).

Within the TSPA-LA, the degree of ground motion damage is assumed to apply to all waste packages and CSNF cladding in the repository (BSC 2004 [DIRS 169183], Section 6.5.3, 6.5.7, and 6.9.2). Within the TSPA-LA, the surface area fraction is calculated assuming two CSNF and 
co-disposal waste package containers analogous to the groups used to account for early waste package failures. These groups combine the EBS damage fraction from ground motion and fault displacement and account for different environmental conditions (e.g., dripping or dry) (BSC 2004 [DIRS 168504], Sections 6.5.1 and 6.5.2).

Supporting Reports: $\quad$ Development of Earthquake Ground Motion Input for Preclosure Seismic Design and Postclosure Performance Assessment of a Geologic Repository at Yucca Mountain, Nevada MDL-MGR-GS-000003 (BSC 2004 [DIRS 170027])

Seismic Consequence Abstraction

MDL-WIS-PA-000003 (BSC 2004 [DIRS 169183])

Mechanical Assessment of the Drip Shield Subject to Vibratory Motion and Dynamic and Static Rock Loading

CAL-WIS-AC-000002 (BSC 2004 [DIRS 169753])

Mechanical Assessment of the Waste Package Subject to Vibratory Ground Motion

CAL-WIS-AC-000001 (BSC 2004 [DIRS 170063])

Drift Degradation Analysis ANL-EBS-MD-000027 (BSC 2004 [DIRS 166107])

\subsubsection{Seismic-Induced Rockfall Damages EBS Components (1.2.03.02.0B)}

FEP Description:

Seismic activity could produce jointed-rock motion and/or changes in rock stress leading to enhanced rockfall that could impact drip shields, waste packages, or other EBS components.

Screening Decision: $\quad$ Excluded - Low Consequence.

Screening Argument:

Vibratory ground motions can cause failure of the host rock around emplacement drifts. This motion could result in damage to the drip shields through mechanical impact mechanisms and possibly the waste packages (if the drip shields fail) via increased seepage through a damaged or separated drip shield. Rockfall calculations indicate potential consequences of rockfall occur in both the lithophysal and nonlithophysal zones substantially below the $10^{-6}$ annual probability of exceedance (PGV $2.44 \mathrm{~m} / \mathrm{s}$ ) (BSC 2004 [DIRS 166107], Sections 6.3 and 6.4). Note that subsequent analyses summarized below indicate rockfall occurring as small rubble or large blocks will not compromise engineered barriers, and therefore this FEP is screened out on the basis of low consequence.

The term, "rockfall", as used in this discussion of the technical basis for inclusion of this FEP, is intended to mean the dislodging of relatively fewer and larger blocks of rock from the sides or 
crown of an emplacement drift. In contrast, an en masse fall of rock fragments constitutes "drift collapse" for FEPs purposes. Seismic-induced drift collapse is addressed as FEP 1.2.03.02.0C in Section 6.2.1.5. Due to the different stratigraphic units that the emplacement drifts will transect, both lithophysal and nonlithophysal rock types are explicitly considered. The ground motion hazard curves developed for the PSHA were extended to address ground motion during the postclosure period as documented in DTN: MO03061E9PSHA1.000 [DIRS 163721]. The seismic time histories were developed starting with the results of the PSHA (CRWMS M\&O 1998 [DIRS 103731]), but taking into account the effect of the upper $300 \mathrm{~m}$ of rock and soil at the site (the site response). These repository-level inputs for postclosure seismic evaluations are presented in Development of Earthquake Ground Motion Input for Preclosure Seismic Design and Postclosure Performance Assessment of a Geologic Repository at Yucca Mountain, Nevada (BSC 2004 [DIRS 170027]).

Site-specific ground motions for five levels of annual probability of exceedance, $5 \times 10^{-4}, 10^{-4}$, $10^{-5}, 10^{-6}$, and $10^{-7}$ per year, are used to assess the postclosure analyses of damage to EBS components from seismic ground motion, seismic-induced rockfall, as well seismic-induced drift collapse (BSC 2004 [DIRS 166107], Sections 6.3.1.2.1 and 6.4.2.2).

In general, vibratory ground motions can cause failure of the host rock around the emplacement drifts. Two potential sources of damage to the drip shield from the en masse rockfall have been considered in the lithophysal zone. The first is damage from the individual rubblized rock fragments that fall onto and impact the drip shield and is emphasized in this FEP. The second potential source of damage in the lithophysal zone is the static load on the drip shield from rubble resulting from drift collapse. This second source of damage is emphasized in FEP 1.2.03.02.0C.

This FEP also evaluates the mechanical response of the drip shield to impacts from large rock blocks in the nonlithophysal zone (BSC 2004 [DIRS 169183], Section 6.6.1 and 6.6.2). Geologic structure and rock strength define the failure mode in the nonlithophysal rock, resulting in a greater distribution of sizes of rock blocks. In lithophysal zones, the rock mass has lower compressive strength due to the presence of closely-spaced lithophysal void spaces that permeate the rock mass in addition to the ubiquitous, closely-spaced fracture network. The rubble resulting from failure is expected to be characteristically smaller in size relative to nonlithophysal zones due to the presence of these lithophysal voids.

Impact damage to the Titanium Grade 7 plates of the drip shield may include tearing or denting of drip shield surface. Mechanical response calculations described in this FEP are used to determine the drip shield areas where the residual tensile stress exceeds the threshold value (50 percent of yield strength) for the Titanium Grade 7 drip shield surface (BSC 2004 [DIRS 169183], Section 6.3.6).

For $10^{-4}$ per year ground motions, little damage is predicted in lithophysal zones, even in unsupported areas of a drift (BSC 2004 [DIRS 166107], Section 6.4.2.2). Fall of rock fragments in the lithophysal zone was also examined for less frequently occurring ground motions (i.e., $10^{5}, 10^{-6}$, and $10^{-7}$ per year probabilities of annual recurrence). Peak ground velocities of about $1.5 \mathrm{~m} / \mathrm{sec}$ result in an approximate damage level below $5 \mathrm{~m}^{3}$ of falling rock fragments per meter of emplacement drift length. In practical terms, this damage level ranges from minor 
spalling, to damage characterized by rock particles filling the invert along the sides of the drip shield. Peak ground velocities from approximately 1.5 to $2 \mathrm{~m} / \mathrm{sec}$ result in approximate damage levels from 5 to $15 \mathrm{~m}^{3}$ of falling rock fragments per meter of emplacement drift length. In practical terms, this damage level is characterized by rock particles covering the sides of the drip shield to approximately the height of the drip shield. Rock particles may also cover the top of the drip shield. Peak ground velocities in excess of about $2.0 \mathrm{~m} / \mathrm{sec}$ result in damage levels above $15 \mathrm{~m}^{3}$ of falling rock fragments per meter of emplacement drift length. Complete collapse of the tunnel is modeled to occur at about the $10^{-6}$ hazard level (BSC 2004 [DIRS 166107], Section 6.4.2.2.2).

As stated, rock fragments associated with the lithophysal zone that contact the drip shield are estimated to be relatively small. Fragments have particle sizes on the order of centimeters to decimeters (BSC 2004 [DIRS 169183], Section 6.6.2.1). The Seismic Consequence Abstraction (BSC 2004 [DIRS 169183], Section 6.6.1.2) provides an example of the low consequence that these small fragments have upon impact with the drip shield. Consider a fragment that (for simplicity) is a cube $0.1 \mathrm{~m}$ on a side. The volume of this fragment is $0.001 \mathrm{~m}^{3}$ and its mass is approximately $2 \mathrm{~kg}(0.0023 \mathrm{MT})$, assuming a tuff density of approximately $2,000 \mathrm{~kg} / \mathrm{m}^{3}$. The terminal velocity of this fragment is $7.7 \mathrm{~m} / \mathrm{s}$, for a 3-m drop under gravitational acceleration and the associated kinetic energy is 59 Joules. The seismic abstraction model report (BSC 2004 [DIRS 169183], Table 6.6-2, Section 6.6.1.2) shows that a fragment with similar kinetic energy does not produce a failed area on the surface of the drip shield. Consequently, expected rock fragment masses (e.g., $0.0023 \mathrm{MT}$ ) associated with the lithophysal zone do not damage drip shields. Damage to the drip shield from falling rock fragments in the lithophysal zone is neglected for TSPA-LA on these bases.

Potential drip shield damage from rockfall impact in the nonlithophysal rock types were also analyzed. Results indicate that vibratory ground motions have the potential to produce larger rock blocks that free-fall at gravitational velocities (calculations of impact energy account for the relative velocity of the drip shield and rock block during a seismic event). Relatively few blocks dislodge at the $5 \times 10^{-4}$ per year ground motion level (BSC 2004 [DIRS 169183], Section 6.6.1), but numerous rock blocks dislodge for the $10^{-6}$ per year and the $10^{-7}$ per year ground motion levels. Rock blocks have the potential to deform the drip shield, resulting in accelerated stress corrosion cracking in areas that exceed the residual stress threshold for Titanium Grade 7 (BSC 2004 [DIRS 169183], Section 6.3.1 and 6.6.1). Such blocks also have the potential to result in immediate puncture or tearing of the drip shield if the localized strain exceeds the ultimate tensile strain limits for the $15 \mathrm{~mm}$ thick Titanium Grade 7 surface sheets.

The Drift Degradation model report (BSC 2004 [DIRS 166107], Section 6.3) provides a detailed description of the nonlithophysal rockfall calculations performed with the 3DEC, three-dimensional discontinuum computer program. Results for the preclosure hazard level of $10^{-4}$ annual probability of exceedance ground motion indicate a total of 535 blocks per km of drift length (BSC 2004 [DIRS 166107], Section 6.3.1.6.1, Tables 6-26 and 6-27). For 10 $0^{-5}, 10^{-6}$, and $10^{-7}$ per year ground motions, results indicate 1,414 blocks, 2,238 blocks, and 3079 blocks per km of emplacement drift length. Median rock sizes range in weight from 0.10 to $0.15 \mathrm{MT}$. Nonlithophysal rock blocks are generally larger than rock fragments in the lithophysal zone and drift profiles show more localized areas of rock failure (BSC 2004 [DIRS 166107], Sections 6.3.4 and 8.1). In general, in nonlithophysal rock, rockfall volumes are sufficient to 
accumulate rock blocks adjacent to the drip shield; however, seismic shaking is not predicted to result in complete collapse of the drift (BSC [DIRS 169183], Section 6.8.3).

Structural response calculations of damage to the drip shield from the impact of individual rock blocks incorporate the potential for corrosion to degrade the drip shield over the first 20,000 years after repository closure. The thickness of the drip shield plates is assumed to be reduced by $2 \mathrm{~mm}$ (BSC 2004 [DIRS 169183], Section 6.6.1.2). Calculations assume mechanical properties of the drip shield materials at $150^{\circ} \mathrm{C}$ to represent the potential degradation in moduli and strength if a seismic hazard occurs during the initial thermal pulse after repository closure. The calculations model six representative rock blocks, ranging in weight from $0.11 \mathrm{MT}$ to $14.5 \mathrm{MT}^{2}$. Rock block kinetic energies generated by ground motions with PGV between $2.44 \mathrm{~m} / \mathrm{s}$ and $5.35 \mathrm{~m} / \mathrm{s}$ vary depending on weight and relative velocities of the drip shield and the falling rock block.

These blocks impact the drip shield from three different angles: vertically downward onto the top of the drip shield, at a $60^{\circ}$ angle (with the horizontal) onto the transition region between the top and side of the drip shield, and horizontally into the side wall. The model assumes that the blocks impact the drip shield edge-on (perpendicular) to maximize damage potential. A key result from this suite of calculations is that the maximum vertical displacement in the drip shield components takes place in the longitudinal stiffener. This result occurs in response to the vertical impact of the 11.5 MT rock block, which has the highest kinetic energy at impact. The drip shield does not buckle or collapse from this impact. It follows that the drip shield continues to provide a mechanical barrier against rockfall for the waste package and cladding.

Because the damaged areas remain physically intact, the most likely damage mechanism affecting the Titanium Grade 7 plates of the drip shield is accelerated stress corrosion cracking (BSC 2004 [DIRS 169183], Section 6.5.4). The deformed or dented region consists of individual, but complex, branching cracks with high surface roughness and tortuosity. This physical morphology has little potential for advective flux through the cracks because of infilling of narrow apertures with corrosion products. A calculation of the expected rate of crack plugging due to evaporation-induced precipitation of calcite has been performed for a pore water of typical composition dripping onto a drip shield. Cracks are sealed within a few hundred years when water is allowed to flow through the cracks at the expected (very low) rate for thin film flow. After a crack is plugged with precipitates, the magnitude of the liquid flux through the crack will become insignificant for two reasons. First is the lack of a significant pressure head or gradient to drive liquid through the crack. Second is high tortuosity and roughness of the crack geometry. Damage to the drip shield from rockfall is neglected for TSPA-LA on these bases (BSC 2004 [DIRS 169183], Section 6.5.4).

TSPA Disposition: $\quad$ Not Applicable

Supporting Reports: $\quad$ Not Applicable

2 The Drift Degradation Analysis (BSC 2004 [DIRS 166107]) shows that in the nonlithophysal rock at the $10^{-6}$ annual exceedance probability, the median dislodged rock block mass is 0.13 MT with a standard deviation of 1.3 MT, a median relative impact velocity of $2.97 \mathrm{~m} / \mathrm{sec}$ and a median impact energy of 576 joules. 


\subsubsection{Seismic-induced Drift Collapse Damages EBS Components (1.2.03.02.0C)}

FEP Description:

Screening Decision:

Screening Argument:
Seismic activity could produce jointed-rock motion and/or changes in rock stress leading to enhanced drift collapse that could impact drip shields, waste packages, or other EBS components. Possible effects include both dynamic and static loading.

Excluded - Low Consequence

The potential consequences of seismic-induced drift collapse require two preceding factors: (1) that drift collapse occurs, and (2) that the weight of the resulting collapsed rock rubble is sufficient to cause structural failure of the drip shields. Drift degradation analysis covered in the following discussion, indicates that drift collapse in lithophysal units can occur. Note that subsequent analyses summarized below show that drift collapse in lithophysal units will not affect the structural integrity of the drip shield. Analyses subsequent to the drift degradation analysis also indicate that complete drift collapse in nonlithophysal units is expected under seismic or time-dependent degradation but is not of concern.

The term "drift collapse", as used in this discussion of the technical basis for exclusion of this FEP, is intended to mean an en masse fall of rock fragments into an emplacement drift. In contrast, a "rockfall" is the dislodging of relatively fewer and larger blocks of rock from the sides or crown of an emplacement drift. Seismic-induced rockfall is addressed as FEP 1.2.03.02.0B in Section 6.2.1.4. Due to the different stratigraphic units that the emplacement drifts will transect, both lithophysal and nonlithophysal rock types are explicitly considered. The ground motion hazard curves developed for the PSHA were extended to address ground motion during the postclosure period as documented in DTN: MO03061E9PSHA1.000 [DIRS 163721]. The seismic time histories were developed starting with the results of the PSHA (CRWMS M\&O 1998 [DIRS 103731]), but taking into account the effect of the upper $300 \mathrm{~m}$ of rock and soil at the site (the site response). These repository-level inputs for postclosure seismic evaluations are presented in Development of Earthquake Ground Motion Input for Preclosure Seismic Design and Postclosure Performance Assessment of a Geologic Repository at Yucca Mountain, Nevada (BSC 2004 [DIRS 170027]).

Site-specific ground motions for five levels of annual probability of exceedance, $5 \times 10^{-4}, 10^{-4}$, $10^{-5}, 10^{-6}$, and $10^{-7}$ per year, are used to assess the postclosure analyses of damage to EBS components from seismic ground motion, seismically-induced rockfall, as well seismically-induced drift collapse (BSC 2004 [DIRS 166107], Sections 6.3.1.2.1 and 6.4.2.2). This FEP addresses rockfall as in FEP 1.2.03.02.0B, but the emphasis is on the static load on the drip shield caused by drift collapse within lithophysal zones. As discussed in FEP, 1.2.03.02.0B, seismic-induced rockfall volumes in nonlithophysal rock, while sufficient to accumulate rock blocks adjacent to the drip shield, is not expected to result in complete collapse of the drift. 
As concluded in FEP 1.2.03.02.0B, at the higher hazard levels (e.g., greater than $10^{-5}$ per year), the response of lithophysal zones to higher ground motion ranges from minor spalling, to filling the invert along the sides of the drip shield or coverage of the top of the drip shield. Within lithophysal zones, rock fragments that contact the drip shield are relatively small, and are governed by the inherent, closely-spaced ubiquitous fracture network and lithophysae spacing. Fragments have particle sizes on the order of centimeters to decimeters (BSC 2004 [DIRS 169183], Section 6.6.2.1). As discussed in FEP 1.2.03.02.0B, the impact of rock particles in lithophysal zones has no effect on the integrity of the drip shields. However, the accumulation of rock particles, up to and including drift collapse, in the lithophysal zones can also impose a quasi-static load on the drip shield from the weight of the rubble that fills the drifts as a result of one or more collapse events.

Rubble loads to the drip shield were estimated from collapse simulations using a discontinuum numerical model (BSC 2004 [DIRS 166107], Section 6.4.2.5). Six realizations of the collapse response and loading to the drip shield structure were conducted and used as input to a three-dimensional finite element structural analysis of the drip shield (BSC 2004 [DIRS 166107], Section 6.4.2.5, Figure 6-174; BSC 2004 [DIRS 169753], Section 5.4.3). These analyses indicate that the drip shield is structurally stable under loads predicted from all scenarios of drift collapse. Further analyses were performed to provide an approximate estimate of the safety margin against collapse. These analyses involved increasing the density of the rock rubble, thereby progressively increasing the vertical and lateral loading applied to the drip shield. These calculations found that the drip shield eventually undergoes excessive deformation (without sudden collapse) due to formation of a plastic hinge on the supporting leg beams. The average vertical load that results in this excessive plastic deformation is approximately 3.25 times the average vertical pressure from the six collapse realizations described above (BSC 2004 [DIRS 169753], Section 5.4.3). Since the drip shield is stable for reasonably-expected collapsed rubble pressures, and since an additional safety margin of several times exists, the effect of drift collapse in lithophysal zones and associated static load is screened from the TSPA-LA on the basis of low consequence.

While the static load is screened from the TSPA-LA, the cumulative effect of seismic-induced drift collapse will have an effect on drip shield separation. As discussed in the response to FEP 1.2.03.02.0A (Seismic ground motion damages EBS components), drip shield separation resulting from vibratory motion is not likely to result in any consequence in an open drift as a result of synchronicity of motion of the interlocked drip shields. However, kinematic analyses presented in Mechanical Assessment of the Drip Shield Subject to Vibratory Motion and Dynamic and Static Rock Loading (BSC 2004 ([DIRS 169753], Section 5.3.3) show that the weight or frictional resistance of rubble against the drip shield completely prevents separation, even at ground motions representative of annual exceedance frequency of $10^{-7}$ per year, or $5.35 \mathrm{~m} / \mathrm{sec}$ PGV level.

Ground motion amplitudes sufficient to separate drip shields are large enough to partially or completely collapse drifts in both lithophysal and nonlithophysal zones of the repository (BSC 2004 [DIRS 169183], Section 6.5.4). In addition, given that smaller seismic events with a probability rate of $10^{-5}$ per year are more likely to occur than extreme events, smaller events will contribute to the buildup of rock fragments around the drip shield before an extreme event occurs. Since multiple higher probability (e.g., $10^{-5}$ per year) events are more likely than single 
lower probability (e.g., $10^{-7}$ per year) events, it is reasonable to assume that significant rubble would exist in the drift to confine the drip shield prior to the occurrence of an event that would result in drip shield displacement (BSC 2004 [DIRS 169753]). The presence of even small frictional or gravitational loads has been shown to restrain the relative motion between adjacent drip shields (BSC [DIRS 169183], Section 6.5.4). Large blocks or small fragments around the drip shields cause sufficient frictional loads on the sides of the drip shield to pin the drip shield in place. See FEP 1.2.03.02.0A for further discussion.

The Drift Degradation model report (BSC 2004 [DIRS 166107], Section 6.3) provides a detailed description of the nonlithophysal rockfall calculations with the 3DEC three-dimensional discontinuum computer program. As stated in FEP 1.2.03.02.0B, numerous rock blocks may dislodge for the $10^{-6}$ per year and the $10^{-7}$ per year ground motion levels. For $10^{-5}, 10^{-6}$, and $10^{-7}$ per year ground motions, results indicate 1,414 blocks, 2,238 blocks, and 3,079 blocks per $\mathrm{km}$ of emplacement drift length (BSC 2004 [DIRS 166107], Section 6.3.1.6.1, Tables 6-26 and 6-27). These larger postclosure ground motions in nonlithophysal zones are characterized by localized areas of rock failure, in some cases sufficient to cover the drip shield (BSC 2004 [DIRS 166107], Section 8.1). However, as stated, seismic-induced rockfall in nonlithophysal rock is not expected to result in complete collapse of the drift. Due to this consideration and the larger size of rock blocks, calculations have emphasized the impact of the size and kinetic energy of these larger blocks on the integrity of the drip shield, rather than the effect of static load (BSC 2004 [DIRS 166107], Section 6.6.1).

Structural response calculations of damage to the drip shield from the impact of individual rock blocks model six representative rock blocks, ranging in weight from $0.11 \mathrm{MT}$ to $14.5 \mathrm{MT}^{3}$ (BSC 2004 [DIRS 169183], Section 6.6.1.2). Rock block kinetic energies generated by ground motions with PGV between $2.44 \mathrm{~m} / \mathrm{s}$ and $5.35 \mathrm{~m} / \mathrm{s}$ vary depending on weight and relative motion of the drip shield. As described in FEP 1.2.03.02.0B, a key result from this suite of calculations is that the drip shield does not buckle or collapse from this impact. It follows that the drip shield continues to provide a mechanical barrier against rockfall for the waste package and cladding. Consequently, the affect of drift collapse within nonlithophysal zones is considered low consequence and is not included in the TSPA-LA.

TSPA Disposition: $\quad$ Not Applicable

Supporting Reports: $\quad$ Not Applicable

\subsubsection{Seismic-Induced Drift Collapse Alters In-Drift Thermohydrology (1.2.03.02.0D)}

FEP Description:

Seismic activity could produce jointed-rock motion and/or changes in rock stress leading to enhanced drift collapse and/or rubble infill throughout part or all of the drifts. Drift collapse could impact

3 The Drift Degradation Analysis (BSC 2004 [DIRS 166107]) shows that in the nonlithophysal rock at the $10^{-6}$ annual exceedance probability, the median dislodged rock block mass is $0.13 \mathrm{MT}$ with a standard deviation of 1.3 MT, a median relative impact velocity of $2.97 \mathrm{~m} / \mathrm{sec}$ and a median impact energy of 576 joules. 
flow pathways and condensation within the EBS, mechanisms for water contact with EBS components, and thermal properties within the EBS.

Screening Decision: $\quad$ Included

Screening Argument: $\quad$ Not Applicable

TSPA Disposition:

The potential consequences of drift collapse require two factors: (1) that drift collapse occurs, and (2) that the volume or amount of collapse is sufficient to change the drift profile such that seepage into the drift and thermal properties are significantly affected. Changes to the seepage and in-drift thermohydrology due to seismic-induced changes in the drift profile are included in the TSPA-LA. Analysis model reports supporting the Screening Decision contain tables of included FEPs with pointers to more detailed background information on this FEP (BSC 2004 [DIRS 169183], Table 6.2-1; BSC 2004 [DIRS 166107], Table 650).

The term "drift collapse", as used in this discussion of the technical basis for inclusion of this FEP, is intended to mean an en masse fall of rock fragments into an emplacement drift. In contrast, a "rockfall" is the dislodging of relatively fewer and larger blocks of rock from the sides or crown of an emplacement drift. Seismic-induced rockfall is addressed as FEP 1.2.03.02.0B in Section 6.2.1.4. Site-specific ground motions for five levels of annual probability of exceedance, $5 \times 10^{-4}, 10^{-4}, 10^{-5}, 10^{-6}$, and $10^{-7}$ per year are used to assess the postclosure analyses of damage to EBS components from seismic ground motion, as well as rockfall and drift collapse (BSC 2004 [DIRS 166107], Sections 6.3.1.2.1 and 6.4.2.2).

The ground motion hazard curves developed for the PSHA were extended to address ground motion during the postclosure period as documented in DTN: MO03061E9PSHA1.000 [DIRS 163721]. The seismic time histories were developed starting with the results of the PSHA (CRWMS M\&O 1998 [DIRS 103731]), but taking into account the effect of the upper $300 \mathrm{~m}$ of rock and soil at the site (the site response). These repository-level inputs for postclosure seismic evaluations are presented in Development of Earthquake Ground Motion Input for Preclosure Seismic Design and Postclosure Performance Assessment of a Geologic Repository at Yucca Mountain, Nevada (BSC 2004 [DIRS 170027]).

The Drift Degradation Analysis (BSC 2004 [DIRS 166107]) evaluated rockfall and drift-collapse effects related to seismic-induced ground motion. As discussed in FEP 1.2.03.02.0C (Seismic-induced drift collapse damages EBS components), lithophysal and nonlithophysal rock units have two fundamentally different failure modes under seismic loading. The collapse of drifts from high amplitude ground motion in the lithophysal zones can fill the drifts with rubble, potentially altering the hydrologic and thermal environment around the EBS components. This FEP is therefore included, and changes to in-drift thermohydrology associated with drift collapse are addressed in the TSPA-LA. 
In lithophysal areas with compete drift collapse, the shape of the drift is altered and the drift is filled with a rubble, resulting in the potential process-level changes in and around the engineered barrier system. Anticipated post-seismic changes in the local in-drift environment include (BSC 2004 [DIRS 169183], Section 6.8):

- Increase in seepage mainly because of the larger size and the different shape of collapsed drifts (e.g., BSC 2004 [DIRS 169131], Section 6.3.1)

- Increase in temperatures of the drip shield and waste package because rubble provides an insulating blanket on top of the drip shield

- Increase in localized corrosion, and increase in dissolution rates of CSNF and high-level radioactive waste glass with increasing temperature.

Seepage estimates have been made for collapsed drift profiles in lithophysal rocks provided in DTN: MO0306MWDDPPDR.000 [DIRS 164736], which were determined from analyses summarized in BSC 2004 ([DIRS 166107], Appendix R). The seepage estimates also take into account the increased rock mass permeability in the periphery of the collapsed drift as well the reduced capillary strength of the drift due to the presence of rubble. Even though a collapsed drift may lead to significantly different seepage behavior, capillary barrier effects still give rise to considerable flow diversion at the interface between the solid rock and the rubble-filled drift. The worst-case (largest collapsed diameter) drift profile predicted by the drift collapse analyses (BSC 2004 [DIRS 166107]) of 11-m diameter circular profile was selected for the collapsed lithophysal drifts. This drift profile results in more seepage due to:

- The total amount of percolation flux arriving at the drift increases with the horizontal drift size (footprint)

- Flow diversion is less effective for a larger drift.

Systematic seepage simulations were conducted for the collapsed drift case using a full set of parametric variations of rock mass parameters, including capillary strength and percolation flux (BSC 2004 [DIRS 169131], Section 6.4.2.4).

The effects of local rockfall in nonlithophysal zones and related drift shape changes are rather small (BSC 2004 [DIRS 169131], Section 6.4.2.4.2). There is no explicit change in the seepage abstraction in the nonlithophysal zones because rockfall is localized and because there is limited impact on the shape and size of the drift profile (BSC 2004 [DIRS 166107], Section 6.3.1). In the nonlithophysal zones, some rockfall and relatively minor changes to drift profiles occur as a result of seismic events with 2.44 and $5.35 \mathrm{~m} / \mathrm{s}$ PGV levels. Seepage analyses using the degraded drift profiles from the $75^{\text {th }}$ percentile and greatest-degradation cases of the rockfall analyses were performed (BSC 2004 [DIRS 169131] Section 6.4.2.4). These analyses show that the impact of drift shape change due to moderate drift degradation representative of the nonlithophysal rock results in negligible differences to the non-degraded, circular drift. Except for local wedge-type rockfall, the drifts in nonlithophysal units remain intact openings with the horizontal extent essentially unchanged. Consequently, there is no explicit change in the seepage flux into the emplacement drifts in the nonlithophysal zones after a seismic event (BSC 2004 
[DIRS 169183], Section 6.8.1). The seepage abstraction does include an implicit enhancement factor for limited collapse of the emplacement drifts in nonlithophysal zones. The nominal seepage abstraction currently includes an enhancement factor of $20 \%$ to account for uncertainties related to local rockfall in the nonlithophysal units, and this enhancement factor is deemed adequate to address the impact of local rockfall related to seismic events (BSC 2004 [DIRS 169131], Section 6.5.1.5). The seepage response determined for the nominal, circular drift profile is used in the seismic scenario for emplacement drifts in the nonlithophysal rocks (BSC 2004 [DIRS 169131], Section 6.4.2.4).

Implementation in the TSPA-LA-In the TSPA-LA model, the seismic scenario class evaluates the impact on EBS components from vibratory ground motion, fault displacement, and ground motion-induced drift collapse. The FEP is shared with Engineered Barrier System Features, Events, and Processes, where TSPA disposition is also described with more emphasis on degradation effects (BSC 2004 [DIRS 169898]). Details on the manner of TSPA-LA disposition of included components of the seismic scenario class in the TSPA-LA are addressed in the model reports, Seismic Consequence Abstraction (BSC 2004 [DIRS 169183]) and the Total System Performance Assessment (TSPA) Model for the License Application (BSC 2004 [DIRS 168504], Section 6.5).

As suggested above, seismically-modified seepage in lithophysal zones is explicitly included in the TSPA-LA abstraction. Seismically modified seepage is explicitly included by modifying the seepage flux in lithophysal zones following seismic-induced drift collapse (BSC 2004 [DIRS 169183], Section 6.9.2). For purposes of TSPA implementation of the seepage abstraction, drift collapse is assumed to occur at all ground motions with a PGV greater than $0.384 \mathrm{~m} / \mathrm{s}$. As indicated above, the $10^{-6}$ hazard level (PGV of $2.0 \mathrm{~m} / \mathrm{s}$ ) is considered a more reasonable threshold for drift collapse in the lithophysal zones (BSC 2004 [DIRS 169183], Section 6.8.1). Modified seepage is determined by using degraded drift seepage response surfaces in the form of look-up tables as a function of seepage-relevant parameters for lithophysal rock units (BSC 2004 [DIRS 169183], Section 6.8.1). The seepage simulations referred to above are the technical basis for the seepage look-up tables.

In addition to switching to the seepage table for collapsed drifts, a temperature constraint is also applied to the seepage flux after drift collapse in the lithophysal zones. Specifically, the seepage onto the waste package is set to zero for the period of above-boiling temperatures by using a $100^{\circ} \mathrm{C}$ threshold temperature. This constraint implies that seepage can enter the drift and be diverted through the rubble to the invert beneath the waste package, but cannot contact the waste package surface until the waste package surface temperature drops below $100^{\circ} \mathrm{C}$. This threshold temperature is based on a sensitivity study of seepage arrival times at the drip shield crown for a collapsed drift that is filled with rubble (BSC 2004 [DIRS 169183], Section 6.8.1). This study considers rubble with high and low values of thermal conductivity and seepage magnitudes that vary between 100 liters/year/WP and 10,000 liters/year/WP. The temperature threshold of $100^{\circ} \mathrm{C}$ is a reasonable upper bound to the ranges of waste package temperature that significantly delay the arrival of seepage at the drip shield crown. In nonlithophysal zones, the temperature constraint on seepage is the same as that used for intact drifts, wherein seepage does not enter the emplacement drifts until the drift wall temperature drops below $100^{\circ} \mathrm{C}$ (BSC 2004 [DIRS 169183], Section 6.8.1). 
Temperature and relative humidity affecting the waste packages after drift collapse in the lithophysal zones is implemented in TSPA at all ground motions with a PGV greater than $0.384 \mathrm{~m} / \mathrm{s}$ (BSC 2004 [DIRS 169183], Section 6.9.2, number 14). The temperature and relative humidity of the waste package after drift collapse are defined by the calculations with the multiscale thermohydrologic model (BSC 2004 [DIRS 169183], Section 6.8.3). These calculations predict the changes in temperature and relative humidity for eight different waste package emplacement configurations using bounding (high or low) values for the thermal conductivity of the rubble surrounding the drip shield. These configurations are intended to define the temperature and relative humidity changes, which are then applied to the CSNF and co-disposal waste package groups used in TSPA-LA (BSC 2004 [DIRS 169183], Section 6.9.2). The fraction of waste packages affected is output from a TSPA-LA .DLL (BSC 2004 [DIRS 168504], Section 6.5.1.3). Within the TSPA-LA, additional TSPA submodels address attendant effects on degradation processes and flow and transport within the engineered barrier system (BSC 2004 [DIRS 169183], Sections 6.8 and 6.9.2).

Supporting Reports: $\quad$ Development of Earthquake Ground Motion Input for Preclosure Seismic Design and Postclosure Performance Assessment of a Geologic Repository at Yucca Mountain, Nevada MDL-MGR-GS-000003 (BSC 2004 [DIRS 170027])

Drift Degradation Analysis

ANL-EBS-MD-000027 (BSC 2004 [DIRS 166107])

Seismic Consequence Abstraction

MDL-WIS-PA-000003 (BSC 2004 [DIRS 169183])

Multiscale Thermohydrologic Model

ANL-EBS-MD-00049 (BSC 2004 [DIRS 169565])

Abstraction of Drift Seepage

MDL-NBS-HS-000019 (BSC 2004 [DIRS 169131])

\subsubsection{Seismicity Associated with Igneous Activity (1.2.03.03.0A)}

FEP Description:

Screening Decision: $\quad$ Included

Screening Argument: $\quad$ Not Applicable

TSPA Disposition:
Seismicity associated with future igneous activity in the Yucca Mountain region may affect repository performance.

Seismicity associated with igneous activity was either specifically considered, or was considered within the background evaluation of ground motion by expert elicitation teams in developing probabilistic ground motion hazards. Because the effects are included in the hazard curves used to evaluate seismic-induced damage, igneous related seismicity is implicitly included in the TSPA-LA. Analysis model reports supporting the Screening 
Decision contain tables of included FEPs with pointers to more detailed background information on this FEP (BSC 2004 [DIRS 170027], Table 6.4-2; BSC 2004 [DIRS 166107], Table 6-50).

The technical basis for inclusion of this FEP is that ground motion associated with igneous activity has the potential to disrupt the integrity of the EBS and waste package components. Repeated vibration of a container and/or container impact with other repository elements could potentially cause the container to be damaged (See FEP 1.2.03.02.0A). These events could lead to decreased performance and to radionuclide release. However, as will be discussed below, all seismic inputs developed to support postclosure seismic analyses account for the igneous component of the seismic hazard during the occurrence of a seismic event.

At Yucca Mountain, earthquakes associated with igneous activity would be related to basaltic intrusion and volcanism. Volcanic eruption is commonly preceded and accompanied by swarms of earthquakes that indicate progressive rock-strength failure as magma migrates to the earth's surface, as reported in a study by Smith et al. (1998 [DIRS 118967], p. 158). That study specifically mentions that magma intrusion into the seismogenic crust tends to supplant large tectonic earthquakes with swarms of low to moderate magnitude earthquakes. Smith et al. (1998 [DIRS 118967], Table 1) summarize published accounts of observed seismicity that is clearly associated with dike intrusion and indicate that dike-induced earthquakes in volcanic rift zones worldwide have a mean maximum magnitude of $3.8 \pm 0.8$, and are generally less than magnitude 5. In the analysis report, Characterize Eruptive Processes at Yucca Mountain Nevada (BSC 2004 [DIRS 169980], Section 6.3.1.3), the dike length distribution used by the PVHA experts is used as a proxy for surface-fault lengths to calculate maximum magnitudes of dike-induced earthquakes. Calculations indicated maximum magnitudes of 4.8, 5.8, and 6.2. An analysis of the ground motion associated with the range of maximum magnitude earthquakes assessed for basalt dike intrusions is presented in Development of Earthquake Ground Motion Input for Preclosure Seismic Design and Postclosure Performance Assessment of a Geologic Repository at Yucca Mountain, Nevada (BSC 2004 [DIRS 170027], Section 6.5).

As stated in Characterize Framework for Seismicity and Structural Deformation at Yucca Mountain, Nevada (BSC 2004 [DIRS 168030], Section 6.4.4), the PSHA was computed by integrating recurrence curves for earthquakes of $\mathrm{Mw} 5.0$ and greater. It is established practice that smaller earthquakes produce no damage to well-engineered structures. Seismicity related to volcanic processes, particularly basaltic volcanoes and dike injection, was explicitly modeled in the volcanic source zones by two of the six expert teams working on the PSHA (as summarized in BSC 2004 [DIRS 168030], Table 5). The maximum magnitudes assigned by the two expert teams put greater weight on magnitudes from 5.4 and 5.8, which is consistent with the range of maximum earthquake magnitudes calculated based on dike length distributions (BSC 2004 [DIRS 169980], Section 6.3.1.3). The other PSHA expert teams presumed that the low magnitude and frequency of igneous-related seismicity was accounted for by the areal source zone evaluation used for the PSHA.

Seismicity associated with igneous activity is implicitly included in TSPA because seismicity associated with igneous activity is included in the PSHA results (through volcanic source zones or areal source zones). Consequently, all seismic inputs developed to support postclosure 
seismic analyses account for the igneous component of the seismic hazard during the occurrence of a seismic event. It is therefore inappropriate to represent igneous-related seismicity in the TSPA-LA by a parameter or submodel independent of the PSHA results. The range in magnitude of dike-induced earthquakes considered does not represent a separate, credible damage mechanism that could contribute to enhanced failure potential of intact waste packages during the 10,000-year performance period. Waste package damage due to a related igneous intrusion is addressed separately in FEP 1.2.04.04.0A (Igneous intrusion interacts with EBS components).

Supporting Reports: $\quad$ Characterize Eruptive Processes at Yucca Mountain, Nevada ANL-MGR-GS-000002 (BSC 2004 [DIRS 169980])

Characterize Framework for Seismicity and Structural

Deformation at Yucca Mountain, Nevada

ANL-CRW-GS-000003 (BSC 2004 [DIRS 168030])

Development of Earthquake Ground Motion Input for Preclosure

Seismic Design and Postclosure Performance Assessment of a

Geologic Repository at Yucca Mountain, Nevada

MDL-MGR-GS-000003 (BSC 2004 [DIRS 170027])

\subsubsection{Hydrologic Response to Seismic Activity (1.2.10.01.0A)}

FEP Description:

Screening Decision: $\quad$ Excluded - Low Consequence.

Screening Argument: $\quad$ This FEP specifically addresses the effects of seismic activity on UZ and SZ flow and transport at the mountain scale, and addresses the possibility of a water-table rise in response to seismic activity (e.g., seismic pumping). However, the changes in flow properties are insignificant at the mountain scale and the potential for a rise in water level is both transient in nature and insignificant with regard to reaching the repository level. The FEP is therefore, excluded.

The technical basis for exclusion of this FEP is discussed in the following paragraphs. It is recognized that seismic activity can cause changes in rock stresses. The change in the state of stress, in turn, has the potential to affect the groundwater flow and the transport properties of the $\mathrm{UZ}$ and/or SZ, and possibly flow through the emplacement drifts. Changes in flow through the drifts have the potential to increase degradation of EBS components and waste packages, leading to a release of radionuclides. Flow change is addressed separately in FEP 1.2.03.02.0D (Seismic-induced drift collapse alters in-drift thermal-hydrology) in Section 6.2.1.6. 
The effects of seismic activity in the UZ could result in changes to the hydrologic characteristics of fractures, as expressed through the UZ model parameter of fracture aperture. The effects of fracture systems changes due to seismic activity on mountain-scale flow and radionuclide transport have been investigated using a sensitivity approach (BSC 2004 [DIRS 170012], Appendix D). The effects of fracture aperture changes are examined because several fracture properties (permeability, capillary pressure, and porosity) are functions of fracture aperture. The results indicate that changes in fracture aperture confined to fault zones show virtually no effect on transport behavior in the UZ and increased fracture aperture applied over the entire UZ domain results in effects that are no more significant than other uncertainties related to infiltration (BSC 2004 [DIRS 170012], Appendix D).

Earthquakes can cause changes in groundwater levels, sometimes at distances far removed from the epicenter. Gauthier et al. (1996 [DIRS 100447], p. 164) evaluated water level responses to normal, listric, and strike-slip faulting. This sensitivity study indicated that, for Yucca Mountain, the greatest strain-induced changes in water-table elevation (approximately $50 \mathrm{~m}$ ) occur with strike-slip faults. Such changes, if permanent, would have the potential to alter groundwater-flow directions, but the fluctuation is transient. The mechanisms for affecting water chemistry and temperature are undefined, but they are presumed linked to a change in groundwater levels and associated changes in geochemical conditions. However, as noted, water-level changes usually are transient, although the reversion to pre-earthquake levels may require several months.

Three seismic events in 1992 provide estimates of water level fluctuations occurring in response to earthquakes. These include the magnitude 7.5 earthquake at Landers, California, occurring on June 28th, 1992, followed a few hours later by the magnitude 6.6 earthquake at Big Bear Lake, California (O'Brien 1993 [DIRS 101276]). These earthquakes were regional, located about $293 \mathrm{~km}$ and $296 \mathrm{~km}$, respectively, away from Yucca Mountain. A third magnitude 5.6 earthquake occurred June 29, 1992, about $23 \mathrm{~km}$ from Yucca Mountain at Little Skull Mountain.

The 1992 data from the groundwater monitoring wells are listed in DTN: GS930108312312.003 [DIRS 171974] documenting the earthquake-induced fluctuations in water level. The Landers earthquake caused about a $90 \mathrm{~cm}$ water level fluctuation at well USW H-5. The following Big Bear Lake earthquake caused a $20 \mathrm{~cm}$ water level fluctuation. The response of well USW H-3 to the Landers earthquake involved a brief water level spike followed by $20 \mathrm{~cm}$ decrease, returning to near normal levels within several hours. The response of wells USW H-5 and USW H-6 to the magnitude 5.6 Little Skull Mountain earthquake was 40 and $20 \mathrm{~cm}$, respectively. The water level decreased about $50 \mathrm{~cm}$ at well UE-25 P\#1 over three days following the earthquake.

Based on the data in DTN: GS930108312312.003, these earthquakes produced mostly short-term water level fluctuations on the order of tens of centimeters. Many other wells showed no response or smaller fluctuations on the order of hours (O'Brien 1993 [DIRS 101276]). For perspective it is noted that the repository would be located approximately $300 \mathrm{~m}$ above the current water table. This suggests that earthquake-induced water level fluctuations can be considered negligible relative to the scale of the total system performance assessment.

Perspectives on seismic pumping and water-level changes are discussed in the Final Environmental Impact Statement (DOE 2002 [DIRS 155970], p. 3-59), which cites the work by a 
panel of the National Research Council (1992 [DIRS 105162]). The panel reviewed an alternative conceptual model that predicted large changes in water levels and concluded that it was infeasible. The panel went on to state that seismic pumping would, at most elevate the water levels a few tens of meters.

By way of corroboration, Gauthier et al. (1996 [DIRS 100447], pp. 163 to 164) analyzed the potential effects of seismic activity on contaminant transport in the SZ due to changes in water-table elevation. Their simulations for TSPA-VA of the timing, amplitude, and duration of water-table rise indicated a maximum rise of $50 \mathrm{~m}$ within an hour of a simulated seismic event. The simulated system returned to steady-state conditions within six months. Gauthier et al. (1996 [DIRS 100447], pp. 163 to 164) conclude that:

In general, seismically induced water-table excursions caused by poroelastic coupling would not influence the models presently being used to determine long-term performance of a repository at Yucca Mountain; therefore, we excluded them from the total-system simulations.

Given the changes in water levels following discrete seismic events as reported by the U.S. Geological Survey (O'Brien 1993 [DIRS 101276]), it would appear that the conclusion by Gauthier et al. (1996 [DIRS 100447]) remains valid.

Sensitivity modeling indicates that changes to faults and fracture properties due to changes in stress and strain are inconsequential to groundwater flow at the mountain scale. Therefore, the FEP is excluded from the TSPA-LA based on low consequence. Additionally, because water-table changes caused by seismic activity do not reach the repository level and are transient, groundwater flow and radionuclide transport are not significantly affected. The hydrologic response to seismic activity, therefore, does not provide a mechanism to significantly affect dose.

TSPA Disposition: $\quad$ Not Applicable

Supporting Reports: $\quad$ Not Applicable

\subsubsection{Seismic Activity Changes Porosity and Permeability of Rock (2.2.06.01.0A)}

FEP Description:

Screening Decision: $\quad$ Excluded - Low Consequence.

Screening Argument:
Seismic activity (fault displacement or vibratory ground motion) has a potential to change rock stresses and result in strains that affect flow properties in rock outside the excavation-disturbed zone. It could result in strains that alter the permeability in the rock matrix. These effects may decrease the transport times for potentially released radionuclides.

Future seismic activity could redistribute strain within the system. Redistribution of strain could increase the aperture of some existing fractures, open new fractures, or close some existing fractures, as presumed by Gauthier et al. (1996 [DIRS 100447], p. 163). Given the extensive fracture network at Yucca Mountain 
and the low rates of seismic/tectonic activity, the rock matrix is largely unaffected by strain redistribution.

This FEP, 2.2.06.01.0A (Seismic activity changes porosity and permeability of rock), and two closely related FEPs, 2.2.06.02.0A (Seismic activity changes porosity and permeability of faults) and 2.2.06.02.0B (Seismic activity changes porosity and permeability of fractures), are all excluded based on low consequence. For the FEPs that address faults and fractures, there are analyses that are directly applicable, but for this FEP that concerns the rock matrix, the technical basis for exclusion relies in part on an approximation developed for a thermal modeling report (BSC 2004 [DIRS 169864]) and in part, on a reasoned logic argument, rather than on specific analyses.

The effects of stress changes on flow in the UZ have been investigated by BSC (2004 [DIRS 169864]). In this model, the effects of thermal stress are evaluated in terms of changes to rock fracture properties, but not rock matrix. This modeling approach is based on the approximation that the effects of changes to the rock matrix porosity and permeability caused by changes in rock stress are negligible compared with changes to the fracture porosity and permeability (BSC 2004 [DIRS 170012], Section 6.7.5). The basis for this approximation is that the fracture aperture is sensitive to mechanical strain due to the small porosity of the fracture continuum. The matrix, on the other hand, has much greater porosity than the fractures in general, and its properties are not expected to be as sensitive to mechanical strain. This approximation is reasonable given the fact that fracture porosity is much less than matrix porosity at Yucca Mountain. This insensitivity to mechanical strain should be true for other sources of mechanical stress, such as seismic activity. In addition, at the scale of the emplacement drifts, the hydrological system is much more affected by the fracture network rather than the fairly impermeable matrix. Therefore, changes to the rock matrix characteristics due to seismic activity are excluded from TSPA-LA on the basis of low consequence.

This reasoned argument relies on the discussion in FEP 1.2.01.01.08 (Tectonic activity-large-scale). The tectonic setting at Yucca Mountain is extensional, the strain rates are low and there is an extensive fracture network in the rock mass. Moreover, it is well known that seismic activity can cause movement along fractures in the rock mass. Given the extensive fracture network in the rock mass, and the relatively high strength of the matrix material, it is expected that the strain introduced by seismic activity will be accommodated by deformation of, and slip along fractures. In addition, damage of the matrix material due to seismic loading would be manifest in the form of inter-lithophysal tensile fractures that coalesce to form observable shear fractures with offset. The exposed lithophysal rocks in the Exploratory Studies Facility and the Enhanced Characterization of the Repository Block (ECRB) Cross-Drift; however, show no fracturing of this type. Observed fracturing is consistent with the typical cooling-fracture related history. Thus, the rocks provide evidence that the matrix material is largely unaffected by redistribution of strain introduced by seismic activity. As discussed in FEP 2.2.06.02.0B, the results of the PSHA are used to infer that the reactivation of existing fractures is a more likely event than the development of new fractures given current geologic conditions and the existing stress field.

Some faults at Yucca Mountain have a strike-slip component of movement and if the fault plane is curved or irregular, local areas of compression can be created, even though the overall setting 
is extensional. The most likely response of the rock mass to these local compressional conditions will be the closing of existing fractures, but in certain cases some strain could be transferred to the rock matrix causing a local decrease in porosity and permeability. These changes, if they occur, would be confined to the fault zones so their impact on flow and transport at the mountain scale would be negligible. Therefore, this FEP is excluded based on low consequence.

TSPA Disposition: $\quad$ Not Applicable

Supporting Reports: $\quad$ Not Applicable

\subsubsection{Seismic Activity Changes Porosity and Permeability of Faults (2.2.06.02.0A)}

FEP Description:

Seismic activity (fault displacement or vibratory ground motion) has a potential to produce jointed-rock motion and change stress and strains that alter the permeability along faults. This could result in reactivation of pre-existing faults or generation of significant new faults, which could significantly change the flow and transport paths, alter or short-circuit the flow paths and flow distributions close to the repository, and/or create new pathways through the repository. These effects may decrease the transport times for potentially released radionuclides.

Screening Decision: $\quad$ Excluded - Low Consequence.

Screening Argument: $\quad$ Future seismic activity could redistribute strain within the system. Redistribution of strain could open new fractures and close some existing fractures, as presumed by Gauthier et al. (1996 [DIRS 100447], p. 163). It is likely that much of this redistribution would occur within the fault zones.

The technical basis for exclusion of this FEP includes a sensitivity analysis of changes to fracture apertures in fault zones in the UZ. As discussed in the following paragraphs, this study demonstrated that the consequence of this FEP in the UZ would be negligible and no more significant that other uncertainties related to infiltration in the UZ. Furthermore, regardless of the strain distribution, the net effect of seismic activity in the SZ is the temporary rise and/or decline in water levels associated with seismic events as addressed in FEP 1.2.10.01.0A (Hydrologic response to seismic activity). That FEP was excluded based on low consequence of a temporary water level rise (or decline) on the order of a few tens of meters.

Relationships between Faults and Fractures-Faulting and fracturing have been studied in considerable detail at Yucca Mountain. Two conclusions from a study by Sweetkind et al. (1997 [DIRS 100183], pp. 67 to 71) suggest that faulting and fracturing are spatially related. First, spatial relationships based on the results of underground mapping of faults have led to the definition and description of zones of influence around faults based on the observation that fracture frequency generally increases as faults are approached. Mapping results show that widths of zones of influence are in general quite narrow, ranging from less than $1 \mathrm{~m}$ to about $7 \mathrm{~m}$ from the faults. The second conclusion is that the width of the zone of influence in the 
immediate vicinity of a fault generally correlates with the amount of cumulative fault offset. Therefore, faults having the largest potential future displacement are the most likely to influence the repository block. Faults having tens of meters of cumulative offset (e.g., faults at Exploratory Studies Facility Stations $11+20,67+88$, and 70+58) have zones of influence that can range up to $10 \mathrm{~m}$ wide. Intrablock faults having very small amounts of cumulative offset $(1 \mathrm{~m}$ to $5 \mathrm{~m}$ ) have zones of influence that are 1 to $2 \mathrm{~m}$ wide.

The presence of gouge and brecciated zones only in close proximity to fault planes suggests that much of the strain will be mechanically dissipated within or near the fault planes. For instance, in the Solitario Canyon fault zone in the ECRB Cross-Drift, the total displacement is approximately $260 \mathrm{~m}$, but the gouge and brecciated zones are limited to less than $20 \mathrm{~m}$ from the main fault trace (Mongano et al. 1999 [DIRS 149850], pp. 59 to 65). As exposed during as-built mapping, the clast-supported breccia is observed between Station 25+80 and 25+99.15.

Similarly, the Dune Wash fault exposed in the Exploratory Studies Facility exhibits a cumulative offset of $65 \mathrm{~m}$, but the zone of increased fracture frequency in the vicinity of the fault is only 6 to $7 \mathrm{~m}$ wide (Sweetkind et al. 1997 [DIRS 100183], Table 21). A third example is the Sundance fault in the ECRB Cross Drift. The Sundance fault has a presumed, though indeterminate, displacement of several meters. However, the footwall rock is intact at a distance of only $10 \mathrm{~cm}$ from the fault plane. The hanging wall of the Sundance fault is slightly more fractured, having an intensely fractured zone about 1-m thick (Mongano et al. 1999 [DIRS 149850], pp. 52 to 54).

Potential for the Development of New Faults-Another aspect of faulting that could be important to repository performance is the formation of new faults. Section 6.2.1.2 and Table 6-1 provide a discussion of probabilistic fault displacements. With regard to the formation of new faults, the PSHA (CRWMS M\&O 1998 [DIRS 103731], p. 8-7; DTN: MO0401MWDRPSHA.000 [DIRS 166962], referring to intact rock at Points $7 \mathrm{~d}$ and $8 \mathrm{~d}$ ) indicates that mean displacements in the intact rock are less than $0.1 \mathrm{~cm}$ for a $10^{-8}$ annual-exceedance probability (see Assumption 5.1 in Section 5). The development of significant new faults and fractures is inferred from the PSHA to be unlikely and is, therefore, not further considered within this FEP.

Potential for the Reactivation of Existing Faults-Many of the existing faults at Yucca Mountain are favorably oriented for movement in the current stress field and any large potential future displacements are expected to occur along the existing block-bounding faults. The largest mean predicted displacement at $10^{-8}$ annual exceedance probability is associated with the Solitario Canyon fault and the mean displacement is estimated to be on the order of $10 \mathrm{~m}$. The median predicted displacement is calculated to be on the order of only a few meters. (See FEP 1.2.02.03.0A, Fault displacement damages EBS components, for a table of estimated displacements). The effects of this range of displacements are addressed by the range of aperture conditions assessed in a sensitivity study, as discussed in the following paragraphs.

Analysis of Fracture Aperture Changes in Fault Zones in the UZ-The effects of changes to fracture systems in the UZ fault zones have been investigated (BSC 2004 [DIRS 170012], Appendix D). A sensitivity study was performed with the nominal UZ three-dimensional flow model using several conservative approaches that together provided bounding cases for determining whether changes in fractures will significantly impact repository performance. The analysis was performed using a dual-permeability active-fracture flow model and was based on 
fracture apertures changes that could result from changes in strain conditions or other factors. Given a change in fracture aperture, other fracture hydrologic properties (permeability, capillary pressure, and porosity) were estimated using theoretical models (BSC 2004 [DIRS 170012], Appendix D). The sensitivity study (BSC 2004 [DIRS 170012], Appendix D) included two bounding cases: that changes in fracture properties occur over the entire UZ domain (fault zones and fractured rock), or that the effects of fault displacement are limited to fracture-property changes in fault zones, which is directly applicable to this FEP. These modeling cases were chosen to bound a presumed range of fracture-aperture changes resulting from fault movement. No direct observations for Yucca Mountain relate stress caused by fault displacement to strain and the resultant changes in fracture aperture (BSC 2004 [DIRS 170012], Appendix D). The bounding cases were used to simulate a response beyond that of the expected geologic response. The second bounding case (effects of fault displacement limited to fault zones) is important to this discussion and is justified based on conclusions by Sweetkind et al. (1997 [DIRS 100183], pp. 67 to 71) and field observations by Mongano et al. (1999 [DIRS 149850]), described above.

A potential conservatism for the sensitivity analysis lies in the estimated fracture aperture for the bounding case. A maximum ten-fold increase in fracture aperture is selected as the model's upper-bound value and was justified in BSC (2004 [DIRS 170012], Appendix D). The justification cites distance-strain relationships derived from models for a 1-m displacement along a strike-slip fault at Yucca Mountain, and for a 1-m displacement on a theoretical normal fault. The changes in fracture apertures for the sensitivity analysis were derived presuming a 10-m fault movement along the Solitario Canyon fault and multiplying the strains cited in the justification for the 1-m faults. The 10-m displacement corresponds to the projected mean value for the Solitario Canyon fault at $10^{-8}$ annual frequency (see Assumption 5.1 in Section 5) and serves as the basis for FEPs screening. The potential for conservatism is mentioned primarily because the presumed $10-\mathrm{m}$ displacement, although a mean value, is greater than the probabilistically determined (median and 85th fractile) and observed fault displacements. The results of the PSHA (CRWMS M\&O 1998 [DIRS 103731], Figure 8-3) indicate that, for the Solitario Canyon fault, there is a large uncertainty range in the potential displacements from $3 \mathrm{~m}$ (the median value) to approximately $9 \mathrm{~m}$ (the 85 th fractile value) at the $10^{-8}$ annual-exceedance probability. By contrast, the maximum measured single-event Quaternary displacement (i.e., during the past 1.6 million years) on the Solitario Canyon fault is only $1.3 \mathrm{~m}$ (Ramelli et al. 1996 [DIRS 101106], Table 4.7.3).

The results of the sensitivity study have shown that fracture aperture changes confined to fault zones resulted in virtually no effect on transport behavior in the UZ (BSC 2004 [DIRS 170012], Appendix D). Because transport is not significantly affected by fracture aperture changes in fault zones, changes in the stress state of fractures in faults do not provide a mechanism to significantly affect dose. Because dose is not significantly affected, the effects of faults and changes on the transport-properties of faults in the UZ are excluded based on low consequence.

Evaluation of Changes in Fault Zones in the SZ-The primary response of regional water levels to seismic events, as discussed in FEP 1.2.10.01.0A, is a transient change (increase or decline) in the water table. The SZ model (Saturated Zone Flow and Transport Model Abstraction (BSC 2004 [DIRS 170042], Section 6.5.2) uses the flowing intervals concept, which is based on site data and indicates that only some of the fractures within the saturated zone contribute to the flow. Additionally, the SZ model implicitly includes fracture zones (faults) in the nominal case 
by considering the horizontal anisotropy in permeability located in the fractured volcanic units downgradient of the repository with the SZ model producing 200 flow fields. The SZ model (BSC 2004 [DIRS 170042], Section 6.5.2) does not explicitly address changes to fracture or fault properties due to changes in stress. However, because of the existing uncertainty considerations for the flow field and because of the conservative choices for flowing-interval spacing used for the analysis, the effect of increasing or decreasing matrix and fracture porosity and permeability, and/or the creation of new fractures in the SZ, would be of no significance to flow and transport characteristics. Because SZ flow characteristics are not significantly changed, dose is not significantly changed and this aspect of the FEP is excluded based on low consequence.

By way of corroboration, an early analysis of the effect of a fault on flow in the SZ was conducted and documented in Chapter 10 of the TSPA-VA (CRWMS M\&O 1998 [DIRS 100369], Section 10.5.3). The analysis suggested that there would be negligible impact on performance, even though fault hydraulic conductivities were varied over five orders of magnitude for the modeling effort.

Also, by way of corroboration, Gauthier et al. (1996 [DIRS 100447], pp. 163 to 164) analyzed the potential effects of seismic activity on contaminant transport in the SZ due to changes in water-table elevation based on TSPA-VA modeling. Their analysis indicates that the greatest strain-induced changes in water-table elevation occur with strike-slip faults. Simulations of the timing, amplitude, and duration of a water-table rise indicate a maximum rise of $50 \mathrm{~m}$ within an hour of a simulated event. The simulated system returns to steady-state conditions within six months. Gauthier et al. (1996 [DIRS 100447], pp. 163 and 164) concluded that:

In general, seismically induced water-table excursions caused by poroelastic coupling would not influence the models presently being used to determine long-term performance of a repository at Yucca Mountain; therefore, we excluded them from the total-system simulations.

Given the response of regional water levels to seismic events, as discussed in FEP 1.2.10.01.0A, the conclusion by Gauthier for TSPA-VA still appears valid for the current analysis.

In summary, effects in the UZ could result in changes to the hydrologic characteristics of fractures, as expressed through the parameter of fracture aperture. The effects of changes to fracture systems due to geologic effects on mountain-scale flow and radionuclide transport have been investigated using a sensitivity approach (BSC 2004 [DIRS 170012], Appendix D). The results indicate that changes in fracture aperture confined to fault zones show virtually no effect on transport behavior in the UZ, and increased fracture aperture applied over the entire UZ domain results in effects that are no more significant than other uncertainties related to infiltration (BSC 2004 [DIRS 170012], Appendix D). Effects in the SZ would not impact dose and would be transient. Therefore, this FEP is of low consequence and is excluded from the TSPA-LA.

TSPA Disposition: $\quad$ Not Applicable

Supporting Reports: $\quad$ Not Applicable 


\subsubsection{Seismic Activity Changes Porosity and Permeability of Fractures (2.2.06.02.0B)}

FEP Description:

Screening Decision:

Screening Argument:
Seismic activity (fault displacement or vibratory ground motion) has a potential to change stress and strains that alter the permeability along fractures. This could result in reactivation of pre-existing fractures or generation of new fractures, which could significantly change the flow and transport paths, alter or short-circuit the flow paths and flow distributions close to the repository, and/or create new pathways through the repository. These effects may decrease the transport times for potentially released radionuclides.

Excluded - Low Consequence.

The tectonic strain rate controlling the seismic and fault displacement events leading to small-scale displacements was evaluated as an uncertain parameter in the PSHA, and the uncertainty in the tectonic rate is, thereby, reflected in the PSHA results (see the FEP 1.2.01.01.0A Tectonic activity-large scale). A sensitivity analysis, discussed below, was performed and demonstrated that the consequence would be negligible.

The technical basis for exclusion of this FEP includes a sensitivity analysis of changes to fracture apertures applied over the entire UZ domain. As discussed in the following paragraphs, this study demonstrated that the consequence of this FEP would be no more significant than other uncertainties related to infiltration in the UZ (BSC 2004 [DIRS 170012], Appendix D) and this FEP can therefore be excluded. Furthermore, regardless of the strain distribution, the net effect of seismic activity in the SZ is the temporary rise and/or decline in water levels associated with seismic events as addressed in FEP 1.2.10.01.0A (Hydrologic response to seismic activity). That FEP was excluded based on low consequence of a temporary water level rise (or decline) on the order of a few tens of meters.

Potential for Fracture Reactivation or the Development of New Fractures-Although an analysis of the reactivation of existing fractures, or the creation of new fractures, was not the primary purpose of the study, the PSHA (CRWMS M\&O 1998 [DIRS 103731], p. 8-7) does examine the probability of movement along existing fractures, both with displacement and with no measurable cumulative displacement (reactivation), and the development of small-scale displacements in the intact rock (new fractures). The results are used to infer that the reactivation of existing fractures is a more likely event than the development of new fractures given current geologic conditions and the existing stress field. This inference concerning small displacement probabilities relates in part, on the definition of fractures.

According to the NRC (1999 [DIRS 135621], p. 55), fractures are characterized by motion perpendicular to the fracture walls (extension fractures), by motion parallel to the fracture walls (shear fractures), or by very small displacement normal to their surfaces and little or no displacement parallel to their surfaces (joints). The range of displacements extends upward to amplitudes that characterize faults, which typically originate as shear fractures capable of 
fracturing across discontinuities. According to Bates and Jackson (1987 [DIRS 164050], p. 257), the term fracture "is a general term for any break in a rock, whether or not it causes displacement, due to mechanical failure by stress. Fracture includes cracks, joints, and faults." Consequently, fractures involve a range from small cracks with no displacement, up to and including, features with considerable displacement that are typically called faults.

As explained in FEP 1.2.02.03.0A, the PSHA (CRWMS M\&O 1998 [DIRS 103731]) examined displacements at specific points along faults, including hypothetical points representing existing small faults, shears, and fractures (Points 7 and 8). Referring to intact rock, or condition (d) at hypothetical Points 7 and 8 within the repository block, the PSHA (CRWMS M\&O 1998 [DIRS 103731], p. 8-7) indicates that the probability of a movement (i.e., minimal displacement of less than $0.1 \mathrm{~cm}$ ) developing in the intact rock (a new fracture) has a less than $10^{-8}$ annual-exceedance probability (see Assumption 5.1 in Section 5). The PSHA (CRWMS M\&O 1998 [DIRS 103731], Figures 8-10 and 8-13 for points 7c and 8c) also indicates that fractures within the current repository area having no measured displacements can be expected to experience on the order of 0.1 to $1 \mathrm{~cm}$ of displacement (reactivation) at the $10^{-8}$ annual-exceedance probability. The PSHA indicates that at the same $10^{-8}$ annual-exceedance probability, existing fractures with $10 \mathrm{~cm}$ of offset, small hypothetical faults with $2 \mathrm{~m}$ of offset, intra-block faults, and block-bounding faults have progressively larger amounts of potential offset (See Table 6-1). By inference, this means that the PSHA anticipates that the vast majority, if not all, future strain would be accommodated on existing faults and fractures with the largest structures (block-bounding faults) experiencing the largest changes. Also by inference from the PSHA, the development of new fractures due to seismic activity and associated fault displacement is inferred to be both of low probability and of low consequence given the existing extensive fracture network. In other words, given the current network of small to large displacement fractures with varying apertures and other characteristics, the very unlikely development of a few more very small displacement (less than $0.1 \mathrm{~cm}$ ) fractures in presently intact rock is not going to noticeably affect flow or transport. The interpretation from the PSHA that movement along existing fractures is more likely than the development of new fractures is directly supported by field observations and consideration of the geologic history of Yucca Mountain.

Strain is more likely to affect existing features, rather than to create new fractures. Field observations indicate that the rock at Yucca Mountain is highly fractured and that existing fractures and joints have been subject to reactivation (BSC 2004 [DIRS 166107]). Evidence for reactivation of joints includes the presence of thin breccia zones along cooling joints and observable slip lineations along joint surfaces (Sweetkind et al. 1996 [DIRS 106957]). Cooling joints, formed originally as tensional openings, have only normal displacement, not shear. However, thin selvages of tectonic breccia are locally present along the trace of cooling joints, indicating later slip. Based on these field observations, the fracture network appears to act as a significant pre-existing weakness in the rock mass that can accommodate extensional strain through distributed slip along many reactivated joints. Coupled with the results of the PSHA for movement in the intact rock, it appears that changes in strain are more likely to be accommodated along existing fractures, rather than the initiation new fractures. Therefore, consideration of new fractures is excluded for this FEP. 
Analysis of Changes to Fractures in the UZ-The effects of changes to fracture systems in the UZ and to fault zones in the UZ have been investigated using a sensitivity approach (Fault Displacement Effects on Transport in the Unsaturated BSC (2004 [DIRS 170012], Appendix D). The sensitivity study was performed with the nominal UZ three-dimensional flow model using several conservative approaches that, together, provide bounding cases for determining whether changes in fractures would significantly impact repository performance. The analysis was performed using a dual-permeability active-fracture flow model and was based on the fracture aperture changes resulting from changes in strain conditions or other factors. Given a change in fracture aperture, other fracture hydrologic properties (permeability, capillary pressure, and porosity) were estimated using theoretical models.

The sensitivity study (BSC 2004 [DIRS 170012], Appendix D) included two bounding cases: (1) that changes in fracture properties occur over the entire UZ domain (fault zones and fractured rock), which is directly applicable to this FEP; or (2) that the effects of fault displacement are limited to fracture-property changes in fault zones (See FEP 2.2.06.02.0A Seismic activity changes porosity and permeability of faults). These were modeling cases chosen to bound a presumed range of fracture-aperture changes resulting from seismic activity and fault movement. There are no direct observations for Yucca Mountain that relate stress caused by fault displacement to strain and resultant changes in fracture aperture. The bounding cases were used to simulate a response beyond that of the expected geologic response.

The results of the sensitivity study (BSC 2004 [DIRS 170012], Appendix D) have shown that changes in fracture aperture confined to fault zones resulted in virtually no effect on transport behavior in the UZ and that increased fracture aperture applied over the entire UZ domain results in effects that are no more significant than other uncertainties related to infiltration (BSC 2004 [DIRS 170012], Appendix D). Changes in fracture aperture are inferred to be equivalent to reactivation of existing fractures for purposes of this FEP.

Because neither flow nor transport is significantly affected by reactivation of fractures that causes a change in fracture aperture, dose is not significantly affected. Therefore, for the UZ, this FEP is excluded based on low consequence.

Evaluation of Changes in Fractures in the SZ-The primary response of regional water levels to seismic events, as discussed in FEP 1.2.10.01.0A, is a transient change (increase or decline) in the water table. The SZ model (Saturated Zone Flow and Transport Model Abstraction (BSC 2004 [DIRS 170042], Section 6.5.2) uses the flowing intervals concept. The flowing interval concept, based on site data, indicates that only some of the fractures within the saturated zone contribute to the flow. Additionally, the SZ model implicitly includes fracture zones in the nominal case by considering the horizontal anisotropy in permeability located in the fractured volcanic units downgradient of the repository, with the SZ model producing 200 flow fields. The SZ model (BSC 2004 [DIRS 170042], Section 6.5.2) does not explicitly address changes to fracture properties due to changes in stress. However, because of the existing uncertainty considerations for the flow field, and because of the conservative choices for flowing-interval spacing used for the analysis, the effect of increasing or decreasing matrix and fracture porosity and permeability, and/or the creation of new fractures in the SZ would be of no significance to flow and transport characteristics. Because SZ flow characteristics are not significantly changed, 
dose is not significantly changed and this aspect of the FEP is excluded based on low consequence.

By way of corroboration, an early analysis of the effect of a fault on flow in the SZ was conducted and documented in Chapter 10 of the TSPA-VA (CRWMS M\&O 1998 [DIRS 100369], Section 10.5.3). The analysis suggested that there would be negligible impact on performance, even though fault (fracture) hydraulic conductivities were varied over five orders of magnitude for the modeling effort.

Also, by way of corroboration, Gauthier et al. (1996 [DIRS 100447], pp. 163 to 164) analyzed the potential effects of seismic activity on contaminant transport in the SZ due to changes in water-table elevation based on TSPA-VA modeling. Their analysis indicates that the greatest strain-induced changes in water table elevation occur with strike-slip faults. Simulations of the timing, amplitude, and duration of a water-table rise indicate a maximum rise of $50 \mathrm{~m}$ within an hour of a simulated event. The simulated system returns to steady-state conditions within six months. Gauthier et al. (1996 [DIRS 100447], pp. 163 and 164) concluded that:

In general, seismically induced water-table excursions caused by poroelastic coupling would not influence the models presently being used to determine long-term performance of a repository at Yucca Mountain; therefore, we excluded them from the total-system simulations.

Given the response of regional water levels to seismic events, as discussed in FEP 1.2.10.01.0A, the conclusion by Gauthier for TSPA-VA still appears valid for the current analysis.

In summary, effects in the UZ could result in changes to the hydrologic characteristics of fractures, as expressed through the parameter of fracture aperture. The effects of changes to fracture systems due to geologic effects on mountain-scale flow and radionuclide transport have been investigated using a sensitivity approach (BSC 2004 [DIRS 170012], Appendix D). The results indicate that changes in fracture aperture confined to fault zones show virtually no effect on transport behavior in the UZ. Furthermore, increased fracture aperture applied over the entire UZ domain results in effects that are no more significant than other uncertainties related to infiltration (BSC 2004 [DIRS 170012], Appendix D). Effects in the SZ would not impact dose and would be transient. Therefore, this FEP is of low consequence and is excluded from the TSPA-LA.

TSPA Disposition: $\quad$ Not Applicable

Supporting Reports: $\quad$ Not Applicable

\subsubsection{Seismic Activity Alters Perched Water Zones (2.2.06.03.0A)}

FEP Description: $\quad$ Strain caused by stress changes from tectonic or seismic events could alter the rock permeabilities that allow formation and persistence of perched-water zones. 
Screening Decision: $\quad$ Excluded - Low Consequence.

Screening Argument: $\quad$ Based on a volumetric argument, the release of perched water would have no significant consequence on exposure or release of radionuclides to the accessible environment and therefore this FEP is excluded on the basis of low consequence.

A change in stress due to seismic activity has the potential to result in strains that affect groundwater flow and transport properties, leading to increased or decreased dose. It appears possible that a change in stress could adequately seal a zone so that perched water develops. Hypothetically, such changes have the potential to result in a relatively sharp pulse of radionuclides if radionuclide-containing perched water is allowed to drain. This FEP is analyzed using the volume of known perched water bodies below the repository and comparing this volume to the volume of the water flux entering the repository footprint. Perched water zones below the elevation of the repository have been found in site characterization boreholes (BSC 2004 [DIRS 170012], Section 6.7.8).

The UZ flow model shows that the volume of perched water in the high-permeability fracture domain below the repository only ranges from about $466 \mathrm{~m}^{3}$ to $1,190 \mathrm{~m}^{3}$ (BSC 2004 [DIRS 170012], Section 6.8.8). This smaller volume in the high permeability fractures may be compared with the water flux entering the repository footprint (i.e., the average infiltration rate times the area of the repository footprint). The annual infiltration volume ranges from 2,000 to $192,000 \mathrm{~m}^{3} / \mathrm{yr}$. As shown in Appendix A (BSC 2004 [DIRS 170012]), the perched water volume is seen to represent about 0.006 to 0.2 years of water flux. Thus, the perched water volume in high-permeability fractures that is subject to rapid drainage is small compared to the water flux through the repository horizon for one year. Even if released instantaneously by a seismic event, the release of perched water would have no significant consequence on exposure or release of radionuclides to the accessible environment. Therefore, this FEP is excluded from the TSPA-LA based on low consequence.

TSPA Disposition: $\quad$ Not Applicable

Supporting Reports: $\quad$ Not Applicable

\subsubsection{Igneous-Related FEPs}

The following subsections provide the screening decision and technical basis for inclusion and exclusion of the following igneous-related FEPs.

1.2.04.02.0A Igneous activity changes rock properties (Section 6.2.2.1)

1.2.04.03.0A Igneous intrusion into repository (Section 6.2.2.2)

1.2.04.04.0A Igneous intrusion interacts with EBS components (Section 6.2.2.3)

1.2.04.04.0B Chemical effects of magma and magmatic volatiles (Section 6.2.2.4)

1.2.04.05.0A Magma or pyroclastic base surge transports waste (Section 6.2.2.5)

1.2.04.06.0A Eruptive conduit to surface intersects repository (Section 6.2.2.6)

1.2.04.07.0A Ashfall (Section 6.2.2.7)

1.2.04.07.0C Ash redistribution via soil and sediment transport (Section 6.2.2.8)

1.2.10.02.0A Hydrologic response to igneous activity (Section 6.2.2.9) 


\subsubsection{Igneous Activity Changes Rock Properties (1.2.04.02.0A)}

FEP Description:

Igneous activity near the underground facility may cause extreme changes in rock stress and the thermal regime, and may lead to rock deformation, including activation, creation, and sealing of faults and fractures. This may cause changes in the rock hydrologic and mineralogic properties. Permeabilities of dikes and sills and the heated regions immediately around them can differ from those of country rock. Mineral alterations can also change the chemical response of the host rock to contaminants.

Screening Decision: $\quad$ Excluded - Low Consequence

Screening Argument:

With regard to extreme changes in hydrologic properties, sills and dikes initially intrude into the country rock as molten material and then cool. Cooling joints are formed and resulting permeabilities may be greater than, equivalent to, or less than the surrounding country rock. However, the scale of these effects is limited to a few meters around the dike and changes in properties are therefore of low consequence.

The technical basis for exclusion of this FEP relies in part on studies of analogue sites in the Yucca Mountain Region. In addition, analyses of igneous activity and analyses of the effects of fault displacement on the UZ are utilized. This FEP is concerned with post-intrusion effects on rock properties; impacts from the igneous intrusion process itself are addressed in FEP 1.2.04.03.0A.

Limited Zone of Influence Around Igneous Intrusions -- An appropriate analogue for understanding the components of a potential future igneous event at Yucca Mountain is the Paiute Ridge intrusive/extrusive center (Byers and Barnes 1967 [DIRS 101859]) on the northeastern margin of the Nevada Test Site. The Paiute Ridge center is a small-volume Miocene volcanic center comparable in volume and composition to Quaternary volcanoes near Yucca Mountain (BSC 2004 [DIRS 169989], Section 6.3.2.1). Paleomagnetic, geochronologic, and geochemical data indicate that the entire intrusive/extrusive complex formed during a brief magmatic pulse and, thus, represents a single volcanic event. The vents and associated dike system formed within a north-northwest-trending extensional graben and there are excellent exposures at a variety of system depths, including remnants of surface lava flows, volcanic conduits, and dikes and sills intruded into tuff country rock at depths of up to $300 \mathrm{~m}$. There is evidence of shallow structural control of dike emplacement at Paiute Ridge, including dike emplacement along fault planes (Byers and Barnes 1967 [DIRS 101859]). Dike lengths at Paiute Ridge range from less than $1 \mathrm{~km}$ to $5 \mathrm{~km}$, which is comparable to the range estimated for post-Miocene volcanism near Yucca Mountain. 
Carter Krogh and Valentine (1996 [DIRS 160928], pp. 7 and 8) described the margins of the Paiute Ridge (PR) dike complex and the interaction of dikes and faults. The description is as follows:

PR dike contains ubiquitous near-vertical joints that result in a pervasive platy texture with plates parallel to the dike-host contact. Conversely, with the exception of local cooling joints in fused wall rock (extending 10-20 cm into the wall rock, perpendicular to the dike margin), joints are never visible in the host rock along the length of the dike. The contact between basalt and the tuff host rock is consistently smooth and shows no brecciation. Along strike at this contact, the tuff host rock is fused or welded to varying degrees: in places the tuff is completely welded and forms black vitrophyre that grades rapidly away from the contact, over a distance of ca $20-100 \mathrm{~cm}$, into nonwelded tuff that is apparently unaffected by the dike. In other places the tuff is only partly welded at the contact and black fiamme are elongated parallel to the contact. We infer that this "contact welding" is the combined result of heat from the dike and compressive stress exerted by the flowing magma on the wall rocks. Welded host rock commonly contains vesicles that are elongated vertically and parallel to the margin. In some places, welded tuff coats the basalt and displays rills or elongate smooth ridges (flutes). Most rills plunge nearly vertically, however, a sub-horizontal rill is present in the central part of the dike. At the dike tip, exposed at Slanted Buttes, scoria patches crop out near the dike-host contact.

The two eastern dikes, $\mathrm{M}$ and $\mathrm{E}$... show geometries and textures similar to those of PR; however, $\mathrm{M}$ dike is much shorter and does not feed a sill, and $\mathrm{E}$ dike was emplaced closest to the paleosurface and feeds two sills. $M$ dike ... visibly occupies a normal fault, oriented $\mathrm{N} 40^{\circ} \mathrm{W}, 61^{\circ} \mathrm{E}, \ldots$ Its host rocks are only Tertiary tuffs, which show no brecciation or jointing near the dike contact ... Texture within the dike is characterized by a vertical platy fabric that parallels the dike margins. E dike is the eastern-most dike studied within the graben. Near the neck, the dike visibly occupies a NNW-trending, steeply E-dipping normal fault that displaces bedded tuffs $3.5 \mathrm{~m}$ and does not cut the dike ...The texture of $\mathrm{E}$ dike is characterized by the pervasive vertical platy fabric common to $\mathrm{M}$ and PR dikes. Adjacent host tuffs are not jointed nor brecciated, except for local vertical jointing of the Rainier Mesa tuff, which is intruded by the dike at its shallowest level. The contact of the dike and host tuff is preserved in places and varies from partly to completely welded in the same manner as described above for the PR dike. Where complete welding has occurred, vesicles are vertical and parallel the dike margin. Contact welding of the host tuffs formed oblate fiamme that parallel the dike-host contact. Visible thermal effects on the wall rocks disappear within $1 \mathrm{~m}$ of the dike margin.

This analogue study suggests that zones of change in rock properties (i.e., formation of vitrophyres and/or various degrees of welding of the host rock and formation of fiamme, which are flattened glassy inclusions) are limited to between a few tens of centimeters to, at most, a meter perpendicular to the dike. Also, features such as the platy texture along the dike margins and vesicles in the welded tuff, are oriented parallel to the dike margins. 
Potential Effects on Permeability-The following discussion on the potential for an intrusion to impact permeability includes an evaluation of the orientation of a possible future dike, since orientation could affect the consequences of an intrusion. Most researchers conclude that when ascending dikes enter the shallow upper crust, their location and orientation is influenced by the orientation of the local stress field and the presence of faults that may locally control alignment. The evidence cited for this conclusion, in addition to the interaction of faults and dikes at the Paiute Ridge center described above, includes several northeast-oriented vent alignments in the Yucca Mountain region and the association of eruptive centers with known or inferred faults (CRWMS M\&O 1996 [DIRS 100116], Appendix E, p. AM-4); Connor et al. 1996 [DIRS 135969], p. 78).

The results of the PVHA are summarized in the analysis report Characterize Framework for Igneous Activity at Yucca Mountain, Nevada (BSC 2004 [DIRS 169989]), which presents probability distributions for the length and orientation of possible future volcanic dikes near the repository. The aggregate dike-length distribution derived from the PVHA has a mean value of $4.0 \mathrm{~km}$, and the most commonly assigned dike orientation centers on $\mathrm{N} 30^{\circ} \mathrm{E}$ (BSC 2004 [DIRS 169989], Section 6.3.2). The anisotropic transmissivity observed in the SZ in the Yucca Mountain region has a maximum principal transmissivity direction of approximately $\mathrm{N} 15^{\circ} \mathrm{E}$ (BSC 2004 [DIRS 170042], Section 6.5.2.10), which is generally consistent with the fault and fracture orientations. A corroborative analysis by Ferrill et al. (1999 [DIRS 118941], p. 1) indicated a $\mathrm{N} 30^{\circ} \mathrm{E}$ orientation. A north-to-northeast orientation parallels or sub-parallels the faults and fractures active in the present-day in situ stress field. Dike features that may form in the future, such as the platy texture and welded surfaces that could affect permeability, will parallel the dike orientation and will likely be aligned in a north-to-northeast orientation.

This parallel to subparallel orientation of dikes and maximum principal transmissivity, coupled with the expected limited affected volume of material around the dikes, indicates that dikes, even if differing in permeability, will not significantly affect groundwater flow patterns at the mountain scale. By way of corroboration, an early analysis of the effect of a dike on flow in the SZ was conducted and documented in Chapter 10 of the TSPA-VA (CRWMS M\&O 1998 [DIRS 100369], Section 10.4.4). The corroborative analysis suggested that there would be negligible impact for a dike oriented north to northeast. The analysis included a variety of dike lengths and locations respective to the repository area. Additionally, the occurrence of such a change is conditional on a low probability event of an igneous intrusion.

The report Synthesis of Volcanism Studies for the Yucca Mountain Site Characterization Project (CRWMS M\&O 1998 [DIRS 105347], p. 5-56) mentions the possibility of perched water forming near low-permeability intrusive bodies, and a concern regarding the potential for a dike to provide a barrier to flow and/or cause impoundments. Because of the parallel to subparallel orientation of dikes with the existing orientation of the anisotropic maximum horizontal permeability in the SZ, a dike would not form a barrier or impoundment that would have any significant effect on flow in the SZ. In the UZ, the primary direction of groundwater flow is vertically downward through the fractures. Because the joints on a dike margin would be near vertical, the formation of a significant perched water zone would be dependent on the formation of a sill. The potential impact of sill formation is addressed in the FEP 1.2.04.03.0A (Igneous intrusion into repository). The formation of a perched water zone is addressed in the 
FEP 2.2.07.07.0A (Perched water develops). Drainage from a perched water zone is addressed in FEP 2.2.06.03.0A (Seismic activity alters perched water zone).

Potential Effects on Faults and Fractures-Change in fault and fracture properties due to igneous activity (i.e., activation, creation, and sealing of faults and fractures) is judged to be of negligible impact on three bases. First, the orientation of the faults and fractures (and possible future dikes) is generally parallel-to-subparallel to the maximum principal transmissivity in the SZ, so alteration of the faults or fractures is considered to have minimal effect as discussed previously. Additionally, the effect of changes in aperture (i.e., the mathematical equivalent of sealing or reactivation) have been examined (BSC 2004 [DIRS 170012], Appendix D) and found to have negligible impact on transport; changes in fault properties were excluded from further consideration in TSPA-LA on that basis. Lastly, the potential for volcanic-generated seismic events was considered within the context of the PSHA and included implicitly in the probabilistic assessment of seismic ground motion hazards (see FEP 1.2.03.03.0A, Seismicity associated with igneous activity). The PSHA seismic source characterization was also used as the basis for the approach to estimating probabilistic fault displacements. Thus, displacements from igneous events have been implicitly included in evaluation of probabilistic fault displacement (i.e., reactivation and creation of new faults) and further consideration is unwarranted.

Potential Effects on Mineralogy-With regard to mineral alterations changing the chemical response of the host rock to contaminants, it is possible that the thermal and geochemical influence of igneous activity could affect the rock mineralogy surrounding the igneous intrusion. However, mineral alterations around igneous intrusions at natural-analogue sites are generally confined to relatively thin zones (CRWMS M\&O 1998 [DIRS 105347], pp. 5-41 and 5-57). In particular, natural-analogue studies in similar host rocks at the Nevada Test Site show that alteration is limited to a zone less than 10 maway from the intrusion/host rock contact (CRWMS M\&O 1998 [DIRS 105347], pp. 5-41 and 5-71). Synthesis of Volcanism Studies for the Yucca Mountain Site Characterization Project (CRWMS M\&O 1998 [DIRS 105347], p. 5-42) further states, "Based on natural-analogue sites, there is no indication for extensive hydrothermal circulation and alteration, brecciation and deformation related to magmatic intrusion, and vapor phase recrystallization during the magmatic intrusion into the vitric and zeolitized tuffs." Because the alteration zone around dikes is limited to the immediate proximity of the dike, and the mineralogical changes are not adverse, then (at the scale of the repository) the changes in mineralogy would be of low consequence.

Summary-In summary, each concern posed in the FEP description has been evaluated based on site data and analyses or natural analogues. The subparallel orientation of potential future dikes to transmissivity, coupled with the expected limited affected volume indicate that dikes, even if differing in permeability, will not significantly affect groundwater flow patterns. Because the joints on the dike margin are near vertical, the formation of a perched water zone would be dependent on the formation of a sill. Furthermore, natural-analogue studies show that mineral alteration is limited to a zone less than $10 \mathrm{~m}$ away from the contact at the Nevada Test Site natural-analogue site, and alteration would not form minerals that would have adverse impacts on radionuclide transport. Consequently, changes in rock properties due to igneous activity do not provide a mechanism to significantly affect exposure or release of radionuclides to the 
accessible environment. Therefore, the FEP is excluded from the TSPA-LA based on low consequence.

TSPA Disposition: $\quad$ Not Applicable

Supporting Reports: $\quad$ Not Applicable

\subsubsection{Igneous Intrusion into Repository (1.2.04.03.0A)}

FEP Description:

Magma from an igneous intrusion may flow into the drifts and extend over a large portion of the repository site, forming a sill, dike, or dike swarm, depending on the stress conditions. This intrusion could involve multiple drifts. The sill could be limited to the drifts or a continuous sill could form along the plane of the repository, bridging between adjacent drifts.

Screening Decision: $\quad$ Included

Screening Argument: $\quad$ Not Applicable

TSPA Disposition: $\quad$ The primary focus of this FEP is magmatic intrusion directly into the repository. The following FEP discussion addresses the potential for such an intrusion and the resulting in-drift conditions and waste package damage, which are included within the TSPA-LA. Analysis model reports supporting the Screening Decision contain tables of included FEPs with pointers to more detailed background information on this FEP (BSC 2004 [DIRS 169989], Table 6-1; BSC 2004 [DIRS 169980], Table 6-1; BSC 2004 [DIRS 170028], Table 6-1]). Related FEPs discuss changes in hydrology and rock properties.

The technical basis for inclusion of this FEP is based on the results of Characterize Framework for Igneous Activity at Yucca Mountain, Nevada (BSC 2004 [DIRS 169989], Table 6-21), which indicates that the computed mean annual frequency of intersection of the LA repository footprint by a dike is $1.7 \times 10^{-8}$ (see Assumption 5.1 in Section 5). The computed 5th and 95th percentiles of the uncertainty distribution for frequency of intersection are $7.4 \times 10^{-10}$ and $5.5 \times 10^{-8}$, respectively. Because of the low mean probability and the probability distribution, as determined in the PVHA (CRWMS M\&O 1996 [DIRS 100116]), multiple independent events are not further addressed in TSPA. The PVHA presented a slightly lower annualized mean probability of $1.5 \times 10^{-8}$, but this was obtained using a somewhat different and smaller repository footprint (CRWMS M\&O 1996 [DIRS 100116], p. 4-10).

Igneous intrusion into the repository (i.e., igneous activity), as indicated in the FEP description, has the potential to affect both the geochemical and hydrologic characteristics of the site (see FEPs 1.2.04.02.0A and 1.2.10.02.0A for discussions of rock properties and hydrologic impacts, respectively) and, due to extreme changes in the in-drift environment, could damage EBS 
components and the waste packages. This damage could result in the release of radionuclides and affect the radiological exposure of the RMEI.

Because the probability of igneous intrusion is greater than the FEP screening probability threshold and because waste package damage cannot be constrained due to the thermal, mechanical, and geochemical environment associated with an intrusion into an emplacement drift, igneous intrusion into the repository is included within the TSPA-LA. The environmental conditions and their effect on waste packages are discussed in the FEP 1.2.04.04.0A (Igneous intrusion interacts with EBS components).

The TSPA-LA approach for incorporating igneous intrusion is outlined in Total System Performance Assessment-License Application Method and Approach (BSC 2003 [DIRS 166296], Section 8.1.2) and Total System Performance Assessment (TSPA) Model for the License Application (BSC 2004 [DIRS 168504], Section 6.4). The two igneous events (with individual probabilities and consequences) modeled by the TSPA-LA are:

- An igneous intrusion groundwater transport modeling case featuring the ascent of a basaltic dike or dike system (i.e., a set, or swarm of multiple dikes comprising a single intrusive event) to the repository level where it intersects drifts (this FEP)

- A volcanic eruption modeling case featuring the development of one or more volcanoes within the repository footprint, each with a conduit that may intersect waste packages (FEP 1.2.04.06.0A).

As a consequence of the first event, which is non-eruptive, waste from breached packages may provide a source of radionuclides when groundwater moves through the damaged packages at some time in the future (igneous intrusion groundwater transport modeling case). The potential consequence of the second event (volcanic eruption modeling case) is that waste packages entrained within a conduit may be breached, releasing radionuclides in an erupting ash plume where they can be dispersed downwind to the RMEI. The location of the RMEI is approximately $18 \mathrm{~km}$ south of the repository, as defined in 10 CFR 63.312 and 10 CFR 63.302 [DIRS 156605].

For the igneous intrusion groundwater transport modeling case, all waste packages in intersected drifts are assumed to provide no further protection and waste is available for release through groundwater flow and transport process. The analysis report, Characterize Eruptive Processes at Yucca Mountain, Nevada (BSC 2004 [DIRS 169980], Section 6) presents information about volcanic systems and the parameters that can be used to model their behavior. In particular, that report addresses the geometry of volcanic feeder systems, which is of primary importance in predicting how much of a repository would be affected by an intrusion. The factors of concern include the probability of the event occurring and the number of drifts and waste packages affected by the igneous intrusion. The particular form of the intrusion (a dike, dike swarm or sill) is of lesser concern. As described below, the model for igneous intrusion allows for the intrusion of multiple drifts and damage to the waste packages within each of the intruded drifts. 
The manner in which the igneous intrusion is incorporated into the TSPA-LA igneous intrusion groundwater transport modeling case includes (BSC 2003 [DIRS 166296], Section 5.2):

- The timing of the igneous intrusion during the 10,000-year modeling period

- Assessment of the number of waste packages hit in an igneous intrusion.

The TSPA-LA Model for the igneous intrusion modeling case considers a single igneous intrusion event per realization. The time of the igneous intrusion is selected from a log-uniform distribution of possible event times with the minimum equal to the end of the first time step and the maximum equal to the end of the simulation period (BSC 2004 [DIRS 168504], Section 6.4.1.1).

For each TSPA realization, a cumulative distribution function (CDF) is sampled to determine the number of impacted waste packages to use as the source term. The CDF is based on a series of 3000 realizations of dike swarm configurations that could intersect the repository (BSC 2004 [DIRS 170001], Section 6.3). Computationally, an average CDF for the numbers of waste packages hit is obtained by overlaying the 3,000 dike swarm configurations onto the repository layout geometry and summing up the number of drifts intersected for each realization. The CDF is based on the TSPA-LA assumption that all waste packages in an intersected drift are compromised. The CDF is also based on a magma bulkhead analyses that concludes magma is contained within an intersected drift (BSC 2004 [DIRS 170001], Section 6.3). The FEP "Igneous intrusion interacts with EBS components" (1.2.04.04.0A) provides additional detail on post-intrusion affects, including behavior of the waste package.

Neither the TSPA-LA nor the supporting models provide results for an initial eruption of pyroclastic magma into the drifts. In this way, the models implicitly define the manner in which igneous intrusion into the repository (by effusive flow) is included in the TSPA-LA model; that is, by defining the maximum length of all intersected drifts that are involved in the direct flow path and totaling the number of waste packages in those drifts.

Supporting Reports: $\quad$ Characterize Framework for Igneous Activity at Yucca Mountain, Nevada ANL-MGR-GS-000001 (BSC 2004 [DIRS 169989])

Characterize Eruptive Processes at Yucca Mountain, Nevada ANL-MGR-GS-000002 (BSC 2004 [DIRS 169980])

Dike/Drift Interactions

MDL-MGR-GS-000005 (BSC 2004 [DIRS 170028])

\subsubsection{Igneous Intrusion Interacts with EBS Components (1.2.04.04.0A)}

FEP Description:
An igneous intrusion in the form of a dike may occur through the repository, intersecting the repository drifts, resulting in magma, pyroclastics, and volcanic gases entering the drift and interacting with the EBS components (drip shields, waste packages, pallet, and invert). This could lead to accelerated drip shield and waste package failure (e.g., attack by magmatic volatiles, damage by 
flowing or fragmented magma, thermal effects) and dissolution or volatilization of waste.

Screening Decision: $\quad$ Included

Screening Argument: $\quad$ Not Applicable

TSPA Disposition: The primary focus of this FEP is interactions between the intrusion, the waste, and the waste packages. These interaction are included in the TSPA-LA because magma could interact with the elements of the EBS and the waste packages could be impaired due to perturbations of the drift environment, thereby resulting in damage to the waste packages and mobilization of waste. Analysis model reports supporting the Screening Decision contain tables of included FEPs with pointers to more detailed background information on this FEP (BSC 2004 [DIRS 169980], Table 6-1; BSC 2004 [DIRS 170028], Table 6-1; BSC 2004 [DIRS 170001], Table 6-1).

The technical basis for inclusion of this FEP is based on the results of Characterize Frameworkfor Igneous Activity at Yucca Mountain, Nevada (BSC 2004 [DIRS 169989], Table 6-21), which indicates that the computed mean annual frequency of intersection of the LA repository footprint by a dike is $1.7 \times 10^{-8}$ (see Assumption 5.1 in Section 5). The computed 5th and 95th percentiles of the uncertainty distribution for frequency of intersection are $7.4 \times 10^{-10}$ and $5.5 \times 10^{-8}$, respectively. The PVHA (CRWMS M\&O 1996 [DIRS 100116], p. 4-10) presented a lower annualized mean probability of $1.5 \times 10^{-8}$, but this was obtained using a somewhat different and smaller repository footprint.

Igneous intrusion into the repository (i.e., igneous activity), as indicated in the description for FEP 1.2.04.03.0A, has the potential to affect both the geochemical and hydrologic characteristics of the site (see FEPs 1.2.04.02.0A and 1.2.10.02.0A for discussions of rock properties and hydrologic impacts respectively). Due to extreme changes in the in-drift environment, igneous intrusion could damage EBS components and the waste packages. This damage could result in the release of radionuclides and affect the radiological exposure of the RMEI.

Because the probability of igneous intrusion is greater than the FEP screening probability threshold and because waste package damage cannot be constrained due to the thermal, mechanical, and geochemical environment associated with an intrusion into an emplacement drift, igneous intrusion interacts with EBS components is included within the TSPA-LA; and the environmental conditions and their effect on waste packages are discussed in this FEP. Transport of radionuclides by groundwater from waste entrained in basalt after seepage has been re-established is considered under FEP 1.2.04.04.0B (Chemical effects of magma and magmatic volatiles).

The TSPA-LA approach for incorporating igneous intrusion is outlined in Total System Performance Assessment-License Application Method and Approach (BSC 2003 [DIRS 166296], Section 8.1.2) and Total System Performance Assessment (TSPA) Model for the License 
Application (BSC 2004 [DIRS 168504], Section 6.4). The two igneous events (with individual probabilities and consequences) being modeled by the TSPA-LA are:

- An igneous intrusion groundwater transport modeling case featuring the ascent of a basaltic dike or dike system (i.e., a set or swarm of multiple dikes comprising a single intrusive event) to repository level where it intersects drifts

- A volcanic eruption modeling case featuring the development of one or more volcanoes within the repository footprint, each with a conduit that may intersect waste packages.

As a consequence of the first event, which is non-eruptive, waste from breached packages may provide a source of radionuclides when groundwater moves through the damaged packages at some time in the future (igneous intrusion groundwater transport modeling case). The potential consequence of the second event (volcanic eruption modeling case) is that waste packages entrained within a conduit may be breached, releasing radionuclides in an erupting ash plume where they can be dispersed downwind to the RMEI. The location of the RMEI is defined as being approximately $18 \mathrm{~km}$ south of the repository (10 CFR 63.312 and 10 CFR 63.302 [DIRS 156605]). Regardless of whether there is an eruption or not, any igneous event that intersects the repository will result in magmatic materials interacting with EBS components, either directly in Zone 1 (intersected emplacement drifts) or possibly indirectly in Zone 2 (emplacement drifts that are not intersected). In the following paragraphs, the potential consequences of a possible future igneous intrusion are constrained as a result of analyses of the interaction of the drift and other EBS components with magma effusively flowing into an intersected drift. Neither the TSPA-LA nor the supporting models provide results for a pyroclastic magma. The models implicitly define the manner in which igneous intrusion into the repository (by effusive flow) is included in the TSPA-LA model-that is, by defining the maximum length of all intersected drifts that are involved in the direct flow path and totaling the number of waste packages in those drifts.

The model report, Dike/Drift Interactions (BSC 2004 [DIRS 170028], Section 6), provides conclusions related to various factors influencing post-intrusion environmental conditions within the drifts. The outputs of the model indicate that the entire length of an intersected drift has the potential to be filled with magmatic materials (BSC 2004 [DIRS 170028], Section 6.4). Several lines of evidence suggest that an igneous intrusion will compromise the structural integrity of waste packages exposed to magma. The temperature of the intruding magma will be at, or near the thermal limitations of the waste package materials. Also, during the course of magma cooling, waste packages and canisters and assemblies may be subject to corrosion (BSC 2004 [DIRS 170028], Section 6.4.8.1). The evaluation of potential damage mechanisms supports the TSPA-LA assumption that waste packages in Zone 1 (intersected) drifts will provide no protection for the contained waste.

Relative to the volatilization or dissolution of the potentially exposed waste form in Zone 1 drifts, Dike/Drift Interactions (BSC 2004 ([DIRS 170028], Section 6.8.8.3) provides information that indicates that spent commercial nuclear fuel, which is a ceramic composed of $\mathrm{UO}_{2}$, will not melt or volatilize in a basalt magma. The melting temperature of the ceramic ranges from approximately $2600^{\circ} \mathrm{C}$ to $2800^{\circ} \mathrm{C}$, while the temperature of the magma is over a thousand degrees less (up to approximately $1169^{\circ} \mathrm{C}$ ). Therefore, melting or volatilization of spent fuel 
does not need to be considered further. However, when waste packages and fuel claddings are damaged, the fuel pellets may be assimilated into cooling basalt magma. As temperatures decrease after magma emplacement, $\mathrm{UO}_{2}$ is expected to fragment, which increases the surface area of the waste (BSC 2004 ([DIRS 170028], Section 6.4.8.3). Under this scenario, two types of processes are expected: chemical interaction between waste forms and the magma, and chemical interaction between the waste forms and the metal of waste package materials and cladding. Dike/Drift Interactions (BSC 2004 ([DIRS 170028], Section 6.4.8.3) indicates that uranium metal may form as well as various $\mathrm{U}-\mathrm{Zr}$ alloys. In addition, radionuclides in the waste could be incorporated into crystallizing silicate mineral phases or form higher oxide phases. The thermodynamic stability of secondary phases likely to form in cooling basalt is poorly known and it is difficult to predict which phases, if any, might form. Fission products (cesium, technetium, etc.) may also be incorporated into new mineral phases, with the size and charge of fission-product ions exerting primary control as to the resulting minerals that might contain them. Thus, there is great uncertainty as to which phases and minerals are likely to accommodate the suite of radionuclides in spent-fuel.

As stated in Dike/Drift Interactions (BSC 2004 ([DIRS 170028], Section 6.4.8.3), a significant fraction of waste packages within the repository will contain radionuclides in a glass matrix. Assuming glass waste is contained within waste packages, glass would be expected to re-melt and re-solidify as the drift is intruded and then cools. Less certain, however, are possible interactions between exposed and partially degraded glass waste and basalt magma. Given the low melting temperature of glass waste and the large difference in composition between glass waste and basalt magma, some reaction between them would be inevitable. The interaction might result in the rimming of olivine crystals with pyroxene or the crystallization of pyroxene, rather than olivine in regions of the cooling drift that are rich in glass. Much like spent fuel, however, there remains considerable uncertainty as to the exact nature of materials that may form through glass-magma interactions (BSC 2004 [DIRS 170028], Section 6.4.8.3).

As summarized in BSC 2004 ([DIRS 170028], Section 6.8.6), although the range of possible secondary mineral phases that may form cannot presently be constrained, they are nonetheless expected to comprise silicate and oxide minerals, rather than salts. As oxide and silicate minerals tend to have slow dissolution rates compared to salts, significantly enhanced dissolution rates of minerals due to reaction of waste with basalt magma within drifts is not anticipated and is not considered further.

The potential for damage to waste packages and waste forms in Zone 2 from heat and migrating gas, is also examined in Dike/Drift Interactions (BSC 2004 [DIRS 170028], Section 6.6). That modeling effort leads to a conclusion that the properties of the host rock and the presence of filled keyways at the ends of the emplacement drifts preclude damage in non-intersected drifts from heat and gas migration from intersected drifts. The fractured and porous rock, as well as the crushed tuff used to fill the perimeter drifts, does represent a possible path for gas flow resulting from magma. However, the results described below indicate that this is not a concern.

Relative to heat effects, if a drift was quickly and entirely filled with basaltic magma at a temperature of approximately $1150^{\circ} \mathrm{C}$, the tuff surrounding the drift would begin to heat up as the magma cooled. With magma cooling and solidification, the temperature profile through the drift and surrounding rock would be expected to decrease with time. The temperature 
distribution for magma filling a Zone 1 emplacement drift can be estimated using an idealized model of one-dimensional unsteady heat conduction in a cylinder. Simulations show that initial temperatures for host rock near the drift are high and attenuate rapidly into the surrounding tuff (BSC 2004 [DIRS 170028], Figures 6-98 and 6-99). Outside the drift, peak temperatures are always less than magmatic temperatures and are not reached until sufficient time has passed to accommodate conductive heating of the wall rock. For example, the peak temperature at a $10-\mathrm{m}$ radius is less than boiling and is attained only after one year from the time of intrusion. The temperature reaches near ambient conditions of approximately $30^{\circ} \mathrm{C}$ at drift center in approximately 30 years (BSC 2004 [DIRS 170028], Figures 6-98 and 6-99). The analysis also shows that the maximum temperature rise in an adjacent, unaffected drift (Zone 2) is small (less than $10^{\circ} \mathrm{C}$ ) because the host rock provides an effective thermal barrier to the impacts of heat transfer from magmatic intrusion. Therefore, heat effects in Zone 2 drifts are not a concern and are not considered further.

Relative to magmatic gas movement between drifts, gases that are exsolved from the cooling basalt would enter the wall rock and migrate away from the intruded Zone 1 drifts. The following discussion describes the effects on waste packages in Zone 2 of gases migrating from Zone 1 drifts.

Simulations of gas flow between drifts were conducted (BSC 2004 [DIRS 170028], Sections 6.6.5.2) and results indicated that after 6 months (BSC 2004 [DIRS 170028], Figure 6-89) relatively high $\mathrm{CO}_{2}$ and $\mathrm{SO}_{2}$ concentrations occur well outside the intruded drift, with localized high $\mathrm{HCl}$ and $\mathrm{HF}$ concentrations close to the drift. After 1 year, the regions of high $\mathrm{CO}_{2}$ and $\mathrm{SO}_{2}$ concentrations have continued to migrate slowly outward, with a small decline in their maximum concentrations. In contrast, gas phase $\mathrm{HCl}$ and $\mathrm{HF}$ relative concentrations have decreased dramatically to values below $10^{-9}$ as a result of cooling and dissolution into fracture condensate and matrix pore water. Over an extended period (500 years), $\mathrm{CO}_{2}$ concentrations slowly decline toward the ambient value of approximately $10^{-3}$ (volume fraction) from the initial volcanic gas composition of approximately 0.14 with no noticeable effect on the adjacent Zone 2 drift. $\mathrm{SO}_{2}$ concentrations decline much more slowly as a result of its lower solubility and smaller diffusivity, with concentrations on the order of $1 \mathrm{ppmv}$, reaching the Zone 2 drift after 500 years (BSC 2004 [DIRS 170028], Figure 6-91). This simulation assumes that there is no longer any waste-generated heat output from the Zone 2 drift (that would result in a less penetrable boiling/condensation zone) and that there is no air flow through the drift to dilute the gas. Although gas-phase $\mathrm{SO}_{2}$ concentrations for this simulation are elevated relative to the background, no impacts are anticipated for Zone 2 waste packages.

A separate simulation was done to evaluate gas transport through the filled keyway at the drift turnout (BSC 2004 [DIRS 170028], Section 6.6.5.3). The simulation considers a volcanic gas consisting of only water vapor, $\mathrm{CO}_{2}$, and $\mathrm{SO}_{2}$. The volcanic gas temperature is fixed to $300^{\circ} \mathrm{C}$, and the pressure is at the ambient value of approximately $88 \mathrm{kPa}$. This model considers a horizontal region (about $5.5 \mathrm{~m}$ in width) filled with crushed tuff extending from the drift wall to the right boundary of the model. The fill material is given the same porosity $(0.545)$ as the invert fill.

Simulation results (BSC 2004 [DIRS 170028], Section 6.6.5.3) indicate that gas transport is more rapid through this material, reaching the model boundary $40.5 \mathrm{~m}$ away in less than 
1.5 months. Temperatures are depressed in this filled zone relative to that in the rock because of the low thermal conductivity of this mostly gas-filled porous material and the lack of a significant advective component out of the drift, which would result in higher temperatures and faster gas migration. As the gas migrates through the filled connecting drifts and into a neighboring emplacement drift, the volcanic gas will be diluted by air, and as the gas source from the magma declines over time, the extent of dilution by air will increase. The crushed tuff filling the connecting drifts would likely have some initial water content and, therefore, retardation of the gas would likely be somewhat greater than the case modeled (BSC 2004 [DIRS 170028], Section 6.6.6). Therefore, it is concluded that the combination of dilution of the magmatic gas by air and retardation of the gas by moisture in the filled keyway material is expected to result in no damage to waste packages in Zone 2 drifts. Only waste packages in Zone 1 emplacement drifts can contribute to dose.

In the event of an igneous intrusion, intersected drifts will fill with magma and compromise waste packages in that drift. The possibility for magma to flow between drifts is assessed in a calculation (BSC 2004 [DIRS 171070]). The calculation assessed the sealing efficiency of a filled keyway at the drift turnout, the key being composed of a sand fill emplaced in a V-shaped roof keyway (plug). The calculations include numerical simulations performed with the computer code, FLAC. It was assumed in this study that magma entered the chamber formed at the backside of the plug under 6-8 MPa pressure. Two arguments based on mechanical and fluid-thermal considerations were used to assess the efficiency of the plug. The first argument, based on plug compressibility and plastic flow, evaluates the extent of closure occurring in the gap on the front side and the gap inside the access main behind the plug under mechanical pressure of the magma in the chamber. The second argument relies on the maximum distance that magma can infiltrate through the sandfill before its temperature reaches the effective solidification temperature due to partial crystallization. It was found that the distance magma can infiltrate before it freezes is only a fraction of the length of the gap closure. Therefore, magma filling a drift resulting from intersection with an igneous dike (Zone 1) will not be able to reach and compromise other waste packages in non-intersected drifts (Zone 2).

The analysis provided in Number of Waste Packages Hit by Igneous Intrusion (BSC 2004 [DIRS 170001]) uses repository design information and outputs from the analysis reports Characterize Framework for Igneous Activity at Yucca Mountain, Nevada (BSC 2004 [DIRS 169989]), and Characterize Eruptive Processes at Yucca Mountain, Nevada (BSC 2004 [DIRS 169980]) to calculate the number of waste packages exposed to Zone 1 (intersected drifts) magmatic environments. The analysis uses spreadsheet calculation operations to evaluate geometric relationships between dike intersection area and conduit geometry and the number of waste packages impacted by dikes and conduits.

The number of waste packages hit analysis results (BSC 2004 [DIRS 170001], Section 6.3.4]) include CDFs for the number of waste packages impacted in an igneous intrusion scenario and in an eruptive release scenario. These CDFs are used directly and explicitly in the TSPA-LA model to determine the source term for the igneous event scenarios. Because the CDFs are dependent on the underlying inputs, the underlying inputs and related FEPs are considered implicitly included in the TSPA-LA model. 
From the above discussion, interactions of the intrusion with Zone 1 are implemented within the TSPA-LA. These interactions are incorporated into the TSPA-LA as assumptions or parameters as follows:

- Assumptions underlying the igneous intrusion groundwater transport modeling case involving the waste package and waste form

- Parameters related to resumption of seepage following cooling of the drift after the magmatic intrusion.

Within the TSPA-LA, no credit is taken for any partial protection that residual elements of the waste package shells and the encapsulating basalt might provide (BSC 2004 [DIRS 170028], Section 6.4.8.1). Waste form solubilities from the nominal case are used to evaluate radionuclide transport for the igneous intrusion groundwater transport case.

Within TSPA-LA, lookup tables are used to model magma temperature as a function of time for the center of the cooling magma body. These look-up tables determine when seepage is reestablished, exposing the encased waste form to seepage flux. The abstraction considers the temperature of the waste form for a period of 100 years following intrusion. The decline in temperature of the waste form and magma body is related to the temperature due to waste heat alone at $25^{\circ} \mathrm{C}, 50^{\circ} \mathrm{C}, 100^{\circ} \mathrm{C}, 150^{\circ} \mathrm{C}$, and $200^{\circ} \mathrm{C}$. Each waste form starting temperature represents a different thermal evolution (BSC 2004 [DIRS 168504], Section 6.4.1.1.2).

Early in the cooling history, the temperatures for times between zero and the length of the TSPA-LA time step (10 years) are sampled uniformly. The temperatures for times greater than the TSPA-LA time step, but less than 100 years are taken directly from the look-up tables (BSC 2004 [DIRS 168504], Section 6.4.1.3).

Temperatures are used in the EBS multi-scale thermal model to determine the waste and invert relative humidity, invert saturation, and invert liquid flux for each waste package type in each percolation subregion after an igneous intrusion (BSC 2004 [DIRS 168504], Section 6.4.1.3). After 100 years, all TSPA-LA model variables, including temperatures, revert back to the nominal scenario thermal-hydrologic abstraction values (BSC 2004 [DIRS 168504], Section 6.4.1.1.2).

Following resumption of seepage, the abstraction used for the TSPA-LA model will use typical seepage flux from the crown, as justified in Dike/Drift Interactions (BSC 2004 [DIRS 170028], Section 5.4.1). FEP 1.2.04.04.0B describes the TSPA method used to simulate basalt-seepage water reactions within the drift for the igneous intrusion groundwater transport model. With regard to the volcanic eruption modeling case, the model report Atmospheric Dispersal and Deposition of Tephra from a Potential Volcanic Eruption at Yucca Mountain, Nevada (BSC 2004 [DIRS 170026]) provides the analysis of a potential eruption through the repository. FEPs 1.2.04.06.0A (Eruptive conduit to surface intersects repository) and 1.2.04.07.0A (Ashfall) describe how eruption scenarios are incorporated into the TSPA-LA. 
Supporting Reports: $\quad$ Characterize Eruptive Processes at Yucca Mountain, Nevada ANL-MGR-GS-000002 (BSC 2004 [DIRS 169980])

Dike/Drift Interactions

MDL-MGR-GS-000005 (BSC 2004 [DIRS 170028])

Number of Waste Packages Hit by Igneous Intrusion

ANL-MGR-GS-000003 (BSC 2004 [DIRS 170001])

\subsubsection{Chemical Effects of Magma and Magmatic Volatiles (1.2.04.04.0B)}

FEP Description:

An igneous intrusion into the repository may be accompanied by the release of magmatic volatiles. The volatiles may affect in-drift chemistry (potentially leading to increased waste package corrosion), or may be absorbed by the host rock, where they could change the chemistry of the water seeping back into the drift following the intrusive event. Seepage water chemistry following magma cooling could also be affected by flowing through and interacting with the intruded basalt.

Screening Decision: $\quad$ Included

Screening Argument: Not applicable

TSPA Disposition:

This FEP is concerned with both magmatic volatiles and their effect of water chemistry, and the basaltic magma that may fill one or more repository drifts and its effect on water chemistry. Analyses discussed below indicate that magmatic volatiles are not a concern and do not need to be considered further, while changes in water chemistry due to interaction with the basalt are included in the TSPA-LA. Analysis model reports supporting the Screening Decision contain tables of included FEPs with pointers to more detailed background information on that FEP (BSC 2004 [DIRS 170028], Table 6-1).

Relative to the potential impact of magmatic volatiles on water chemistry, magmatic volatile release may lead to zones of low $\mathrm{pH}$ in regions adjacent to potential igneous intrusions (BSC 2004 [DIRS 170028], Section 6.6). The high solubility of acidic volatiles indicates that the formation of low-pH fluids near the boiling point isotherm around Zone 1 drifts is likely. These low-pH fluids should be neutralized by hydrolysis reactions with feldspar and other minerals. The following equation (BSC 2004 [DIRS 170028], Eq. 6-112) clearly shows that hydrogen ions are consumed in hydrolysis reactions, leading to the neutralization of acidity.

$2 \mathrm{NaAlSi}_{3} \mathrm{O}_{8}$ (albite) $+2 \mathrm{H}^{+}+9 \mathrm{H}_{2} \mathrm{O} \rightarrow \mathrm{Al}_{2} \mathrm{Si}_{2} \mathrm{O}_{5}(\mathrm{OH})_{4}$ (kaolinite) $+4 \mathrm{H}_{4} \mathrm{SiO}_{4}+2 \mathrm{Na}^{+}$

Therefore, chemically aggressive fluids could exist near intruded drifts for some period following intrusion until the fluids are neutralized by natural processes. During the first year or two, temperatures at the edge of the drift remain above $100{ }^{\circ} \mathrm{C}$ preventing seepage into the drift 
(BSC 2004 [DIRS 170028] Figure 6-88). Simulations suggest that the zone of decreased pH extends into the wall rock only a relative short distance, perhaps 20 or $25 \mathrm{~m}$. Between one and five years, the narrow zone of decreased $\mathrm{pH}$ (approximately $\mathrm{pH} 7$ ) is evident in simulations (BSC 2004 [DIRS 170028], Figure 6-93). These minor changes in pH indicate low impact to water chemistry.

This analysis indicating low impact is supported by the arguments presented in FEP 1.2.04.02.0A (Igneous activity changes rock properties), which was excluded based on low consequence. In that FEP, natural analogue studies at Paiute Ridge (Carter Krogh and Valentine 1996 [DIRS 160928], pp. 7 and 8) demonstrated that the zone of alteration around an igneous intrusion was generally limited to $1 \mathrm{~m}$ or less from the intrusive contact. Therefore, any impacts on water chemistry will be limited in both time and space, so this aspect of the FEP is not considered further.

Migration of magmatic volatiles between drifts is addressed in FEP 1.2.04.04.0A (Igneous intrusion interacts with EBS components). Analyses presented there demonstrate that migration of magmatic volatiles to Zone 2 drifts (non-intersected drifts) is not a concern and does not need to be considered further (BSC 2004 [DIRS 170028], Section 6.6). Refer to FEP 1.2.04.04.0A for a complete discussion of this issue.

Assuming that an igneous intrusion occurs and the magma subsequently cools to ambient conditions, seepage water is expected to flow through and react with the basalt in the intruded emplacement drifts. The chemical interaction of the seepage water chemistry with the mineralogy of basalt is included in the TSPA-LA as described below.

The technical basis for inclusion of this process is based upon EQ3/6 software simulations involving interaction of seepage water with the basalt and the resulting hydrochemistry (BSC 2004 [DIRS 170028], Section 6.8). The EQ3/6 software package analyzes groundwater chemistry data, calculates chemical species and solubility limits, and determines the state of equilibrium for reaction of water and basalt to alter the $\mathrm{pH}$ of percolating water.

Modeling of dissolution rates using EQ6 is based on a hypothetical 1-m block of basalt. The dissolution rates for basaltic minerals are derived from literature. The composition and flow rate of the water percolating through the basalt block are modeled using the EQ3-equilibrated Bin 8 seepage water used in supporting calculations and analysis for the nominal case seepage abstraction. The water composition used in water-basalt interaction sensitivity cases also includes Bin 11 seepage water and J-13 well water. These two water types represent seepage waters that are respectively, (1) more concentrated and (2) more dilute than the Bin 8 seepage water runs. Multiple calculations were based upon varied seepage rates, $\mathrm{fCO}_{2}$ values, matrix saturations, and mineral surface areas (BSC 2004 [DIRS 170028], Section 6.8).

The water chemistry parameters required for use in TSPA are temporal values for $\mathrm{pH}$ and ionic strength. The temporal variation of $\mathrm{pH}$ and ionic strength, along with corresponding uncertainty in the form of maximum and minimum values are implemented in the TSPA-LA in look-up tables. The look-up tables present minimum and maximum parameter values for $\mathrm{pH}$ and ionic 
strength as a function of time at and $\log \left(\mathrm{fCO}_{2} / \mathrm{bar}\right)=-2,-2.5,-3,-3.5$ and -4 . The time intervals are defined in the TSPA-LA as follows (BSC 2004 [DIRS 170028], Section 6.8.4, Table 6-25):

$$
\begin{aligned}
& x \leq 25 \text { years } \\
& 25>x \leq 250 \text { years } \\
& 250>x \leq 2500 \text { years } \\
& 2500>x \leq 20000 \text { years }
\end{aligned}
$$

The minimum and maximum of the time-weighted averages from the EQ3/6 calculations are consistent with the large time steps used in the TSPA-LA igneous intrusion groundwater transport model (BSC 2004 [DIRS 170028], Section 6.4.8.1). The two most important parameters affecting the solubility of radioelements include $\mathrm{pH}$ and $\mathrm{fCO}_{2}$. To use the solubility look-up table in Dissolved Concentration Limits of Radioactive Elements (BSC 2004 [DIRS 169425]), a constant value for these parameters is used for any time interval (BSC 2004 [DIRS 170028], Section 6.8.4.1).

In some instances, TSPA-LA may need $\mathrm{pH}$ and ionic strength values for a range of parameters that are outside the range of values presented in the look-up tables. Such parameters include flux and $\log \mathrm{fCO}_{2}$. For flux rates less than $50 \mathrm{~mm} /$ year, the look-up tables are used directly. For flux rates greater than $50 \mathrm{~mm} /$ year, a flux rate of $50 \mathrm{~mm} /$ year is used in the TSPA-LA. At this point, the $\mathrm{pH}$ and ionic strength of the water (equilibrated with atmospheric gas levels) percolating into the basalt block equals the $\mathrm{pH}$ and the ionic strength of the water leaving the basalt block. Results show that for flux rates above $50 \mathrm{~mm} /$ year, little or no reaction occurs (BSC 2004 [DIRS 170028], Section 6.8.3). Convergence difficulties arise in EQ6 calculations carried out at high $\mathrm{pH}$ and low $\mathrm{CO}_{2}$ levels. Consequently, for TSPA-LA calculations where the $\log \mathrm{fCO}_{2}$ is between -.4 MPa and $-.5 \mathrm{MPa}$, the parameters for $\log \mathrm{fCO}_{2}$ of $-.4 \mathrm{MPa}$ are used (BSC 2004 [DIRS 170028], Section 6.8.3).

Supporting Reports: $\quad$ Dike/Drift Interactions MDL-MGR-GS-000005 (BSC 2004 [DIRS 170028])

\subsubsection{Magma or Pyroclastic Base Surge Transports Waste (1.2.04.05.0A)}

FEP Description:

Screening Decision:

Screening Argument:
As a result of an igneous intrusion, extrusive processes may result in a pyroclastic density flow, base surge, dike apron, effusive lava flows, and/or development of a volcanic vent at land surface. Some of the waste (entrained, dissolved, or volatized) could then be transported away from the repository. Of most concern is transport directly along the land surface to the RMEI.

Excluded - Low Consequence.

This FEP is focused on near-surface eruption-related phenomena and on magmatic-related transport of entrained wastes. 
Hydrovolcanic phenomena also are addressed under this FEP. Due to the distance to the RMEI, and the low probability of a maar crater extending to the repository depth and exhuming waste, hydrovolcanic phenomena have been excluded based on low consequence. Incorporation and transport directly to the receptor biosphere by an ash plume and/or subsequent reworking of the deposited ash following an eruptive event is addressed separately in FEP 1.02.04.07.0A (Ashfall) and its companion FEP 1.02.04.07.0C (Ash redistribution via soil and sediment transport).

The technical basis for exclusion for this FEP is presented in the following paragraphs. This basis relies in part on the definitions and concepts associated with the terms, "accessible environment," "controlled area" and "RMEI." These definitions and concepts indicate that the RMEI is located no closer to the repository than $18 \mathrm{~km}$ to the south (which is in the direction of groundwater flow) and over a contaminated groundwater plume, and that the limit of the controlled area is no greater than $5 \mathrm{~km}$ from the repository in any other direction (10 CFR 63.312 and 10 CFR 63.302 [DIRS 156605]). In order for flowing lava or a pyroclastic base surge (potentially with entrained waste contained in them) to be of consequence to the accessible environment or the RMEI, it would have to travel across the land surface a distance of 5 to $18 \mathrm{~km}$. In contrast to these distances, Quaternary volcanoes in the vicinity of Yucca Mountain are small volume (approximately $0.1 \mathrm{~km}^{3}$ or less), and typically consist of a single main scoria cone surrounded by a small field of $a a$ lava flows that extend approximately $1 \mathrm{~km}$ from the scoria cone (Characterize Framework for Igneous Activity at Yucca Mountain, Nevada, BSC 2004 [DIRS 169989], Section 6.2). Consequently, it is not credible to presume that extruded basalts with entrained wastes will extend beyond the controlled area, or to the RMEI located $18 \mathrm{~km}$ south of the repository. Pyroclastic surge deposits are also of limited geographic extent as will be described below.

Pyroclastic deposits consist of a wide range of materials, transport mechanisms, and depositional environments. Pyroclastic eruptive mechanisms associated with Strombolian eruptions may result in transport of pyroclastic tephra (e.g., lapilli and ash) to distances sufficient to reach the RMEI. This aspect of an eruptive scenario has been included and is addressed separately in FEP 1.02.04.07.0A (Ashfall), and its companion FEP 1.02.04.07.0C (Ash redistribution via soil and sediment transport); they are not discussed further in this section.

Of particular interest for this FEP are hydrovolcanic deposits or pyroclastic surge deposits. Hydrovolcanic deposits consisting mostly of ash are the result of density currents (surges) that leave distinctive thin $(\leq 1 \mathrm{~cm})$ planar beds and cross-beds. Pyroclastic surge deposits at Lathrop Wells volcano have been observed and are inferred to represent hydrovolcanic eruptions during various stages of the evolution of the basalt center. A detailed description of hydrovolcanic

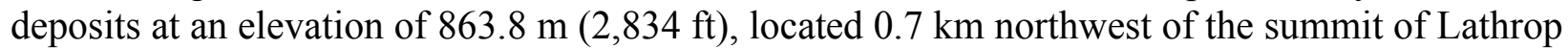
Wells volcano is provided in Characterize Eruptive Processes at Yucca Mountain. Nevada (BSC 2004 [DIRS 169980], Appendix C.3.3). Within the area flanked by the cinder cone and the protruding ridge of Miocene tuff there is a transition southward over a distance of approximately $400 \mathrm{~m}$ from thousands of thin beds of hydrovolcanic facies, to hundreds, and eventually to one or two resistant ash beds sandwiched between coarse lapilli beds. 
Observations in trenches immediately southwest of the cone also indicate a southward thinning hydrovolcanic sequence. BSC (2004 [DIRS 169980], Appendix C.3.3) notes that the field relations suggest that this limited deposit resulted from a ground-hugging sector blast (surge) directed to the northwest. Because the unit slopes approximately 8 degrees back toward the cone and projects to beneath the cone base, the exact relations are covered, but there are currently no field data indicating a concentric hydrovolcanic facies tuff ring (Wohletz 1986 [DIRS 140956], p. 262), such as might result from a large hydrovolcanic event. Also at the Lathrop Wells volcano, about 6-m below the south summit at an elevation of $954 \mathrm{~m}(3,130 \mathrm{ft})$, there is a $40-\mathrm{cm}$ thick, well-sorted, finely bedded, cross-bedded ash and coarse ash deposit. This deposit appears to be the result of a brief hydrovolcanic event late in the cone-building history (BSC 2004 [DIRS 169980], Appendix C.2.1). Crowe et al. (1986 [DIRS 101532], pp. 32 to 34) identified similar features in pyroclastic surge deposits at the southern and middle centers of the basalts of Nye Canyon. The Nye Canyon features were on the scale of $1 \mathrm{~km}$ or less.

Given the lateral scale of the observed hydrovolcanic deposits (on the order of $1 \mathrm{~km}$ or less), it is not credible to presume that pyroclastic surges with entrained wastes will reach from the vent to the RMEI located $18 \mathrm{~km}$ south or to the controlled area boundaries at no greater than $5 \mathrm{~km}$ from the repository in other directions.

A related concern is the possibility that a large steam explosion could occur, such that a large phreatic or a phreatomagmatic crater (maar) might form. Such a process could directly excavate waste and disperse it over a large area of the surrounding surface. Hydrovolcanic activity requires that rising magma encounter water in an aquifer(s) or a shallow water body at the ground surface (BSC 2004 [DIRS 169980], Section 6.1.3.2; Fisher and Schmincke 1984 [DIRS 162806], pp. 231 to 264; Wohletz and Heiken 1992 [DIRS 105544], pp. 85 to 154). The resulting steam explosion finely fragments the magma and produces large amounts of kinetic energy. If the encounter occurs below the ground surface, the host rocks are fragmented and are incorporated in the eruption products, which are elevated in lithic clast content. For a large, disruptive steam explosion to occur, magma must come in rapid contact with a large volume of water at a shallow depth. Confining pressures must be sufficiently low to permit the formation of steam and to allow disruption of the surrounding rock as the steam violently expands. Crowe et al. (1986 [DIRS 101532], p. 47) suggest that a limited area of contact, such as a dike projecting through a thin (less than $10 \mathrm{~m}$ ) aquifer, does not allow development of explosive instability, whereas contact with a standing body of water or thick (greater than $30 \mathrm{~m}$ ) horizon of water-saturated rock permits water to vaporize at explosive rates. They also suggest that magma/water mixing and explosion associated with maars, tuff rings, and tuff cones generally occur at depths less than $200 \mathrm{~m}$, which corresponds to a confining pressure of $5 \mathrm{MPa}$ or less, but also acknowledge that deeper aquifers contribute to hydroexplosions as well. They note, however, that deep interaction at confining pressures above the critical point of water probably involves a different set of explosive mechanisms.

Crowe et al. (1986 [DIRS 101532], Figure 19) present a plot of the relative frequency of crater depth for hydrovolcanic craters, maars, and tuff rings. The plot is positively skewed with a mean of $91 \pm 67 \mathrm{~m}$, and the maximum crater depth is approximately $365 \mathrm{~m}$. Crowe et al. (1986 [DIRS 101532], pp. 58 to 59) conclude that, "exhumation of a repository by explosive cratering associated with water/magma interaction is unlikely - the depth of burial of a repository at Yucca Mountain exceeds the crater depth of the largest known hydrovolcanic craters." 
However, this conclusion was based on a previously proposed repository depth of $380 \mathrm{~m}$. The maximum overburden thickness of the currently planned TSPA-LA repository is approximately $450 \mathrm{~m}$ (BSC 2003 [DIRS 166183], Section 4.2.1). The minimum depth to the TSPA-LA repository is $215 \mathrm{~m}$ (BSC 2004 [DIRS 164519]). The relative frequency of occurrence of hydrovolcanic craters greater than $215 \mathrm{~m}$ deep is less than approximately 10 to 15 percent (Crowe et al. 1986 [DIRS 101532], Figure 19). Note that the hydrovolcanic event is conditional on a geologic and hydrologic setting conducive to the occurrence of a hydrovolcanic event. Consequently, the net probability of occurrence of a 215-m hydrovolcanic crater associated with intrusion of the repository falls below the FEPs screening probability threshold. This assertion is based on: (1) a probability of 10 to 15 percent for a hydrovolcanic eruption resulting in a crater depth of $215 \mathrm{~m}$ or greater, (2) an assumed independence of a hydrovolcanic explosion from a dike intrusion into the repository, and (3) a calculated value of $1.3 \times 10^{-8}$ for the mean probability of an eruptive center forming within the repository footprint (BSC 2004 [DIRS 169989], Table 6-21).

In addition to the low probability of occurrence of a very large (greater than 215-m deep) hydrovolcanic explosion, the distribution of existing hydrovolcanic deposits in the Yucca Mountain region is limited to a radius on the order of $1 \mathrm{~km}$ or less from the vent, which is insufficient to reach the controlled area boundary, and the TSPA-LA includes a volcanic eruption modeling case that distributes ash to the location of the RMEI. Consequently, transport by a hydrovolcanic cratering event as a separate modeling case can be excluded from the TSPA-LA based on low consequence.

TSPA Disposition: $\quad$ Not Applicable

Supporting Reports: $\quad$ Not Applicable

\subsubsection{Eruptive Conduit to Surface Intersects Repository (1.2.04.06.0A)}

FEP Description:

Screening Decision: $\quad$ Included

Screening Argument:

TSPA Disposition: waste.
As a result of an igneous intrusion, one or more volcanic vents may form at land surface. The conduit(s) supplying the vent(s) could pass through the repository, interacting with and entraining

Not Applicable

FEP 1.2.04.06.0A (Eruptive conduit to surface intersects repository) is included in the TSPA-LA and is addressed through the modeling of an eruptive event. Consequences of an igneous intrusion through the repository and a resulting eruptive event are explicitly included in the TSPA-LA through the resulting ashfall, and the consequences are appropriately weighted by the probability of occurrence of the event. Analysis model reports supporting the Screening Decision contain tables of included FEPs with pointers to more detailed background information on this FEP (BSC 2004 
[DIRS 169980], Table 6-1; BSC 2004 [DIRS 170001], Table 6-1; BSC 2004 [DIRS 170026], Table 6-1; BSC 2004 [DIRS 169989], Table 6-1).

The technical basis for inclusion of this FEP relies on the results of Characterize Framework for Igneous Activity at Yucca Mountain, Nevada (BSC 2004 [DIRS 169989]). Characterize Framework for Igneous Activity at Yucca Mountain, Nevada (BSC 2004 [DIRS 169989], Table 6-21) indicates that the annualized frequency of one or more eruptive centers occurring within the repository footprint as a result of an igneous intrusion is $1.3 \times 10^{-8}$, which is greater than the low probability threshold for FEPs screening (see Assumption 5.1 in Section 5). Additionally, the lateral extent of an ashfall from such an event is sufficient to reach the location of the RMEI, so the FEP has been included.

The TSPA-LA approach for addressing igneous intrusion is outlined in Total System Performance Assessment-License Application Method and Approach (BSC 2003 [DIRS 166296], Section 8.1.2) and Total System Performance Assessment (TSPA) Model for the License Application (BSC 2004 [DIRS 168504], Section 6.4). The two igneous events (with individual probabilities and consequences) modeled by the TSPA-LA are:

- An igneous intrusion groundwater transport modeling case featuring the ascent of a basaltic dike or dike system (i.e., a set or swarm of multiple dikes comprising a single intrusive event) to the repository level where it intersects drifts (FEP 1.2.04.03.0A)

- A volcanic eruption modeling case featuring the development of one or more volcanoes within the repository footprint, each with a conduit that may intersect waste packages (this FEP).

As a consequence of the first event, which is non-eruptive, waste from breached packages may provide a source of radionuclides when groundwater moves through the damaged packages at some time in the future (igneous intrusion groundwater transport modeling case). The potential consequence of the second event (volcanic eruption modeling case) is that waste packages entrained within a conduit may be breached, releasing radionuclides in an erupting ash plume where they can be dispersed downwind to the RMEI. The location of the RMEI is assumed to be approximately $18 \mathrm{~km}$ south of the repository (10 CFR 63.312 and 10 CFR 63.302 [DIRS 156605]).

Properties and characteristics of the modeled basaltic eruption are described in Characterize Eruptive Processes at Yucca Mountain, Nevada (BSC 2004 [DIRS 169980], Section 6). The eruption characteristics used in the TSPA-LA model are based on the observed characteristics of past basaltic eruptions in the Yucca Mountain region and other analogous eruptions. For the volcanic eruption modeling case, a dike rises to the repository level, intersects one or more drifts in the repository, and proceeds vertically toward the surface. After lava in the dike encounters the ground surface, a fissure eruption develops, which proceeds to focus on one or more eruption sites as initial conduits are established. Conduits then develop from the surface downward. Conduits within the repository footprint are presumed in the TSPA-LA to be located randomly along intersecting dikes. It is presumed that where conduits intersect drifts, the waste packages in the intersected areas no longer provide any protection for the waste, which is then entrained in 
a pyroclastic eruption. The model report, Atmospheric Dispersal and Deposition of Tephra from a Potential Volcanic Eruption at Yucca Mountain, Nevada provides the basis for assuming the erupted waste materials are finely divided particles amenable for airborne transport (BSC 2004 [DIRS 170026], Section 6.5.2.16).

Other eruptive scenarios have been considered. The model report, Dike/Drift Interactions (BSC 2004 [DIRS 170028]), provides conclusions related to various conceptual models for magma flow in drifts and on to the land surface, including consideration of the "dog-leg scenario." The "dog-leg" scenario involves magma flow from the point of the dike/drift intersection to the end of the drift, where an eruptive conduit continues to the land surface. With regard to the "dog-leg," the model report states in Section 6.4.5 (BSC 2004 [DIRS 170028]), as follows:

- In the case of effusive flow, magma will continue along the trajectory of the original dike after intruding the drift complex. In the unlikely event that an existing joint at the drift periphery is invaded by magma, the flow will be interrupted by magma freezing long before it is able to reach the surface.

- In the very unlikely event that magma encounters a pond of water in the drift, and that the mixing of magma and water is thorough enough to warrant a hydrovolcanic explosion next to an existing joint, a limited amount of magma is likely to vent to the surface. However, the volume of magma involved would be small (about $100 \mathrm{~m}^{3}$ ), and the new secondary dike would freeze as soon as the pressure from the explosion levels out.

- The Woods et al. (2002 [DIRS 163662]) model of magma expansion into a drift greatly overestimates the violence of the encounter. Use of realistic initial conditions would preclude the formation of a shock wave for all but the most rapid magma ascent rates, while realistic boundary conditions would greatly reduce a shock wave, should any occur. In addition, the thermal aspects of the propagation of a thin secondary dike (i.e., magma freezing) were overlooked.

Consequently, the "dog-leg" alternative conceptual model is not considered credible and is not further considered in the TSPA-LA.

The Total System Performance Assessment (TSPA) Model for the License Application implements the eruptive model and its impact on the RMEI through the model for airborne transport (Section 6.4). For the volcanic eruption modeling case, a CDF is sampled to calculate the number of waste packages hit by eruptive conduits in a TSPA realization (BSC 2004 [DIRS 170001] Section 6.4; BSC 2004 [DIRS 168504], Section 6.4). The CDF is based on a relationship between conduit areas and the fraction of the repository area occupied by waste packages. This relationship was used in conjunction with a distribution incorporating the variability in eruptive conduit diameters and the number of eruptive conduits that could intersect the repository. The CDF is used directly by the TSPA-LA for the volcanic eruption modeling case featuring the development of one or more volcanoes above the repository with one or more 
conduits that intersect waste packages. The CDF provides the mass of waste available for incorporation with ash particles, which is required as an input for the ASHPLUME_DLL_LA V2.0 within the TSPA LA (BSC 2004 [DIRS 170026], Section 1.0 and 6.5.2).

The mass of waste to be included in the eruptive event is calculated based on the proportion of CSNF to co-disposal waste packages in the repository and a sampled parameter that selects the number of waste packages affected by the eruptive event (BSC 2004 [DIRS 168504], Section 6.4.2.3). The CDF is explicitly implemented within TSPA-LA. Because the CDF is dependent on the underlying inputs, the underlying inputs and related FEPs are considered implicitly included in the TSPA-LA model. In addition to the mass of waste that might be included in an eruptive event, the particle sizes of the waste are important to subsequent eruption and dispersal calculations. Dispersal and Deposition of Tephra from a Potential Volcanic Eruption at Yucca Mountain, Nevada (BSC 2004 [DIRS 170026] Appendix H, Table H-2) indicates that mean particle size diameters vary from $0.002 \mathrm{~cm}$ for unaltered fuel to $0.0002 \mathrm{~cm}$ for corroded fuel.

Once entrained and erupted, atmospheric transport of ash and radionuclides is modeled directly in TSPA-LA using the ASHPLUME_DLL_LA V2.0 as identified and discussed in Section 8.1 of BSC (2004 [DIRS 170026]). The ASHPLUME_DLL_LA V2.0 code implemented in the TSPA-LA is the same as the stand-alone ASHPLUME V2.0 code. In this FEP, ASHPLUME_DLL_LA V2.0 is used when discussing TSPA-LA implementation, and involves running multiple realizations with different sampled parameter inputs. The term, "ASHPLUME" model, is used when discussing generic features of the ASHPLUME V2.0 code for atmospheric dispersal and subsequent deposition of ash on the land surface from a potential volcanic eruption.

Sections 6.5.1 and 6.5.2 of BSC (2004 [DIRS 170026]) describe the mathematical model and parameter inputs, respectively, used in the ASHPLUME model to calculate ash-and-waste dispersal in the wind. The TSPA-LA model stochastically samples the number of waste packages hit and the parameters used as input in each single ASHPLUME_DLL_LA V2.0 realization. The ASHPLUME_DLL_LA V2.0 code is executed from within the TSPA LA GoldSim model and ASHPLUME results are calculated and post-processed within GoldSim (BSC 2004 [DIRS 170026], Section 1.0). Consequently, the processes defined by the ASHPLUME mathematical model are considered as explicitly included in the TSPA-LA.

In brief, for the volcanic eruption modeling case, the TSPA-LA model presumes that a hypothetical violent Strombolian eruption occurs vertically through a section of the repository, entraining radionuclide-bearing wastes in an ash plume. ASHPLUME_DLL_LA V2.0 is used within the TSPA GoldSim code to estimate radionuclide concentrations in contaminated ash falling on the ground surface at the location of the RMEI approximately $18 \mathrm{~km}$ south of the repository. The consequence (dose) of a volcanic eruption event at any given time is the sum of all of the probability-weighted consequences from all of the events that could have previously occurred. Within TSPA-LA, biosphere dose conversion factors calculated for the volcanic eruption modeling cases are used to calculate doses. This calculation is implemented within TSPA-LA by having the same volcanic eruption event occur at each time-step, probability-weighting the consequences, and then summing consequences from all time steps. The summation of events at a given time step is done within the GoldSim SoilExp_LA DLL as part of the source-term-multiplier calculations (BSC 2004 [DIRS 168504], Section 6.4.2.3). 
Supporting Reports: $\quad$ Characterize Eruptive Processes at Yucca Mountain, Nevada, ANL-MGR-GS-000002 (BSC 2004 [DIRS 169980])

Number of Waste Packages Hit by Igneous Intrusion, ANL-MGR-GS-000003 (BSC 2004 [DIRS 170001])

Atmospheric Dispersal and Deposition of Tephra from a Potential

Volcanic Eruption at Yucca Mountain, Nevada, MDL-MGR-GS-000002 (BSC 2004 [DIRS 170026])

Characterize Framework for Igneous Activity at Yucca Mountain, Nevada, ANL-MGR-GS-000001 (BSC 2004 [DIRS 169989])

\subsubsection{Ashfall (1.2.04.07.0A)}

FEP Description:

Screening Decision: $\quad$ Included

Screening Argument: $\quad$ Not applicable.

TSPA Disposition:
Finely divided waste particles may be carried up a volcanic vent and deposited on the land surface from an ash cloud.

Ashfall is included in the TSPA-LA and is addressed through the modeling of an eruptive event coupled with airborne transport and ash deposition. Consequences of the resulting ashfall are explicitly included in the TSPA-LA, and are appropriately weighted by the probability of occurrence of the event. Analysis model reports supporting the Screening Decision contain tables of included FEPs with pointers to more detailed background information on this FEP (BSC 2004 [DIRS 169980], Table 6-1; BSC 2004 [DIRS 170026], Table 6-1).

The technical basis for inclusion of this FEP relies on the results of Characterize Framework for Igneous Activity at Yucca Mountain, Nevada (BSC 2004 [DIRS 169989]). Characterize Framework for Igneous Activity at Yucca Mountain, Nevada (BSC 2004 [DIRS 169989], Table 6-21) indicates that the annualized frequency of one or more eruptive centers occurring within the repository footprint as a result of an igneous intrusion is $1.3 \times 10^{-8}$, which is slightly greater than the low probability threshold for FEPs screening (see Assumption 5.1 in Section 5). Additionally, the lateral extent of an ashfall from such an event is sufficient to reach the location of the RMEI, so the FEP has been included.

The overall TSPA-LA approach for addressing igneous intrusion is outlined in Total System Performance Assessment-License Application Method and Approach (BSC 2003 [DIRS 166296], Section 8.1.2) and Total System Performance Assessment (TSPA) Model for the License 
Application (BSC 2004 [DIRS 168504], Section 6.4). The two igneous events (with individual probabilities and consequences) modeled by the TSPA-LA are:

- An igneous intrusion groundwater transport modeling case featuring the ascent of a basaltic dike or dike system (i.e., a set or swarm of multiple dikes comprising a single intrusive event) to the repository level where it intersects drifts (FEP 1.2.04.03.0A)

- A volcanic eruption modeling case featuring the development of one or more volcanoes within the repository footprint, each with a conduit that may intersect waste packages (FEP 1.2.04.06.0A).

As a consequence of the first event, which is non-eruptive, waste from breached packages may provide a source of radionuclides when groundwater moves through the damaged packages at some time in the future (igneous intrusion groundwater transport modeling case). The potential consequence of the second event (volcanic eruption modeling case) is that waste packages entrained within a conduit may be breached, releasing radionuclides in an erupting ash plume where they can be dispersed downwind to the RMEI. The location of the RMEI is assumed to be approximately $18 \mathrm{~km}$ south of the repository (10 CFR 63.312 and 10 CFR 63.302 [DIRS 156605]). The Total System Performance Assessment (TSPA) Model for the License Application implements this airborne pathway and assesses its impact on the RMEI (BSC 2004 [DIRS 168504], Section 6.4). The conceptual model for the eruptive process is discussed under FEP 1.2.04.06.0A (Eruptive conduit to surface intersects repository). The following discussion is focused on the eruption of an ash-waste mixture into the atmosphere and subsequent transport and deposition.

The analysis report, Characterize Eruptive Processes at Yucca Mountain, Nevada (BSC 2004 [DIRS 169980]) is based on the observed characteristics of past basaltic eruptions in the Yucca Mountain region and other analogous eruptions. This analysis report includes the results of field investigations dealing with physical volcanology and ash and tephra distribution and includes the conceptual models for eruptive processes. This information is used to develop parameter value distributions appropriate for analysis of the consequences of volcanic eruptions through a proposed repository at Yucca Mountain, Nevada. The parameters developed (BSC 2004 [DIRS 169980], Table 7-1) and related to this FEP include the following:

- Eruptive power

- Eruption duration for formation of an entire volcano

- Duration of a single explosive phase constituting a violent Strombolian eruptive phase

- Tephra fall or ash volume

- Mean particle size erupted during violent Strombolian phases

- Standard deviation of particle size distribution for a given mean

- Clast characteristics

- Density of erupted particles

- Tephra deposit density.

The results of the analysis report (BSC 2004 [DIRS 169980]) do not directly feed to the TSPA-LA model. Some results provide recommended inputs to the report, Atmospheric Dispersal and Deposition of Tephra from a Potential Volcanic Eruption at Yucca Mountain, 
Nevada (BSC 2004 [DIRS 170026], Table 6-3). Many other outputs in Table 7-1 (BSC 2004 [DIRS 169980]) support analyses resulting in parameter distributions that indirectly or directly feed the TSPA-LA (e.g., conduit diameter and waste packages hit CDF) or support the conceptual model implemented in the TSPA-LA (e.g., magma chemistry) (BSC 2004 [DIRS 169980]). Thus, these inputs are implicitly included in the TSPA-LA model.

The model report, Atmospheric Dispersal and Deposition of Tephra from a Potential Volcanic Eruption at Yucca Mountain, Nevada (BSC 2004 [DIRS 170026], Table 6-3), lists parameters used to implement this FEP within the TSPA-LA. Those parameters developed within the analysis report, Characterize Eruptive Processes at Yucca Mountain, Nevada (BSC 2004 [DIRS 169980]), include:

- Mean ash particle diameter

- Ash particle diameter standard deviation for particle size distribution

- Ash particle shape factor

- Ash particle density at minimum, and a maximum, particle size

- Log ash particle size for ash particle density at minimum, and at maximum, particle density

- Eruptive power and eruption duration.

The technical basis for parameters developed within the Atmospheric Dispersal and Deposition of Tephra from a Potential Volcanic Eruption at Yucca Mountain, Nevada (BSC 2004 [DIRS 170026]) model report include, but are not limited to, the following (BSC 2004 [DIRS 170026], Section 6.5.2):

- Column diffusion constant, which affects the distribution of particles within the ash column

- Waste incorporation ratio, a mathematical construct used to transport a density-corrected "combined" ash and fuel particle

- Waste particle size (min, max, mode)

- Maximum particle diameter for transport

- Wind speed and wind direction, based on site-specific data collected over the appropriate range of ash column height

- Initial rise velocity of plume

- Eddy diffusivity constant, with the simplification made that particle diffusion time equals particle fall time. 
Atmospheric transport of the ash-waste mixture is modeled directly in TSPA-LA using the ASHPLUME_DLL_LA V2.0, as identified and discussed in Section 8.1 of BSC (2004 [DIRS 170026]). The ASHPLUME_DLL_LA V2.0 code implemented in the TSPA-LA is the same as the stand-alone ASHPLUME V2.0 code. In this FEP, ASHPLUME_DLL_LA V2.0 is used when discussing TSPA implementation. The TSPA-LA model stochastically samples different parameters used as inputs for different ASHPLUME_DLL_LA V2.0 realizations. The term, "ASHPLUME" model, is used when discussing generic features of the ASHPLUME V2.0 model for atmospheric dispersal and subsequent deposition of ash on the land surface from a potential volcanic eruption.

In brief, for the volcanic eruption modeling case, the TSPA-LA model presumes that a hypothetical violent Strombolian eruption occurs vertically through a section of the repository, entraining radionuclide-bearing wastes in an ash plume. ASHPLUME_DLL_LA V2.0 models dispersal and deposition of the contaminated ash downwind on the ground surface. The ASHPLUME_DLL_LA V2.0 is used within the TSPA-LA model to estimate radionuclide concentrations in contaminated ash falling at the location of the RMEI, approximately $18 \mathrm{~km}$ south of the repository.

The ASHPLUME_DLL_LA V2.0 code is executed from within the TSPA-LA GoldSim model and ASHPLUME results are calculated and post-processed within GoldSim. The wind speed and direction that result in atmospheric transport of the erupted material are represented in ASHPLUME_DLL_LA V2.0 within the TSPA-LA in terms of cumulative distribution (BSC 2004 [DIRS 170026], Section 6.5.2). These cumulative distribution functions are specified for $1 \mathrm{~km}$ height increments between $0 \mathrm{~km}$ and $13 \mathrm{~km}$ above the mountain.

Sections 6.5.1 and 6.5.2 of BSC (2004 [DIRS 170026]) describe the mathematical model and parameter inputs, respectively, used in the ASHPLUME model to calculate ash-and-waste dispersal in the wind. The TSPA-LA model stochastically samples the number of waste packages hit and the parameters used as input in each single ASHPLUME_DLL_LA V2.0 realization. The ASHPLUME model specifically addresses the issues of waste incorporation into the volcanic ash, the extent of the ash plume into the atmosphere, the atmospheric transport of the ash and entrained waste, and the thickness of ash deposits in the vicinity of the RMEI. GoldSim first samples the inputs that are probability distributions and then passes this input to the ASHPLUME_DLL_LA V2.0. The ASHPLUME_DLL_LA V2.0 code then calculates the waste and ash deposition results $\left(\mathrm{g} / \mathrm{cm}^{2}\right)$ at the RMEI location. The TSPA-LA model then converts the waste deposition at the RMEI location back to the masses of the individual radionuclide species and allows for radioactive decay (BSC 2004 [DIRS 168504], Section 6.4.2). The ASHPLUME model and supporting parameters are explicitly included in the TSPA-LA model.

Supporting Reports: $\quad$ Characterize Eruptive Processes at Yucca Mountain, Nevada ANL-MGR-GS-000002 (BSC 2004 [DIRS 169980])

Atmospheric Dispersal and Deposition of Tephra from a Potential Volcanic Eruption at Yucca Mountain, Nevada MDL-MGR-GS-000002 (BSC 2004 [DIRS 170026]) 


\subsubsection{Ash Redistribution via Soil and Sediment Transport (1.2.04.07.0C)}

FEP Description:

Following deposition of contaminated ash on the surface, ash deposits may be redistributed on the surface via eolian and fluvial processes.

Screening Decision: $\quad$ Included

Screening Argument: $\quad$ Not Applicable

TSPA Disposition: $\quad$ Ashfall events and processes are directly addressed in Atmospheric Dispersal and Deposition of Tephra from a Potential Volcanic Eruption at Yucca Mountain, Nevada (BSC 2004 [DIRS 170026]). The TSPA-LA includes consideration of exposure from redistributed ash. Analysis model reports supporting the Screening Decision contain tables of included FEPs with pointers to more detailed background information on this FEP (BSC 2004 [DIRS 170026], Table 6-1; BSC 2004 [DIRS 169980], Table 6-1).

The technical basis for inclusion of this FEP relies on the results of Characterize Framework for Igneous Activity at Yucca Mountain, Nevada (BSC 2004 [DIRS 169989]). Characterize Framework for Igneous Activity at Yucca Mountain, Nevada (BSC 2004 [DIRS 169989], Table 6-1) indicates that the annualized frequency of one or more eruptive centers occurring within the repository footprint as a result of an igneous intrusion is $1.3 \times 10^{-8}$ (see Assumption 5.1 in Section 5), which is slightly greater than the low probability threshold for FEPs screening. Additionally, the lateral extent of an ashfall from such an event is sufficient to reach the location of the RMEI. Ash that falls at the location of the RMEI and between that location and the eruptive vent, is subject to redistribution on the surface by eolian and fluvial processes. In other words, tephra that did not originally fall at the RMEI location could be redistributed to the RMEI location by sedimentary processes, therefore this FEP has been included.

For the volcanic eruption modeling case, the TSPA-LA presumes that a hypothetical violent Strombolian eruption occurs through a section of the repository, entraining radionuclide-bearing wastes in an ash plume that disperses downwind and deposits contaminated ash on the ground surface (BSC 2004 [DIRS 170026], Section 6.5). Using the ASHPLUME_DLL_LA V2.0 code, the TSPA-LA model estimates radionuclide concentrations in contaminated ash falling at the location of the RMEI, approximately $18 \mathrm{~km}$ south of the repository (10 CFR 63.312 and 10 CFR 63.302 [DIRS 156605]).

The ASHPLUME_DLL_LA V2.0 code implemented in the TSPA-LA is the same as the stand-alone ASHPLUME V2.0 code. In this FEP, ASHPLUME_DLL_LA V2.0 is used when discussing TSPA implementation, which involves multiple realizations with different sampled parameter inputs. The term "ASHPLUME" model is used when referring to the results of a separate 100-realization model study that is used in the redistribution abstraction, and refers to used of mean primary and geometric mean concentrations (see Table 6-3). 
After deposition of the tephra sheet, the tephra and waste are available for redistribution by fluvial and eolian processes that could erode, transport, mix, and redeposit the tephra (BSC 2004 [DIRS 170026], Section 8.1). The ash redistribution calculations for a probability-weighted volcanic event are performed within TSPA-LA using the SoilExp_LA DLL (BSC 2003 [DIRS 166296], Section 2.1). The TSPA-LA approach for calculating exposure through the use of volcanic-specific biosphere dose conversion factors is outlined in Total System Performance Assessment-License Application Method and Approach (BSC 2003 [DIRS 166296], Section 8.1.2). Total System Performance Assessment (TSPA) Model for the License Application calculates dose from exposure due to inhalation, ingestion, and external exposure and its impact on the RMEI (BSC 2004 [DIRS 168504], Section 6.4.2.3). To determine dose, biosphere dose conversion factors are applied as developed according to the biosphere model component.

Within TSPA-LA, there are two possible outcomes of an eruption through the repository and the subsequent redistribution of the ash:

- Outcome 1 addresses primary ash fall on the RMEI location and local redistribution of the ash

- Outcome 2 addresses primary ash fall in the upper Fortymile Wash drainage basin and subsequent redistribution of that ash to the location of the RMEI.

The Soil_Exp DLL implements Table 6-3 below as the abstraction within the TSPA-LA (BSC 2004 [DIRS 168504], Sections 6.4.2.3).

In Outcome 1, direct deposition of ash and waste occurs in the vicinity of the RMEI and represents the greatest degree of exposure from an eruptive process (BSC 2004 [DIRS 170026], Sections 6.3.2 and 6.6.3). All other mechanisms (e.g., eolian or fluvial processes) allow for mixing and dilution of the ash and waste through distance and with time. Presumably, a volume of transported sediment with a diluted ash component would have less impact on the RMEI than would a primary ash fall that fell directly on the RMEI (BSC 2004 [DIRS 170026], Section 5.1.3).

In Outcome 2, direct deposition of ash and waste occurs in the upper Fortymile Wash drainage basin, outside the vicinity of the RMEI. Tephra sheet deposition may occur in any direction, depending on the sampled wind direction. However, other tephra-sheet orientations either eliminate ash from reaching the RMEI location, or reduce the available volume of ash to be redistributed to the RMEI location (BSC 2004 [DIRS 170026], Sections 5.1.3 and 6.3.2). For the TSPA-LA, the tephra sheet is assumed to be deposited within the Fortymile Wash drainage basin (consistent with prevailing southwesterly winds), making ash available upstream from the RMEI location in all realizations. 
Both Outcomes 1 and 2, presented in Table 6-3, explicitly consider two different geomorphic areas that respond differently to ash fall and redistribution (BSC 2004 [DIRS 170026], Sections 6.7.2.3 and 6.7.2.4):

- On interchannel divides, the dominant geomorphic process is presumed to be erosion, resulting in ash removal

- Within the channels, sediment transport processes will move contaminated ash through the region in response to storm events.

In Outcome 1, on interchannel divides, ash-layer (tephra) thickness and areal waste concentration is calculated by ASHPLUME_DLL_LA V2.0 in the TSPA_LA model. Ash removal is assumed to occur at a rate uniformly distributed between 0.02 to $0.04 \mathrm{~cm} / \mathrm{yr}$. After ash removal, residual contamination is assumed to remain within a $9-\mathrm{cm}$ contaminated soil layer beneath the initial ash, as explained in Table 6-3. In Outcome 2, where deposition would occur away from the RMEI, areal waste concentration on interchannel divides is derived from the separate ASHPLUME model results, discussed above, with wind direction fixed southward (see Table 6-3). Possible contamination by eolian processes or major flood events is approximated by a 1 to $2 \mathrm{~cm}$ (uniform distribution) layer with 1/100th of the initial mean primary waste concentration derived from the separate ASHPLUME calculation. The layer is assumed to remain indefinitely.

Table 6-3. Ash Redistribution Factors for the TSPA Model

\begin{tabular}{|c|c|c|}
\hline & Interchannel Divide & Distributary Channels \\
\hline $\begin{array}{l}\text { AREAL } \\
\text { WEIGHT }\end{array}$ & 0.82 & 0.18 \\
\hline $\begin{array}{l}\text { Outcome } 1 \\
\text { Primary } \\
\text { tephra (ash } \\
\text { fall) in the } \\
\text { vicinity of } \\
\text { the RMEl } \\
\text { location. }\end{array}$ & $\begin{array}{l}\text { Initial Ash-layer (tephra) thickness } \\
\text { calculated by ASHPLUME_DLL_LA in the } \\
\text { TSPA model. } \\
\text { Initial waste areal concentration calculated } \\
\text { in TSPA for the ash layer at the location of } \\
\text { the RMEI. } \\
\text { Ash removal } \\
\text { At a rate uniformly distributed between } \\
0.02 \text { to } 0.04 \mathrm{~cm} / \mathrm{yr} \text {. } \\
\text { Residual } \\
9 \text {-cm contaminated soil layer beneath } \\
\text { initial ash. Volumetric concentration of the } \\
\text { waste (as specified in Table } 6-5 \text { from } \\
\text { BSC } 2004 \text { [DIRS } 170026 \text { ]) in this layer } \\
\text { decreases linearly from the initial value } \\
\text { calculated in the ash to } 1 / 100 t h \text { of that } \\
\text { value at } 9 \text { cm. This layer is removed at the } \\
\text { same rate as the initial ash layer, } \\
\text { consistent with }{ }^{137} \text { Cs observations. The } \\
\text { linear volumetric concentration decrease is } \\
\text { conservative with respect to the } \\
\text { exponential decrease observed for }{ }^{137} \text { Cs. } \\
\text { Below the } 9 \text {-cm layer is an additional } 1 \text { to } 2 \\
\text { cm (uniform distribution) layer with } 1 / 100 \text { th } \\
\text { of the initial volumetric concentration. } \\
\text { Assumed to remain indefinitely. } \\
\text { Represents infiltration from initial ash layer } \\
\text { before removal. }\end{array}$ & $\begin{array}{l}\text { Initial condition } \\
\text { Initial ash-layer thickness: uniform distribution from } 1 \text { to } \\
15 \mathrm{~cm} \text {, or the initial ash layer thickness calculated for the } \\
\text { divide areas in the TSPA model, whichever is greater. } \\
\text { Initial waste concentration: mean primary waste } \\
\text { concentration (as specified in Table } 6-5 \text { from BSC } 2004 \\
\text { [DIRS } 170026] \text { ), except for realizations in which the ash } \\
\text { thickness calculated in the TSPA is greater than the } \\
\text { thickness sampled from the } 1 \text { to } 15 \text { cm uniform } \\
\text { distribution; in those cases, use the waste volumetric } \\
\text { concentration calculated in TSPA for the ash layer at the } \\
\text { location of the RMEl. } \\
\text { Ash removal } \\
\text { Volumetric concentration of waste in the ash layer } \\
\text { decreases linearly from its initial volumetric concentration } \\
\text { to } 1 / 100 \text { th of its initial volumetric concentration within a } \\
\text { time period uniformly distributed between } 100 \text { and } 1,000 \\
\text { years. This decrease in volumetric concentration } \\
\text { represents dilution during removal and replacement of } \\
\text { the initial sediment. } \\
\text { Residual outcome } \\
\text { After removal of the initial volumetric concentration, a } \\
\text { layer with the same initial thickness but with } 1 / 100 \text { th of } \\
\text { the initial volumetric concentration is assumed to remain } \\
\text { indefinitely. } \\
\text { This residual layer represents lower levels of } \\
\text { contamination that may be brought down the wash or } \\
\text { exposed from underlying soil. }\end{array}$ \\
\hline
\end{tabular}


Table 6-3. Ash Redistribution Factors for the TSPA Model (Continued)

\begin{tabular}{|c|c|c|}
\hline & Interchannel Divide & Distributary Channels \\
\hline AREAL WEIGHT & 0.82 & 0.18 \\
\hline $\begin{array}{l}\text { Outcome } 2 \\
\text { No primary tephra fall } \\
\text { on, or near the RMEI } \\
\text { location. Primary } \\
\text { tephra deposition in } \\
\text { upper Fortymile Wash } \\
\text { drainage basin. }\end{array}$ & $\begin{array}{l}\text { Possible contamination by eolian } \\
\text { processes or major flood events is } \\
\text { approximated by a } 1 \text { to } 2 \mathrm{~cm} \\
\text { (uniform distribution) layer with } \\
1 / 100 \text { th of the initial mean primary } \\
\text { waste concentration (as specified in } \\
\text { Table } 6-5 \text { from BSC } 2004 \\
\text { [DIRS } 170026] \text { ), from the } 18-\mathrm{km} \\
\text { ASHPLUME calculations and is } \\
\text { assumed to remain indefinitely. }\end{array}$ & $\begin{array}{l}\text { Initial condition } \\
\text { Initial ash-layer thickness: uniform distribution from } \\
1 \text { to } 15 \mathrm{~cm} \text {. } \\
\text { Initial waste concentration: geometric mean } 18-\mathrm{km} \\
\text { ASHPLUME volumetric concentration. } \\
\text { Ash removal } \\
\text { Volumetric concentration of waste in the ash layer } \\
\text { decreases linearly from its initial volumetric } \\
\text { concentration to } 1 / 100 \text { th of its initial volumetric } \\
\text { concentration within a time period uniformly } \\
\text { distributed between } 100 \text { and } 1,000 \text { years. This } \\
\text { decrease in volumetric concentration represents } \\
\text { dilution during removal and replacement of the } \\
\text { initial sediment. } \\
\text { Residual outcome } \\
\text { After removal of the initial volumetric concentration, } \\
\text { a layer with the same initial thickness, but with } \\
1 / 100 \text { th of the initial volumetric concentration is } \\
\text { assumed to remain indefinitely. } \\
\text { This residual layer represents lower levels of } \\
\text { contamination that may be brought down the wash } \\
\text { or exposed from underlying soil. }\end{array}$ \\
\hline
\end{tabular}

Source: BSC 2004 [DIRS 170026], Section 6.7.2.2 and Table 6-5.

Within distributary channels, Outcomes 1 and 2 are treated similarly. The initial ash-layer thickness is derived from a uniform distribution from 1 to $15 \mathrm{~cm}$. The initial areal ash concentrations are generally derived from the separate ASHPLUME model results with wind direction fixed southward, as described above and in Table 6-3. The volumetric concentration of waste in the ash layer decreases linearly from its initial volumetric concentration to $1 / 100$ th of its initial volumetric concentration within a time period uniformly distributed between 100 and 1,000 years. Eventually, within the channels, the watershed would be depleted of contaminated ash, but the duration for this process is unknown. Mixing processes will also dilute the ash with uncontaminated sediment, but existing data are insufficient to quantify that dilution. Given these uncertainties, the TSPA-LA assumes a layer to remain indefinitely with the sampled initial thickness but with 1/100th of the initial volumetric concentration derived from the separate ASHPLUME calculation (BSC 2004 [DIRS 170026], Sections 1.3.2 and 6.7.2.4).

The analysis and model reports Characterize Eruptive Processes at Yucca Mountain, Nevada (BSC 2004 [DIRS 169980], Section 6.5) and Atmospheric Dispersal and Deposition of Tephra from a Potential Volcanic Eruption at Yucca Mountain, Nevada (BSC 2004 [DIRS 170026]) include the results of field investigations and present the detailed conceptual and technical basis for the ash redistribution model that is then abstracted as described here and implemented within TSPA-LA.

The TSPA-LA model performs calculations for the ash redistribution model based on the results of an ASHPLUME_DLL_LA V2.0 calculation for a particular realization (see Section 6.2.2.7). The SoilExp_LA DLL within GoldSim defines such parameters as mean ash and waste concentrations; percentage of the initial volumetric concentration, which remains indefinitely in 
the soil; areal weight fraction of the interchannel divides and the distributary channels; ash removal rate; initial and residual ash thicknesses; ash removal time; and biosphere model component inputs (BSC 2004 [DIRS 166296], Section 2.1; BSC 2004 [DIRS 170026], Section 6.7.2; BSC 2004 [DIRS 168504], Section 6.4.2.3). SoilExp_LA performs redistribution calculations for each TSPA Model time step within a realization with the probability-weighted consequence equaling the sum of all time steps in each realization (see Section 6.2.2.6).

Supporting Reports: $\quad$ Characterize Eruptive Processes at Yucca Mountain, Nevada ANL-MGR-GS-000002 (BSC 2004 [DIRS 169980])

Atmospheric Dispersal and Deposition of Tephra from a Potential Volcanic Eruption at Yucca Mountain, Nevada MDL-MGR-GS-000002 (BSC 2004 [DIRS 170026])

\subsubsection{Hydrologic Response to Igneous Activity (1.2.10.02.0A)}

FEP Description:

Igneous activity includes magmatic intrusions, which may alter groundwater flow pathways, and thermal effects that may heat up groundwater and rock. Igneous activity may change the groundwater flow directions, water level, water chemistry, and temperature. Eruptive and extrusive phases may change the topography, surface drainage patterns, and surface soil conditions. This may affect infiltration rates and locations.

Screening Decision: $\quad$ Excluded - Low Consequence

Screening Argument: $\quad$ Igneous intrusion into the repository (i.e., igneous activity) could potentially alter the hydrologic characteristics of the site and thereby affect flow-and-transport characteristics and release to the accessible environment and exposure. However, the orientation of the dikes and the limited scale of a few meters indicate that the hydrologic response would be of low consequence.

The technical basis for exclusion of this FEP relies on a variety of information including observed phenomena at analogue sites, analysis of effects on ground water flow pathways, and information on thermal effects on rock properties. These are discussed in the following paragraphs. The reader should keep in mind that not all the studies discussed here were preformed for the purpose of assessing igneous impacts on hydrology, and in several instances inferences are drawn. For example, if thermal effects, as indicated by mineralogic changes, are confined to a narrow zone around an intruded dike, it is inferred that any resulting changes in water chemistry and permeability are also confined to that narrow zone.

Observed Phenomena at Analogue Sites-An appropriate analogue for understanding the characteristics of a volcanic event at Yucca Mountain is the Paiute Ridge intrusive/extrusive center (Byers and Barnes 1967 [DIRS 101859]) on the northeastern margin of the Nevada Test Site. The Paiute Ridge center is a small-volume Miocene volcanic center comparable in volume and composition to Quaternary volcanoes near Yucca Mountain (BSC 2004 [DIRS 169989], Section 6.3.2.1). Paleomagnetic, geochronologic, and geochemical data indicate that the entire 
intrusive/extrusive complex formed during a brief magmatic pulse and thus represents a single volcanic event. The vents and associated dike system formed within a north-northwest-trending extensional graben and there are excellent exposures of a variety of system depths. This includes remnants of surface lava flows, volcanic conduits, and dikes and sills intruded into tuff country rock at depths of up to $300 \mathrm{~m}$. There is evidence of shallow structural control of dike emplacement at Paiute Ridge, including dike emplacement along fault planes (Byers and Barnes 1967 [DIRS 101859]). Dike lengths at Paiute Ridge range from less than $1 \mathrm{~km}$ to $5 \mathrm{~km}$, comparable to the range estimated for post-Miocene volcanism near Yucca Mountain.

Carter Krogh and Valentine (1996 [DIRS 160928], pp. 7 and 8) described the margins of the Paiute Ridge (PR) dike complex as follows:

PR dike contains ubiquitous near-vertical joints that result in a pervasive platy texture with plates parallel to the dike-host contact. Conversely, with the exception of local cooling joints in fused wall rock (extending $10 \mathrm{~cm}$ to $20 \mathrm{~cm}$ into the wall rock, perpendicular to the dike margin), joints are never visible in the host rock along the length of the dike. The contact between basalt and the tuff host rock is consistently smooth and shows no brecciation. Along strike at this contact, the tuff host rock is fused or welded to varying degrees: in places the tuff is completely welded and forms black vitrophyre that grades rapidly away from the contact, over a distance of ca $20 \mathrm{~cm}$ to $100 \mathrm{~cm}$, into nonwelded tuff that is apparently unaffected by the dike. In other places the tuff is only partly welded at the contact and black fiamme are elongated parallel to the contact. We infer that this "contact welding" is the combined result of heat from the dike and compressive stress exerted by the flowing magma on the wall rocks. Welded host rock commonly contains vesicles that are elongated vertically and parallel to the margin. In some places, welded tuff coats the basalt and displays rills or elongate smooth ridges (flutes). Most rills plunge nearly vertically, however, a sub-horizontal rill is present in the central part of the dike. At the dike tip, exposed at Slanted Buttes, scoria patches crop out near the dike-host contact.

The two eastern dikes, $\mathrm{M}$ and $\mathrm{E}$... show geometries and textures similar to those of PR; however, $\mathrm{M}$ dike is much shorter and does not feed a sill, and $\mathrm{E}$ dike was emplaced closest to the paleosurface and feeds two sills. M dike ... visibly occupies a normal fault, oriented $\mathrm{N} 40^{\circ} \mathrm{W}, 61^{\circ} \mathrm{E}, \ldots$ Its host rocks are only Tertiary tuffs, which show no brecciation or jointing near the dike contact ... Texture within the dike is characterized by a vertical platy fabric that parallels the dike margins. E dike is the eastern-most dike studied within the graben. Near the neck, the dike visibly occupies a NNW-trending, steeply E-dipping normal fault that displaces bedded tuffs $3.5 \mathrm{~m}$ and does not cut the dike ...The texture of E dike is characterized by the pervasive vertical platy fabric common to $\mathrm{M}$ and PR dikes. Adjacent host tuffs are not jointed nor brecciated, except for local vertical jointing of the Rainier Mesa tuff, which is intruded by the dike at its shallowest level. The contact of the dike and host tuff is preserved in places and varies from partly to completely welded in the same manner as described above for the PR dike. Where complete welding has occurred, vesicles are vertical and parallel the dike margin. Contact welding of the host tuffs formed oblate fiamme 
that parallel the dike-host contact. Visible thermal effects on the wall rocks disappear within 1-m of the dike margin.

This description suggests that zones of change in rock properties (i.e., formation of vitrophyres and/or various degrees of welding of the host rock and formation of fiamme, which are flattened glassy inclusions) are limited to between a few tens of centimeters, to at most a meter perpendicular to the dike. Other features such as the platy texture along the dike margins and vesicles in the welded tuff are oriented parallel to the dike margins. This orientation suggests that the primary direction of increased or decreased permeability (if any) is parallel with the dike margins.

Effects on Groundwater Flow Pathways-The following discussion on the potential for an intrusion to effect groundwater flow pathways includes an evaluation of the orientation of a possible future dike because orientation could affect the consequences of an intrusion. Most researchers conclude that after ascending dikes enter the shallow upper crust, their location and orientation are influenced by the orientation of the local stress field and the presence of faults that may locally control alignment. The evidence cited for this conclusion, in addition to the interaction of faults and dikes at the Paiute Ridge center described above, includes several northeast-oriented vent alignments in the Yucca Mountain region and the association of eruptive centers with known or inferred faults (CRWMS M\&O 1996 [DIRS 100116], Appendix E, p. AM-4; Connor et al. 1996 [DIRS 135969], p. 78).

The results of the PVHA are summarized in the analysis report Characterize Framework for Igneous Activity at Yucca Mountain, Nevada (BSC 2004 [DIRS 169989]), which presents probability distributions for the length and orientation of possible future volcanic dikes near the repository. The aggregate dike-length distribution derived from the PVHA has a mean value of $4.0 \mathrm{~km}$, and the most commonly assigned dike orientation centers on N30 ${ }^{\circ} \mathrm{E}$ (BSC 2004 [DIRS 169989], Section 6.3.2). The anisotropic transmissivity observed in the SZ in the Yucca Mountain region has a maximum principal transmissivity direction of approximately $\mathrm{N} 15^{\circ} \mathrm{E}$ (BSC 2004 [DIRS 170042], Section 6.5.2.10), which is generally consistent with the fault and fracture orientations. A corroborative analysis by Ferrill et al. (1999 [DIRS 118941], p. 1) indicated a $\mathrm{N} 30^{\circ} \mathrm{E}$ orientation. A north-to-northeast orientation parallels or sub-parallels the faults and fractures active in the present-day in situ stress field. Dike features that may form in the future, such as the platy texture and welded surfaces that could affect the permeability, will parallel the dike orientation, and will likely be aligned in a north-to-northeast orientation.

This parallel to subparallel orientation of dikes and maximum principal transmissivity, coupled with the expected limited affected volume of material around the dikes, indicates that dikes, even if differing in permeability, will not significantly affect groundwater flow patterns at the mountain scale. By way of corroboration, an early analysis of the effect of a dike on flow in the SZ was conducted and documented in Chapter 10 of the TSPA-VA (CRWMS M\&O 1998 [DIRS 100369], Section 10.4.4). The corroborative analysis suggested that there would be negligible impact for a dike oriented north to northeast. The analysis included a variety of dike lengths and locations respective to the repository area. Additionally, the occurrence of such a change is conditional on a low probability event of an igneous intrusion. 
The report Synthesis of Volcanism Studies for the Yucca Mountain Site Characterization Project (CRWMS M\&O 1998 [DIRS 105347], p. 5-56) mentions the possibility of perched water forming near low-permeability intrusive bodies and a concern regarding the potential for a dike to provide a barrier to flow and/or cause impoundments. Because of the parallel, to subparallel orientation of dikes with the existing orientation of the anisotropic maximum horizontal permeability in the SZ, a dike would not form a barrier or impoundment that would have any significant effect on flow in the SZ. By way of corroborative information, for a dike initially intruding into the SZ, Rojstaczer (1991 [DIRS 163416], Abstract) indicates a possible rise in the water table of only a few tens of meters. In the UZ, the primary direction of groundwater flow is vertically downward through the fractures. Because the joints on a dike margin would be near-vertical, the formation of a significant perched water zone would be dependant on the formation of a sill. The potential impact of sill formation is addressed in the FEP 1.2.04.03.0A (Igneous intrusion into repository). The formation of a perched water zone is addressed in the FEP 2.2.07.07.0A (Perched water develops). Drainage from a perched water zone is addressed in FEP 2.2.06.03.0A (Seismic activity alters perched water zone).

Relative to groundwater flow paths that might be impacted in or near the repository as a result of post-intrusion in-drift conditions, the TSPA-LA addresses these potential conditions through the assumption that the permeability of any contact metamorphic aureole surrounding the intruded drifts is as great as that of the bulk host rock (see BSC 2004 [DIRS 170028], Section 5.4.1). The basalt is assumed to fracture during cooling so that it provides no barrier to flow from the formation. Therefore, the seepage abstraction changes, in the case of an igneous event, because there is probably no capillary barrier to seepage in basalt-filled drifts (BSC 2004 [DIRS 169131], Section 6.5.1.7). After post-intrusive magma cooling, seepage water is expected to flow through the contact metamorphic aureole and react with the basalt in the intruded emplacement drifts. The geochemical interactions of the seepage water and rock and the resulting hydrochemistry are addressed in FEP 1.2.04.04.0B in Section 6.2.2.4 of this report.

Potential Thermal and Geochemical Effects-With regard to possible geochemical changes and based on studies of natural-analogue sites, Synthesis of Volcanism Studies for the Yucca Mountain Site Characterization Project (CRWMS M\&O 1998 [DIRS 105347], pp. 5-1 and 5-2) states that for shallow, small-volume basaltic intrusions, the chemical and mineralogical studies of host tuffs indicate that alteration is limited to within a few tens of meters of the intrusion. More specifically, from a study of the Paiute Ridge analogue site, there is no indication of extensive hydrothermal circulation and alteration, brecciation, and deformation related to magmatic intrusion, or vapor-phase recrystallization during the magmatic intrusions into the vitric and zeolitized tuffs (CRWMS M\&O 1998 [DIRS 105347], p. 5-42). The analogue studies show that alteration is quite limited and is typically only found within 5 to $10 \mathrm{~m}$ of intrusions (CRWMS M\&O 1998 [DIRS 105347], p. 5-41). At the Paiute Ridge center, low-temperature secondary minerals persist near the contact with intrusions (CRWMS M\&O 1998 [DIRS 105347], p. 5-46). This persistence suggests that little destruction of pre-existing sorptive minerals is expected. Given the limited area of alteration and the consequent change of rock properties around the intrusion, the effect of alteration is minimal and alteration does not provide a mechanism to significantly change the dose. Therefore, this aspect of this FEP is excluded from the TSPA-LA based on low consequence. 
Potential for Development of a Hydrothermal System-Synthesis of Volcanism Studies for the Yucca Mountain Site Characterization Project (CRWMS M\&O 1998 [DIRS 105347], p. 5-86) considered the effects of hydrothermal systems (the heating up of groundwater and rock) resulting from igneous intrusions. Findings from the Paiute Ridge analogue site indicate that, "the occurrence of clinoptilolite and opal also suggests that thermal transfer into the adjacent country rock was minimal" (CRWMS M\&O 1998 [DIRS 105347], p. 5-57). Findings from the Grants Ridge analogue site in New Mexico suggest the absence of a hydrothermal system at that location (CRWMS M\&O 1998 [DIRS 105347], p. 5-74). Further, the study concluded that, “....an intrusion at Yucca Mountain would not result in large amounts of hydrothermally driven mass transfer" (CRWMS M\&O 1998 [DIRS 105347], p. 5-74). Consequently, the development of hydrothermal systems from igneous activity is excluded from the TSPA-LA based on low consequence due to their limited size relative to the repository footprint.

Potential Topographic and Surface Effects Following an Eruption-There is a potential for igneous activity (primarily via eruption or effusive flow) to change surface topography, and subsequently affect drainage and infiltration. The effects could hypothetically result in temporary damming of a drainage intersected by a lava flow at the surface or from the sloughing of ash or soil materials from hill slopes into drainages. The steep topographic gradients at Yucca Mountain above the repository and the limited extent of effusive flow from small-scale volcanoes, such as Lathrop Wells, would limit the consequences of any such topographic changes. The net result through time would likely resemble something akin to the Lathrop Wells volcano, where drainage patterns readjust and re-equilibrate to match the change in conditions, resulting in relocation of the drainage. This, rather than any significant ponding or increased infiltration effects. Therefore the topographic aspect of the FEP is excluded based on low consequence. FEP 1.2.04.07.0C (Section 6.2.2.8) discusses assumptions regarding infiltration of radionuclides into underlying soil following ashfall and subsequent redistribution.

Summary-The parallel orientation of potential future dikes with the direction of maximum transmissivity in the SZ, coupled with the limited volume of the dike and adjacent affected rock, indicates that dikes (even if differing in permeability from the host rock) will not significantly affect groundwater-flow patterns or water levels. Because there would be no significant change to the flow system, hydrologic response to igneous activity does not provide a mechanism for significantly changing dose. Given the limited area of any thermal or geochemical alteration, and the consequent change of rock properties around an intrusion, the effect of alteration would be minimal and alteration would not provide a mechanism to significantly change the dose. The potential development of a hydrothermal system from igneous activity is not likely based on analogue studies and would be of low consequence due to its limited size relative to the repository footprint. Any possible changes to topography and soils from extrusive activity are also of low consequence. Consequently, the FEP "Hydrologic response to igneous activity" is excluded from the TSPA-LA based on low consequence.

TSPA Disposition: $\quad$ Not Applicable

Supporting Reports: $\quad$ Not Applicable 


\section{CONCLUSIONS}

Table 7-1 summarizes the disruptive events FEP-screening decisions and the basis for the decisions. This analysis report may be affected by technical product input information that requires confirmation. Any changes to the document that are required because of completing the confirmation activities will be reflected in subsequent revisions. The quality status of the technical product input may be confirmed by review of the FEP database.

Table 7-1. Summary of Disruptive Events FEP Screening Decisions

\begin{tabular}{|c|c|c|c|}
\hline $\begin{array}{l}\text { TSPA-LA FEP } \\
\text { Number }\end{array}$ & TSPA-LA FEP Name & $\begin{array}{l}\text { Screening Decision } \\
\text { and Basis }\end{array}$ & $\begin{array}{c}\text { Section Where } \\
\text { Addressed }\end{array}$ \\
\hline 1.2.01.01.0A & Tectonic activity-large scale & $\begin{array}{l}\text { Excluded - Low } \\
\text { Consequence }\end{array}$ & 6.2.1.1 \\
\hline 1.2.02.03.0A & Fault displacement damages EBS components & Included & 6.2.1.2 \\
\hline 1.2.03.02.0A & Seismic ground motion damages EBS components & Included & 6.2.1.3 \\
\hline 1.2.03.02.0B & Seismic-induced rockfall damages EBS components & $\begin{array}{l}\text { Excluded - Low } \\
\text { Consequence }\end{array}$ & 6.2.1.4 \\
\hline 1.2.03.02.0C & Seismic-induced drift collapse damages EBS components & $\begin{array}{l}\text { Excluded - Low } \\
\text { Consequence }\end{array}$ & 6.2.1.5 \\
\hline 1.2.03.02.0D & $\begin{array}{l}\text { Seismic-induced drift collapse alters in-drift } \\
\text { thermohydrology }\end{array}$ & Included & 6.2.1.6 \\
\hline 1.2.03.03.0A & Seismicity associated with igneous activity & Included & 6.2.1.7 \\
\hline 1.2.04.02.0A & Igneous activity changes rock properties & $\begin{array}{l}\text { Excluded - Low } \\
\text { Consequence }\end{array}$ & 6.2.2.1 \\
\hline 1.2.04.03.0A & Igneous intrusion into repository & Included & 6.2.2.2 \\
\hline 1.2.04.04.0A & Igneous intrusion interacts with EBS components & Included & 6.2.2.3 \\
\hline 1.2.04.04.0B & Chemical effects of magma and magmatic volatiles & Included & 6.2.2.4 \\
\hline 1.2.04.05.0A & Magma or pyroclastic base surge transports waste & $\begin{array}{l}\text { Excluded - Low } \\
\text { Consequence }\end{array}$ & 6.2 .2 .5 \\
\hline 1.2.04.06.0A & Eruptive conduit to surface intersects repository & Included & 6.2.2.6 \\
\hline 1.2.04.07.0A & Ashfall & Included & 6.2.2.7 \\
\hline 1.2.04.07.0C & Ash redistribution via soil and sediment transport & Included & 6.2.2.8 \\
\hline 1.2.10.01.0A & Hydrologic response to seismic activity & $\begin{array}{l}\text { Excluded - Low } \\
\text { Consequence }\end{array}$ & 6.2.1.8 \\
\hline 1.2.10.02.0A & Hydrologic response to igneous activity & $\begin{array}{l}\text { Excluded - Low } \\
\text { Consequence }\end{array}$ & 6.2 .2 .9 \\
\hline 2.2.06.01.0A & Seismic activity changes porosity and permeability of rock & $\begin{array}{l}\text { Excluded - Low } \\
\text { Consequence }\end{array}$ & 6.2.1.9 \\
\hline 2.2.06.02.0A & Seismic activity changes porosity and permeability of faults & $\begin{array}{l}\text { Excluded - Low } \\
\text { Consequence }\end{array}$ & 6.2.1.10 \\
\hline 2.2.06.02.0B & $\begin{array}{l}\text { Seismic activity changes porosity and permeability of } \\
\text { fractures }\end{array}$ & $\begin{array}{l}\text { Excluded - Low } \\
\text { Consequence }\end{array}$ & 6.2.1.11 \\
\hline 2.2.06.03.0A & Seismic activity alters perched water zones & $\begin{array}{l}\text { Excluded - Low } \\
\text { Consequence }\end{array}$ & 6.2.1.12 \\
\hline
\end{tabular}


The conclusions from this document (FEP Screening Decision, TSPA Disposition for included FEPs, or Screening Argument for excluded FEPs) along with any modifications to the FEP list, FEP names, and/or FEP descriptions will be incorporated in the Yucca Mountain TSPA-LA FEP database. Because this is the only subsequent use for the conclusions of this report, there are no restrictions on this use. Any uncertainties or limitations are generally related to input documents and repository design and have been previously described in Section 1.3.

The FEP database will contain all Yucca Mountain FEPs considered for TSPA-LA with FEP number, name, description, and relevant FEP analysis reports where the documentation of the screening of specific FEPs is summarized. The FEP database will also contain screening decisions (Include or Exclude), screening arguments, and TSPA dispositions quoted from this and all other FEP analysis reports.

All FEP information, including the 21 disruptive events FEPs considered in this report, will be submitted to the Technical Data Management System by the Yucca Mountain FEP database team as a final LA FEP list represented by a Data Tracking Number (DTN). Documentation of the FEP database is given in The Development of the Total System Performance Assessment License Application Features, Events, and Processes (BSC 2004 [DIRS 168706]). These final data will be qualified as technical product output within the above document. The final LA FEP list DTN will supersede all of the previous DTNs.

Section 4.2.2 listed the relevant YMRP review criteria that apply to this report. Table 7-2 lists how this report addresses these criteria.

Table 7-2. YMRP Acceptance Criteria Addressed in AMR

\begin{tabular}{|c|c|c|c|}
\hline $\begin{array}{l}\text { YMRP } \\
\text { Section }\end{array}$ & $\begin{array}{l}\text { Acceptance } \\
\text { Criterion }\end{array}$ & Description & $\begin{array}{c}\text { How Addressed in this } \\
\text { Analysis Report }\end{array}$ \\
\hline \multirow[t]{2}{*}{$\begin{array}{l}\text { Scenario } \\
\text { Analysis and } \\
\text { Event } \\
\text { Probability: } \\
\text { Scenario } \\
\text { Analysis } \\
\text { (from } \\
\text { Section } \\
2.2 .1 .2 .1 .3 \\
\text { NUREG- } \\
\text { 1804 } \\
\text { [DIRS } 16327 \\
\text { 4]) }\end{array}$} & $\begin{array}{l}\text { 1. The } \\
\text { Identification of } \\
\text { a List of FEPs } \\
\text { Is Adequate }\end{array}$ & $\begin{array}{l}\text { The safety analysis report contains a complete list } \\
\text { of FEPs related to the geologic setting or the } \\
\text { degradation, deterioration, or alteration of } \\
\text { engineered barriers (including those processes that } \\
\text { would affect the performance of natural barriers) } \\
\text { that have the potential to influence repository } \\
\text { performance. The list is consistent with the site } \\
\text { characterization data. The comprehensive } \\
\text { features, events, and processes list includes, but is } \\
\text { not limited to, potentially disruptive events related } \\
\text { to igneous activity (extrusive and intrusive); seismic } \\
\text { shaking (high-frequency-low magnitude, and rare } \\
\text { large-magnitude events); tectonic evolution (slip on } \\
\text { existing faults and formation of new faults); climatic } \\
\text { change (change to pluvial conditions); and } \\
\text { criticality. }\end{array}$ & $\begin{array}{l}\text { The list of disruptive } \\
\text { events FEPs is provided in } \\
\text { Section } 1.2 \text { (Table } 1-1) \text {, } \\
\text { and FEP descriptions are } \\
\text { provided in Section } 6.2 \text {. } \\
\text { See Section } 6.1 .1 \text { of this } \\
\text { analysis report for a } \\
\text { description and origin of } \\
\text { the disruptive events FEP } \\
\text { list and descriptions. }\end{array}$ \\
\hline & $\begin{array}{l}\text { 2. Screening } \\
\text { of the Initial } \\
\text { List of FEPs Is } \\
\text { Appropriate }\end{array}$ & $\begin{array}{l}\text { The DOE has identified all FEPs related to either } \\
\text { the geologic setting or to the degradation, } \\
\text { deterioration, or alteration of engineered barriers } \\
\text { (including those processes that would affect the } \\
\text { performance of natural barriers) that have been } \\
\text { excluded. }\end{array}$ & $\begin{array}{l}\text { See Table } 7-1 \text { for a list of } \\
\text { excluded disruptive events } \\
\text { FEPs. }\end{array}$ \\
\hline
\end{tabular}


Table 7-2. YMRP Acceptance Criteria Addressed in AMR (Continued)

\begin{tabular}{|c|c|c|c|}
\hline $\begin{array}{l}\text { YMRP } \\
\text { Section }\end{array}$ & $\begin{array}{l}\text { Acceptance } \\
\text { Criterion }\end{array}$ & Description & $\begin{array}{l}\text { How Addressed in this } \\
\text { Analysis Report }\end{array}$ \\
\hline & & $\begin{array}{l}\text { The DOE has provided justification for those FEPs } \\
\text { that have been excluded. An acceptable } \\
\text { justification for excluding FEPs is that either the } \\
\text { FEP is specifically excluded by regulation; } \\
\text { probability of the FEP (generally an event) falls } \\
\text { below the regulatory criterion; or omission of the } \\
\text { feature, and process does not significantly change } \\
\text { the magnitude and time of the resulting radiological } \\
\text { exposures to the reasonably maximally exposed } \\
\text { individual, or radionuclide releases to the } \\
\text { accessible environment. }\end{array}$ & $\begin{array}{l}\text { See the method and } \\
\text { approach discussion } \\
\text { provided in Section } 6.1 .2 \\
\text { and the individual } \\
\text { justification (by regulation, } \\
\text { low probability, low } \\
\text { consequence) for } \\
\text { excluding FEPs. The } \\
\text { justification is also } \\
\text { included in Table } 7-1 .\end{array}$ \\
\hline & & $\begin{array}{l}\text { The DOE has provided an adequate technical } \\
\text { basis for each FEP, excluded from the } \\
\text { performance assessment, to support the } \\
\text { conclusion that either the FEP is specifically } \\
\text { excluded by regulation; the probability of the FEP } \\
\text { falls below the regulatory criterion; or omission of } \\
\text { the FEP does not significantly change the } \\
\text { magnitude and time of the resulting radiological } \\
\text { exposures to the reasonably maximally exposed } \\
\text { individual, or radionuclide releases to the } \\
\text { accessible environment. }\end{array}$ & $\begin{array}{l}\text { See Section } 6.2 \text { for } \\
\text { discussion of the individual } \\
\text { FEP screening arguments } \\
\text { and supporting technical } \\
\text { bases. }\end{array}$ \\
\hline \multirow[t]{3}{*}{$\begin{array}{l}\text { Scenario } \\
\text { Analysis and } \\
\text { Event } \\
\text { Probability: }\end{array}$} & \multirow[t]{2}{*}{$\begin{array}{l}\text { 1. Events are } \\
\text { Adequately } \\
\text { Defined }\end{array}$} & $\begin{array}{l}\text { Events or event classes are defined without } \\
\text { ambiguity and used consistently in probability } \\
\text { models, such that probabilities for each event or } \\
\text { event class are estimated separately. }\end{array}$ & $\begin{array}{l}\text { See the FEP disposition } \\
\text { and screening argument } \\
\text { provided for each FEP in } \\
\text { Section } 6.2 \text {. }\end{array}$ \\
\hline & & $\begin{array}{l}\text { Probabilities of intrusive and extrusive igneous } \\
\text { events are calculated separately. Definitions of } \\
\text { faulting and earthquakes are derived from the } \\
\text { historical record, paleoseismic studies, or } \\
\text { geological analyses. Criticality events are } \\
\text { calculated separately by location. }\end{array}$ & $\begin{array}{l}\text { See the FEP disposition } \\
\text { and screening argument } \\
\text { provided for each FEP in } \\
\text { Section 6.2. }\end{array}$ \\
\hline & $\begin{array}{l}\text { 2. Probability } \\
\text { Estimates for } \\
\text { Future Events } \\
\text { Are Supported } \\
\text { by Appropriate } \\
\text { Technical } \\
\text { Bases }\end{array}$ & $\begin{array}{l}\text { Probabilities for future natural events are based on } \\
\text { past patterns of the natural events in the Yucca } \\
\text { Mountain region, considering the likely future } \\
\text { conditions and interactions of the natural and } \\
\text { engineered repository system. These probability } \\
\text { estimates have specifically included igneous } \\
\text { events, faulting and seismic events, and criticality } \\
\text { events. }\end{array}$ & $\begin{array}{l}\text { See the FEP disposition } \\
\text { and screening argument } \\
\text { provided for each FEP in } \\
\text { Section } 6.2 \text {. }\end{array}$ \\
\hline
\end{tabular}


Table 7-2. YMRP Acceptance Criteria Addressed in AMR (Continued)

\begin{tabular}{|l|l|l|l|}
\hline $\begin{array}{l}\text { YMRP } \\
\text { Section }\end{array}$ & $\begin{array}{c}\text { Acceptance } \\
\text { Criterion }\end{array}$ & \begin{tabular}{l}
\multicolumn{1}{c|}{ Description } \\
5. Uncertainty \\
in Event \\
Probability is \\
Adequately \\
Evaluated
\end{tabular} & $\begin{array}{l}\text { How Addressed in this } \\
\text { Analysis Report }\end{array}$ \\
\hline & $\begin{array}{l}\text { Probability values appropriately reflect } \\
\text { uncertainties. Specifically: } \\
\text { a. The DOE provides a technical basis for } \\
\text { the uncertainty in the probability estimates. } \\
\text { b. The uncertainty for reported probability values } \\
\text { adequately reflects the influence of parameter } \\
\text { uncertainty on the range of model results (i.e., } \\
\text { precision) and the model uncertainty, as it affects } \\
\text { the timing and magnitude of past events (i.e., } \\
\text { accuracy). }\end{array}$ & $\begin{array}{l}\text { The technical basis and } \\
\text { discussion of uncertainties } \\
\text { used for exclusion of FEPs } \\
\text { are discussed in the } \\
\text { screening arguments of } \\
\text { Section } 6.2 \text { for the } \\
\text { individual FEPs. }\end{array}$ & \\
\hline
\end{tabular}




\section{INPUTS AND REFERENCES}

\subsection{DOCUMENTS CITED}

Bates, R.L. and Jackson, J.A., eds. 1987. Glossary of Geology. 3rd Edition.

164050 Alexandria, Virginia: American Geological Institute. TIC: 8832.

Bohannon, R.G. and Parsons, T. 1995. "Tectonic Implications of Post-30 Ma Pacific

101865 and North American Relative Plate Motions." Geological Society of America Bulletin, 107, (8), 937-959. Boulder, Colorado: Geological Society of America. TIC: 233033.

BSC (Bechtel SAIC Company) 2003. 21-PWR Waste Package Side and End 162293 Impacts. 000-00C-DSU0-01000-000-00B. Las Vegas, Nevada: Bechtel SAIC Company. ACC: ENG.20030227.0067.

BSC (Bechtel SAIC Company) 2003. Maximum Accelerations on the Fuel 162602 Assemblies of a 21-PWR Waste Package During End Impacts. 000-00C-DSU0-01100-000-00A. Las Vegas, Nevada: Bechtel SAIC Company. ACC: ENG.20030327.0002.

BSC (Bechtel SAIC Company) 2003. Scoping Analysis on Sensitivity and 166183 Uncertainty of Emplacement Drift Stability. 800-K0C-TEG0-00600-000-000. Las Vegas, Nevada: Bechtel SAIC Company. ACC: ENG.20031125.0002.

BSC (Bechtel SAIC Company) 2003. Structural Calculations of Drip Shield 163425 Exposed to Vibratory Ground Motion. 000-00C-PEC0-00100-000-00A. Las Vegas, Nevada: Bechtel SAIC Company. ACC: ENG.20030618.0009.

BSC (Bechtel SAIC Company) 2003. Total System Performance Assessment166296 License Application Methods and Approach. TDR-WIS-PA-000006 REV 00 ICN 01. Las Vegas, Nevada: Bechtel SAIC Company. ACC: DOC.20031215.0001.

BSC (Bechtel SAIC Company) 2003. Underground Layout Configuration. 800-P0C-MGR0-00100-000-00E. Las Vegas, Nevada: Bechtel SAIC Company. ACC: ENG.20031002.0007.

BSC (Bechtel SAIC Company) 2004. 21-PWR Waste Package End Impacts - A 170844 Mesh Study. 000-00C-WIS0-02100-000-00A. Las Vegas, Nevada: Bechtel SAIC Company. ACC: ENG.20040617.0005.

BSC (Bechtel SAIC Company) 2004. Abstraction of Drift Seepage.

MDL-NBS-HS-000019, Rev. 01. Las Vegas, Nevada: Bechtel SAIC Company.

BSC (Bechtel SAIC Company) 2004. Additional Structural Calculations of Waste 168385 Package Exposed to Vibratory Ground Motion. 000-00C-WIS0-01700-000-00A. Las Vegas, Nevada: Bechtel SAIC Company. ACC: ENG.20040318.0011. 
BSC (Bechtel SAIC Company) 2004. Alternative Damaged Area Evaluation for

Waste Package Exposed to Vibratory Ground Motion.

000-00C-WIS0-01900-000-00A. Las Vegas, Nevada: Bechtel SAIC Company.

ACC: ENG.20040420.0010.

BSC (Bechtel SAIC Company) 2004. Atmospheric Dispersal and Deposition of

170026

Tephra from a Potential Volcanic Eruption at Yucca Mountain, Nevada.

MDL-MGR-GS-000002 REV 01. Las Vegas, Nevada: Bechtel SAIC Company.

ACC: DOC.20041025.0003.

BSC (Bechtel SAIC Company) 2004. Characterize Eruptive Processes at Yucca

169980

Mountain, Nevada. ANL-MGR-GS-000002 REV 02. Las Vegas, Nevada: Bechtel

SAIC Company. ACC: DOC.20041004.0006.

BSC (Bechtel SAIC Company) 2004. Characterize Framework for Igneous Activity

169989 at Yucca Mountain, Nevada. ANL-MGR-GS-000001 REV 02. Las Vegas, Nevada: Bechtel SAIC Company. ACC: DOC.20041015.0002.

BSC (Bechtel SAIC Company) 2004. Characterize Framework for Seismicity and 168030

Structural Deformation at Yucca Mountain, Nevada. ANL-CRW-GS-000003

REV 00 [Errata 001]. Las Vegas, Nevada: Bechtel SAIC Company.

ACC: MOL.20000510.0175; DOC.20040223.0007.

BSC (Bechtel SAIC Company) 2004. D\&E / PA/C IED Subsurface Facilities.

164519 800-IED-WIS0-00101-000-00A. Las Vegas, Nevada: Bechtel SAIC Company. ACC: ENG.20040309.0026.

BSC (Bechtel SAIC Company) 2004. Development of Earthquake Ground Motion 170027 Input for Preclosure Seismic Design and Postclosure Performance Assessment of a Geologic Repository at Yucca Mountain, NV. MDL-MGR-GS-000003, Rev. 01. Las Vegas, Nevada: Bechtel SAIC Company.

BSC (Bechtel SAIC Company) 2004. Development of Seismic Inputs, Preparation 169886 of Seismic Topical Reports, and Evaluation of Disruptive Events Features, Events, and Processes. TWP-MGR-GS-000001 REV 03 ICN 01. Las Vegas, Nevada: Bechtel SAIC Company. ACC: DOC.20040601.0001.

BSC (Bechtel SAIC Company) 2004. Dike/Drift Interactions.

170028

MDL-MGR-GS-000005, Rev. 01. Las Vegas, Nevada: Bechtel SAIC Company.

BSC (Bechtel SAIC Company) 2004. Dissolved Concentration Limits of 169425

Radioactive Elements. ANL-WIS-MD-000010, Rev. 03. Las Vegas, Nevada: Bechtel SAIC Company.

BSC (Bechtel SAIC Company) 2004. Drift Degradation Analysis.

ANL-EBS-MD-000027 REV 03. Las Vegas, Nevada: Bechtel SAIC Company. ACC: DOC.20040915.0010. 
BSC (Bechtel SAIC Company) 2004. Drift Scale THM Model.

169864

MDL-NBS-HS-000017 REV 01. Las Vegas, Nevada: Bechtel SAIC Company.

ACC: DOC.20041012.0001.

BSC (Bechtel SAIC Company) 2004. Drip Shield Structural Response to Rock Fall. 168993 000-00C-SSE0-00300-000-00A. Las Vegas, Nevada: Bechtel SAIC Company.

ACC: ENG.20040405.0019.

BSC (Bechtel SAIC Company) 2004. Engineered Barrier System Features, Events, and Processes. ANL-WIS-PA-000002, Rev. 03. Las Vegas, Nevada: Bechtel SAIC Company.

BSC (Bechtel SAIC Company) 2004. Features, Events, and Processes in UZ Flow

170012 and Transport. ANL-NBS-MD-000001, Rev. 03. Las Vegas, Nevada: Bechtel SAIC Company.

BSC (Bechtel SAIC Company) 2004. Magma Bulkhead Analysis.

171070 800-K0C-SSP0-00100-000-00A. Las Vegas, Nevada: Bechtel SAIC Company.

BSC (Bechtel SAIC Company) 2004. Mechanical Assessment of the Drip Shield 169753 Subject to Vibratory Motion and Dynamic and Static Rock Loading. CAL-WIS-AC-000002 REV 00A. Las Vegas, Nevada: Bechtel SAIC Company. ACC: DOC.20041028.0004.

BSC (Bechtel SAIC Company) 2004. Mechanical Assessment of the Waste Package Subject to Vibratory Ground Motion. CAL-WIS-AC-000001 REV 00A. Las Vegas, Nevada: Bechtel SAIC Company. ACC: DOC.20041014.0007.

BSC (Bechtel SAIC Company) 2004. Multistage Thermo hydrologic Model. 169898 ANL-EBS-MD-000049 REV 02. Las Vegas, Nevada: Bechtel SAIC Company. ACC: DOC.20041014.0008.

BSC (Bechtel SAIC Company) 2004. Number of Waste Packages Hit by Igneous 170001 Intrusion. ANL-MGR-GS-000003 REV 01. Las Vegas, Nevada: Bechtel SAIC Company. ACC: DOC.20041015.0001.

BSC (Bechtel SAIC Company) 2004. Q-List. 000-30R-MGR0-00500-000-000 REV 00. Las Vegas, Nevada: Bechtel SAIC Company.

ACC: ENG.20040721.0007.

BSC (Bechtel SAIC Company) 2004. Qualification of Igneous Inputs to Features, 171999 Events, and Processes: Disruptive Events. TDR-WIS-PA-000013 REV 00. Las Vegas, Nevada: Bechtel SAIC Company. ACC: DOC.20041022.0002.

BSC (Bechtel SAIC Company) 2004. Saturated Zone Flow and Transport Model Abstraction. MDL-NBS-HS-000021 REV 02. Las Vegas, Nevada: Bechtel SAIC Company. ACC: DOC.20041028.0003. 
BSC (Bechtel SAIC Company) 2004. Seismic Consequence Abstraction.

169183

MDL-WIS-PA-000003 REV 01. Las Vegas, Nevada: Bechtel SAIC Company.

ACC: DOC.20041025.0004.

BSC (Bechtel SAIC Company) 2004. Structural Calculations of Waste Package

167083

Exposed to Vibratory Ground Motion. 000-00C-WIS0-01400-000-00A. Las Vegas,

Nevada: Bechtel SAIC Company. ACC: ENG.20040217.0008.

BSC (Bechtel SAIC Company) 2004. Structural Stability of a Drip Shield Under

170791

Quasi-Static Pressure. 000-00C-SSE0-00500-000-00A. Las Vegas, Nevada:

Bechtel SAIC Company. ACC: ENG.20040830.0032.

BSC (Bechtel SAIC Company) 2004. Subsurface Facility Description Document. 800-3YD-SS00-00100-000-000. Las Vegas, Nevada: Bechtel SAIC Company.

ACC: ENG.20040915.0008.

BSC (Bechtel SAIC Company) 2004. The Development of the Total System

168706

Performance Assessment-License Application Features, Events, and Processes.

TDR-WIS-MD-000003, Rev. 01. Las Vegas, Nevada: Bechtel SAIC Company.

BSC (Bechtel SAIC Company) 2004. Total System Performance Assessment

168504

(TSPA) Model/Analysis for the License Application. MDL-WIS-PA-000004, Rev.

00. Las Vegas, Nevada: Bechtel SAIC Company.

Byers, F.M., Jr. and Barnes, H. 1967. Geologic Map of the Paiute Ridge

101859

Quadrangle, Nye and Lincoln Counties, Nevada. Map GQ-577. Washington, D.C.:

U.S. Geological Survey. ACC: HQS.19880517.1104.

Canori, G.F. and Leitner, M.M. 2003. Project Requirements Document.

166275

TER-MGR-MD-000001 REV 02. Las Vegas, Nevada: Bechtel SAIC Company.

ACC: DOC.20031222.0006.

Carter Krogh, K.E. and Valentine, G.A. 1996. Structural Control on Basaltic Dike

160928

and Sill Emplacement, Paiute Ridge Mafic Intrusion Complex, Southern Nevada.

LA-13157-MS. Los Alamos, New Mexico: Los Alamos National Laboratories.

ACC: MOL.20030828.0138.

Connor, C.B.; Stamatakos, J.; Ferrill, D.; Hill, B.E.; Magsino, S.B.L.; La Femina, P.; and Martin, R.H. 1996. "Integrating Structural Models into Probabilistic Volcanic Hazard Analyses: An Example from Yucca Mountain, NV." Abstracts with Programs - Geological Society of America, 28, (7), A-192. Boulder, Colorado: Geological Society of America. TIC: 247409.

Crowe, B.; Perry, F.; Geissman, J.; McFadden, L.; Wells, S.; Murrell, M.; Poths, J.; Valentine, G.A.; Bowker, L.; and Finnegan, K. 1995. Status of Volcanism Studies for the Yucca Mountain Site Characterization Project. LA-12908-MS. Los Alamos, New Mexico: Los Alamos National Laboratory. ACC: HQO.19951115.0017. 
Crowe, B.M.; Wohletz, K.H.; Vaniman, D.T.; Gladney, E.; and Bower, N. 1986.

101532

Status of Volcanic Hazard Studies for the Nevada Nuclear Waste Storage

Investigations. LA-9325-MS. Volume II. Los Alamos, New Mexico: Los Alamos

National Laboratory. ACC: NNA.19890501.0157.

CRWMS M\&O 1996. Probabilistic Volcanic Hazard Analysis for Yucca Mountain,

100116

Nevada. BA0000000-01717-2200-00082 REV 0. Las Vegas, Nevada: CRWMS

M\&O. ACC: MOL.19971201.0221.

CRWMS M\&O 1998. "Disruptive Events." Chapter 10 of Total System

100369

Performance Assessment-Viability Assessment (TSPA-VA) Analyses Technical Basis Document. B00000000-01717-4301-00010 REV 01. Las Vegas, Nevada: CRWMS M\&O. ACC: MOL.19981008.0010.

CRWMS M\&O 1998. Probabilistic Seismic Hazard Analyses for Fault Displacement and Vibratory Ground Motion at Yucca Mountain, Nevada. Milestone SP32IM3, September 23, 1998. Three volumes. Las Vegas, Nevada: CRWMS M\&O. ACC: MOL.19981207.0393.

CRWMS M\&O 1998. Synthesis of Volcanism Studies for the Yucca Mountain Site Characterization Project. Deliverable 3781MR1. Las Vegas, Nevada: CRWMS M\&O. ACC: MOL.19990511.0400.

Day, W.C.; Potter, C.J.; Sweetkind, D.S.; Dickerson, R.P.; and Keefer, W.R. 1996. "Structural Geology of the Central Block of Yucca Mountain." Chapter 2-I of Seismotectonic Framework and Characterization of Faulting at Yucca Mountain, Nevada. Whitney, J.W., ed. Milestone 3GSH100M. Denver, Colorado: U.S. Geological Survey. TIC: 237980. ACC: MOL.19970129.0041.

Dixon, T.H.; Robaudo, S.; Lee, J.; and Reheis, M.C. 1995. "Constraints on Present-Day Basin and Range Deformation from Space Geodesy." Tectonics, 14, (4), 755-772. Washington, D.C.: American Geophysical Union. TIC: 234271.

DOE (U.S. Department of Energy) 2002. Final Environmental Impact Statement for a Geologic Repository for the Disposal of Spent Nuclear Fuel and High-Level Radioactive Waste at Yucca Mountain, Nye County, Nevada. DOE/EIS-0250. Washington, D.C.: U.S. Department of Energy, Office of Civilian Radioactive Waste Management. ACC: MOL.20020524.0314; MOL.20020524.0315; MOL.20020524.0316; MOL.20020524.0317; MOL.20020524.0318; MOL.20020524.0319; MOL.20020524.0320.

Ferrill, D.A.; Winterle, J.; Wittmeyer, G.; Sims, D.; Colton, S.; Armstrong, A.; and 118941 Morris, A.P. 1999. "Stressed Rock Strains Groundwater at Yucca Mountain, Nevada." GSA Today, 9, (5), 1-8. Boulder, Colorado: Geological Society of America. TIC: 246229. 
Fisher, R.V. and Schmincke, H.-U. 1984. Pyroclastic Rocks. New York, 162806 New York: Springer-Verlag. TIC: 223562.

Fridrich, C.J. 1999. "Tectonic Evolution of the Crater Flat Basin, Yucca Mountain 118942 Region, Nevada." Chapter 7 of Cenozoic Basins of the Death Valley Region. Wright, L.A. and Troxel, B.W., eds. Special Paper 333. Boulder, Colorado: Geological Society of America. TIC: 248054.

Fridrich, C.J.; Whitney, J.W.; Hudson, M.R.; and Crowe, B.M. 1998. Space-Time Patterns of Late Cenozoic Extension, Vertical-Axis Rotation, and Volcanism in the Crater Flat Basin, Southwest Nevada. Open-File Report 98-461. Denver, Colorado: U.S. Geological Survey. ACC: MOL.19981014.0299.

Fridrich, C.J.; Whitney, J.W.; Hudson, M.R.; Keefer, W.R.; and Crowe, B.M. 1996. "Space-Time Patterns of Extension, Vertical-Axis Rotation, and Volcanism in the Crater Flat Basin." Chapter 2.II of Seismotectonic Framework and Characterization of Faulting at Yucca Mountain, Nevada. Whitney, J.W., ed. Milestone 3GSH100M. Denver, Colorado: U.S. Geological Survey. TIC: 237980.

ACC: MOL.19970129.0041.

Gauthier, J.H.; Wilson, M.L.; Borns, D.J.; and Arnold, B.W. 1996. "Impacts of Seismic Activity on Long-Term Repository Performance at Yucca Mountain." Proceedings of the Topical Meeting on Methods of Seismic Hazards Evaluation, Focus '95, September 18-20, 1995, Las Vegas, Nevada. Pages 159-168. La Grange Park, Illinois: American Nuclear Society. TIC: 232628.

Lachenbruch, A.H. and Sass, J.H. 1978. "Models of an Extending Lithosphere and Heat Flow in the Basin and Range Province." Chapter 9 of Cenozoic Tectonics and Regional Geophysics of the Western Cordillera. Smith, R.B. and Eaton, G.P., eds. Memoir 152. Pages 209-250. Boulder, Colorado: Geological Society of America. TIC: 225059.

Mongano, G.S.; Singleton, W.L.; Moyer, T.C.; Beason, S.C.; Eatman, G.L.W.; 149850 Albin, A.L.; and Lung, R.C. 1999. Geology of the ECRB Cross Drift - Exploratory Studies Facility, Yucca Mountain Project, Yucca Mountain, Nevada. [Deliverable SPG42GM3]. Denver, Colorado: U.S. Geological Survey.

ACC: MOL.20000324.0614.

National Research Council. 1992. Ground Water at Yucca Mountain, How High Can It Rise? Final Report of the Panel on Coupled Hydrologic/Tectonic/Hydrothermal Systems at Yucca Mountain. Washington, D.C.: National Academy Press. TIC: 204931.

NRC (U.S. Nuclear Regulatory Commission) 1999. Issue Resolution Status Report Key Technical Issue: Structural Deformation and Seismicity. Rev. 2. Washington, D.C.: U.S. Nuclear Regulatory Commission. ACC: MOL.19991214.0623. 
NRC (U.S. Nuclear Regulatory Commission) 2003. Yucca Mountain Review Plan,

Final Report. NUREG-1804, Rev. 2. Washington, D.C.: U.S. Nuclear Regulatory Commission, Office of Nuclear Material Safety and Safeguards. TIC: 254568.

O'Brien, G.M. 1993. Earthquake-Induced Water-Level Fluctuations at Yucca

101276 Mountain, Nevada, June 1992. Open-File Report 93-73. Denver, Colorado: U.S. Geological Survey. ACC: NNA.19930326.0022.

Parsons, T.; Thompson, G.A.; and Sleep, N.H. 1994. "Mantle Plume Influence on 106479 the Neogene Uplift and Extension of the U.S. Western Cordillera?" Geology, 22, 83-86. Boulder, Colorado: Geological Society of America. TIC: 233034.

Ramelli, A.R.; Oswald, J.A.; Vadurro, G.; Menges, C.M.; and Paces, J.B. 1996. 101106 "Quaternary Faulting on the Solitario Canyon Fault." Chapter 4.7 of Seismotectonic Framework and Characterization of Faulting at Yucca Mountain, Nevada. Whitney, J.W., ed. Milestone 3GSH100M. Denver, Colorado: U.S. Geological Survey. TIC: 237980. ACC: MOL.19970129.0041.

Rogers, A.M.; Harmsen, S.C.; and Meremonte, M.E. 1987. Evaluation of the 100176 Seismicity of the Southern Great Basin and Its Relationship to the Tectonic Framework of the Region. Open-File Report 87-408. Denver, Colorado: U.S. Geological Survey. ACC: HQX.19880315.0004.

Rojstaczer, S. 1991. "Elastic Deformation as a Second Order Influence on 163416 Groundwater Flow in Areas of Crustal Unrest." Eos Transactions (Supplement), 72, (17), [N/A]. [Washington, D.C.]: American Geophysical Union. TIC: 216706.

Savage, J.C.; Lisowski, M.; Svarc, J.L.; and Gross, W.K. 1995. "Strain Accumulation Across the Central Nevada Seismic Zone, 1973-1994." Journal of Geophysical Research, 100, (B10), 20,257 to 20,269. Washington, D.C.: American Geophysical Union. TIC: 236811.

Savage, J.C.; Svarc, J.L.; and Prescott, W.H. 1999. "Strain Accumulation at Yucca 118952 Mountain, Nevada, 1983-1998." Journal of Geophysical Research, 104, (B8), 17627-17631. Washington, D.C.: American Geophysical Union. TIC: 245645.

Smith, R.P.; Jackson, S.M.; and Hackett, W.R. 1998. "Magma Intrusion and 118967 Seismic-Hazards Assessment in the Basin and Range Province." Proceedings Volume, Basin and Range Province (BRP) Seismic-Hazards Summit, Reno, Nevada, May 13-15, 1997. Miscellaneous Publication 98-2, 155-166. Salt Lake City, Utah: Utah Geological Survey. TIC: 246749.

Stock, J.M. and Healy, J.H. 1988. "Stress Field at Yucca Mountain, Nevada." 101022 Chapter 6 of Geologic and Hydrologic Investigations of a Potential Nuclear Waste Disposal Site at Yucca Mountain, Southern Nevada. Carr, M.D. and Yount, J.C., eds. Bulletin 1790. Denver, Colorado: U.S. Geological Survey. TIC: 203085. 
Stock, J.M.; Healy, J.H.; Hickman, S.H.; and Zoback, M.D. 1985. "Hydraulic

101027

Fracturing Stress Measurements at Yucca Mountain, Nevada, and Relationship to the Regional Stress Field.” Journal of Geophysical Research, 90, (B10), 8691-8706.

Washington, D.C.: American Geophysical Union. TIC: 219009.

Stuckless, J.S. 1996. "Current Status of Paleohydrologic Studies at Yucca Mountain and Vicinity, Nevada." High Level Radioactive Waste Management, Proceedings of the Seventh Annual International Conference, Las Vegas, Nevada, April 29-May 3, 1996. Pages 98-101. La Grange Park, Illinois: American Nuclear Society.

TIC: 226494.

Sweetkind, D.S.; Barr, D.L.; Polacsek, D.K.; and Anna, L.O. 1997. Administrative 100183 Report: Integrated Fracture Data in Support of Process Models, Yucca Mountain, Nevada. Milestone SPG32M3. [Las Vegas, Nevada]: U.S. Geological Survey. ACC: MOL.19971017.0726.

Sweetkind, D.S.; Potter, C.J.; and Verbeek, E.R. 1996. "Interaction Between Faults 106957 and the Fracture Network at Yucca Mountain, Nevada." Eos Transactions, S266. Washington, D.C.: American Geophysical Union. TIC: 236789.

Thatcher, W.; Foulger, G.R.; Julian, B.R.; Svarc, J.; Quilty, E.; and Bawden, G.W. 1999. "Present-Day Deformation Across the Basin and Range Province, Western United States." Science, 283, (5408), 1714-1718. Washington, D.C.: American Association for the Advancement of Science. TIC: 246227.

Wernicke, B.; Davis, J.L.; Bennett, R.A.; Elosegui, P.; Abolins, M.J.; Brady, R.J.; 103485 House, M.A.; Niemi, N.A.; and Snow, J.K. 1998. "Anomalous Strain Accumulation in the Yucca Mountain Area, Nevada." Science, 279, 2096-2100. New York, New York: American Association for the Advancement of Science. TIC: 235956.

Whitney, J.W., ed. 1996. Seismotectonic Framework and Characterization of 100188 Faulting at Yucca Mountain, Nevada. Milestone 3GSH100M. Denver, Colorado: U.S. Geological Survey. ACC: MOL.19970129.0041; MOL.19970129.0042; MOL.19970129.0043; MOL.19970129.0044; MOL.19970129.0045; MOL.19970129.0046; MOL.19970129.0047; MOL.19970129.0048; MOL.19970129.0049; MOL.19970129.0050; MOL.19970129.0051; MOL.19970129.0052; MOL.19970129.0053; MOL.19970129.0054; MOL.19970129.0055; MOL.19970129.0056; MOL.19970129.0057; MOL.19970129.0058; MOL.19970129.0059; MOL.19970129.0060; MOL.19970129.0061; MOL.19970129.0062.

Williams, N.H. 2001. "Contract No. DE-AC08-01RW12101 - KTI Deliverable to 161728 NRC - October 2001.” Letter from N.H. Williams (BSC) to S.J. Brocoum (DOE/YMSCO), October 16, 2001, 1012010135, LTS:cdg, with enclosures. ACC: MOL.20020206.0018. 
Wilson, S.F. and Cline, J.S. 2001. "Paragenesis, Temperature and Timing of 155426 Secondary Minerals at Yucca Mountain." "Back to the Future - Managing the Back End of the Nuclear Fuel Cycle to Create a More Secure Energy Future," Proceedings of the 9th International High-Level Radioactive Waste Management Conference (IHLRWM), Las Vegas, Nevada, April 29-May 3, 2001. La Grange Park, Illinois: American Nuclear Society. TIC: 247873.

Wohletz, K. and Heiken, G. 1992. Volcanology and Geothermal Energy. Berkeley, 105544 California: University of California Press. TIC: 241603.

Wohletz, K.H. 1986. "Explosive Magma-Water Interactions: Thermodynamics, 140956 Explosion Mechanisms, and Field Studies.” Bulletin of Volcanology, 48, 245-264. Berlin, Germany: Springer-Verlag. TIC: 225183.

Woods, A.W.; Sparks, S.; Bokhove, O.; LeJeune, A-M.; Conner, C.B.; and Hill, B.E. 2002. "Modeling Magma-Drift Interaction at the Proposed High-Level Radioactive Waste Repository at Yucca Mountain, Nevada, USA." Geophysical Research Letters, 29, (13), 19-1 through 19-4. [Washington, D.C.]: American Geophysical Union. TIC: 254467.

\subsection{CODES, STANDARDS, REGULATIONS, AND PROCEDURES}

10 CFR 63. Energy: Disposal of High-Level Radioactive Wastes in a Geologic Repository at Yucca Mountain, Nevada. Readily available.

AP-2.22Q, Rev. 1 ICN 1. Classification Analyses and Maintenance of the Q-List. Washington, D.C.: U.S. Department of Energy, Office of Civilian Radioactive Waste Management. ACC: DOC.20040714.0002.

AP-3.15Q, Rev. 4 ICN 5 Managing Technical Product Inputs. Washington, D.C.: U.S. Department of Energy, Office of Civilian Radioactive Waste Management. ACC: DOC.20040812.0004.

AP-SIII.2Q, Rev. 1, ICN 2. Qualification of Unqualified Data. Washington, D.C.: U.S. Department of Energy, Office of Civilian Radioactive Waste Management. ACC: DOC.20040127.0008.

AP-SIII.9Q, Rev. 1 ICN 7. Scientific Analyses. Washington, D.C.: U.S. Department of Energy, Office of Civilian Radioactive Waste Management. ACC: DOC.20040920.0001.

LP-SI.11Q, Rev 0 ICN 1. Software Management. Washington, D.C.: U.S. Department of Energy, Office of Civilian Radioactive Waste Management. ACC: DOC.20041005.0008. 


\subsection{SOURCE DATA, LISTED BY DATA TRACKING NUMBER}

GS930108312312.003. Earthquake-Induced Water-Level Fluctuations at Yucca

171974

Mountain, Nevada, June, 1992. Submittal date: 01/21/1993.

MO03061E9PSHA1.000. Spectral Acceleration and Velocity Hazard Curves

163721

Extended to 1E-9 Based on the Results of the PSHA for Yucca Mountain. Submittal date: $06 / 09 / 2003$.

MO0306MWDDPPDR.000. Drift Profile Prediction and Degraded Rock Mass

164736

Characteristics. Submittal date: 06/18/2003.

MO0401MWDRPSHA.000. Results of the Yucca Mountain Probabilistic Seismic Hazard Analysis (PSHA). Submittal date: 01/21/2004.

166962

MO0407SEPFEPLA.000. LA FEP List. Submittal date: 07/20/2004.

170760 
APPENDIX A

LIST OF DIRECT INPUTS FOR INCLUDED AND EXCLUDED FEPS 


\section{APPENDIX A LIST OF DIRECT INPUTS FOR INCLUDED AND EXCLUDED FEPS}

Table A-1. Table of Direct Inputs for Included and Excluded Features, Events, and Processes

\begin{tabular}{|c|c|c|c|c|}
\hline Document Source & $\begin{array}{l}\text { Citation } \\
\text { from } \\
\text { Source }\end{array}$ & $\begin{array}{c}\text { Direct Use } \\
\text { In }\end{array}$ & Description & $\begin{array}{l}\text { Input } \\
\text { Category }\end{array}$ \\
\hline \multirow{3}{*}{$\begin{array}{l}\text { CRWMS M\&O 1996. Probabilistic } \\
\text { Volcanic Hazard Analysis for Yucca } \\
\text { Mountain, Nevada. BA0000000- } \\
\text { 01717-2200-00082 REV 0. } \\
\text { Las Vegas, Nevada: CRWMS M\&O. } \\
\text { ACC: MOL.19971201.0221. } \\
100116\end{array}$} & Entire & $\begin{array}{l}\text { Sections } \\
6.2 .1 .1, \mathrm{C} 2.4\end{array}$ & $\begin{array}{l}\text { Probabilistic Volcanic Hazard } \\
\text { Assessment (PVHA) - technical } \\
\text { basis for assessing hazards } \\
\text { related to volcanism }\end{array}$ & Data \\
\hline & p. 4-10 & $\begin{array}{l}\text { Sections } \\
6.2 .2 .2 \\
6.2 .2 .3\end{array}$ & $\begin{array}{l}\text { Value of mean and percentile } \\
\text { probability of dike intersections for } \\
\text { PVHA }\end{array}$ & Data \\
\hline & $\begin{array}{l}\text { Appendix E, p. } \\
\text { AM-4 }\end{array}$ & $\begin{array}{l}\text { Sections } \\
6.2 .2 .1 \\
6.2 .2 .9\end{array}$ & $\begin{array}{l}\text { Factors affecting drift orientation } \\
\text { and vent alignment }\end{array}$ & Data \\
\hline \multirow[t]{5}{*}{$\begin{array}{l}\text { * Crowe, B.M.; Wohletz, K.H.; } \\
\text { Vaniman, D.T.; Gladney, E.; and } \\
\text { Bower, N. 1986. Status of Volcanic } \\
\text { Hazard Studies for the Nevada } \\
\text { Nuclear Waste Storage } \\
\text { Investigations. LA-9325-MS. Volume } \\
\text { II. Los Alamos, New Mexico: Los } \\
\text { Alamos National Laboratory. } \\
\text { ACC: NNA.19890501.0157. } \\
101532\end{array}$} & Entire & Section 6.1 .4 & $\begin{array}{l}\text { Used as direct input in Section } \\
6.2 .2 .5 \text { for FEP 1.2.04.05.0A }\end{array}$ & $\begin{array}{l}\text { Data } \\
\text { (qualified } \\
\text { per AP- } \\
\text { SIII.2Q*) }\end{array}$ \\
\hline & pp. 58-59 & $\begin{array}{l}\text { Section } \\
6.2 .2 .5\end{array}$ & $\begin{array}{l}\text { Conclusion that "exhumation of a } \\
\text { repository by explosive cratering } \\
\text { associated with water/magma } \\
\text { interaction is unlikely; the depth of } \\
\text { burial of a repository at Yucca } \\
\text { Mountain exceeds the crater } \\
\text { depth of the largest known } \\
\text { hydrovolcanic craters." } \\
\text { (Statement made on previously } \\
\text { proposed repository depth of } 380 \\
\text { meters.) }\end{array}$ & $\begin{array}{l}\text { Data } \\
\text { (qualified } \\
\text { per AP- } \\
\text { SIII.2Q*) }\end{array}$ \\
\hline & pp. 32-34 & $\begin{array}{l}\text { Section } \\
6.2 .2 .5\end{array}$ & $\begin{array}{l}\text { Nye Canyon hydrovolcanic facies } \\
\text { are on the scale of } 1 \mathrm{~km} \text { or less }\end{array}$ & $\begin{array}{l}\text { Data } \\
\text { (qualified } \\
\text { per AP- } \\
\text { SIII.2Q*) }\end{array}$ \\
\hline & p. 47 & $\begin{array}{l}\text { Section } \\
6.2 .2 .5\end{array}$ & $\begin{array}{l}\text { Listing of conditions conducive to } \\
\text { hydrovolcanic feature formation }\end{array}$ & $\begin{array}{l}\text { Data } \\
\text { (qualified } \\
\text { per AP- } \\
\text { SIII.2Q*) }\end{array}$ \\
\hline & Figure 19 & $\begin{array}{l}\text { Section } \\
6.2 .2 .5\end{array}$ & $\begin{array}{l}\text { Plot of the relative frequency of } \\
\text { crater depth for hydrovolcanic } \\
\text { craters, maars, and tuff rings. The } \\
\text { relative frequency of occurrence } \\
\text { of hydrovolcanic craters greater } \\
\text { than } 215 \text { meters deep is less than } \\
\text { approximately } 10 \text { to } 15 \text { percent. }\end{array}$ & $\begin{array}{l}\text { Data } \\
\text { (qualified } \\
\text { per AP- } \\
\text { SIII.2Q*) }\end{array}$ \\
\hline
\end{tabular}


Table A-1. Table of Direct Inputs for Included and Excluded Features, Events, and Processes (Continued)

\begin{tabular}{|c|c|c|c|c|}
\hline Document Source & $\begin{array}{l}\text { Citation } \\
\text { from } \\
\text { Source }\end{array}$ & $\begin{array}{l}\text { Direct } \\
\text { Use In }\end{array}$ & Description & $\begin{array}{c}\text { Input } \\
\text { Category }\end{array}$ \\
\hline \multirow{9}{*}{$\begin{array}{l}\text { CRWMS M\&O 1998. Probabilistic } \\
\text { Seismic Hazard Analyses for Fault } \\
\text { Displacement and Vibratory Ground } \\
\text { Motion at Yucca Mountain, Nevada. } \\
\text { Milestone SP32IM3, September 23, } \\
\text { 1998. Three volumes. Las Vegas, } \\
\text { Nevada: CRWMS M\&O. } \\
\text { ACC: MOL.19981207.0393. } \\
\text { 103731 }\end{array}$} & Figure 8-5 & Table 6-2 & Annual frequency values & Data \\
\hline & Figure 4-9 & $\begin{array}{l}\text { Section } \\
6.2 .1 .2\end{array}$ & $\begin{array}{l}\text { The Drill Hole Wash fault, Pagany } \\
\text { Wash fault, and Sever Wash fault } \\
\text { are northwest-trending parallel } \\
\text { intra-block faults that intersect the } \\
\text { emplacement drifts in the northeast } \\
\text { section of the repository. }\end{array}$ & Data \\
\hline & Entire & $\begin{array}{l}\text { Sections } \\
6.2 .1 .1 \\
6.2 .1 .2 \\
6.2 .1 .3 \\
6.2 .1 .4 \\
6.2 .1 .5 \\
6.2 .1 .6 \\
6.2 .1 .11 \\
\end{array}$ & $\begin{array}{l}\text { General cite to document providing } \\
\text { results of expert elicitation on } \\
\text { ground motion and fault } \\
\text { displacement - source of ground } \\
\text { motion and fault displacement } \\
\text { data; and to support character of } \\
\text { extensional tectonics }\end{array}$ & Data \\
\hline & p. 8-7 & $\begin{array}{l}\text { Sections } \\
6.2 .1 .2 \\
6.2 .1 .10 \\
6.2 .1 .11\end{array}$ & $\begin{array}{l}\text { Results of expert elicitation for } \\
\text { points } 7 d \text { and } 8 d \text { for intact rock - } \\
\text { inference that new fractures will } \\
\text { not affect porosity and permeability } \\
\text { of fractures; reactivation of existing } \\
\text { fractures is a more likely event } \\
\text { than the development of new } \\
\text { fractures. }\end{array}$ & Data \\
\hline & Figure 8-3 & $\begin{array}{l}\text { Table 6-2; } \\
\text { Section } \\
6.2 .1 .10 \\
\end{array}$ & $\begin{array}{l}\text { Fault displacement hazards for } \\
\text { block-bounding faults }\end{array}$ & Data \\
\hline & $\begin{array}{l}\text { Figures } 8.2 \\
\text { through } 8.14 \\
\text { p. } 8-7\end{array}$ & $\begin{array}{l}\text { Section } \\
6.2 .1 .1 \\
\text { Table } 6-2\end{array}$ & $\begin{array}{l}\text { Fault displacement and other } \\
\text { displacement hazards for } \\
\text { intrablock faults and features likely } \\
\text { to be found within the repository }\end{array}$ & Data \\
\hline & $\begin{array}{l}\text { Figures } 8.8 \\
\text { through } 8.13\end{array}$ & $\begin{array}{l}\text { Section } \\
6.2 .1 .2\end{array}$ & $\begin{array}{l}\text { Displacement hazard for features } \\
\text { within the waste emplacement } \\
\text { area }\end{array}$ & Data \\
\hline & $\begin{array}{l}\text { Figures } 8.10 \\
\text { and } 8.13 \text { (for } \\
\text { points } 7 c \text { and } \\
8 \mathrm{c} \text { ) }\end{array}$ & $\begin{array}{l}\text { Section } \\
6.2 .1 .11\end{array}$ & $\begin{array}{l}\text { Displacement hazards for fractures } \\
\text { with no existing displacement }\end{array}$ & Data \\
\hline & Section 8.2 .1 & Table 6-2 & $\begin{array}{l}\text { General section reference of } \\
\text { figures showing fault displacement } \\
\text { hazard curves }\end{array}$ & Data \\
\hline
\end{tabular}


Table A-1. Table of Direct Inputs for Included and Excluded Features, Events, and Processes (Continued)

\begin{tabular}{|c|c|c|c|c|}
\hline Document Source & $\begin{array}{l}\text { Citation } \\
\text { from } \\
\text { Source }\end{array}$ & $\begin{array}{l}\text { Direct } \\
\text { Use In }\end{array}$ & Description & $\begin{array}{l}\text { Input } \\
\text { Category }\end{array}$ \\
\hline & $\begin{array}{l}\text { Section } 7.1 .1 \\
\text { and } 8.1 .3 \text { and } \\
\text { Appendix } E\end{array}$ & $\begin{array}{l}\text { Section } \\
6.2 .1 .1\end{array}$ & $\begin{array}{l}\text { Discussions of the treatment of } \\
\text { various types of uncertainty, } \\
\text { specifically those related to rates, } \\
\text { and summary of expert elicitations } \\
\text { by team. }\end{array}$ & Data \\
\hline \multirow{2}{*}{$\begin{array}{l}\text { National Research Council. } 1992 . \\
\text { Ground Water at Yucca Mountain, } \\
\text { How High Can It Rise? Final Report } \\
\text { of the Panel on Coupled } \\
\text { Hydrologic/Tectonic/Hydrothermal } \\
\text { Systems at Yucca Mountain. } \\
\text { Washington, D.C.: National Academy } \\
\text { Press. TIC: 204931. } \\
105162\end{array}$} & Entire & Section C1 & $\begin{array}{l}\text { External source qualified for } \\
\text { intended use }\end{array}$ & $\begin{array}{l}\text { Data } \\
\text { (qualified for } \\
\text { intended } \\
\text { use - see } \\
\text { Appendix C) }\end{array}$ \\
\hline & Entire & $\begin{array}{l}\text { Section } \\
\text { 6.2.1.8 } \\
\end{array}$ & $\begin{array}{l}\text { Evaluation of seismic pumping } \\
\text { hypothesis. }\end{array}$ & Data \\
\hline \multirow[t]{7}{*}{$\begin{array}{l}\text { CRWMS M\&O 1998. Synthesis of } \\
\text { Volcanism Studies for the Yucca } \\
\text { Mountain Site Characterization } \\
\text { Project. Deliverable 3781MR1. } \\
\text { Las Vegas, Nevada: CRWMS M\&O. } \\
\text { ACC: MOL.19990511.0400. } \\
105347\end{array}$} & p. 5-42 & $\begin{array}{l}\text { Sections } \\
6.2 .2 .1 \\
6.2 .2 .9\end{array}$ & $\begin{array}{l}\text { Based on natural-analogue sites, } \\
\text { there is no indication for extensive } \\
\text { hydrothermal circulation and } \\
\text { alteration, brecciation and } \\
\text { deformation related to magmatic } \\
\text { intrusion, and vapor phase } \\
\text { recrystallization during the } \\
\text { magmatic intrusion into the vitric } \\
\text { and zeolitized tuffs. }\end{array}$ & Data \\
\hline & p. 5-56 & $\begin{array}{l}\text { Sections } \\
6.2 .2 .1 \\
6.2 .2 .9 \\
\end{array}$ & $\begin{array}{l}\text { Possibility of formation of perched } \\
\text { water formation due to dike } \\
\text { structure }\end{array}$ & Data \\
\hline & $\begin{array}{l}\text { p. 5-41 and p. } \\
5-57\end{array}$ & $\begin{array}{l}\text { Section } \\
6.2 .2 .1\end{array}$ & $\begin{array}{l}\text { Mineral alterations around igneous } \\
\text { intrusions at natural-analogue sites } \\
\text { are generally confined to relatively } \\
\text { thin zones. }\end{array}$ & Data \\
\hline & pp. 5-41, 5-72 & $\begin{array}{l}\text { Section } \\
6.2 .2 .1\end{array}$ & $\begin{array}{l}\text { Natural-analogue studies in similar } \\
\text { host rocks at the Nevada Test Site } \\
\text { show that alteration is limited to a } \\
\text { zone less than } 10 \text { meters away } \\
\text { from the intrusion/host rock } \\
\text { contact. }\end{array}$ & Data \\
\hline & $\begin{array}{l}\text { pp. 5-1 and 5- } \\
2\end{array}$ & $\begin{array}{l}\text { Section } \\
6.2 .2 .9\end{array}$ & $\begin{array}{l}\text { Chemical and mineralogical } \\
\text { studies of host tuffs indicated that, } \\
\text { for shallow, small-volume basaltic } \\
\text { intrusions, alteration is limited to } \\
\text { within a few tens of meters of the } \\
\text { intrusion itself. }\end{array}$ & Data \\
\hline & p. 5-46 & $\begin{array}{l}\text { Section } \\
6.2 .2 .9\end{array}$ & $\begin{array}{l}\text { At the Paiute Ridge center, low- } \\
\text { temperature secondary minerals } \\
\text { persist near the contact with } \\
\text { intrusions. }\end{array}$ & Data \\
\hline & p. 5-86 & $\begin{array}{l}\text { Section } \\
6.2 .2 .9\end{array}$ & $\begin{array}{l}\text { Consideration of the effects of } \\
\text { hydrothermal systems (the heating } \\
\text { up of groundwater and rock) } \\
\text { resulting from igneous intrusions }\end{array}$ & Data \\
\hline
\end{tabular}


Table A-1. Table of Direct Inputs for Included and Excluded Features, Events, and Processes (Continued)

\begin{tabular}{|c|c|c|c|c|}
\hline Document Source & $\begin{array}{l}\text { Citation } \\
\text { from } \\
\text { Source }\end{array}$ & $\begin{array}{l}\text { Direct } \\
\text { Use In }\end{array}$ & Description & $\begin{array}{c}\text { Input } \\
\text { Category }\end{array}$ \\
\hline & p. 5-57 & $\begin{array}{l}\text { Section } \\
6.2 .2 .9\end{array}$ & $\begin{array}{l}\text { Findings from the Paiute Ridge } \\
\text { analogue site indicate that "the } \\
\text { occurrence of clinoptilolite and opal } \\
\text { also suggests that thermal transfer } \\
\text { into the adjacent country rock was } \\
\text { minimal." }\end{array}$ & Data \\
\hline & p. 5-74 & $\begin{array}{l}\text { Section } \\
6.2 .2 .9\end{array}$ & $\begin{array}{l}\text { Findings from the Grants Ridge } \\
\text { site suggest the absence of a } \\
\text { hydrothermal system, except for } \\
\text { localized recrystallization of } \\
\text { volcanic glass within the contact } \\
\text { zone and leads to the conclusion } \\
\text { that an intrusion at Yucca } \\
\text { Mountain would not result in large } \\
\text { amounts of hydrothermally driven } \\
\text { mass transfer. }\end{array}$ & Data \\
\hline & p. 5-41 & $\begin{array}{l}\text { Section } \\
6.2 .2 .9\end{array}$ & $\begin{array}{l}\text { The analogue studies show that } \\
\text { alteration is quite limited, typically } \\
\text { only found within } 5 \text { to } 10 \mathrm{~m} \text { of } \\
\text { intrusions. }\end{array}$ & Data \\
\hline \multirow[t]{5}{*}{$\begin{array}{l}10 \text { CFR } 63 . \text { Energy: Disposal of High- } \\
\text { Level Radioactive Wastes in a } \\
\text { Geologic Repository at Yucca } \\
\text { Mountain, Nevada. Readily available. } \\
156605\end{array}$} & $\begin{array}{l}\text { Section } 114 \\
(\mathrm{~d}),(\mathrm{e}) \text {, and }(\mathrm{f})\end{array}$ & Section 1 & $\begin{array}{l}\text { The inclusion or exclusion of } \\
\text { disruptive events FEPs with } \\
\text { respect to modeling used to } \\
\text { support the TSPA-LA is required. }\end{array}$ & $\begin{array}{l}\text { Established } \\
\text { fact }\end{array}$ \\
\hline & $\begin{array}{l}\text { Section } 73 ; \\
\text { Subparts F } \\
\text { and G; also } \\
\text { see } \\
\text { requirements } \\
\text { in Sections } \\
32,44, \text { and } \\
131 \\
\end{array}$ & $\begin{array}{l}\text { Sections } \\
1.3,6.1 .6 \\
\text { Assumption } \\
5.3\end{array}$ & $\begin{array}{l}\text { Engineering and design changes } \\
\text { are subject to evaluation to } \\
\text { determine whether there are any } \\
\text { adverse impacts to safety. }\end{array}$ & $\begin{array}{l}\text { Established } \\
\text { fact }\end{array}$ \\
\hline & Entire & $\begin{array}{l}\text { Sections } \\
4.1,4.2,4.3 \\
6.1 .2\end{array}$ & $\begin{array}{l}\text { The regulations provide direct } \\
\text { inputs to the FEPs screening } \\
\text { process. }\end{array}$ & $\begin{array}{l}\text { Established } \\
\text { fact }\end{array}$ \\
\hline & Section 2 & Table 4-1 & $\begin{array}{l}\text { Regulatory definition for reference } \\
\text { biosphere is given. }\end{array}$ & $\begin{array}{l}\text { Established } \\
\text { fact }\end{array}$ \\
\hline & Section 302 & Table 4-1 & $\begin{array}{l}\text { Regulatory definitions for } \\
\text { accessible environment and } \\
\text { controlled area are given. }\end{array}$ & $\begin{array}{l}\text { Established } \\
\text { fact }\end{array}$ \\
\hline
\end{tabular}


Table A-1. Table of Direct Inputs for Included and Excluded Features, Events, and Processes (Continued)

\begin{tabular}{|c|c|c|c|c|}
\hline Document Source & $\begin{array}{l}\text { Citation } \\
\text { from } \\
\text { Source }\end{array}$ & $\begin{array}{l}\text { Direct } \\
\text { Use In }\end{array}$ & Description & $\begin{array}{c}\text { Input } \\
\text { Category }\end{array}$ \\
\hline & $\begin{array}{l}\text { Sections } \\
305(a),(b)\end{array}$ & $\begin{array}{l}\text { Section 4.1; } \\
\text { Table 4-1 }\end{array}$ & $\begin{array}{l}\text { The reference biosphere must be } \\
\text { consistent with present knowledge } \\
\text { of conditions in the region, and } \\
\text { changes in the biosphere (other } \\
\text { than climate) from conditions at the } \\
\text { time of license application } \\
\text { submittal should not be projected. }\end{array}$ & $\begin{array}{l}\text { Established } \\
\text { fact }\end{array}$ \\
\hline & Section 305(c) & $\begin{array}{l}\text { Table 4-1; } \\
\text { Assumption } \\
5.2\end{array}$ & $\begin{array}{l}\text { Regulatory requirement given that } \\
\text { the DOE vary factors based upon } \\
\text { cautious, but reasonable, } \\
\text { assumptions consistent with } \\
\text { present knowledge of factors that } \\
\text { could affect Yucca Mountain over } \\
\text { the next } 10,000 \text { years. }\end{array}$ & $\begin{array}{l}\text { Established } \\
\text { fact }\end{array}$ \\
\hline & Section 312 & Table 4-1 & $\begin{array}{l}\text { Regulatory characteristics of the } \\
\text { RMEI are given. }\end{array}$ & $\begin{array}{l}\text { Established } \\
\text { fact }\end{array}$ \\
\hline & $\begin{array}{l}\text { Section } \\
312(a),(b), \\
(c),(d), \text { and } \\
(e)\end{array}$ & Section 4.1 & $\begin{array}{l}\text { The location of the RMEl is defined } \\
\text { specifically. }\end{array}$ & $\begin{array}{l}\text { Established } \\
\text { fact }\end{array}$ \\
\hline & Section 302 & $\begin{array}{l}\text { Sections } \\
4.1,6.2 .2 .5\end{array}$ & $\begin{array}{l}\text { Definition of the limit of the } \\
\text { controlled area from the repository } \\
\text { in directions other than south (i.e., } \\
\text { south in the direction of } \\
\text { groundwater flow referred to in } \\
\text { Section 312). }\end{array}$ & $\begin{array}{l}\text { Established } \\
\text { fact }\end{array}$ \\
\hline & $\begin{array}{l}\text { Sections } \\
102(i), 305, \\
\text { and } 312\end{array}$ & Section 4.1 & $\begin{array}{l}\text { Characteristics of the reference } \\
\text { biosphere and the RMEI are to be } \\
\text { based on current human behavior } \\
\text { and biospheric conditions in the } \\
\text { region. }\end{array}$ & $\begin{array}{l}\text { Established } \\
\text { fact }\end{array}$ \\
\hline & $\begin{array}{l}\text { Section } \\
114(\mathrm{a}),(\mathrm{b}) \text {, } \\
(\mathrm{d}),(\mathrm{e}), \text { and } \\
(\mathrm{f}) \text {; Section } \\
342 \\
\end{array}$ & Table 4-2 & $\begin{array}{l}\text { Applicable regulatory requirements } \\
\text { pertinent to FEPs screening }\end{array}$ & $\begin{array}{l}\text { Established } \\
\text { fact }\end{array}$ \\
\hline & Section 114(d) & $\begin{array}{l}\text { Sections } \\
4.2 .3,6.1 .2\end{array}$ & $\begin{array}{l}\text { The low-probability criterion is } \\
\text { stated. }\end{array}$ & $\begin{array}{l}\text { Established } \\
\text { fact }\end{array}$ \\
\hline & Section 342 & \begin{tabular}{|l} 
Sections \\
$4.2 .3,6.1 .2$
\end{tabular} & $\begin{array}{l}\text { The low-probability criterion is } \\
\text { supported. }\end{array}$ & $\begin{array}{l}\text { Established } \\
\text { fact }\end{array}$ \\
\hline & $\begin{array}{l}\text { Section 114(e) } \\
\text { and }(\mathrm{f})\end{array}$ & \begin{tabular}{|l} 
Sections \\
$4.2 .3,6.1 .2$ \\
\end{tabular} & $\begin{array}{l}\text { The low-consequence criterion is } \\
\text { stated. }\end{array}$ & $\begin{array}{l}\text { Established } \\
\text { fact }\end{array}$ \\
\hline & Section 342 & $\begin{array}{l}\text { Section } \\
4.2 .3\end{array}$ & $\begin{array}{l}\text { The low-consequence criterion is } \\
\text { supported. }\end{array}$ & $\begin{array}{l}\text { Established } \\
\text { fact }\end{array}$ \\
\hline & Section 102(j) & $\begin{array}{l}\text { Section } \\
4.2 .3 \\
\end{array}$ & $\begin{array}{l}\text { The concept of a performance } \\
\text { assessment is given. }\end{array}$ & $\begin{array}{l}\text { Established } \\
\text { fact }\end{array}$ \\
\hline & Section 113(b) & $\begin{array}{l}\text { Section } \\
4.2 .3\end{array}$ & $\begin{array}{l}\text { Included in the concept of a } \\
\text { performance assessment are } \\
\text { those FEPs expected to materially } \\
\text { affect compliance with what is } \\
\text { stated in Section } 113(\mathrm{~b}) \text {. }\end{array}$ & $\begin{array}{l}\text { Established } \\
\text { fact }\end{array}$ \\
\hline
\end{tabular}


Table A-1. Table of Direct Inputs for Included and Excluded Features, Events, and Processes (Continued)

\begin{tabular}{|c|c|c|c|c|}
\hline Document Source & $\begin{array}{l}\text { Citation } \\
\text { from } \\
\text { Source }\end{array}$ & $\begin{array}{l}\text { Direct } \\
\text { Use In }\end{array}$ & Description & $\begin{array}{c}\text { Input } \\
\text { Category }\end{array}$ \\
\hline & Entire & $\begin{array}{l}\text { Sections 4, } \\
6.2 .2 .2 \\
6.2 .2 .3 \\
6.2 .2 .5 \\
6.2 .2 .6 \\
6.2 .2 .7 \\
6.2 .2 .8\end{array}$ & $\begin{array}{l}\text { Code of Federal Regulation rules } \\
\text { governing the licensing of the U.S. } \\
\text { Department of Energy to receive } \\
\text { and possess source, special } \\
\text { nuclear, and by-product material at } \\
\text { a geologic repository operations } \\
\text { area sited, constructed, or } \\
\text { operated at Yucca Mountain, } \\
\text { Nevada, in accordance with the } \\
\text { Nuclear Waste Policy Act of } 1982, \\
\text { as amended, and the Energy } \\
\text { Policy Act of 1992. }\end{array}$ & $\begin{array}{l}\text { Established } \\
\text { fact }\end{array}$ \\
\hline & $\begin{array}{l}\text { Sections } 312 \\
\text { and } 302\end{array}$ & $\begin{array}{l}\text { Sections } \\
6.2 .2 .2 \\
6.2 .2 .3 \\
6.2 .2 .5 \\
6.2 .2 .6 \\
6.2 .2 .7 \\
6.2 .2 .8\end{array}$ & $\begin{array}{l}\text { The location of the RMEI is } \\
\text { approximately } 18 \mathrm{~km} \text { south of the } \\
\text { repository. }\end{array}$ & $\begin{array}{l}\text { Established } \\
\text { fact }\end{array}$ \\
\hline $\begin{array}{l}\text { BSC (Bechtel SAIC Company) } 2003 . \\
21-P W R \text { Waste Package Side and } \\
\text { End Impacts. 000-00C-DSU0-01000- } \\
\text { 000-00B. Las Vegas, Nevada: } \\
\text { Bechtel SAIC Company. } \\
\text { ACC: ENG.20030227.0067. } \\
162293\end{array}$ & Entire & $\begin{array}{l}\text { Section } \\
6.2 .1 .3\end{array}$ & $\begin{array}{l}\text { Damage to waste package and } \\
\text { cladding supporting calculations } \\
\text { include damage assessment of the } \\
\text { 21-PWR waste package. }\end{array}$ & Data \\
\hline $\begin{array}{l}\text { BSC (Bechtel SAIC Company) } 2003 . \\
\text { Maximum Accelerations on the Fuel } \\
\text { Assemblies of a 21-PWR Waste } \\
\text { Package During End Impacts. 000- } \\
\text { 00C-DSU0-01100-000-00A. } \\
\text { Las Vegas, Nevada: Bechtel SAIC } \\
\text { Company. } \\
\text { ACC: ENG.20030327.0002. } \\
162602\end{array}$ & Entire & $\begin{array}{l}\text { Section } \\
6.2 .1 .3\end{array}$ & $\begin{array}{l}\text { Damage to waste package and } \\
\text { cladding calculations include } \\
\text { determination of acceleration and } \\
\text { damage to cladding package. }\end{array}$ & Data \\
\hline $\begin{array}{l}\text { BSC (Bechtel SAIC Company) } 2003 . \\
\text { Structural Calculations of Drip Shield } \\
\text { Exposed to Vibratory Ground Motion. } \\
000-00 C-P E C 0-00100-000-00 A . \\
\text { Las Vegas, Nevada: Bechtel SAIC } \\
\text { Company. } \\
\text { ACC: ENG.20030618.0009. } \\
163425\end{array}$ & Entire & $\begin{array}{l}\text { Section } \\
6.2 .1 .3\end{array}$ & $\begin{array}{l}\text { Calculations that address damage } \\
\text { to the drip shield from vibratory } \\
\text { motion }\end{array}$ & Data \\
\hline $\begin{array}{l}\text { MO03061E9PSHA1.000. Spectral } \\
\text { Acceleration and Velocity Hazard } \\
\text { Curves Extended to 1E-9 Based on } \\
\text { the Results of the PSHA for Yucca } \\
\text { Mountain. Submittal date: } \\
06 / 09 / 2003 . \\
163721 \\
\end{array}$ & Entire & $\begin{array}{l}\text { Sections } \\
6.2 .1 .3 \\
6.2 .1 .4 \\
6.2 .1 .5 \\
6.2 .1 .6\end{array}$ & $\begin{array}{l}\text { Ground motion input data used in } \\
\text { supporting analysis report }\end{array}$ & Data \\
\hline
\end{tabular}


Table A-1. Table of Direct Inputs for Included and Excluded Features, Events, and Processes (Continued)

\begin{tabular}{|c|c|c|c|c|}
\hline Document Source & $\begin{array}{l}\text { Citation } \\
\text { from } \\
\text { Source } \\
\end{array}$ & $\begin{array}{l}\text { Direct } \\
\text { Use In }\end{array}$ & Description & $\begin{array}{c}\text { Input } \\
\text { Category }\end{array}$ \\
\hline $\begin{array}{l}\text { BSC (Bechtel SAIC Company) } 2004 . \\
\text { D\&E / PA/C IED Subsurface } \\
\text { Facilities. 800-IED-WIS0-00101-000- } \\
\text { 00A. Las Vegas, Nevada: Bechtel } \\
\text { SAIC Company. } \\
\text { ACC: ENG.20040309.0026. } \\
164519\end{array}$ & Entire & $\begin{array}{l}\text { Sections } \\
6.2 .1 .2 \\
6.2 .2 .5\end{array}$ & $\begin{array}{l}\text { The minimum depth of the } \\
\text { currently planned TSPA-LA } \\
\text { repository is } 215 \text { meters. }\end{array}$ & Data \\
\hline $\begin{array}{l}\text { MO0306MWDDPPDR.000. Drift } \\
\text { Profile Prediction and Degraded Rock } \\
\text { Mass Characteristics. Submittal date: } \\
06 / 18 / 2003 . \\
164736 \\
\end{array}$ & Entire & $\begin{array}{l}\text { Section } \\
6.2 .1 .6\end{array}$ & $\begin{array}{l}\text { Seepage estimates made for } \\
\text { collapsed drift profiles in } \\
\text { lithophysal rocks }\end{array}$ & Data \\
\hline \multirow[t]{3}{*}{$\begin{array}{l}\text { BSC (Bechtel SAIC Company) } 2003 . \\
\text { Underground Layout Configuration. } \\
\text { 800-P0C-MGR0-00100-000-00E. } \\
\text { Las Vegas, Nevada: Bechtel SAIC } \\
\text { Company. } \\
\text { ACC: ENG.20031002.0007. } \\
165572\end{array}$} & $\begin{array}{l}\text { Sections } \\
7.1 .3,7.3 .1\end{array}$ & $\begin{array}{l}\text { Section } \\
6.2 .1 .2\end{array}$ & $\begin{array}{l}\text { A standoff must be maintained } \\
\text { from the closest edge of a } \\
\text { repository opening to the main } \\
\text { trace of any Type I fault zones. } \\
\text { The preference location of the } \\
\text { repository should be in the } \\
\text { proposed repository block as } \\
\text { defined by block bounding faults. }\end{array}$ & Data \\
\hline & Section 7.1 .3 & $\begin{array}{l}\text { Section } \\
6.2 .1 .2\end{array}$ & $\begin{array}{l}\text { The only Type I faults that would } \\
\text { be required to have standoffs are } \\
\text { the Solitario and Bow Ridge faults. }\end{array}$ & Data \\
\hline & Entire & $\begin{array}{l}\text { Section } \\
6.2 .1 .2\end{array}$ & $\begin{array}{l}\text { Consideration of Exhumation due } \\
\text { to Fault Displacement versus } \\
\text { depth of repository }\end{array}$ & Data \\
\hline \multirow[t]{5}{*}{$\begin{array}{l}\text { BSC (Bechtel SAIC Company) } 2004 . \\
\text { Drift Degradation Analysis. ANL-EBS- } \\
\text { MD-000027, Rev. 03. Las Vegas, } \\
\text { Nevada: Bechtel SAIC Company. } \\
166107\end{array}$} & $\begin{array}{l}\text { Section } \\
6.3 .1 .6 .1 \\
\text { Tables 6-26, } \\
6-27\end{array}$ & $\begin{array}{l}\text { Section } \\
6.2 .1 .4\end{array}$ & $\begin{array}{l}\text { Results for the preclosure hazard } \\
\text { level of } 1 \times 10^{-4} \text { annual probability } \\
\text { of exceedance ground motion } \\
\text { indicate a total of } 535 \text { blocks per } \\
\mathrm{km} \text { of drift length. }\end{array}$ & Data \\
\hline & Entire & $\begin{array}{l}\text { Section } \\
6.2 .1 .11\end{array}$ & $\begin{array}{l}\text { Field observations indicate that the } \\
\text { rock at Yucca Mountain is highly } \\
\text { fractured and that existing } \\
\text { fractures and joints have been } \\
\text { subject to reactivation. }\end{array}$ & Data \\
\hline & $\begin{array}{l}\text { Sections } \\
6.3 .1 .6 .1 \\
6.4 .2 .2 .2 \\
\end{array}$ & $\begin{array}{l}\text { Section } \\
6.2 .1 .3\end{array}$ & $\begin{array}{l}\text { Drift collapse occurs within the first } \\
\text { second or two of the arrival of large } \\
\text { amplitude ground motions. }\end{array}$ & Data \\
\hline & $\begin{array}{l}\text { Sections } \\
6.3 .4,8.1\end{array}$ & $\begin{array}{l}\text { Section } \\
6.2 .1 .4\end{array}$ & $\begin{array}{l}\text { Nonlithophysal rock blocks are } \\
\text { generally larger than rock } \\
\text { fragments in the lithophysal zone, } \\
\text { and drift profiles show more } \\
\text { localized areas of rock failure. }\end{array}$ & Data \\
\hline & $\begin{array}{l}\text { Sections } \\
6.3 .1 .2 .1 \\
6.4 .2 .2\end{array}$ & $\begin{array}{l}\text { Sections } \\
6.2 .1 .4 \\
6.2 .1 .5 \\
6.2 .1 .6\end{array}$ & $\begin{array}{l}\text { Site-specific ground motions for } \\
\text { five levels of annual probability of } \\
\text { exceedance are used to assess } \\
\text { the postclosure seismically } \\
\text { induced rock fall and seismic- } \\
\text { induced drift collapse }\end{array}$ & Data \\
\hline
\end{tabular}


Table A-1. Table of Direct Inputs for Included and Excluded Features, Events, and Processes (Continued)

\begin{tabular}{|c|c|c|c|c|}
\hline Document Source & $\begin{array}{l}\text { Citation } \\
\text { from } \\
\text { Source }\end{array}$ & $\begin{array}{l}\text { Direct } \\
\text { Use In }\end{array}$ & Description & $\begin{array}{c}\text { Input } \\
\text { Category }\end{array}$ \\
\hline & $\begin{array}{l}\text { Section } \\
6.4 .2 .2\end{array}$ & $\begin{array}{l}\text { Sections } \\
6.2 .1 .4 \\
6.2 .1 .6\end{array}$ & $\begin{array}{l}\text { For } 10^{-4} \text { per year ground motions, } \\
\text { little damage is predicted in } \\
\text { lithophysal zones, even in } \\
\text { unsupported areas of the drift }\end{array}$ & Data \\
\hline & $\begin{array}{l}\text { Section } \\
6.4 .2 .2 .2\end{array}$ & $\begin{array}{l}\text { Section } \\
6.2 .1 .4\end{array}$ & $\begin{array}{l}\text { Peak ground velocities in excess of } \\
\text { about } 2.0 \mathrm{~m} / \mathrm{sec} \text { result in damage } \\
\text { levels above } 15 \mathrm{~m}^{3} \text { of rockfall per } \\
\text { meter of emplacement drift length. } \\
\text { This damage level is characterized } \\
\text { by complete collapse of the tunnel } \\
\text { at about the } 10^{-6} \text { hazard level }\end{array}$ & Data \\
\hline & $\begin{array}{l}\text { Section } \\
6.4 .2 .5 ; \text { Figure } \\
6-174\end{array}$ & $\begin{array}{l}\text { Section } \\
6.2 .1 .5\end{array}$ & $\begin{array}{l}\text { Rubble loads to the drip shield } \\
\text { were estimated from collapse } \\
\text { simulations using a discontinuum } \\
\text { numerical model, and a three- } \\
\text { dimensional finite element } \\
\text { structural analysis of the drip shield } \\
\text { was undertaken. }\end{array}$ & Data \\
\hline & Entire & $\begin{array}{l}\text { Sections } \\
6.2 .1 .3 \\
6.2 .1 .6 \\
\text { Table 6-1 }\end{array}$ & $\begin{array}{l}\text { General reference to technical } \\
\text { product addressing specifics of } \\
\text { rockfall and drift collapse }\end{array}$ & Data \\
\hline & Table 6-50 & $\begin{array}{l}\text { Sections } \\
6.2 .1 .3 \\
6.2 .1 .6 \\
6.2 .1 .7 \\
\end{array}$ & General basis for inclusion & Data \\
\hline & Section 1.1 & $\begin{array}{l}\text { Section } \\
6.2 .1 .6\end{array}$ & $\begin{array}{l}\text { The nonlithophysal rocks also } \\
\text { comprise only } 15 \text { percent of the } \\
\text { emplacement area }\end{array}$ & Data \\
\hline & $\begin{array}{l}\text { Section } \\
6.4 .2 .2\end{array}$ & $\begin{array}{l}\text { Section } \\
6.2 .1 .6\end{array}$ & $\begin{array}{l}\text { Damage evaluations for lithophysal } \\
\text { rockfall and drift collapse at } 5 \times 10^{-4} \\
\text { and at } 10^{-6} \text { ground motions. Drifts } \\
\text { in the lithophysal zones collapse } \\
\text { under the } 10^{-6} \text { per year (and by } \\
\text { inference the larger, } 10^{-7} \text { per year) } \\
\text { vibratory ground motions }\end{array}$ & Data \\
\hline & $\begin{array}{l}\text { Sections } 6.3 \\
\text { and } 6.4\end{array}$ & $\begin{array}{l}\text { Section } \\
6.2 .1 .3 \\
6.2 .1 .4 \\
6.2 .1 .5\end{array}$ & $\begin{array}{l}\text { Detailed description of the } \\
\text { nonlithophysal rockfall calculations } \\
\text { with the } 3 \text {-DEC computer program } \\
\text { ( } 6.3 \text { rockfall) and results } \\
\text { summarized. Basis for argument } \\
\text { that drift collapse occurs before } \\
\text { drip separation occurs. }\end{array}$ & Data \\
\hline & $\begin{array}{l}\text { Sections } 6.3 \\
\text { and } 6.4\end{array}$ & $\begin{array}{l}\text { Section } \\
6.2 .1 .4\end{array}$ & $\begin{array}{l}\text { Rockfall occurs in both lithophysal } \\
\text { and nonlithophysal zones } \\
\text { substantially below the } 10^{-6} \text { annual } \\
\text { probability of exceedance (PGV } \\
2.44 \mathrm{~m} / \mathrm{s} \text { ) }\end{array}$ & Data \\
\hline & $\begin{array}{l}\text { Section } \\
6.4 .2 .2\end{array}$ & $\begin{array}{l}\text { Section } \\
\text { 6.2.1.6 }\end{array}$ & $\begin{array}{l}\text { Drift collapse in nonlithophysal } \\
\text { zones. }\end{array}$ & Data \\
\hline
\end{tabular}


Table A-1. Table of Direct Inputs for Included and Excluded Features, Events, and Processes (Continued)

\begin{tabular}{|c|c|c|c|c|}
\hline Document Source & $\begin{array}{l}\text { Citation } \\
\text { from } \\
\text { Source }\end{array}$ & $\begin{array}{l}\text { Direct } \\
\text { Use In }\end{array}$ & Description & $\begin{array}{c}\text { Input } \\
\text { Category }\end{array}$ \\
\hline & $\begin{array}{l}\text { Section } \\
6.3 .1 .6 .1 \\
\text { Tables 6-26, } \\
6-27\end{array}$ & $\begin{array}{l}\text { Section } \\
6.2 .1 .5\end{array}$ & $\begin{array}{l}\text { For } 10^{-5}, 10^{-6} \text {, and } 10^{-7} \text { per year } \\
\text { ground motions, results indicate } \\
1,414 \text { blocks, } 2,238 \text { blocks and } \\
3079 \text { blocks per km of } \\
\text { emplacement drift length, } \\
\text { respectively, may move. }\end{array}$ & Data \\
\hline & Section 8.1 & $\begin{array}{l}\text { Section } \\
6.2 .1 .5\end{array}$ & $\begin{array}{l}\text { Larger postclosure ground motions } \\
\text { in nonlithophysal zones are } \\
\text { characterized by localized areas of } \\
\text { rock failure, in some cases } \\
\text { sufficient to cover the drip shield. }\end{array}$ & Data \\
\hline & Section 6.6.1 & $\begin{array}{l}\text { Section } \\
6.2 .1 .5\end{array}$ & $\begin{array}{l}\text { Due to the larger size of rock } \\
\text { blocks, calculations have } \\
\text { emphasized the impact of the size } \\
\text { and kinetic energy of these larger } \\
\text { blocks on the integrity of the drip } \\
\text { shield, rather than the static load } \\
\text { associated with lithophysal rubble. }\end{array}$ & Data \\
\hline & Appendix R & $\begin{array}{l}\text { Section } \\
6.2 .1 .6\end{array}$ & $\begin{array}{l}\text { Seepage estimates made for } \\
\text { collapsed drift profiles in } \\
\text { lithophysal rocks provided in } \\
\text { DTN: MO0306MWDDPPDR.000 } \\
\text { determined from analyses }\end{array}$ & Data \\
\hline & Entire & $\begin{array}{l}\text { Section } \\
6.2 .1 .6\end{array}$ & $\begin{array}{l}\text { The worst-case (largest collapsed } \\
\text { diameter) drift profile predicted by } \\
\text { the drift-collapse analyses }\end{array}$ & Data \\
\hline & Section 6.3 .1 & $\begin{array}{l}\text { Section } \\
6.2 .1 .6\end{array}$ & $\begin{array}{l}\text { There is no explicit change in the } \\
\text { seepage abstraction in the } \\
\text { nonlithophysal zones because } \\
\text { rockfall is localized and because } \\
\text { there is limited impact on the } \\
\text { shape and size of the drift profile. }\end{array}$ & Data \\
\hline $\begin{array}{l}\text { BSC (Bechtel SAIC Company) } 2003 . \\
\text { Scoping Analysis on Sensitivity and } \\
\text { Uncertainty of Emplacement Drift } \\
\text { Stability. 800-K0C-TEG0-00600-000- } \\
\text { 000. Las Vegas, Nevada: Bechtel } \\
\text { SAIC Company. } \\
\text { ACC: ENG.20031125.0002. } \\
166183\end{array}$ & Section 4.2.1 & $\begin{array}{l}\text { Section } \\
6.2 .2 .5\end{array}$ & $\begin{array}{l}\text { The maximum overburden } \\
\text { thickness of the currently planned } \\
\text { TSPA-LA repository is } \\
\text { approximately } 450 \text { meters. }\end{array}$ & Data \\
\hline \multirow{2}{*}{$\begin{array}{l}\text { MO0401MWDRPSHA.000. Results of } \\
\text { the Yucca Mountain Probabilistic } \\
\text { Seismic Hazard Analysis (PSHA). } \\
\text { Submittal date: } 01 / 21 / 2004 \text {. } \\
166962\end{array}$} & $\begin{array}{l}\text { Fault } \\
\text { displacement } \\
\text { values }\end{array}$ & Table 6-2 & $\begin{array}{l}\text { Probabilistic fault displacement } \\
\text { data for nine selected points in or } \\
\text { near Yucca Mountain }\end{array}$ & Data \\
\hline & $\begin{array}{l}\text { Fault } \\
\text { displacement } \\
\text { values }\end{array}$ & $\begin{array}{l}\text { Section } \\
6.2 .1 .10\end{array}$ & $\begin{array}{l}\text { Results of the PSHA - data source } \\
\text { for fault displacements and ground } \\
\text { motions }\end{array}$ & Data \\
\hline
\end{tabular}


Table A-1. Table of Direct Inputs for Included and Excluded Features, Events, and Processes (Continued)

\begin{tabular}{|c|c|c|c|c|}
\hline Document Source & $\begin{array}{l}\text { Citation } \\
\text { from } \\
\text { Source }\end{array}$ & $\begin{array}{l}\text { Direct } \\
\text { Use In }\end{array}$ & Description & $\begin{array}{l}\text { Input } \\
\text { Category }\end{array}$ \\
\hline $\begin{array}{l}\text { BSC (Bechtel SAIC Company) } 2004 . \\
\text { Structural Calculations of Waste } \\
\text { Package Exposed to Vibratory } \\
\text { Ground Motion. 000-00C-WIS0- } \\
\text { 01400-000-00A. Las Vegas, Nevada: } \\
\text { Bechtel SAIC Company. } \\
\text { ACC: ENG.20040217.0008. } \\
167083\end{array}$ & Entire & $\begin{array}{l}\text { Section } \\
6.2 .1 .3\end{array}$ & $\begin{array}{l}\text { Damage to waste package and } \\
\text { cladding supporting calculations } \\
\text { include analysis of the waste } \\
\text { package vibratory motion. }\end{array}$ & Data \\
\hline \multirow[t]{8}{*}{$\begin{array}{l}\text { BSC (Bechtel SAIC Company) } 2004 . \\
\text { Characterize Framework for } \\
\text { Seismicity and Structural Deformation } \\
\text { at Yucca Mountain, Nevada. ANL- } \\
\text { CRW-GS-000003 REV 00 [Errata } \\
\text { 001]. Las Vegas, Nevada: Bechtel } \\
\text { SAIC Company. } \\
\text { ACC: MOL.20000510.0175; } \\
\text { DOC.20040223.0007. } \\
168030 \\
\end{array}$} & Entire & $\begin{array}{l}\text { Sections } \\
6.2 .1 .2 \\
6.2 .1 .7 \\
\text { Table } 6-1\end{array}$ & $\begin{array}{l}\text { General reference to analyses as } \\
\text { supporting AMR. }\end{array}$ & Data \\
\hline & Entire & $\begin{array}{l}\text { Section } \\
6.2 .1 .2\end{array}$ & $\begin{array}{l}\text { Supporting report for Fault } \\
\text { Displacement Damages EBS } \\
\text { Components FEP. }\end{array}$ & Data \\
\hline & $\begin{array}{l}\text { Glossary and } \\
\text { Section } 6.4 .2\end{array}$ & $\begin{array}{l}\text { Assumption } \\
5.1\end{array}$ & $\begin{array}{l}\text { Definition of annual exceedance } \\
\text { probability }\end{array}$ & Data \\
\hline & Section 6.3 .1 & $\begin{array}{l}\text { Sections } \\
6.2 .1 .1\end{array}$ & $\begin{array}{l}\text { Extensional strain rate is low to } \\
\text { moderate, with low to moderate } \\
\text { seismicity. Experiencing declining } \\
\text { strain rate. Time of peak tectonism } \\
\text { was } 12.7 \text { to } 11.6 \text { million years ago. }\end{array}$ & Data \\
\hline & Table 6 & $\begin{array}{l}\text { Section } \\
6.2 .1 .2\end{array}$ & Fault slip rates at Yucca Mountain. & Data \\
\hline & Table 6 & $\begin{array}{l}\text { Section } \\
\text { 6.2.1.1 } \\
\end{array}$ & $\begin{array}{l}\text { Relevant fault-slip rates are in the } \\
\text { range of } 0.001-0.03 \mathrm{~mm} / \text { year. }\end{array}$ & Data \\
\hline & Table 5 & $\begin{array}{l}\text { Section } \\
6.2 .1 .7 \\
\end{array}$ & $\begin{array}{l}\text { Volcanic source zones } \\
\text { considerations by expert teams }\end{array}$ & Data \\
\hline & Section 6.4 .4 & \begin{tabular}{|l} 
Section \\
6.2 .1 .7
\end{tabular} & PSHA method & Data \\
\hline $\begin{array}{l}\text { BSC (Bechtel SAIC Company) } 2004 . \\
\text { Additional Structural Calculations of } \\
\text { Waste Package Exposed to Vibratory } \\
\text { Ground Motion. 000-00C-WIS0- } \\
\text { 01700-000-00A. Las Vegas, Nevada: } \\
\text { Bechtel SAIC Company. } \\
\text { ACC: ENG.20040318.0011. } \\
168385\end{array}$ & Entire & $\begin{array}{l}\text { Section } \\
6.2 .1 .3\end{array}$ & $\begin{array}{l}\text { Sensitivity studies conducted on } \\
\text { variations in input ground motion } \\
\text { parameters. }\end{array}$ & Data \\
\hline $\begin{array}{l}\text { BSC (Bechtel SAIC Company) } 2004 . \\
\text { Total System Performance } \\
\text { Assessment (TSPA) Model/Analysis } \\
\text { for the License Application. MDL- } \\
\text { WIS-PA-000004, Rev. 00. Las Vegas, } \\
\text { Nevada: Bechtel SAIC Company. } \\
168504\end{array}$ & $\begin{array}{l}\text { Section } \\
6.5 .1 .3\end{array}$ & $\begin{array}{l}\text { Section } \\
6.2 .1 .6\end{array}$ & $\begin{array}{l}\text { The fraction of waste packages } \\
\text { affected is output from a TSPA-LA } \\
\text { DLL }\end{array}$ & Data \\
\hline
\end{tabular}


Table A-1. Table of Direct Inputs for Included and Excluded Features, Events, and Processes (Continued)

\begin{tabular}{|c|c|c|c|c|}
\hline Document Source & $\begin{array}{l}\text { Citation } \\
\text { from } \\
\text { Source }\end{array}$ & $\begin{array}{l}\text { Direct } \\
\text { Use In }\end{array}$ & Description & $\begin{array}{c}\text { Input } \\
\text { Category }\end{array}$ \\
\hline & Section 6.5 & $\begin{array}{l}\text { Sections } \\
6.2 .1 .2 \\
6.2 .1 .3 \\
6.2 .1 .6 \\
\end{array}$ & $\begin{array}{l}\text { General reference to disposition of } \\
\text { included components of the } \\
\text { seismic scenario class in the } \\
\text { TPSA-LA. }\end{array}$ & Data \\
\hline & Section 6.5 .2 & $\begin{array}{l}\text { Section } \\
6.2 .1 .2\end{array}$ & $\begin{array}{l}\text { Consequences from fault } \\
\text { displacement and vibratory ground } \\
\text { motion are calculated } \\
\text { simultaneously in each TSPA-LA } \\
\text { realization as damage } \\
\text { abstractions. } \\
\end{array}$ & Data \\
\hline & Section 6.5 & $\begin{array}{l}\text { Section } \\
6.2 .1 .2\end{array}$ & $\begin{array}{l}\text { Output of fault displacement } \\
\text { abstraction is number of waste } \\
\text { packages failed by fault } \\
\text { displacement and the combined } \\
\text { surface area from all waste } \\
\text { packages exposed to waste form } \\
\text { dissolution and release. }\end{array}$ & Data \\
\hline & Section 6.5 & $\begin{array}{l}\text { Section } \\
6.2 .1 .2\end{array}$ & $\begin{array}{l}\text { The total failed area from a faulting } \\
\text { event is the weighted sum of the } \\
\text { damage to each waste package } \\
\text { group. }\end{array}$ & Data \\
\hline & $\begin{array}{l}\text { Sections } \\
6.5 .1,6.5 .2\end{array}$ & $\begin{array}{l}\text { Sections } \\
6.2 .1 .2 \\
6.2 .1 .3\end{array}$ & $\begin{array}{l}\text { Fault-failed waste packages are } \\
\text { further grouped into two bins: } \\
\text { commercial spent nuclear fuel } \\
\text { (CSNF) and co-disposal waste } \\
\text { packages (CDSP), representing } \\
\text { PWR, BWR and Naval waste } \\
\text { packages and high level waste } \\
\text { packages, respectively. These } \\
\text { groups combine the EBS damage } \\
\text { fraction from ground motion and } \\
\text { fault displacement and account for } \\
\text { different environmental conditions } \\
\text { (e.g. dripping or dry). }\end{array}$ & Data \\
\hline & Entire & $\begin{array}{l}\text { Sections } \\
6.2 .2 .2 \\
6.2 .2 .4 \\
6.2 .2 .6 \\
6.2 .2 .7 \\
6.2 .2 .8 \\
\text { Table } 6-1\end{array}$ & $\begin{array}{l}\text { General reference to the document } \\
\text { as a supporting report for included } \\
\text { FEP }\end{array}$ & Data \\
\hline & Section 6.4 & $\begin{array}{l}\text { Sections } \\
6.2 .2 .2 \\
6.2 .2 .3 \\
6.2 .2 .4 \\
6.2 .2 .6 \\
6.2 .2 .7 \\
6.2 .2 .8 \\
\end{array}$ & $\begin{array}{l}\text { General reference to disposition of } \\
\text { included components of the } \\
\text { igneous scenario class in the } \\
\text { TSPA-LA. }\end{array}$ & Data \\
\hline
\end{tabular}


Table A-1. Table of Direct Inputs for Included and Excluded Features, Events, and Processes (Continued)

\begin{tabular}{|c|c|c|c|c|}
\hline Document Source & $\begin{array}{l}\text { Citation } \\
\text { from } \\
\text { Source }\end{array}$ & $\begin{array}{l}\text { Direct } \\
\text { Use In }\end{array}$ & Description & $\begin{array}{c}\text { Input } \\
\text { Category }\end{array}$ \\
\hline & $\begin{array}{l}\text { Section } \\
6.4 .1 .1\end{array}$ & $\begin{array}{l}\text { Section } \\
6.2 .2 .2\end{array}$ & $\begin{array}{l}\text { The time of the igneous intrusion is } \\
\text { selected from a log-uniform } \\
\text { distribution of possible event times } \\
\text { with the minimum equal to the end } \\
\text { of the first time step and the } \\
\text { maximum equal to the end of the } \\
\text { simulation period. }\end{array}$ & Data \\
\hline & $\begin{array}{l}\text { Sections } \\
6.4 .1 .3 \text { and } \\
6.4 .1 .1 .2\end{array}$ & $\begin{array}{l}\text { Section } \\
6.2 .2 .3\end{array}$ & $\begin{array}{l}\text { Lookup tables are used to model } \\
\text { magma temperature as a function } \\
\text { of time to determine when seepage } \\
\text { is reestablished. After } 100 \text { years, } \\
\text { all TSPA-LA model variables, } \\
\text { including temperatures, revert back } \\
\text { to the nominal scenario TH } \\
\text { abstraction values. }\end{array}$ & Data \\
\hline & $\begin{array}{l}\text { Section } \\
6.4 .2 .3\end{array}$ & $\begin{array}{l}\text { Section } \\
6.2 .2 .6\end{array}$ & $\begin{array}{l}\text { The mass of waste to be included } \\
\text { in the eruptive event is calculated } \\
\text { based on the proportion of CSNF } \\
\text { to CDSP waste packages in the } \\
\text { repository and a sampled } \\
\text { parameter that selects the number } \\
\text { of waste packages affected by the } \\
\text { eruptive event. The summation of } \\
\text { events at a given time step is done } \\
\text { within the GoldSim SoilExp_LA } \\
\text { DLL as part of the source term } \\
\text { multiplier calculations. }\end{array}$ & Data \\
\hline & Section 6.4 .2 & $\begin{array}{l}\text { Section } \\
6.2 .2 .7\end{array}$ & $\begin{array}{l}\text { The ASHPLUME code calculates } \\
\text { the waste and ash deposition } \\
\text { results }(\mathrm{g} / \mathrm{cm}) \text { at the RMEI location. } \\
\text { The TSPA-LA model then converts } \\
\text { the waste deposition at the RMEI } \\
\text { location back to the masses of the } \\
\text { individual radionuclide species and } \\
\text { allows for radioactive decay. }\end{array}$ & Data \\
\hline & $\begin{array}{l}\text { Section } \\
6.4 .2 .3\end{array}$ & $\begin{array}{l}\text { Section } \\
6.2 .2 .8\end{array}$ & $\begin{array}{l}\text { Ash redistribution calculations for a } \\
\text { probabiltiy-weighted volcanic event } \\
\text { are performed within TSPA-LA } \\
\text { using the SoilExp_LA DLL. }\end{array}$ & Data \\
\hline & $\begin{array}{l}\text { Section } \\
6.4 .2 .3\end{array}$ & $\begin{array}{l}\text { Section } \\
6.2 .2 .8\end{array}$ & $\begin{array}{l}\text { The TSPA model for the LA } \\
\text { calculates dose from exposure due } \\
\text { to inhalation, ingestion, and } \\
\text { external exposure and its impact } \\
\text { on the RMEI. }\end{array}$ & Data \\
\hline $\begin{array}{l}\text { BSC (Bechtel SAIC Company) } 2004 . \\
\text { Drip Shield Structural Response to } \\
\text { Rock Fall. 000-00C-SSE0-00300- } \\
\text { 000-00A. Las Vegas, Nevada: } \\
\text { Bechtel SAIC Company. } \\
\text { ACC: ENG.20040405.0019. } \\
168993\end{array}$ & Entire & $\begin{array}{l}\text { Section } \\
6.2 .1 .3\end{array}$ & $\begin{array}{l}\text { Calculations that address damage } \\
\text { to the drip shield from rockfall } \\
\text { impact }\end{array}$ & Data \\
\hline
\end{tabular}


Table A-1. Table of Direct Inputs for Included and Excluded Features, Events, and Processes (Continued)

\begin{tabular}{|c|c|c|c|c|}
\hline Document Source & $\begin{array}{l}\text { Citation } \\
\text { from } \\
\text { Source }\end{array}$ & $\begin{array}{l}\text { Direct } \\
\text { Use In }\end{array}$ & Description & $\begin{array}{c}\text { Input } \\
\text { Category }\end{array}$ \\
\hline \multirow{6}{*}{$\begin{array}{l}\text { BSC (Bechtel SAIC Company) } 2004 . \\
\text { Abstraction of Drift Seepage. MDL- } \\
\text { NBS-HS-000019, Rev. 01. } \\
\text { Las Vegas, Nevada: Bechtel SAIC } \\
\text { Company. } \\
169131 \\
\end{array}$} & Entire & Table 6-1 & Supporting report for included FEP & Data \\
\hline & $\begin{array}{l}\text { Section } \\
6.5 .1 .7\end{array}$ & $\begin{array}{l}\text { Section } \\
6.2 .2 .9\end{array}$ & $\begin{array}{l}\text { The seepage abstraction changes } \\
\text { in the case of an igneous event } \\
\text { because there is probably no } \\
\text { capillary barrier to seepage in } \\
\text { basalt-filled drifts. }\end{array}$ & Data \\
\hline & Section 6.3.1 & $\begin{array}{l}\text { Section } \\
6.2 .1 .6\end{array}$ & $\begin{array}{l}\text { Anticipated post-seismic changes } \\
\text { in the local in-drift environment } \\
\text { include an increase in seepage } \\
\text { mainly because of the larger size } \\
\text { and the different shape of } \\
\text { collapsed drifts. }\end{array}$ & Data \\
\hline & $\begin{array}{l}\text { Section } \\
6.4 .2 .4\end{array}$ & $\begin{array}{l}\text { Section } \\
6.2 .1 .6\end{array}$ & $\begin{array}{l}\text { Systematic seepage simulations } \\
\text { were conducted for the collapsed } \\
\text { drift case using a full set of } \\
\text { parametric variations of rock mass } \\
\text { parameters, including capillary } \\
\text { strength and percolation flux. } \\
\text { Seepage analyses using the } \\
\text { degraded drift profiles from the } \\
\text { 75th percentile and greatest- } \\
\text { degradation cases of the rockfall } \\
\text { analyses were performed. The } \\
\text { seepage response determined for } \\
\text { the nominal, circular drift profile is } \\
\text { used in the seismic scenario for } \\
\text { emplacement drifts in the } \\
\text { nonlithophysal rocks. }\end{array}$ & Data \\
\hline & \begin{tabular}{|l|} 
Section \\
6.4 .2 .4 .2
\end{tabular} & $\begin{array}{l}\text { Section } \\
6.2 .1 .6\end{array}$ & $\begin{array}{l}\text { The effects of local rockfall in } \\
\text { nonlithophysal zones and related } \\
\text { drift- shape changes are small. }\end{array}$ & Data \\
\hline & $\begin{array}{l}\text { Section } \\
6.5 .1 .5\end{array}$ & $\begin{array}{l}\text { Section } \\
6.2 .1 .6\end{array}$ & $\begin{array}{l}\text { The nominal seepage abstraction } \\
\text { currently includes an enhancement } \\
\text { factor of } 20 \% \text { to account for } \\
\text { uncertainties related to local } \\
\text { rockfall in the nonlithophysal units, } \\
\text { and this enhancement factor is } \\
\text { deemed adequate to address the } \\
\text { impact of local rockfall related to } \\
\text { seismic events. }\end{array}$ & Data \\
\hline $\begin{array}{l}\text { BSC (Bechtel SAIC Company) } 2004 . \\
\text { Seismic Consequence Abstraction. } \\
\text { MDL-WIS-PA-000003, Rev. } 01 . \\
\text { Las Vegas, Nevada: Bechtel SAIC } \\
\text { Company. } \\
169183\end{array}$ & \begin{tabular}{|l} 
Sections \\
$6.6 .1,6.6 .24$
\end{tabular} & $\begin{array}{l}\text { Section } \\
6.2 .1 .4\end{array}$ & $\begin{array}{l}\text { Impact energy for single and } \\
\text { multiple rock blocks and related } \\
\text { damage (lithophysal) and impact } \\
\text { energy nonlithophysal (rockfall and } \\
\text { drift collapse) }\end{array}$ & Data \\
\hline
\end{tabular}


Table A-1. Table of Direct Inputs for Included and Excluded Features, Events, and Processes (Continued)

\begin{tabular}{|c|c|c|c|c|}
\hline Document Source & $\begin{array}{l}\text { Citation } \\
\text { from } \\
\text { Source }\end{array}$ & $\begin{array}{l}\text { Direct } \\
\text { Use In }\end{array}$ & Description & $\begin{array}{c}\text { Input } \\
\text { Category }\end{array}$ \\
\hline & Section 6.5 .4 & $\begin{array}{l}\text { Section } \\
6.2 .1 .4\end{array}$ & $\begin{array}{l}\text { Since the damaged areas remain } \\
\text { physically intact, the most likely } \\
\text { damage mechanism affecting the } \\
\text { Titanium Grade } 7 \text { plates of the drip } \\
\text { shield is accelerated stress } \\
\text { corrosion cracking. Damage to the } \\
\text { drip shield from rockfall is } \\
\text { neglected for TSPA-LA }\end{array}$ & Data \\
\hline & $\begin{array}{l}\text { Section } \\
6.6 .1 .2 ; \\
\text { Table } 6.6-2\end{array}$ & $\begin{array}{l}\text { Section } \\
6.2 .1 .4\end{array}$ & $\begin{array}{l}\text { Example of the low consequence } \\
\text { that these small fragments have } \\
\text { upon impact with the drip shield } \\
\text { shows that a lithophysal rock } \\
\text { fragment kinetic energy does not } \\
\text { produce a failed area on the } \\
\text { surface of the drip shield } \\
\text { (lithophysal) }\end{array}$ & Data \\
\hline & Table 6.2-1 & $\begin{array}{l}\text { Sections } \\
6.2 .1 .2 \\
6.2 .1 .3 \\
6.2 .1 .6\end{array}$ & $\begin{array}{l}\text { General reference to basis for } \\
\text { inclusion }\end{array}$ & Data \\
\hline & Entire & $\begin{array}{l}\text { Sections } \\
6.2 .1 .2 \\
6.2 .1 .3 \\
6.2 .1 .6 \\
\text { Table 6-1 } \\
\end{array}$ & $\begin{array}{l}\text { General reference as supporting } \\
\text { document for included FEP }\end{array}$ & Data \\
\hline & Section 6.7.4 & $\begin{array}{l}\text { Section } \\
6.2 .1 .2\end{array}$ & $\begin{array}{l}\text { At mean annual exceedance } \\
\text { frequencies between } 10^{-7} \text { and } 10^{-8} \\
\text { per year, waste package failure } \\
\text { may occur for any of the waste } \\
\text { packages placed directly over } \\
\text { certain identified locations. The } \\
\text { probability of a fault displacement } \\
\text { event severe enough to cause } \\
\text { waste package failure is a function } \\
\text { of both the specific fault (different } \\
\text { fault displacements for a given } \\
\text { probability) as well as the specific } \\
\text { waste package design (different } \\
\text { allowable displacements). }\end{array}$ & Data \\
\hline & $\begin{array}{l}\text { Sections 6.7, } \\
6.7 .2\end{array}$ & $\begin{array}{l}\text { Section } \\
6.2 .1 .2\end{array}$ & $\begin{array}{l}\text { Fault displacement along block- } \\
\text { bounding and intra-block faults and } \\
\text { features could impact waste } \\
\text { packages mechanical damage } \\
\text { caused by the fault displacement }\end{array}$ & Data \\
\hline & $\begin{array}{l}\text { Section } \\
6.6 .1 .2\end{array}$ & $\begin{array}{l}\text { Sections } \\
6.2 .1 .4 \\
6.2 .1 .5\end{array}$ & $\begin{array}{l}\text { Impact energy for single and } \\
\text { multiple rock blocks and related } \\
\text { damage (lithophysal) and impact } \\
\text { energy and stress corrosion } \\
\text { cracking in nonlithophysal (rockfall) }\end{array}$ & Data \\
\hline & $\begin{array}{l}\text { Section } \\
6.6 .2 .1\end{array}$ & $\begin{array}{l}\text { Sections } \\
6.2 .1 .4 \\
6.2 .1 .5 \\
\end{array}$ & $\begin{array}{l}\text { Lithophysal rock fragments have } \\
\text { particle sizes on the order of } \\
\text { centimeters to decimeters. }\end{array}$ & Data \\
\hline
\end{tabular}


Table A-1. Table of Direct Inputs for Included and Excluded Features, Events, and Processes (Continued)

\begin{tabular}{|c|c|c|c|c|}
\hline Document Source & $\begin{array}{l}\text { Citation } \\
\text { from } \\
\text { Source }\end{array}$ & $\begin{array}{l}\text { Direct } \\
\text { Use In }\end{array}$ & Description & $\begin{array}{c}\text { Input } \\
\text { Category }\end{array}$ \\
\hline & $\begin{array}{l}\text { Sections } \\
6.7 .5,6.9 .2\end{array}$ & $\begin{array}{l}\text { Section } \\
6.2 .1 .2\end{array}$ & $\begin{array}{l}\text { Uniform distribution sampled to } \\
\text { develop abstraction for waste } \\
\text { packages hit, assumes lower bond } \\
\text { of } 0 \mathrm{~m}^{2} \text { and an upper bond equal to } \\
\text { the area of the waste package lid. } \\
\text { Allows advective and diffusive } \\
\text { transport out of the waste package } \\
\text { lid. }\end{array}$ & Data \\
\hline & Section 6.9.2 & $\begin{array}{l}\text { Sections } \\
6.2 .1 .2 \\
6.2 .1 .6\end{array}$ & $\begin{array}{l}\text { Fraction of failed surface area as a } \\
\text { function of waste-package-type } \\
\text { surface areas used in fault } \\
\text { displacement abstraction. } \\
\text { Seismically modified seepage is } \\
\text { explicitly included by modifying the } \\
\text { seepage flux in lithophysal zones } \\
\text { following seismic-induced drift } \\
\text { collapse. }\end{array}$ & Data \\
\hline & Section 5.1 & $\begin{array}{l}\text { Section } \\
6.2 .1 .3\end{array}$ & $\begin{array}{l}\text { No damage to waste package and } \\
\text { drip shield with horizontal peak } \\
\text { ground velocities (PGV) of } 0.190 \\
\mathrm{~m} / \mathrm{s} \text { and } 0.384 \mathrm{~m} / \mathrm{s}\end{array}$ & Data \\
\hline & $\begin{array}{l}\text { Sections } \\
6.7 .4,6.7 .5\end{array}$ & $\begin{array}{l}\text { Section } \\
6.2 .1 .2\end{array}$ & $\begin{array}{l}\text { Number of waste packages failed } \\
\text { based on correlation between } \\
\text { displacement exceedance } \\
\text { probabilities and expected number } \\
\text { of failures for representative waste } \\
\text { packages. }\end{array}$ & Data \\
\hline & Section 6.5 & $\begin{array}{l}\text { Section } \\
6.2 .1 .2\end{array}$ & $\begin{array}{l}\text { Total failed area from faulting } \\
\text { event is weighed sum of damage } \\
\text { to waste package groups. }\end{array}$ & Data \\
\hline & $\begin{array}{l}\text { Section } \\
6.5 .4 .1\end{array}$ & $\begin{array}{l}\text { Section } \\
6.2 .1 .3\end{array}$ & $\begin{array}{l}\text { Set of ground-motion time histories } \\
\text { identical with that used for } \\
\text { analyses of seismic rock fall and } \\
\text { waste package structural } \\
\text { response. }\end{array}$ & Data \\
\hline & $\begin{array}{l}\text { Section } \\
6.5 .7 .2\end{array}$ & $\begin{array}{l}\text { Section } \\
6.2 .1 .3\end{array}$ & $\begin{array}{l}\text { Most, if not all, fuel pins will fail } \\
\text { under vibratory ground motions at } \\
\text { the } 10^{-6} \text { per year and the } 10^{-7} \text { per } \\
\text { year levels. }\end{array}$ & Data \\
\hline & Section 6.7.5 & $\begin{array}{l}\text { Section } \\
6.2 .1 .2\end{array}$ & $\begin{array}{l}\text { A sheared drip shield will allow all } \\
\text { seepage to pass through it for } \\
\text { TSPA-LA. }\end{array}$ & Data \\
\hline & Section 6.3.2 & $\begin{array}{l}\text { Section } \\
6.2 .1 .3\end{array}$ & $\begin{array}{l}\text { Waste package damaged area } \\
\text { larger than effective area } \\
\text { susceptible to accelerated stress } \\
\text { corrosion cracking. }\end{array}$ & Data \\
\hline
\end{tabular}


Table A-1. Table of Direct Inputs for Included and Excluded Features, Events, and Processes (Continued)

\begin{tabular}{|c|c|c|c|c|}
\hline Document Source & $\begin{array}{l}\text { Citation } \\
\text { from } \\
\text { Source }\end{array}$ & $\begin{array}{l}\text { Direct } \\
\text { Use In }\end{array}$ & Description & $\begin{array}{c}\text { Input } \\
\text { Category }\end{array}$ \\
\hline & $\begin{array}{l}\text { Sections } \\
6.9 .1 .1,5.1\end{array}$ & $\begin{array}{l}\text { Section } \\
6.2 .1 .3\end{array}$ & $\begin{array}{l}\text { Response range assumed } 10^{-4} \text { and } \\
10^{-8} 1 / \mathrm{yr} \text { spans the response of the } \\
\text { system, from no damage at } 10^{-4} \\
\text { per year to the regulatory limit at } \\
10^{-8} \text { per year. Horizontal } \mathrm{PGV} \\
\text { value corresponding to the } 10^{-4} \text { per } \\
\text { year point on the hazard curve is } \\
0.0384 \mathrm{~m} / \mathrm{s}\end{array}$ & Data \\
\hline & Section 5.2 & $\begin{array}{l}\text { Section } \\
6.2 .1 .2\end{array}$ & $\begin{array}{l}\text { Fault displacement hazard for Drill } \\
\text { Hole Wash fault assumed to apply } \\
\text { to Pagany Wash fault and Sever } \\
\text { Wash fault. }\end{array}$ & Data \\
\hline & $\begin{array}{l}\text { Sections } \\
6.7 .1,6.7 .2 .1 \\
6.7 .4 ; \text { Tables } \\
6.7-5,6.7-8\end{array}$ & $\begin{array}{l}\text { Section } \\
6.2 .1 .2\end{array}$ & $\begin{array}{l}\text { Maximum allowable (vertical) fault } \\
\text { displacement compared to } \\
\text { clearance between waste package } \\
\text { and the drip shield. Comparison of } \\
\text { clearances considers waste } \\
\text { package group and collapsed or } \\
\text { uncollapsed drifts }\end{array}$ & Data \\
\hline & Section 6.7 .4 & $\begin{array}{l}\text { Section } \\
6.2 .1 .2\end{array}$ & $\begin{array}{l}\text { Analysis concludes no damage will } \\
\text { occur to waste package without } \\
\text { tunnel collapse. }\end{array}$ & Data \\
\hline & $\begin{array}{l}\text { Sections } \\
6.6 .1 .2 \text { and } \\
6.3 .6\end{array}$ & $\begin{array}{l}\text { Section } \\
6.2 .1 .4\end{array}$ & $\begin{array}{l}\text { Damage to the drip shield from } \\
\text { impact of individual rock blocks is } \\
\text { determined by structural response } \\
\text { calculations. Damage calculations } \\
\text { to drip shield areas use - residual } \\
\text { stress exceeds the threshold value } \\
\text { ( } 50 \text { percent of yield strength) for } \\
\text { Titanium Grade } 7\end{array}$ & Data \\
\hline & $\begin{array}{l}\text { Sections } 6.3 .1 \\
\text { and } 6.6 .1\end{array}$ & $\begin{array}{l}\text { Section } \\
6.2 .1 .4\end{array}$ & $\begin{array}{l}\text { Rock blocks have the potential to } \\
\text { result in immediate puncture or } \\
\text { tearing of the drip shield if the } \\
\text { localized strain exceeds the } \\
\text { ultimate tensile strain }\end{array}$ & Data \\
\hline & Section 6.7 .4 & $\begin{array}{l}\text { Section } \\
6.2 .1 .2\end{array}$ & $\begin{array}{l}\text { Fault displacement values in } \\
\text { Table } 6-2 \text { exceed the maximum } \\
\text { allowable displacements for the } \\
\text { binned waste types PWR, BWR, } \\
\text { Naval and high-level radioactive } \\
\text { waste }\end{array}$ & Data \\
\hline & Section 6.7 & $\begin{array}{l}\text { Section } \\
6.2 .1 .2\end{array}$ & $\begin{array}{l}\text { Fault displacement consequences } \\
\text { also includes pathway for seepage } \\
\text { to contact the waste packages }\end{array}$ & Data \\
\hline
\end{tabular}


Table A-1. Table of Direct Inputs for Included and Excluded Features, Events, and Processes (Continued)

\begin{tabular}{|c|c|c|c|c|}
\hline Document Source & $\begin{array}{l}\text { Citation } \\
\text { from } \\
\text { Source }\end{array}$ & $\begin{array}{l}\text { Direct } \\
\text { Use In }\end{array}$ & Description & $\begin{array}{c}\text { Input } \\
\text { Category }\end{array}$ \\
\hline & Section 6.7 & $\begin{array}{l}\text { Section } \\
6.2 .1 .2\end{array}$ & $\begin{array}{l}\text { Shearing is assumed to occur } \\
\text { perpendicular to the tunnel axis } \\
\text { with the displacement being purely } \\
\text { vertical }\end{array}$ & Data \\
\hline & $\begin{array}{l}\text { Section } \\
6.9 .1 .2\end{array}$ & $\begin{array}{l}\text { Section } \\
6.2 .1 .3\end{array}$ & $\begin{array}{l}\text { PGVh is the } 1 \mathrm{D} \text { look-up table } \\
\text { associated with mean annual } \\
\text { exceedance frequencies between } \\
10^{-4} \text { and } 10^{-8} 1 / y r \text { and PGV is the } \\
\text { bounding PGV distribution used to } \\
\text { calibrate results }\end{array}$ & Data \\
\hline & $\begin{array}{l}\text { Sections } \\
6.5 .1 .3,6.9 .2\end{array}$ & $\begin{array}{l}\text { Section } \\
6.2 .1 .3\end{array}$ & $\begin{array}{l}\text { Damage to the waste package is } \\
\text { applied to all waste packages in } \\
\text { the repository. The damage } \\
\text { abstraction for a waste package is } \\
\text { defined by a uniform distribution } \\
\text { with a lower bound of } 0 \text { percent } \\
\text { damaged area and an upper } \\
\text { bound that is a linear function of } \\
\text { PGV. }\end{array}$ & Data \\
\hline & $\begin{array}{l}\text { Sections } \\
6.5 .3,6.5 .7 \\
\text { and } 6.9 .2\end{array}$ & $\begin{array}{l}\text { Section } \\
6.2 .1 .3\end{array}$ & $\begin{array}{l}\text { Within the TSPA-LA, the degree of } \\
\text { ground motion damage is assumed } \\
\text { to apply to all waste packages and } \\
\text { CSNF cladding in the repository }\end{array}$ & Data \\
\hline & $\begin{array}{l}\text { Section } \\
6.5 .7 .3\end{array}$ & $\begin{array}{l}\text { Section } \\
6.2 .1 .3\end{array}$ & $\begin{array}{l}\text { There is no spatial variability in the } \\
\text { damage because damage to the } \\
\text { cladding occurs within all waste } \\
\text { packages }\end{array}$ & Data \\
\hline & $\begin{array}{l}\text { Section 6.7.4; } \\
\text { Table 6.7-9 }\end{array}$ & $\begin{array}{l}\text { Section } \\
6.2 .1 .2\end{array}$ & $\begin{array}{l}\text { Fault displacement hazard curves } \\
\text { are used to tabulate the predicted } \\
\text { fault displacement as a function of } \\
\text { probability of the event and the } \\
\text { resulting fault exceedance } \\
\text { probabilities that would cause } \\
\text { waste package failure. }\end{array}$ & Data \\
\hline & Section 6.8 & $\begin{array}{l}\text { Section } \\
6.2 .1 .6\end{array}$ & $\begin{array}{l}\text { Post-seismic changes in the local } \\
\text { in-drift environment in these zones } \\
\text { are implemented in TSPA-LA }\end{array}$ & Data \\
\hline & Section 6.8 .1 & $\begin{array}{l}\text { Section } \\
6.2 .1 .6\end{array}$ & $\begin{array}{l}\text { Abstraction modifies seepage flux } \\
\text { in lithophysal zones. The } 10^{-6} \\
\text { hazard level (PGV of } 2.0 \mathrm{~m} / \mathrm{s} \text { ) is } \\
\text { considered a more reasonable } \\
\text { threshold for drift collapse in the } \\
\text { lithophysal zones. }\end{array}$ & Data \\
\hline & $\begin{array}{l}\text { Sections } \\
6.7 .2 .1 \text { and } \\
6.7 .2 .2\end{array}$ & $\begin{array}{l}\text { Section } \\
6.2 .1 .2\end{array}$ & $\begin{array}{l}\text { Intrablock faults and features are } \\
\text { explicitly implemented within the } \\
\text { TSPA-LA as consequences from } \\
\text { damage to waste packages from } \\
\text { fault displacement. }\end{array}$ & Data \\
\hline
\end{tabular}


Table A-1. Table of Direct Inputs for Included and Excluded Features, Events, and Processes (Continued)

\begin{tabular}{|c|c|c|c|c|}
\hline Document Source & $\begin{array}{c}\begin{array}{c}\text { Citation } \\
\text { from } \\
\text { Source }\end{array} \\
\end{array}$ & $\begin{array}{l}\text { Direct } \\
\text { Use In }\end{array}$ & Description & $\begin{array}{c}\text { Input } \\
\text { Category }\end{array}$ \\
\hline & $\begin{array}{l}\text { Section } \\
6.7 .2 .1\end{array}$ & $\begin{array}{l}\text { Section } \\
6.2 .1 .2\end{array}$ & $\begin{array}{l}\text { The western splay off the Ghost } \\
\text { Dance fault intersects the } \\
\text { repository in a contingency area; } \\
\text { however, waste package } \\
\text { placement there is uncertain and is } \\
\text { also not considered in the analysis. }\end{array}$ & Data \\
\hline & $\begin{array}{l}\text { Sections } 6.7 .5 \\
\text { and 6.9.2 }\end{array}$ & $\begin{array}{l}\text { Section } \\
6.2 .1 .2\end{array}$ & $\begin{array}{l}\text { Cladding becomes } 100 \text { percent } \\
\text { perforated in response to a fault } \\
\text { displacement that can shear a } \\
\text { waste package. }\end{array}$ & Data \\
\hline & Table 6.7-5 & Table 6-2 & Mean displacement values & Data \\
\hline & Section 4.1 & $\begin{array}{l}\text { Section } \\
6.2 .1 .3\end{array}$ & $\begin{array}{l}\text { PGV of } 2.44 \mathrm{~m} / \mathrm{s} \text { corresponds to } \\
\text { the } 10^{-6} \text { per year exceedance } \\
\text { frequency. PGV of } 5.35 \mathrm{~m} / \mathrm{s} \\
\text { corresponds to the } 10^{-7} \text { per year } \\
\text { exceedance frequency }\end{array}$ & Data \\
\hline & $\begin{array}{l}\text { Section } \\
6.5 .7 .2\end{array}$ & $\begin{array}{l}\text { Section } \\
6.2 .1 .3\end{array}$ & $\begin{array}{l}\text { To address the potential for } \\
\text { damage at } 1.05 \mathrm{~m} / \mathrm{s}\left(10^{-5}\right) \text {, the } \\
\text { TSPA-LA conservatively assumes } \\
\text { cladding damage }\end{array}$ & Data \\
\hline & Section 6.5 .5 & $\begin{array}{l}\text { Section } \\
6.2 .1 .3\end{array}$ & $\begin{array}{l}\text { Drip shield separation is excluded } \\
\text { from TSPA-LA because (1) ground } \\
\text { motion amplitudes that are } \\
\text { sufficient to cause drip shield } \\
\text { separation are also large enough } \\
\text { to partially or completely collapse } \\
\text { drifts in the repository, and (2) } \\
\text { rockfall occurs within the first } \\
\text { second or two of the arrival of } \\
\text { these large amplitude ground } \\
\text { motion. In this situation, rockfall } \\
\text { provides restraints on the motion of } \\
\text { the drip shields, preventing } \\
\text { differential motion that could lead } \\
\text { to separation }\end{array}$ & Data \\
\hline & Entire & $\begin{array}{l}\text { Section } \\
6.2 .1 .3\end{array}$ & $\begin{array}{l}\text { Used structural response } \\
\text { calculations for the waste package } \\
\text { and drip shield as the basis for } \\
\text { predicting failed areas for } \\
\text { advective flow and transport }\end{array}$ & Data \\
\hline & Section 6.8 .1 & $\begin{array}{l}\text { Section } \\
6.2 .1 .6\end{array}$ & $\begin{array}{l}\text { Modified seepage is determined by } \\
\text { using degraded drift seepage } \\
\text { response surfaces in the form of } \\
\text { look-up tables for lithophysal rock } \\
\text { units }\end{array}$ & Data \\
\hline & $\begin{array}{l}\text { Sections 6.8, } \\
6.9 .2\end{array}$ & $\begin{array}{l}\text { Section } \\
6.2 .1 .6\end{array}$ & $\begin{array}{l}\text { Within the TSPA-LA, additional } \\
\text { TSPA submodels address } \\
\text { attendant effects on engineered } \\
\text { barrier system flow }\end{array}$ & Data \\
\hline & Section 6.7.3 & $\begin{array}{l}\text { Section } \\
6.2 .1 .2\end{array}$ & $\begin{array}{l}\text { Ghost Dance fault not considered } \\
\text { in TSPA. }\end{array}$ & Data \\
\hline
\end{tabular}


Table A-1. Table of Direct Inputs for Included and Excluded Features, Events, and Processes (Continued)

\begin{tabular}{|c|c|c|c|c|}
\hline Document Source & $\begin{array}{l}\text { Citation } \\
\text { from } \\
\text { Source }\end{array}$ & $\begin{array}{l}\text { Direct } \\
\text { Use In }\end{array}$ & Description & $\begin{array}{c}\text { Input } \\
\text { Category }\end{array}$ \\
\hline & $\begin{array}{l}\text { Section } \\
6.7 .2 .2\end{array}$ & $\begin{array}{l}\text { Section } \\
6.2 .1 .2\end{array}$ & $\begin{array}{l}\text { For faulting at locations other than } \\
\text { at known faults, studies determine } \\
\text { that } 119.85 \text { small fault } \\
\text { intersections occur within drifts in } \\
\text { lithophysal zones and } 21.15 \text { small } \\
\text { fault intersections occur within } \\
\text { drifts in nonlithophysal zones. This } \\
\text { analysis is based on a study that } \\
\text { quantified the likelihood of such } \\
\text { smaller faults to intersect the } \\
\text { emplacement drifts. }\end{array}$ & Data \\
\hline & Section 6.8.3 & $\begin{array}{l}\text { Section } \\
6.2 .1 .5\end{array}$ & $\begin{array}{l}\text { In general, in nonlithophysal rock, } \\
\text { rockfall volumes are sufficient to } \\
\text { accumulate rock blocks adjacent to } \\
\text { the drip shield; however, seismic } \\
\text { shaking is not predicted to result in } \\
\text { complete collapse of the drift. }\end{array}$ & Data \\
\hline & Section 6.5 .4 & $\begin{array}{l}\text { Section } \\
6.2 .1 .5\end{array}$ & $\begin{array}{l}\text { Ground motion amplitudes } \\
\text { sufficient to separate drip shields } \\
\text { are large enough to partially or } \\
\text { completely collapse drifts in both } \\
\text { lithophysal or nonlithophysal zones } \\
\text { of the repository. The presence of } \\
\text { even small frictional or gravitational } \\
\text { loads has been shown to restrain } \\
\text { the relative motion between } \\
\text { adjacent drip shields. }\end{array}$ & Data \\
\hline & $\begin{array}{l}\text { Sections } \\
6.1 .3,6.4 .4\end{array}$ & $\begin{array}{l}\text { Section } \\
6.2 .1 .3\end{array}$ & $\begin{array}{l}\text { Site-specific ground motions used } \\
\text { to assess postclosure analyses of } \\
\text { damage to EBS components. }\end{array}$ & Data \\
\hline & $\begin{array}{l}\text { Tables 4-1, } \\
6.1-1\end{array}$ & $\begin{array}{l}\text { Section } \\
6.1 .2\end{array}$ & $\begin{array}{l}\text { For postclosure evaluation of fault- } \\
\text { displacement and seismic FEPs } \\
\text { requiring ground motion inputs, the } \\
\text { FEP screening statements are } \\
\text { applied based on the mean value } \\
\text { of the event at an annual- } \\
\text { exceedance probability of } 10^{-8} \text {. }\end{array}$ & Data \\
\hline & $\begin{array}{l}\text { Section } \\
6.6 .1 .2\end{array}$ & $\begin{array}{l}\text { Section } \\
6.2 .1 .5\end{array}$ & $\begin{array}{l}\text { Structural response calculations of } \\
\text { damage to the drip shield from the } \\
\text { impact of individual rock blocks } \\
\text { model six representative rock } \\
\text { blocks, ranging in weight from } 0.11 \\
\text { MT to } 14.5 \text { MT. }\end{array}$ & Data \\
\hline & Section 6.8 .1 & $\begin{array}{l}\text { Section } \\
6.2 .1 .6\end{array}$ & $\begin{array}{l}\text { There is no explicit change in the } \\
\text { seepage flux into the emplacement } \\
\text { drifts in nonlithophysal zones. }\end{array}$ & Data \\
\hline & Section 6.8 .1 & $\begin{array}{l}\text { Section } \\
6.2 .1 .6\end{array}$ & $\begin{array}{l}\text { A threshold temperature of } 100 \\
\text { degrees } C \text { is based on a sensitivity } \\
\text { study of seepage arrival times at } \\
\text { the drip shield crown for a } \\
\text { collapsed drift that is filled with } \\
\text { rubble. }\end{array}$ & Data \\
\hline
\end{tabular}


Table A-1. Table of Direct Inputs for Included and Excluded Features, Events, and Processes (Continued)

\begin{tabular}{|c|c|c|c|c|}
\hline Document Source & $\begin{array}{c}\text { Citation } \\
\text { from } \\
\text { Source }\end{array}$ & $\begin{array}{l}\text { Direct } \\
\text { Use In }\end{array}$ & Description & $\begin{array}{c}\text { Input } \\
\text { Category }\end{array}$ \\
\hline & $\begin{array}{l}\text { Section } 6.9 .2 \\
\text { Number } 14\end{array}$ & $\begin{array}{l}\text { Section } \\
6.2 .1 .6\end{array}$ & $\begin{array}{l}\text { Temperature and relative humidity } \\
\text { affecting the waste packages after } \\
\text { drift collapse in the lithophysal } \\
\text { zones is implemented in TSPA at } \\
\text { all ground motions with a PGV } \\
\text { greater than } 0.384 \mathrm{~m} / \mathrm{s} \text {. }\end{array}$ & Data \\
\hline & Section 6.8 .3 & $\begin{array}{l}\text { Section } \\
6.2 .1 .6\end{array}$ & $\begin{array}{l}\text { The temperature and relative } \\
\text { humidity of the waste package } \\
\text { after drift collapse are defined by } \\
\text { the calculations with the multiscale } \\
\text { thermohydrologic model. }\end{array}$ & Data \\
\hline $\begin{array}{l}\text { BSC (Bechtel SAIC Company) } 2004 . \\
\text { Dissolved Concentration Limits of } \\
\text { Radioactive Elements. ANL-WIS-MD- } \\
000010, \text { Rev. 03. Las Vegas, } \\
\text { Nevada: Bechtel SAIC Company. } \\
169425\end{array}$ & Entire & $\begin{array}{l}\text { Section } \\
6.2 .2 .4\end{array}$ & $\begin{array}{l}\text { Use the solubility look-up table in } \\
\text { TSPA implementation. }\end{array}$ & Data \\
\hline $\begin{array}{l}\text { BSC (Bechtel SAIC Company) } 2004 . \\
\text { Multiscale Thermohydrologic Model. } \\
\text { ANL-EBS-MD-000049, Rev. } 02 . \\
\text { Las Vegas, Nevada: Bechtel SAIC } \\
\text { Company. } \\
169565\end{array}$ & Entire & $\begin{array}{l}\text { Section } \\
6.2 .1 .6 ; \\
\text { Table 6-1 }\end{array}$ & $\begin{array}{l}\text { Supporting document for included } \\
\text { FEP }\end{array}$ & Data \\
\hline \multirow[t]{3}{*}{$\begin{array}{l}\text { BSC (Bechtel SAIC Company) } 2004 . \\
\text { Mechanical Assessment of the Drip } \\
\text { Shield Subject to Vibratory Motion } \\
\text { and Dynamic and Static Rock } \\
\text { Loading. CAL-WIS-AC-000002 REV } \\
\text { 00. Las Vegas, Nevada: Bechtel } \\
\text { SAIC Company. } \\
169753\end{array}$} & Entire & $\begin{array}{l}\text { Section } \\
6.2 .1 .3\end{array}$ & $\begin{array}{l}\text { Calculations of the waste package } \\
\text { and cladding damage resulting } \\
\text { from vibratory motion are } \\
\text { summarized; used structural } \\
\text { response calculations for the waste } \\
\text { package and drip shield as the } \\
\text { basis for predicting failed areas for } \\
\text { advective flow and transport. } \\
\text { Consideration of the timing and } \\
\text { effects of seismic-induced drift } \\
\text { collapse and rock fall to potential } \\
\text { drip shield separation is done. }\end{array}$ & Data \\
\hline & Entire & $\begin{array}{l}\text { Section } \\
6.2 .1 .3 ; \\
\text { Table 6-1 }\end{array}$ & $\begin{array}{l}\text { Supporting report for included } \\
\text { FEP. }\end{array}$ & Data \\
\hline & Entire & $\begin{array}{l}\text { Section } \\
6.2 .1 .5\end{array}$ & $\begin{array}{l}\text { Higher probability (e.g., } 10^{-5} \text { ) } \\
\text { events are more likely than single, } \\
\text { lower probability (e.g., } 10^{-7} \text { ) events, } \\
\text { suggesting drift will be filled prior to } \\
\text { an extreme, more unlikely seismic } \\
\text { event. Significant rubble is } \\
\text { expected in the drift to confine the } \\
\text { drip shield prior to the occurrence } \\
\text { of an extreme event that would } \\
\text { result in drip shield displacement. }\end{array}$ & Data \\
\hline
\end{tabular}


Table A-1. Table of Direct Inputs for Included and Excluded Features, Events, and Processes (Continued)

\begin{tabular}{|c|c|c|c|c|}
\hline Document Source & $\begin{array}{c}\text { Citation } \\
\text { from } \\
\text { Source }\end{array}$ & $\begin{array}{l}\text { Direct } \\
\text { Use In }\end{array}$ & Description & $\begin{array}{c}\text { Input } \\
\text { Category }\end{array}$ \\
\hline & Entire & $\begin{array}{l}\text { Section } \\
6.2 .1 .3\end{array}$ & $\begin{array}{l}\text { Damage to drip shield from } \\
\text { vibratory ground motion is } \\
\text { determined by structural response } \\
\text { calculations that consider seismic- } \\
\text { induced rockfall and seismic- } \\
\text { induced drift collapse. }\end{array}$ & Data \\
\hline & Section 5.3 .3 & $\begin{array}{l}\text { Sections } \\
6.2 .1 .3 \\
6.2 .1 .5\end{array}$ & $\begin{array}{l}\text { Idealized dynamic kinematic } \\
\text { analyses of a large number of } \\
\text { interlocked drip shields subjected } \\
\text { to selected ground motion time } \\
\text { histories with PGV of } 2.44 \mathrm{~m} / \mathrm{s} \text { and } \\
5.35 \mathrm{~m} / \mathrm{sec} \text { were completed. These } \\
\text { analyses show that the weight or } \\
\text { frictional resistance of rubble } \\
\text { against the drip shield completely } \\
\text { prevents separation, even at } \\
\text { ground motions representative of } \\
\text { annual exceedance frequency of } \\
1 \times 10^{-7} \text { per year, or } 5.35 \mathrm{~m} / \mathrm{sec} \\
\text { PGV level. }\end{array}$ & Data \\
\hline & Entire & $\begin{array}{l}\text { Section } \\
6.2 .1 .3\end{array}$ & $\begin{array}{l}\text { Calculations of the waste package } \\
\text { and cladding damage resulting } \\
\text { from vibratory motion are } \\
\text { summarized; used structural } \\
\text { response calculations for the waste } \\
\text { package and drip shield as the } \\
\text { basis for predicting failed areas for } \\
\text { advective flow and transport. } \\
\text { Consideration of the timing and } \\
\text { effects of seismic-induced drift } \\
\text { collapse and rock fall to potential } \\
\text { drip shield separation is done. }\end{array}$ & Data \\
\hline & Section 5.4 .3 & $\begin{array}{l}\text { Section } \\
6.2 .1 .5\end{array}$ & $\begin{array}{l}\text { Six realizations of the collapse } \\
\text { response and loading to the drip } \\
\text { shield structure were conducted } \\
\text { and used as input to a three- } \\
\text { dimensional finite element } \\
\text { structural analysis of the drip } \\
\text { shield. }\end{array}$ & Data \\
\hline & Section 5.4 .3 & $\begin{array}{l}\text { Section } \\
6.2 .1 .5\end{array}$ & $\begin{array}{l}\text { The average vertical load that } \\
\text { results in excessive plastic } \\
\text { deformation is approximately } 3.25 \\
\text { times the average vertical pressure } \\
\text { from the six collapse realizations } \\
\text { described above. }\end{array}$ & Data \\
\hline $\begin{array}{l}\text { BSC (Bechtel SAIC Company) } 2004 . \\
\text { Drift Scale THM Model. MDL-NBS- } \\
\text { HS-000017, Rev. 01. Las Vegas, } \\
\text { Nevada: Bechtel SAIC Company. } \\
169864\end{array}$ & Entire & $\begin{array}{l}\text { Section } \\
6.2 .1 .9\end{array}$ & $\begin{array}{l}\text { The effects of thermal stress are } \\
\text { evaluated in terms of changes to } \\
\text { rock fracture properties, but not } \\
\text { rock matrix, implicitly recognizing } \\
\text { the negligible impact of stress- } \\
\text { induced changes on rock matrix. }\end{array}$ & Data \\
\hline
\end{tabular}


Table A-1. Table of Direct Inputs for Included and Excluded Features, Events, and Processes (Continued)

\begin{tabular}{|c|c|c|c|c|}
\hline Document Source & $\begin{array}{l}\text { Citation } \\
\text { from } \\
\text { Source }\end{array}$ & $\begin{array}{l}\text { Direct } \\
\text { Use In }\end{array}$ & Description & $\begin{array}{c}\text { Input } \\
\text { Category }\end{array}$ \\
\hline $\begin{array}{l}\text { BSC (Bechtel SAIC Company) } 2004 . \\
\text { Engineered Barrier System Features, } \\
\text { Events, and Processes. ANL-WIS- } \\
\text { PA-000002, Rev. 03. Las Vegas, } \\
\text { Nevada: Bechtel SAIC Company. } \\
169898\end{array}$ & Entire & $\begin{array}{l}\text { Sections } \\
6.2 .1 .2 \\
6.2 .1 .3 \\
6.2 .1 .6\end{array}$ & $\begin{array}{l}\text { Fault displacement - shared FEP } \\
\text { seismic consequence fault } \\
\text { displacement and ground motion. }\end{array}$ & Data \\
\hline \multirow{8}{*}{$\begin{array}{l}\text { BSC (Bechtel SAIC Company) } 2004 . \\
\text { Characterize Eruptive Processes at } \\
\text { Yucca Mountain, Nevada. ANL-MGR- } \\
\text { GS-000002, Rev. 02. Las Vegas, } \\
\text { Nevada: Bechtel SAIC Company. } \\
169980\end{array}$} & Table 7-1 & $\begin{array}{l}\text { Section } \\
6.2 .2 .7\end{array}$ & $\begin{array}{l}\text { Summary of parameters and } \\
\text { distributions for the analysis }\end{array}$ & Data \\
\hline & Table 6-1 & $\begin{array}{l}\text { Sections } \\
6.2 .2 .2 \\
6.2 .2 .3 \\
6.2 .2 .6 \\
6.2 .2 .7 \\
6.2 .2 .8 \\
\end{array}$ & $\begin{array}{l}\text { General reference to justification } \\
\text { for inclusion of FEP }\end{array}$ & Data \\
\hline & Entire & \begin{tabular}{|l} 
Sections \\
6.2 .1 .7 \\
6.2 .2 .2$, \\
6.2 .2 .3$, \\
6.2 .2 .5 \\
6.2 .2 .6 \\
6.2 .2 .7 \\
$6.2 .2 .8 ;$ \\
Table 6-1 \\
\end{tabular} & $\begin{array}{l}\text { General reference to the analysis } \\
\text { as a supporting document for } \\
\text { included FEP }\end{array}$ & Data \\
\hline & Section 6.5 & $\begin{array}{l}\text { Sections } \\
6.2 .2 .7 \\
6.2 .2 .8\end{array}$ & $\begin{array}{l}\text { Includes the results of field } \\
\text { investigations and presents the } \\
\text { detailed conceptual and technical } \\
\text { basis for the ash redistribution } \\
\text { model }\end{array}$ & Data \\
\hline & Section 6 & $\begin{array}{l}\text { Sections } \\
6.2 .2 .2 \\
6.2 .2 .3 \\
6.2 .2 .6 \\
6.2 .2 .7 \\
\end{array}$ & $\begin{array}{l}\text { General reference to analyses and } \\
\text { field observations pertinent to } \\
\text { basaltic eruptions, and to } \\
\text { properties and characteristics of } \\
\text { basaltic magma }\end{array}$ & Data \\
\hline & $\begin{array}{l}\text { Section } \\
6.3 .1 .3\end{array}$ & $\begin{array}{l}\text { Section } \\
6.2 .1 .7\end{array}$ & $\begin{array}{l}\text { Dike length distribution used by the } \\
\text { PVHA used as a proxy for surface- } \\
\text { fault lengths to calculate maximum } \\
\text { magnitudes of dike-induced } \\
\text { earthquakes }\end{array}$ & Data \\
\hline & $\begin{array}{l}\text { Appendix } \\
\text { C3.3 }\end{array}$ & $\begin{array}{l}\text { Section } \\
6.2 .2 .5\end{array}$ & $\begin{array}{l}\text { A detailed description of } \\
\text { hydrovolcanic or pyroclastic surge } \\
\text { deposits at the Lathrop Wells } \\
\text { volcano. }\end{array}$ & Data \\
\hline & Entire & $\begin{array}{l}\text { Section } \\
6.2 .2 .3\end{array}$ & $\begin{array}{l}\text { General reference that output is } \\
\text { used to assess the number of } \\
\text { waste packages exposed to Zone } \\
1 \text { (intersected drifts) magmatic } \\
\text { environment }\end{array}$ & Data \\
\hline
\end{tabular}


Table A-1. Table of Direct Inputs for Included and Excluded Features, Events, and Processes (Continued)

\begin{tabular}{|c|c|c|c|c|}
\hline Document Source & $\begin{array}{l}\text { Citation } \\
\text { from } \\
\text { Source }\end{array}$ & $\begin{array}{l}\text { Direct } \\
\text { Use In }\end{array}$ & Description & $\begin{array}{c}\text { Input } \\
\text { Category }\end{array}$ \\
\hline & $\begin{array}{l}\text { Section } \\
\text { 6.1.3.2 } \\
\end{array}$ & $\begin{array}{l}\text { Section } \\
6.2 .2 .5 \\
\end{array}$ & $\begin{array}{l}\text { Definition of hydrovolcanic eruption } \\
\text { process }\end{array}$ & Data \\
\hline & $\begin{array}{l}\text { Appendix } \\
\text { C2.1 }\end{array}$ & $\begin{array}{l}\text { Section } \\
6.2 .2 .5\end{array}$ & $\begin{array}{l}\text { Evidence of a brief hydrovolcanic } \\
\text { event late in the cone-building } \\
\text { history of Lathrop Wells volcano }\end{array}$ & Data \\
\hline \multirow{9}{*}{$\begin{array}{l}\text { BSC (Bechtel SAIC Company) } 2004 . \\
\text { Characterize Framework for lgneous } \\
\text { Activity at Yucca Mountain, Nevada. } \\
\text { ANL-MGR-GS-000001, Rev. 02. } \\
\text { Las Vegas, Nevada: Bechtel SAIC } \\
\text { Company. } \\
169989\end{array}$} & Section 6.3 .2 & $\begin{array}{l}\text { Sections } \\
6.2 .2 .1 \\
6.2 .2 .9\end{array}$ & $\begin{array}{l}\text { The aggregate dike-length } \\
\text { distribution derived from the PVHA } \\
\text { has a mean value of } 4.0 \mathrm{~km} \text {, and } \\
\text { the most commonly assigned dike } \\
\text { orientation centers on } \mathrm{N} 30^{\circ} \mathrm{E} \text {. }\end{array}$ & Data \\
\hline & $\begin{array}{l}\text { Sections } \\
6.1 .1 .1 \\
6.4 .1 .1 \\
\end{array}$ & $\begin{array}{l}\text { Section } \\
6.2 .1 .1\end{array}$ & $\begin{array}{l}\text { Description of fault blocks and their } \\
\text { formation in Yucca Mountain } \\
\text { region. }\end{array}$ & Data \\
\hline & Table 6-1 & $\begin{array}{l}\text { Sections } \\
6.2 .2 .2 \\
6.2 .2 .3 \\
6.2 .2 .6 \\
\end{array}$ & $\begin{array}{l}\text { Direct input source for inclusion of } \\
\text { FEP 1.2.04.03.0A. }\end{array}$ & Data \\
\hline & Entire & $\begin{array}{l}\text { Sections } \\
6.2 .2 .2 \\
6.2 .2 .3 \\
6.2 .2 .6 \\
6.2 .2 .8 \\
\text { Table } 6-1 \\
\end{array}$ & $\begin{array}{l}\text { General reference as basis for } \\
\text { inclusion of FEP as supporting } \\
\text { analysis report. }\end{array}$ & Data \\
\hline & Entire & $\begin{array}{l}\text { Sections } \\
6.2 .1 .1 \\
6.2 .2 .1 \\
6.2 .2 .3 \\
6.2 .2 .6 \\
6.2 .2 .7 \\
6.2 .2 .8 \\
6.2 .2 .9 \\
\end{array}$ & $\begin{array}{l}\text { General reference to the analysis } \\
\text { report, which presents probability } \\
\text { distributions for length and } \\
\text { orientation of dikes. }\end{array}$ & Data \\
\hline & Table 6-21 & $\begin{array}{l}\text { Sections } \\
6.2 .2 .2 \\
6.2 .2 .3 \\
6.2 .2 .5 \\
6.2 .2 .6 \\
6.2 .2 .7 \\
6.2 .2 .8 \\
\end{array}$ & $\begin{array}{l}\text { Probability of igneous intrusion and } \\
\text { probability of eruptive center } \\
\text { forming within the repository } \\
\text { footprint }\end{array}$ & Data \\
\hline & Section 6.2 & $\begin{array}{l}\text { Sections } \\
6.2 .2 .1 \text { and } \\
6.2 .2 .9\end{array}$ & $\begin{array}{l}\text { Probabilistic distribution of dikes } \\
\text { and Paiute Ridge }\end{array}$ & Data \\
\hline & $\begin{array}{l}\text { Section } \\
6.3 .2 .1\end{array}$ & $\begin{array}{l}\text { Sections } \\
6.2 .2 .1 \text { and } \\
6.2 .2 .9 \\
\end{array}$ & $\begin{array}{l}\text { Paiute Ridge as natural analogue } \\
\text { to assess change in rock } \\
\text { properties }\end{array}$ & Data \\
\hline & Section 6.2 & $\begin{array}{l}\text { Section } \\
6.2 .2 .5\end{array}$ & $\begin{array}{l}\text { Extent and volume of lava flows } \\
\text { from the surrounding Quaternary } \\
\text { basaltic volcanoes }\end{array}$ & Data \\
\hline
\end{tabular}


Table A-1. Table of Direct Inputs for Included and Excluded Features, Events, and Processes (Continued)

\begin{tabular}{|c|c|c|c|c|}
\hline Document Source & $\begin{array}{l}\text { Citation } \\
\text { from } \\
\text { Source }\end{array}$ & $\begin{array}{l}\text { Direct } \\
\text { Use In }\end{array}$ & Description & $\begin{array}{c}\text { Input } \\
\text { Category }\end{array}$ \\
\hline & $\begin{array}{l}\text { Section } \\
6.3 .1 .3\end{array}$ & $\begin{array}{l}\text { Section } \\
6.2 .1 .1\end{array}$ & $\begin{array}{l}\text { PVHA experts incorporated the } \\
\text { possibility that volcanic events are } \\
\text { clustered in time or to describe the } \\
\text { possible waning or waxing of } \\
\text { volcanic activity in the region }\end{array}$ & Data \\
\hline \multirow[t]{6}{*}{$\begin{array}{l}\text { BSC (Bechtel SAIC Company) } 2004 . \\
\text { Number of Waste Packages Hit by } \\
\text { Igneous Intrusion. ANL-MGR-GS- } \\
000003, \text { Rev. 01. Las Vegas, } \\
\text { Nevada: Bechtel SAIC Company. } \\
170001\end{array}$} & Section 6.4 & $\begin{array}{l}\text { Section } \\
6.2 .2 .6\end{array}$ & $\begin{array}{l}\text { For the volcanic eruption modeling } \\
\text { case, a CDF is sampled to } \\
\text { calculate the number of waste } \\
\text { packages hit by eruptive conduits } \\
\text { in a TSPA realization. }\end{array}$ & Data \\
\hline & Section 6.3.4 & $\begin{array}{l}\text { Section } \\
6.2 .2 .3\end{array}$ & $\begin{array}{l}\text { The number of waste packages hit } \\
\text { analysis results include CDFs for } \\
\text { the number of waste packages } \\
\text { impacted in an igneous intrusion } \\
\text { scenario and in an eruptive release } \\
\text { scenario. }\end{array}$ & Data \\
\hline & Table 6-1 & $\begin{array}{l}\text { Sections } \\
6.2 .2 .3 \\
6.2 .2 .6 \\
\end{array}$ & $\begin{array}{l}\text { Table of included FEPS in the } \\
\text { document: basis for inclusion. }\end{array}$ & Data \\
\hline & Entire & $\begin{array}{l}\text { Sections } \\
6.2 .2 .2 \\
6.2 .2 .3 \\
6.2 .2 .6 \\
\text { Table 6-1 }\end{array}$ & $\begin{array}{l}\text { General reference to the analysis } \\
\text { as supporting the included FEP. }\end{array}$ & Data \\
\hline & Section 6.3 & $\begin{array}{l}\text { Section } \\
6.2 .2 .2\end{array}$ & $\begin{array}{l}\text { For each TSPA realization, a CDF } \\
\text { is sampled to determine the } \\
\text { number of destroyed waste } \\
\text { packages to use as the source } \\
\text { term. The CDF is based on a } \\
\text { series of } 3000 \text { realizations of dike } \\
\text { swarm configurations that could } \\
\text { intersect the repository, a TSPA- } \\
\text { LA assumption that all waste } \\
\text { packages in an intersected drift are } \\
\text { compromised, and on a magma } \\
\text { bulkhead analysis that concludes } \\
\text { that magma is contained within an } \\
\text { intersected drift. }\end{array}$ & Data \\
\hline & Entire & $\begin{array}{l}\text { Sections } \\
6.2 .2 .2 \\
6.2 .2 .3 \\
6.2 .2 .6\end{array}$ & $\begin{array}{l}\text { General reference to the analysis } \\
\text { of number of waste package hit by } \\
\text { igneous intrusion or eruptive event. }\end{array}$ & Data \\
\hline
\end{tabular}


Table A-1. Table of Direct Inputs for Included and Excluded Features, Events, and Processes (Continued)

\begin{tabular}{|c|c|c|c|c|}
\hline Document Source & $\begin{array}{l}\text { Citation } \\
\text { from } \\
\text { Source } \\
\end{array}$ & $\begin{array}{l}\text { Direct } \\
\text { Use In }\end{array}$ & Description & $\begin{array}{c}\text { Input } \\
\text { Category }\end{array}$ \\
\hline \multirow[t]{5}{*}{$\begin{array}{l}\text { BSC (Bechtel SAIC Company) } 2004 . \\
\text { Features, Events, and Processes in } \\
\text { UZ Flow and Transport. ANL-NBS- } \\
\text { MD-000001, Rev. 03. Las Vegas, } \\
\text { Nevada: Bechtel SAIC Company. } \\
170012\end{array}$} & Appendix D & $\begin{array}{l}\text { Sections } \\
6.2 .1 .1 \\
6.2 .1 .8 \\
6.2 .1 .10 \\
6.2 .1 .11 \\
6.2 .2 .1\end{array}$ & $\begin{array}{l}\text { Effect of increased fracture } \\
\text { aperture on percolation flux on UZ } \\
\text { domain scale is negligible } \\
\text { compared to infiltration uncertainty. } \\
\text { The results also show that fracture } \\
\text { aperture changed confined to fault } \\
\text { zones result in virtually no effect on } \\
\text { transport behavior in the UZ. } \\
\text { Changes in fault and fracture } \\
\text { properties due to igneous activity } \\
\text { (i.e., activation, creation, and } \\
\text { sealing of faults and fractures) are } \\
\text { also judged to be of negligible } \\
\text { impact. }\end{array}$ & Data \\
\hline & Section 6.8 .8 & $\begin{array}{l}\text { Section } \\
6.2 .1 .12\end{array}$ & $\begin{array}{l}\text { The UZ flow model shows that the } \\
\text { volume of perched water in the } \\
\text { high-permeability fracture domain } \\
\text { below the repository only ranges } \\
\text { from about } 466 \mathrm{~m}^{3} \text { to } 1,190 \mathrm{~m}^{3} \text {. }\end{array}$ & Data \\
\hline & Section 6.7.5 & $\begin{array}{l}\text { Section } \\
6.2 .1 .9\end{array}$ & $\begin{array}{l}\text { Changes to the rock matrix } \\
\text { porosity and permeability caused } \\
\text { by changes in rock stress are } \\
\text { negligible compared with changes } \\
\text { to the fracture porosity and } \\
\text { permeability }\end{array}$ & Data \\
\hline & Section 6.7.8 & $\begin{array}{l}\text { Section } \\
6.2 .1 .12\end{array}$ & $\begin{array}{l}\text { Perched water zones below the } \\
\text { elevation of the repository have } \\
\text { been found in site characterization } \\
\text { boreholes. }\end{array}$ & Data \\
\hline & Appendix A & $\begin{array}{l}\text { Section } \\
6.2 .1 .12 \\
\end{array}$ & $\begin{array}{l}\text { Perched water zone volume } \\
\text { calculation. }\end{array}$ & Data \\
\hline \multirow{2}{*}{$\begin{array}{l}\text { BSC (Bechtel SAIC Company) } 2004 . \\
\text { Atmospheric Dispersal and } \\
\text { Deposition of Tephra from a Potential } \\
\text { Volcanic Eruption at Yucca Mountain, } \\
\text { Nevada. MDL-MGR-GS-000002, } \\
\text { Rev. 01. Las Vegas, Nevada: Bechtel } \\
\text { SAIC Company. } \\
170026 \\
\end{array}$} & $\begin{array}{l}\text { Sections } 1.0 \\
\text { and } 6.5 .2\end{array}$ & $\begin{array}{l}\text { Section } \\
6.2 .2 .6\end{array}$ & $\begin{array}{l}\text { A CDF provides the mass of waste } \\
\text { available for incorporation with ash } \\
\text { particles, which is required as an } \\
\text { input for the ASHPLUME_DLL_LA } \\
\text { software within the TSPA LA. }\end{array}$ & Data \\
\hline & $\begin{array}{l}\text { Sections } \\
6.3 .2,6.6 .3\end{array}$ & $\begin{array}{l}\text { Section } \\
6.2 .2 .8\end{array}$ & $\begin{array}{l}\text { A hypothetical direct deposition of } \\
\text { ash and waste in the vicinity of the } \\
\text { RMEl, and local redistribution of } \\
\text { that waste, presumably represents } \\
\text { the greatest degree of exposure } \\
\text { from an eruptive process. }\end{array}$ & Data \\
\hline
\end{tabular}


Table A-1. Table of Direct Inputs for Included and Excluded Features, Events, and Processes (Continued)

\begin{tabular}{|c|c|c|c|c|}
\hline Document Source & $\begin{array}{l}\text { Citation } \\
\text { from } \\
\text { Source }\end{array}$ & $\begin{array}{l}\text { Direct } \\
\text { Use In }\end{array}$ & Description & $\begin{array}{c}\text { Input } \\
\text { Category }\end{array}$ \\
\hline & Section 6.5 & $\begin{array}{l}\text { Section } \\
6.2 .2 .8\end{array}$ & $\begin{array}{l}\text { For the volcanic eruption modeling } \\
\text { case, the TSPA-LA presumes that } \\
\text { a hypothetical violent Strombolian } \\
\text { eruption occurs through a section } \\
\text { of the repository, entraining } \\
\text { radionuclide-bearing wastes in an } \\
\text { ash plume that disperses } \\
\text { downwind and deposits } \\
\text { contaminated ash on the ground } \\
\text { surface. }\end{array}$ & Data \\
\hline & Section 6.7.2 & $\begin{array}{l}\text { Section } \\
6.2 .2 .8\end{array}$ & $\begin{array}{l}\text { Parameters used by SoilExp_LA } \\
\text { DLL within GoldSim }\end{array}$ & Data \\
\hline & $\begin{array}{l}\text { Sections } \\
6.3 .2,6.6 .3\end{array}$ & $\begin{array}{l}\text { Section } \\
6.2 .2 .8\end{array}$ & $\begin{array}{l}\text { A hypothetical direct deposition of } \\
\text { ash and waste in the vicinity of the } \\
\text { RMEI, and local redistribution of } \\
\text { that waste, presumably represents } \\
\text { the greatest degree of exposure } \\
\text { from an eruptive process }\end{array}$ & Data \\
\hline & Section 5.1.3 & $\begin{array}{l}\text { Section } \\
6.2 .2 .8\end{array}$ & $\begin{array}{l}\text { For Outcome } 1 \text { (discussed in Table } \\
6-3 \text { - A volume of transported } \\
\text { sediment with a diluted ash } \\
\text { component would have less impact } \\
\text { on the RMEl than would a primary } \\
\text { ashfall that fell directly on the } \\
\text { RMEl. }\end{array}$ & Data \\
\hline & $\begin{array}{l}\text { Sections } \\
5.1 .3,6.3 .2\end{array}$ & $\begin{array}{l}\text { Section } \\
6.2 .2 .8\end{array}$ & $\begin{array}{l}\text { For Outcome } 2 \text { (discussed in } \\
\text { Table 6-3) - Direct deposition of } \\
\text { ash and waste occurs outside the } \\
\text { vicinity of the RMEl. Deposition } \\
\text { may occur in any direction, } \\
\text { depending on the sampled wind } \\
\text { direction. Other tephra-sheet } \\
\text { orientations either eliminate ash } \\
\text { from reaching the RMEI location, } \\
\text { or reduce the available volume of } \\
\text { ash to be redistributed to the RMEI } \\
\text { location. }\end{array}$ & Data \\
\hline & $\begin{array}{l}\text { Sections } \\
1.3 .2,6.7 .2 .4\end{array}$ & $\begin{array}{l}\text { Section } \\
6.2 .2 .8\end{array}$ & $\begin{array}{l}\text { Given uncertainties, the TSPA-LA } \\
\text { assumes an ash layer to remain } \\
\text { indefinitely with the sampled initial } \\
\text { thickness but with } 1 / 100 \text { th of the } \\
\text { initial volumetric concentration } \\
\text { derived from the separate } \\
\text { ASHPLUME calculation. }\end{array}$ & Data \\
\hline & Table H-2 & $\begin{array}{l}\text { Section } \\
6.2 .2 .6\end{array}$ & $\begin{array}{l}\text { Mean particle size diameters of } \\
\text { waste vary from } 0.002 \mathrm{~cm} \text { for } \\
\text { unaltered fuel to } 0.0002 \mathrm{~cm} \text { for } \\
\text { corroded fuel. }\end{array}$ & Data \\
\hline & $\begin{array}{l}\text { Sections } 6.5 .1 \\
\text { and } 6.5 .2\end{array}$ & $\begin{array}{l}\text { Sections } \\
6.2 .2 .6 \\
6.2 .2 .7\end{array}$ & $\begin{array}{l}\text { The mathematical model and } \\
\text { parameter inputs used in the } \\
\text { ASHPLUME model to calculate } \\
\text { ash-and-waste dispersal in the } \\
\text { wind. }\end{array}$ & Data \\
\hline
\end{tabular}


Table A-1. Table of Direct Inputs for Included and Excluded Features, Events, and Processes (Continued)

\begin{tabular}{|c|c|c|c|c|}
\hline Document Source & $\begin{array}{l}\text { Citation } \\
\text { from } \\
\text { Source }\end{array}$ & $\begin{array}{l}\text { Direct } \\
\text { Use In }\end{array}$ & Description & $\begin{array}{l}\text { Input } \\
\text { Category }\end{array}$ \\
\hline & $\begin{array}{l}\text { Section } \\
6.5 .2 .16\end{array}$ & $\begin{array}{l}\text { Section } \\
6.2 .2 .6\end{array}$ & $\begin{array}{l}\text { Technical basis for assuming } \\
\text { erupted materials are finely divided } \\
\text { particles amenable for airborne } \\
\text { transport }\end{array}$ & Data \\
\hline & Table 6-1 & \begin{tabular}{|l} 
Sections \\
6.2 .2 .6 \\
6.2 .2 .7 \\
6.2 .2 .8 \\
Table 6-1 \\
\end{tabular} & Reference for inclusion as FEP & Data \\
\hline & Entire & $\begin{array}{l}\text { Sections } \\
6.2 .2 .3 \\
6.2 \cdot 2.6 \\
6.2 .2 .7 \\
6.2 .2 .8\end{array}$ & $\begin{array}{l}\text { General reference to models and } \\
\text { analyses addressing transport of } \\
\text { waste in volcanic ash }\end{array}$ & Data \\
\hline & Table 6-3 & $\begin{array}{l}\text { Section } \\
6.2 .2 .7\end{array}$ & $\begin{array}{l}\text { Parameters used to implement } \\
\text { FEP 1.2.04.07.0A within the TSPA- } \\
\text { LA }\end{array}$ & Data \\
\hline & Section 6.5.2 & $\begin{array}{l}\text { Section } \\
6.2 \cdot 2.7\end{array}$ & $\begin{array}{l}\text { Technical basis for parameters } \\
\text { developed within the ASHPLUME } \\
\text { model report }\end{array}$ & Data \\
\hline & \begin{tabular}{|l|} 
Sections \\
$1.3 .2,6.6$ \\
\end{tabular} & $\begin{array}{l}\text { Section } \\
6.2 .2 .8\end{array}$ & Conceptual model for redistribution & Data \\
\hline & $\begin{array}{l}\text { Section } \\
6.7 .2 .2 \\
\text { Table } 6-5\end{array}$ & Table 6-3 & $\begin{array}{l}\text { Ash redistribution factors for the } \\
\text { TSPA model. }\end{array}$ & Data \\
\hline & $\begin{array}{l}\text { Sections } \\
6.7 .2 .3 \text { and } \\
6.7 .2 .4\end{array}$ & $\begin{array}{l}\text { Section } \\
6.2 .2 .8\end{array}$ & $\begin{array}{l}\text { Redistribution conceptual model, } \\
\text { including landforms, interchannel } \\
\text { divide areas }(82 \%) \text {, and } \\
\text { distributary channels (18\%) used in } \\
\text { TSPA-LA redistribution abstraction } \\
\text { are discussed. Also, discussed are } \\
\text { two different geomorphic settings } \\
\text { areas and how they respond } \\
\text { differently to ash fall and } \\
\text { redistribution. }\end{array}$ & Data \\
\hline & Section 8.1 & $\begin{array}{l}\text { Sections } \\
6.2 .2 .6 \\
6.2 .2 .7 \\
6.2 .2 .8\end{array}$ & $\begin{array}{l}\text { Reference to discussion regarding } \\
\text { use of ASHPLUME model }\end{array}$ & Data \\
\hline $\begin{array}{l}\text { BSC (Bechtel SAIC Company) } 2004 . \\
\text { Development of Earthquake Ground } \\
\text { Motion Input for Preclosure Seismic } \\
\text { Design and Postclosure Performance } \\
\text { Assessment of a Geologic Repository } \\
\text { at Yucca Mountain, NV. MDL-MGR- } \\
\text { GS-000003, Rev. 01. Las Vegas, } \\
\text { Nevada: Bechtel SAIC Company. } \\
170027\end{array}$ & Table 6.4-2 & $\begin{array}{l}\text { Section } \\
6.2 .1 .7\end{array}$ & $\begin{array}{l}\text { Supporting model report } \\
\text { documenting decision to include } \\
\text { the FEP and providing TSPA } \\
\text { disposition information }\end{array}$ & Data \\
\hline
\end{tabular}


Table A-1. Table of Direct Inputs for Included and Excluded Features, Events, and Processes (Continued)

\begin{tabular}{|c|c|c|c|c|}
\hline Document Source & $\begin{array}{l}\text { Citation } \\
\text { from } \\
\text { Source }\end{array}$ & $\begin{array}{l}\text { Direct } \\
\text { Use In }\end{array}$ & Description & $\begin{array}{c}\text { Input } \\
\text { Category }\end{array}$ \\
\hline & Entire & $\begin{array}{l}\text { Sections } \\
6.2 .1 .3 \\
6.2 .1 .4 \\
6.2 .1 .5 \\
6.2 .1 .6 \\
\text { Table } 6-1 \\
\end{array}$ & $\begin{array}{l}\text { General reference to document } \\
\text { providing ground motion input } \\
\text { analysis }\end{array}$ & Data \\
\hline & Section 6.5 & $\begin{array}{l}\text { Section } \\
6.2 .1 .7\end{array}$ & $\begin{array}{l}\text { An analysis of the ground motion } \\
\text { associated with the range of } \\
\text { maximum magnitude earthquakes } \\
\text { assessed for basalt dike intrusions } \\
\text { is presented. }\end{array}$ & Data \\
\hline \multirow[t]{8}{*}{$\begin{array}{l}\text { BSC (Bechtel SAIC Company) } 2004 . \\
\text { Dike/Drift Interactions. MDL-MGR- } \\
\text { GS-000005, Rev. 01. Las Vegas, } \\
\text { Nevada: Bechtel SAIC Company. } \\
170028\end{array}$} & Section 6.8.6 & $\begin{array}{l}\text { Section } \\
6.2 .2 .3\end{array}$ & $\begin{array}{l}\text { As oxide and silicate minerals tend } \\
\text { to have slow dissolution rates } \\
\text { compared to salts, significantly } \\
\text { enhanced dissolution rates of } \\
\text { minerals due to reaction of waste } \\
\text { with basalt magma within drifts is } \\
\text { not anticipated, and is not } \\
\text { considered further. }\end{array}$ & Data \\
\hline & $\begin{array}{l}\text { Section } \\
6.5 .5 .1 \text { and } \\
\text { Figure } 6-93\end{array}$ & $\begin{array}{l}\text { Section } \\
6.2 .2 .4\end{array}$ & $\begin{array}{l}\text { Simulations suggest only a brief } \\
\text { and minimal decrease in } \mathrm{pH} \\
\text { around the drift in the liquid phase } \\
\text { at about one year. }\end{array}$ & Data \\
\hline & Section 6.6 & $\begin{array}{l}\text { Section } \\
6.2 .2 .4\end{array}$ & $\begin{array}{l}\text { Relative to the potential impact of } \\
\text { magmatic volatiles on water } \\
\text { chemistry, magmatic volatile } \\
\text { release may lead to zones of low } \\
\text { pH in regions adjacent to potential } \\
\text { igneous intrusions. }\end{array}$ & Data \\
\hline & Equation 6-95 & $\begin{array}{l}\text { Equation 6- } \\
1\end{array}$ & $\begin{array}{l}\text { Shows that hydrogen ions are } \\
\text { consumed in hydrolysis reactions, } \\
\text { leading to the neutralization of } \\
\text { acidity. }\end{array}$ & Data \\
\hline & Figure 6-88 & $\begin{array}{l}\text { Section } \\
6.2 .2 .4\end{array}$ & $\begin{array}{l}\text { During the first year or two } \\
\text { following intrusion, temperatures at } \\
\text { the edge of the drift remain above } \\
100 \text { degrees } C \text {, which prevents } \\
\text { seepage into the drift. }\end{array}$ & Data \\
\hline & Figure 6-93 & $\begin{array}{l}\text { Section } \\
6.2 .2 .4\end{array}$ & $\begin{array}{l}\text { Between one and five years } \\
\text { following intrusion, the narrow } \\
\text { zone of decreased pH is not } \\
\text { evident in simulations. }\end{array}$ & Data \\
\hline & Section 6.6 & $\begin{array}{l}\text { Section } \\
6.2 .2 .4\end{array}$ & $\begin{array}{l}\text { Analyses demonstrate that } \\
\text { migration of magmatic volatiles to } \\
\text { Zone } 2 \text { drifts (non-intersected } \\
\text { drifts) is not a concern. }\end{array}$ & Data \\
\hline & Entire & $\begin{array}{l}\text { Sections } \\
6.2 .2 .2 \\
6.2 .2 .3 \\
6.2 .2 .4 \\
6.2 .2 .5 \\
6.2 .2 .6\end{array}$ & $\begin{array}{l}\text { General reference to the dike/drift } \\
\text { interaction models and analyses }\end{array}$ & Data \\
\hline
\end{tabular}


Table A-1. Table of Direct Inputs for Included and Excluded Features, Events, and Processes (Continued)

\begin{tabular}{|c|c|c|c|c|}
\hline Document Source & $\begin{array}{l}\text { Citation } \\
\text { from } \\
\text { Source }\end{array}$ & $\begin{array}{l}\text { Direct } \\
\text { Use In }\end{array}$ & Description & $\begin{array}{l}\text { Input } \\
\text { Category }\end{array}$ \\
\hline & Section 6.4 .5 & $\begin{array}{l}\text { Section } \\
6.2 .2 .6 \\
\end{array}$ & $\begin{array}{l}\text { Discussion of the treatment of the } \\
\text { "dog-leg" scenario }\end{array}$ & Data \\
\hline & Section 6 & $\begin{array}{l}\text { Section } \\
6.2 .2 .3\end{array}$ & $\begin{array}{l}\text { Potential migration of heat and gas } \\
\text { between Zone } 1 \text { (intersected drifts) } \\
\text { and Zone } 2 \text { (non intersected drifts) }\end{array}$ & Data \\
\hline & Table 6-1 & $\begin{array}{l}\text { Section } \\
6.2 .2 .2 \\
6.2 .2 .3 \\
6.2 .2 .4 \\
\text { Table } 6-1 \\
\end{array}$ & $\begin{array}{l}\text { General reference for inclusion or } \\
\text { as a supporting document }\end{array}$ & Data \\
\hline & Section 6 & $\begin{array}{l}\text { Section } \\
6.2 .2 .3\end{array}$ & $\begin{array}{l}\text { Factors influencing post-intrusion } \\
\text { environmental conditions within the } \\
\text { drifts }\end{array}$ & Data \\
\hline & Section 6.4 & $\begin{array}{l}\text { Section } \\
6.2 .2 .3\end{array}$ & $\begin{array}{l}\text { The outputs of the model indicate } \\
\text { that the entire length of an } \\
\text { intersected drift has the potential to } \\
\text { be filled with magmatic materials. }\end{array}$ & Data \\
\hline & Section 6.4 .9 & $\begin{array}{l}\text { Section } \\
6.2 .2 .3\end{array}$ & $\begin{array}{l}\text { During the course of magma } \\
\text { cooling, waste packages and } \\
\text { canisters /assemblies may be } \\
\text { subject to corrosion. Within the } \\
\text { TSPA-LA, no credit is taken for any } \\
\text { partial protection that residual } \\
\text { elements of the waste package } \\
\text { shells and the encapsulating basalt } \\
\text { might provide. }\end{array}$ & Data \\
\hline & $\begin{array}{l}\text { Figures 6-88 } \\
\text { and 6-89 }\end{array}$ & $\begin{array}{l}\text { Section } \\
6.2 .2 .3\end{array}$ & $\begin{array}{l}\text { Figures show temperatures } \\
\text { associated with igneous intrusion } \\
\text { attenuate rapidly into tuff } \\
\text { surrounding the drift. }\end{array}$ & Data \\
\hline & $\begin{array}{l}\text { Sections } \\
6.6 .5 .1 \text { and } \\
6.6 .5 .2\end{array}$ & $\begin{array}{l}\text { Section } \\
6.2 .2 .3\end{array}$ & $\begin{array}{l}\text { Simulations of gas flow show no } \\
\text { impacts are anticipated for Zone } 2 \\
\text { waste packages. }\end{array}$ & Data \\
\hline & Figure 6-86 & $\begin{array}{l}\text { Section } \\
6.2 .2 .3\end{array}$ & \begin{tabular}{|l|} 
Initially high $\mathrm{CO}_{2}$ and $\mathrm{SO}_{2}$ \\
concentrations migrate well outside \\
drifts as magmatic volatiles
\end{tabular} & Data \\
\hline & $\begin{array}{l}\text { Sections } \\
\text { 6.6.5.3 and } \\
6.6 .6\end{array}$ & $\begin{array}{l}\text { Section } \\
6.2 .2 .3\end{array}$ & $\begin{array}{l}\text { Separate calculation to evaluate } \\
\text { gas flow through backfill keyway } \\
\text { indicates migration occurs, but } \\
\text { combination of dilution of } \\
\text { magmatic gases by air (in adjacent } \\
\text { drift) and retardation of gas by } \\
\text { moisture in pore space in backfill } \\
\text { keyway indicates no damage to } \\
\text { waste packages in Zone } 2 \\
\end{array}$ & Data \\
\hline & $\begin{array}{l}\text { Section } \\
6.4 .8 .3\end{array}$ & $\begin{array}{l}\text { Section } \\
6.2 .2 .3\end{array}$ & $\begin{array}{l}\text { As temperatures decrease after } \\
\text { magma emplacement, } \mathrm{UO}_{2} \text { is } \\
\text { expected to fragment, which } \\
\text { increases the surface area of the } \\
\text { waste. }\end{array}$ & Data \\
\hline
\end{tabular}


Table A-1. Table of Direct Inputs for Included and Excluded Features, Events, and Processes (Continued)

\begin{tabular}{|c|c|c|c|c|}
\hline Document Source & $\begin{array}{l}\text { Citation } \\
\text { from } \\
\text { Source }\end{array}$ & $\begin{array}{l}\text { Direct } \\
\text { Use In }\end{array}$ & Description & $\begin{array}{c}\text { Input } \\
\text { Category }\end{array}$ \\
\hline & Section 6.8 & $\begin{array}{l}\text { Section } \\
6.2 .2 .4\end{array}$ & $\begin{array}{l}\text { Seepage reaction with cooled } \\
\text { basalt and hydrochemistry using } \\
\text { the software package EQ3/6 }\end{array}$ & Data \\
\hline & Section 6.8 .4 & $\begin{array}{l}\text { Section } \\
6.2 .2 .4\end{array}$ & $\begin{array}{l}\text { TSPA look-up tables for seepage } \\
\text { composition - time intervals are } \\
\text { defined in the TSPA-LA. }\end{array}$ & Data \\
\hline & Section 6.8 .3 & $\begin{array}{l}\text { Section } \\
6.2 .2 .4\end{array}$ & $\begin{array}{l}\text { Minimum and maximum of the } \\
\text { time-weighted averages from the } \\
\text { EQ3/6 calculations are consistent } \\
\text { with the large time steps used in } \\
\text { the TSPA-LA igneous intrusion } \\
\text { groundwater transport model. }\end{array}$ & Data \\
\hline & Section 5.4 .1 & $\begin{array}{l}\text { Sections } \\
6.2 .2 .3 \\
6.2 .2 .9\end{array}$ & $\begin{array}{l}\text { Following resumption of seepage, } \\
\text { the abstraction used for the TSPA } \\
\text { LA model will use typical seepage } \\
\text { flux from the crown. The } \\
\text { permeability of any contact } \\
\text { metamorphic aureole surrounding } \\
\text { the intruded drifts is as great as } \\
\text { that of the bulk host rock. }\end{array}$ & Data \\
\hline \multirow{2}{*}{$\begin{array}{l}\text { BSC (Bechtel SAIC Company) } 2004 . \\
\text { Saturated Zone Flow and Transport } \\
\text { Model Abstraction. MDL-NBS-HS- } \\
\text { 000021, Rev. 02. Las Vegas, } \\
\text { Nevada: Bechtel SAIC Company. } \\
170042\end{array}$} & Section 6.5 .2 & $\begin{array}{l}\text { Sections } \\
6.2 .1 .10 \\
6.2 .1 .11\end{array}$ & $\begin{array}{l}\text { General reference to flowing } \\
\text { interval method used to address } \\
\text { fracture effects in the SZ modeling }\end{array}$ & Data \\
\hline & $\begin{array}{l}\text { Section } \\
6.5 .2 .10\end{array}$ & $\begin{array}{l}\text { Sections } \\
6.2 .2 .1 \\
6.2 .2 .9 \\
\end{array}$ & $\begin{array}{l}\text { Direction of anisotropic maximum } \\
\text { transmissivity may be N15 degrees } \\
\text { E. }\end{array}$ & Data \\
\hline $\begin{array}{l}\text { BSC (Bechtel SAIC Company) } 2004 . \\
\text { Mechanical Assessment of the Waste } \\
\text { Package Subject to Vibratory Ground } \\
\text { Motion. CAL-WIS-AC-000001 REV } \\
\text { 00A. Las Vegas, Nevada: Bechtel } \\
\text { SAIC Company. } \\
170063\end{array}$ & Entire & $\begin{array}{l}\text { Section } \\
6.2 .1 .3 \\
\text { Table 6-1 }\end{array}$ & $\begin{array}{l}\text { Used structural response } \\
\text { calculations for the waste package } \\
\text { and drip shield as the basis for } \\
\text { predicting failed areas for } \\
\text { advective flow and transport. A } \\
\text { supporting document for inclusion } \\
\text { of a FEP. }\end{array}$ & Data \\
\hline $\begin{array}{l}\text { MO0407SEPFEPLA.000. LA FEP } \\
\text { List. Submittal date: 07/20/2004. } \\
170760\end{array}$ & S04311_001 & $\begin{array}{l}\text { Sections } 1 \\
1.2,4.1 \\
6.1 .1\end{array}$ & $\begin{array}{l}\text { Features, events, and processes } \\
\text { applicable to the Yucca Mountain } \\
\text { Project as revised for the License } \\
\text { Application phase. }\end{array}$ & Data \\
\hline $\begin{array}{l}\text { BSC (Bechtel SAIC Company) } 2004 . \\
\text { Structural Stability of a Drip Shield } \\
\text { Under Quasi-Static Pressure. 000- } \\
\text { 00C-SSE0-00500-000-00A. } \\
\text { Las Vegas, Nevada: Bechtel SAIC } \\
\text { Company. } \\
\text { ACC: ENG.20040830.0032. } \\
\text { 170791 }\end{array}$ & Entire & $\begin{array}{l}\text { Section } \\
6.2 .1 .3\end{array}$ & $\begin{array}{l}\text { Calculations that address damage } \\
\text { to the drip shield from quasi-static } \\
\text { pressure from rockfall rubble }\end{array}$ & Data \\
\hline
\end{tabular}


Table A-1. Table of Direct Inputs for Included and Excluded Features, Events, and Processes (Continued)

\begin{tabular}{|c|c|c|c|c|}
\hline Document Source & $\begin{array}{l}\text { Citation } \\
\text { from } \\
\text { Source }\end{array}$ & $\begin{array}{l}\text { Direct } \\
\text { Use In }\end{array}$ & Description & $\begin{array}{c}\text { Input } \\
\text { Category }\end{array}$ \\
\hline $\begin{array}{l}\text { BSC (Bechtel SAIC Company) } 2004 . \\
\text { Alternative Damaged Area Evaluation } \\
\text { for Waste Package Exposed to } \\
\text { Vibratory Ground Motion. 000-00C- } \\
\text { WIS0-01900-000-00A. Las Vegas, } \\
\text { Nevada: Bechtel SAIC Company. } \\
\text { ACC: ENG.20040420.0010. } \\
170843\end{array}$ & Entire & $\begin{array}{l}\text { Section } \\
6.2 .1 .3\end{array}$ & $\begin{array}{l}\text { Sensitivity studies conducted on } \\
\text { variations in input ground motion } \\
\text { parameters. }\end{array}$ & Data \\
\hline $\begin{array}{l}\text { BSC (Bechtel SAIC Company) } 2004 . \\
21-P W R \text { Waste Package End } \\
\text { Impacts - A Mesh Study. 000-00C- } \\
\text { WIS0-02100-000-00A. Las Vegas, } \\
\text { Nevada: Bechtel SAIC Company. } \\
\text { ACC: ENG.20040617.0005. } \\
170844\end{array}$ & Entire & $\begin{array}{l}\text { Section } \\
6.2 .1 .3\end{array}$ & $\begin{array}{l}\text { Damage to waste package and } \\
\text { cladding calculations include } \\
\text { sensitivity studies of the } 21-P W R \\
\text { finite element model. }\end{array}$ & Data \\
\hline $\begin{array}{l}\text { BSC (Bechtel SAIC Company) } 2004 . \\
\text { Magma Bulkhead Analysis. 800-K0C- } \\
\text { SSP0-00100-000-00A. Las Vegas, } \\
\text { Nevada: Bechtel SAIC Company. } \\
171070\end{array}$ & Entire & $\begin{array}{l}\text { Section } \\
6.2 .2 .3\end{array}$ & $\begin{array}{l}\text { The possibility for magma flow to } \\
\text { flow between drifts is assessed in } \\
\text { a calculation. }\end{array}$ & Data \\
\hline $\begin{array}{l}\text { BSC (Bechtel SAIC Company) } 2004 . \\
\text { Subsurface Facility Description } \\
\text { Document. 800-3YD-SS00-00100- } \\
\text { 000-000. Las Vegas, Nevada: } \\
\text { Bechtel SAIC Company. } \\
\text { ACC: ENG.20040915.0008. } \\
171676\end{array}$ & $\begin{array}{l}\text { Section } \\
3.1 .1 .4 .8 .6\end{array}$ & $\begin{array}{l}\text { Section } \\
6.2 .1 .2\end{array}$ & $\begin{array}{l}\text { Standoff from Quaternary faults } \\
\text { with potential for significant } \\
\text { displacement requirement }\end{array}$ & Data \\
\hline $\begin{array}{l}\text { GS930108312312.003. Earthquake- } \\
\text { Induced Water-Level Fluctuations at } \\
\text { Yucca Mountain, Nevada, June, } \\
\text { 1992. Submittal date: 01/21/1993. } \\
\text { 171974 }\end{array}$ & Entire & $\begin{array}{l}\text { Section } \\
6.2 .1 .8\end{array}$ & $\begin{array}{l}\text { Data from the groundwater } \\
\text { monitoring wells document the } \\
1992 \text { earthquake-induced } \\
\text { fluctuations in water level. }\end{array}$ & Data \\
\hline
\end{tabular}

* Qualification of Igneous Inputs to Features, Events, and Processes: Disruptive Events (BSC 2004 [DIRS 171999]). 


\section{INTENTIONALLY LEFT BLANK}


APPENDIX B

LIST OF INDIRECT INPUTS FOR INCLUDED AND EXCLUDED FEPS 


\section{APPENDIX B LIST OF INDIRECT INPUTS FOR INCLUDED AND EXCLUDED FEPS}

Table B-1. Table of Indirect Inputs for Included and Excluded Features, Events, and Processes

\begin{tabular}{|c|c|c|c|c|}
\hline Document Source & $\begin{array}{l}\text { Citation } \\
\text { from } \\
\text { Source }\end{array}$ & $\begin{array}{l}\text { Direct Use } \\
\text { In }\end{array}$ & Description & $\begin{array}{l}\text { Input } \\
\text { Category }\end{array}$ \\
\hline \multirow[t]{4}{*}{$\begin{array}{l}\text { Crowe, B.; Perry, F.; Geissman, J.; } \\
\text { McFadden, L.; Wells, S.; Murrell, M.; } \\
\text { Poths, J.; Valentine, G.A.; Bowker, L.; } \\
\text { and Finnegan, K. 1995. Status of } \\
\text { Volcanism Studies for the Yucca } \\
\text { Mountain Site Characterization Project. } \\
\text { LA-12908-MS. Los Alamos, New } \\
\text { Mexico: Los Alamos National } \\
\text { Laboratory. } \\
\text { ACC: HQO.19951115.0017. } \\
\text { 100110 }\end{array}$} & p. $5-5$ & $\begin{array}{l}\text { Section } \\
6.2 .1 .1\end{array}$ & $\begin{array}{l}\text { In the Yucca Mountain region, } \\
\text { there has been episodic, small- } \\
\text { volume generation of basaltic } \\
\text { magma, with }<0.5 \mathrm{~km}^{3} \text { volume } \\
\text { generated during Quaternary. This } \\
\text { is consistent with a waning tectonic } \\
\text { setting. }\end{array}$ & $\begin{array}{l}\text { Indirect } \\
\text { Input }\end{array}$ \\
\hline & $\begin{array}{l}\text { p. 5-2 and } \\
\text { Figure 5-1 }\end{array}$ & $\begin{array}{l}\text { Section } \\
6.2 .1 .1\end{array}$ & $\begin{array}{l}\text { Basaltic magma generated from } \\
\text { sources at depths ranging from } 45 \\
\mathrm{~km} \text { to approximately } 60 \mathrm{~km} \text {. }\end{array}$ & $\begin{array}{l}\text { Indirect } \\
\text { Input }\end{array}$ \\
\hline & pp. 4-1, 4-2 & $\begin{array}{l}\text { Section } \\
6.2 .1 .1\end{array}$ & $\begin{array}{l}\text { Significance of advent of basaltic } \\
\text { magmatism in the Yucca Mountain } \\
\text { Regions in relation to decline and } \\
\text { end of crustal-level magmatism } \\
\text { and indicative of waning tectonic } \\
\text { source }\end{array}$ & $\begin{array}{l}\text { Indirect } \\
\text { Input }\end{array}$ \\
\hline & pp. 5-2, 5-6 & $\begin{array}{l}\text { Section } \\
6.2 .1 .1\end{array}$ & $\begin{array}{l}\text { Once basaltic magma is } \\
\text { segregated, it must move rapidly to } \\
\text { the surface to avoid solidification }\end{array}$ & $\begin{array}{l}\text { Indirect } \\
\text { Input }\end{array}$ \\
\hline $\begin{array}{l}\text { Rogers, A.M.; Harmsen, S.C.; and } \\
\text { Meremonte, M.E. 1987. Evaluation of } \\
\text { the Seismicity of the Southern Great } \\
\text { Basin and Its Relationship to the } \\
\text { Tectonic Framework of the Region. } \\
\text { Open-File Report 87-408. Denver, } \\
\text { Colorado: U.S. Geological Survey. } \\
\text { ACC: HQX.19880315.0004. } \\
100176\end{array}$ & p. 82 & $\begin{array}{l}\text { Section } \\
6.2 .1 .1\end{array}$ & $\begin{array}{l}\text { Low strain rate in vicinity of Yucca } \\
\text { Mountain }\end{array}$ & $\begin{array}{l}\text { Indirect } \\
\text { Input }\end{array}$ \\
\hline \multirow{2}{*}{$\begin{array}{l}\text { Sweetkind, D.S.; Barr, D.L.; Polacsek, } \\
\text { D.K.; and Anna, L.O. 1997. } \\
\text { Administrative Report: Integrated } \\
\text { Fracture Data in Support of Process } \\
\text { Models, Yucca Mountain, Nevada. } \\
\text { Milestone SPG32M3. [Las Vegas, } \\
\text { Nevada]: U.S. Geological Survey. } \\
\text { ACC: MOL.19971017.0726. } \\
100183\end{array}$} & Table 21 & $\begin{array}{l}\text { Section } \\
6.2 .1 .10\end{array}$ & $\begin{array}{l}\text { Strain exhibited by faults is } \\
\text { constrained to relatively narrow } \\
\text { fault zones (Dune Wash, } \\
\text { Sundance). }\end{array}$ & $\begin{array}{l}\text { Indirect } \\
\text { Input }\end{array}$ \\
\hline & pp. 67 to 71 & $\begin{array}{l}\text { Section } \\
6.2 .1 .10\end{array}$ & $\begin{array}{l}\text { Conclusions for spatial } \\
\text { relationships of faulting and } \\
\text { fracturing }\end{array}$ & $\begin{array}{l}\text { Indirect } \\
\text { Input }\end{array}$ \\
\hline
\end{tabular}


Table B-1. Table of Indirect Inputs for Included and Excluded Features, Events, and Processes (Continued)

\begin{tabular}{|c|c|c|c|c|}
\hline Document Source & $\begin{array}{l}\text { Citation } \\
\text { from } \\
\text { Source }\end{array}$ & $\begin{array}{c}\text { Direct Use } \\
\text { In }\end{array}$ & Description & $\begin{array}{c}\text { Input } \\
\text { Category }\end{array}$ \\
\hline $\begin{array}{l}\text { Whitney, J.W., ed. 1996. } \\
\text { Seismotectonic Framework and } \\
\text { Characterization of Faulting at Yucca } \\
\text { Mountain, Nevada. Milestone } \\
\text { 3GSH100M. Denver, Colorado: U.S. } \\
\text { Geological Survey. } \\
\text { ACC: MOL.19970129.0041; } \\
\text { MOL.19970129.0042; } \\
\text { MOL.19970129.0043; } \\
\text { MOL.19970129.0044; } \\
\text { MOL.19970129.0045; } \\
\text { MOL.19970129.0046; } \\
\text { MOL.19970129.0047; } \\
\text { MOL.19970129.0048; } \\
\text { MOL.19970129.0049; } \\
\text { MOL.19970129.0050; } \\
\text { MOL.19970129.0051; } \\
\text { MOL.19970129.0052; } \\
\text { MOL.19970129.0053; } \\
\text { MOL.19970129.0054; } \\
\text { MOL.19970129.0055; } \\
\text { MOL.19970129.0056; } \\
\text { MOL.19970129.0057; } \\
\text { MOL.19970129.0058; } \\
\text { MOL.19970129.0059; } \\
\text { MOL.19970129.0060; } \\
\text { MOL.19970129.0061; } \\
\text { MOL.19970129.0062. } \\
\text { 100188 }\end{array}$ & Entire & $\begin{array}{l}\text { Section } \\
6.2 .1 .2\end{array}$ & $\begin{array}{l}\text { Extensive fault characterization at } \\
\text { YM }\end{array}$ & $\begin{array}{l}\text { Indirect } \\
\text { Input }\end{array}$ \\
\hline \multirow[t]{2}{*}{$\begin{array}{l}\text { CRWMS M\&O 1998. "Disruptive } \\
\text { Events." Chapter } 10 \text { of Total System } \\
\text { Performance Assessment-Viability } \\
\text { Assessment (TSPA-VA) Analyses } \\
\text { Technical Basis Document. } \\
\text { B00000000-01717-4301-00010 REV } \\
\text { 01. Las Vegas, Nevada: CRWMS } \\
\text { M\&O. ACC: MOL.19981008.0010. } \\
\text { 100369 }\end{array}$} & Section 10.4.4 & $\begin{array}{l}\text { Sections } \\
6.2 .2 .1 \\
6.2 .2 .9\end{array}$ & $\begin{array}{l}\text { An early analysis of the effect of a } \\
\text { dike on flow in the SZ was } \\
\text { conducted and documented. }\end{array}$ & $\begin{array}{l}\text { Indirect } \\
\text { Input }\end{array}$ \\
\hline & Section 10.5.3 & $\begin{array}{l}\text { Sections } \\
6.2 .1 .10 \\
6.2 .1 .11\end{array}$ & $\begin{array}{l}\text { Corroboration of negligible impact } \\
\text { on performance from change of } \\
\text { fault properties for TSPA-VA SZ } \\
\text { flow models }\end{array}$ & $\begin{array}{l}\text { Indirect } \\
\text { Input }\end{array}$ \\
\hline
\end{tabular}


Table B-1. Table of Indirect Inputs for Included and Excluded Features, Events, and Processes (Continued)

\begin{tabular}{|c|c|c|c|c|}
\hline Document Source & $\begin{array}{l}\text { Citation } \\
\text { from } \\
\text { Source }\end{array}$ & $\begin{array}{l}\text { Direct Use } \\
\text { In }\end{array}$ & Description & $\begin{array}{l}\text { Input } \\
\text { Category }\end{array}$ \\
\hline \multirow{4}{*}{$\begin{array}{l}\text { Gauthier, J.H.; Wilson, M.L.; Borns, } \\
\text { D.J.; and Arnold, B.W. 1996. "Impacts } \\
\text { of Seismic Activity on Long-Term } \\
\text { Repository Performance at Yucca } \\
\text { Mountain." Proceedings of the Topical } \\
\text { Meeting on Methods of Seismic } \\
\text { Hazards Evaluation, Focus '95, } \\
\text { September 18-20, 1995, Las Vegas, } \\
\text { Nevada. Pages 159-168. La Grange } \\
\text { Park, Illinois: American Nuclear } \\
\text { Society. TIC: 232628. } \\
100447\end{array}$} & p. 163 & $\begin{array}{l}\text { Sections } \\
6.2 .1 .9 \\
6.2 .1 .10\end{array}$ & $\begin{array}{l}\text { Redistribution of strain could open } \\
\text { new fractures and close some } \\
\text { existing fractures }\end{array}$ & $\begin{array}{l}\text { Indirect } \\
\text { Input }\end{array}$ \\
\hline & pp. $163-164$ & $\begin{array}{l}\text { Sections } \\
6.2 .1 .1 \\
6.2 .1 .8 \\
6.2 .1 .10 \\
6.2 .1 .11\end{array}$ & $\begin{array}{l}\text { Seismically induced water table } \\
\text { excursions (seismic pumping) } \\
\text { caused by poroelastic coupling } \\
\text { would not influence the models } \\
\text { used for TSPA-VA. }\end{array}$ & $\begin{array}{l}\text { Indirect } \\
\text { Input }\end{array}$ \\
\hline & p. 164 & $\begin{array}{l}\text { Section } \\
6.2 .1 .1\end{array}$ & $\begin{array}{l}\text { Maximum water-table rise was } 50 \\
\mathrm{~m} \text { within } 1 \mathrm{hr} \text { of simulated seismic } \\
\text { event. }\end{array}$ & $\begin{array}{l}\text { Indirect } \\
\text { Input }\end{array}$ \\
\hline & p. 164 & 6.2.1.8 & $\begin{array}{l}\text { Greatest strain-induced changes in } \\
\text { water table elevation associated } \\
\text { with strike-slip faults. }\end{array}$ & $\begin{array}{l}\text { Indirect } \\
\text { Input }\end{array}$ \\
\hline $\begin{array}{l}\text { Stock, J.M. and Healy, J.H. } 1988 . \\
\text { "Stress Field at Yucca Mountain, } \\
\text { Nevada." Chapter } 6 \text { of Geologic and } \\
\text { Hydrologic Investigations of a Potential } \\
\text { Nuclear Waste Disposal Site at Yucca } \\
\text { Mountain, Southern Nevada. Carr, M.D. } \\
\text { and Yount, J.C., eds. Bulletin 1790. } \\
\text { Denver, Colorado: U.S. Geological } \\
\text { Survey. TIC: 203085. } \\
101022\end{array}$ & p. 92 & $\begin{array}{l}\text { Section } \\
6.2 .1 .2\end{array}$ & $\begin{array}{l}\text { General reference for source of in } \\
\text { situ measurements, in support of } \\
\text { assertion that faults at YM are } \\
\text { weak and at the point of failure }\end{array}$ & $\begin{array}{l}\text { Indirect } \\
\text { Input }\end{array}$ \\
\hline $\begin{array}{l}\text { Stock, J.M.; Healy, J.H.; Hickman, S.H.; } \\
\text { and Zoback, M.D. 1985. "Hydraulic } \\
\text { Fracturing Stress Measurements at } \\
\text { Yucca Mountain, Nevada, and } \\
\text { Relationship to the Regional Stress } \\
\text { Field." Journal of Geophysical } \\
\text { Research, 90, (B10), 8691-8706. } \\
\text { Washington, D.C.: American } \\
\text { Geophysical Union. TIC: } 219009 . \\
101027\end{array}$ & p. 8705 & $\begin{array}{l}\text { Section } \\
6.2 .1 .2\end{array}$ & $\begin{array}{l}\text { Pre-existing faults likely to slip } \\
\text { under increased stress loads }\end{array}$ & $\begin{array}{l}\text { Indirect } \\
\text { Input }\end{array}$ \\
\hline
\end{tabular}


Table B-1. Table of Indirect Inputs for Included and Excluded Features, Events, and Processes (Continued)

\begin{tabular}{|c|c|c|c|c|}
\hline Document Source & $\begin{array}{l}\text { Citation } \\
\text { from } \\
\text { Source }\end{array}$ & $\begin{array}{l}\text { Direct Use } \\
\text { In }\end{array}$ & Description & $\begin{array}{l}\text { Input } \\
\text { Category }\end{array}$ \\
\hline $\begin{array}{l}\text { Ramelli, A.R.; Oswald, J.A.; Vadurro, } \\
\text { G.; Menges, C.M.; and Paces, J.B. } \\
\text { 1996. "Quaternary Faulting on the } \\
\text { Solitario Canyon Fault." Chapter } 4.7 \text { of } \\
\text { Seismotectonic Framework and } \\
\text { Characterization of Faulting at Yucca } \\
\text { Mountain, Nevada. Whitney, J.W., ed. } \\
\text { Milestone 3GSH100M. Denver, } \\
\text { Colorado: U.S. Geological Survey. } \\
\text { TIC: 237980. } \\
\text { ACC: MOL.19970129.0041. } \\
\text { 101106 }\end{array}$ & Table 4.7.3 & $\begin{array}{l}\text { Section } \\
6.2 .1 .10\end{array}$ & $\begin{array}{l}\text { Mid to late Quaternary offsets, the } \\
\text { largest may be as much as } 130 \\
\mathrm{~cm} \text {, occurred at } 70-80 \mathrm{Ka}\end{array}$ & $\begin{array}{l}\text { Indirect } \\
\text { Input }\end{array}$ \\
\hline $\begin{array}{l}\text { O'Brien, G.M. 1993. Earthquake- } \\
\text { Induced Water-Level Fluctuations at } \\
\text { Yucca Mountain, Nevada, June } 1992 . \\
\text { Open-File Report 93-73. Denver, } \\
\text { Colorado: U.S. Geological Survey. } \\
\text { ACC: NNA.19930326.0022. } \\
101276\end{array}$ & Entire & $\begin{array}{l}\text { Section } \\
6.2 .1 .8\end{array}$ & $\begin{array}{l}\text { Earthquake-induced water level } \\
\text { changes at YM. }\end{array}$ & $\begin{array}{l}\text { Indirect } \\
\text { Input }\end{array}$ \\
\hline $\begin{array}{l}\text { Byers, F.M., Jr. and Barnes, H. } 1967 . \\
\text { Geologic Map of the Paiute Ridge } \\
\text { Quadrangle, Nye and Lincoln Counties, } \\
\text { Nevada. Map GQ-577. Washington, } \\
\text { D.C.: U.S. Geological Survey. } \\
\text { ACC: HQS.19880517.1104. } \\
\text { 101859 }\end{array}$ & Entire & $\begin{array}{l}\text { Sections } \\
6.2 .2 .1 \\
6.2 .2 .9\end{array}$ & $\begin{array}{l}\text { Descriptions of Paiute Ridge dike } \\
\text { complex and use as analogue }\end{array}$ & $\begin{array}{l}\text { Indirect } \\
\text { Input }\end{array}$ \\
\hline $\begin{array}{l}\text { Bohannon, R.G. and Parsons, T. } 1995 . \\
\text { "Tectonic Implications of Post-30 Ma } \\
\text { Pacific and North American Relative } \\
\text { Plate Motions." Geological Society of } \\
\text { America Bulletin, 107, (8), 937-959. } \\
\text { Boulder, Colorado: Geological Society } \\
\text { of America. TIC: 233033. } \\
101865\end{array}$ & p. 957 & $\begin{array}{l}\text { Section } \\
6.2 .1 .1\end{array}$ & $\begin{array}{l}\text { Reference for conditions resulting } \\
\text { in rapid change of geothermal } \\
\text { gradient and a weakened } \\
\text { subducting slab }\end{array}$ & $\begin{array}{l}\text { Indirect } \\
\text { Input }\end{array}$ \\
\hline $\begin{array}{l}\text { Dixon, T.H.; Robaudo, S.; Lee, J.; and } \\
\text { Reheis, M.C. 1995. "Constraints on } \\
\text { Present-Day Basin and Range } \\
\text { Deformation from Space Geodesy." } \\
\text { Tectonics, 14, (4), 755-772. } \\
\text { Washington, D.C.: American } \\
\text { Geophysical Union. TIC: } 234271 . \\
102793\end{array}$ & p. 765 & $\begin{array}{l}\text { Section } \\
6.2 .1 .1\end{array}$ & $\begin{array}{l}\text { Locus of tectonic activity has } \\
\text { moved west of YM. }\end{array}$ & $\begin{array}{l}\text { Indirect } \\
\text { Input }\end{array}$ \\
\hline $\begin{array}{l}\text { Wernicke, B.; Davis, J.L.; Bennett, } \\
\text { R.A.; Elosegui, P.; Abolins, M.J.; Brady, } \\
\text { R.J.; House, M.A.; Niemi, N.A.; and } \\
\text { Snow, J.K. 1998. "Anomalous Strain } \\
\text { Accumulation in the Yucca Mountain } \\
\text { Area, Nevada." Science, 279, 2096- } \\
\text { 2100. New York, New York: American } \\
\text { Association for the Advancement of } \\
\text { Science. TIC: } 235956 . \\
103485\end{array}$ & Entire & $\begin{array}{l}\text { Section } \\
6.2 .1 .1\end{array}$ & $\begin{array}{l}\text { Summary of strain-rate data in the } \\
\text { Yucca Mountain area }\end{array}$ & $\begin{array}{l}\text { Indirect } \\
\text { Input }\end{array}$ \\
\hline
\end{tabular}


Table B-1. Table of Indirect Inputs for Included and Excluded Features, Events, and Processes (Continued)

\begin{tabular}{|c|c|c|c|c|}
\hline Document Source & $\begin{array}{l}\text { Citation } \\
\text { from } \\
\text { Source }\end{array}$ & $\begin{array}{l}\text { Direct Use } \\
\text { In }\end{array}$ & Description & $\begin{array}{l}\text { Input } \\
\text { Category }\end{array}$ \\
\hline \multirow{2}{*}{$\begin{array}{l}\text { Savage, J.C.; Lisowski, M.; Svarc, J.L.; } \\
\text { and Gross, W.K. 1995. "Strain } \\
\text { Accumulation Across the Central } \\
\text { Nevada Seismic Zone, 1973-1994." } \\
\text { Journal of Geophysical Research, 100, } \\
\text { (B10), 20,257 to 20,269. Washington, } \\
\text { D.C.: American Geophysical Union. } \\
\text { TIC: } 236811 . \\
\text { 104553 }\end{array}$} & p. 20263 & $\begin{array}{l}\text { Section } \\
6.2 .1 .1\end{array}$ & $\begin{array}{l}\text { Central Nevada Seismic Zone } \\
\text { (now referred to as part of the } \\
\text { Intermountain seismic belt) located } \\
\text { generally north of } 37 \mathrm{~N}\end{array}$ & $\begin{array}{l}\text { Indirect } \\
\text { Input }\end{array}$ \\
\hline & $\begin{array}{l}\text { p. 20263, } \\
\text { Figure } 9\end{array}$ & $\begin{array}{l}\text { Section } \\
6.2 .1 .1\end{array}$ & $\begin{array}{l}\text { YM and its setting have a lower } \\
\text { strain rate than adjacent seismic } \\
\text { belts }\end{array}$ & $\begin{array}{l}\text { Indirect } \\
\text { Input }\end{array}$ \\
\hline $\begin{array}{l}\text { Fridrich, C.J.; Whitney, J.W.; Hudson, } \\
\text { M.R.; Keefer, W.R.; and Crowe, B.M. } \\
\text { 1996. "Space-Time Patterns of } \\
\text { Extension, Vertical-Axis Rotation, and } \\
\text { Volcanism in the Crater Flat Basin." } \\
\text { Chapter 2.II of Seismotectonic } \\
\text { Framework and Characterization of } \\
\text { Faulting at Yucca Mountain, Nevada. } \\
\text { Whitney, J.W., ed. Milestone } \\
\text { 3GSH100M. Denver, Colorado: U.S. } \\
\text { Geological Survey. TIC: 237980. } \\
\text { ACC: MOL.19970129.0041. } \\
\text { 105086 }\end{array}$ & pp. 2-21, 2-22 & $\begin{array}{l}\text { Section } \\
6.2 .1 .1\end{array}$ & $\begin{array}{l}\text { Corroboration of PSHA view that } \\
\text { the majority of future strain will be } \\
\text { accommodated on block-bounding } \\
\text { faults by a critical tilting angle of } \\
\text { approximately } 25^{\circ} \text {. }\end{array}$ & $\begin{array}{l}\text { Indirect } \\
\text { Input }\end{array}$ \\
\hline $\begin{array}{l}\text { Wohletz, K. and Heiken, G. } 1992 . \\
\text { Volcanology and Geothermal Energy. } \\
\text { Berkeley, California: University of } \\
\text { California Press. TIC: } 241603 . \\
105544\end{array}$ & pp. 85-154 & $\begin{array}{l}\text { Section } \\
6.2 .2 .5\end{array}$ & $\begin{array}{l}\text { Description of a hydrovolcanic } \\
\text { event }\end{array}$ & $\begin{array}{l}\text { Indirect } \\
\text { Input }\end{array}$ \\
\hline $\begin{array}{l}\text { Parsons, T.; Thompson, G.A.; and } \\
\text { Sleep, N.H. 1994. "Mantle Plume } \\
\text { Influence on the Neogene Uplift and } \\
\text { Extension of the U.S. Western } \\
\text { Cordillera?" Geology, 22, 83-86. } \\
\text { Boulder, Colorado: Geological Society } \\
\text { of America. TIC: } 233034 \text {. } \\
106479\end{array}$ & p. 83 & $\begin{array}{l}\text { Section } \\
6.2 .1 .1\end{array}$ & $\begin{array}{l}\text { General reference - description of } \\
\text { conditions needed to create a rapid } \\
\text { change in geothermal gradient - } \\
\text { hot spot }\end{array}$ & $\begin{array}{l}\text { Indirect } \\
\text { Input }\end{array}$ \\
\hline $\begin{array}{l}\text { Sweetkind, D.S.; Potter, C.J.; and } \\
\text { Verbeek, E.R. 1996. "Interaction } \\
\text { Between Faults and the Fracture } \\
\text { Network at Yucca Mountain, Nevada." } \\
\text { Eos Transactions, S266. Washington, } \\
\text { D.C.: American Geophysical Union. } \\
\text { TIC: } 236789 . \\
106957\end{array}$ & Entire & $\begin{array}{l}\text { Section } \\
6.2 .1 .11\end{array}$ & $\begin{array}{l}\text { Observations regarding evidence } \\
\text { for reactivation of joints }\end{array}$ & $\begin{array}{l}\text { Indirect } \\
\text { Input }\end{array}$ \\
\hline
\end{tabular}


Table B-1. Table of Indirect Inputs for Included and Excluded Features, Events, and Processes (Continued)

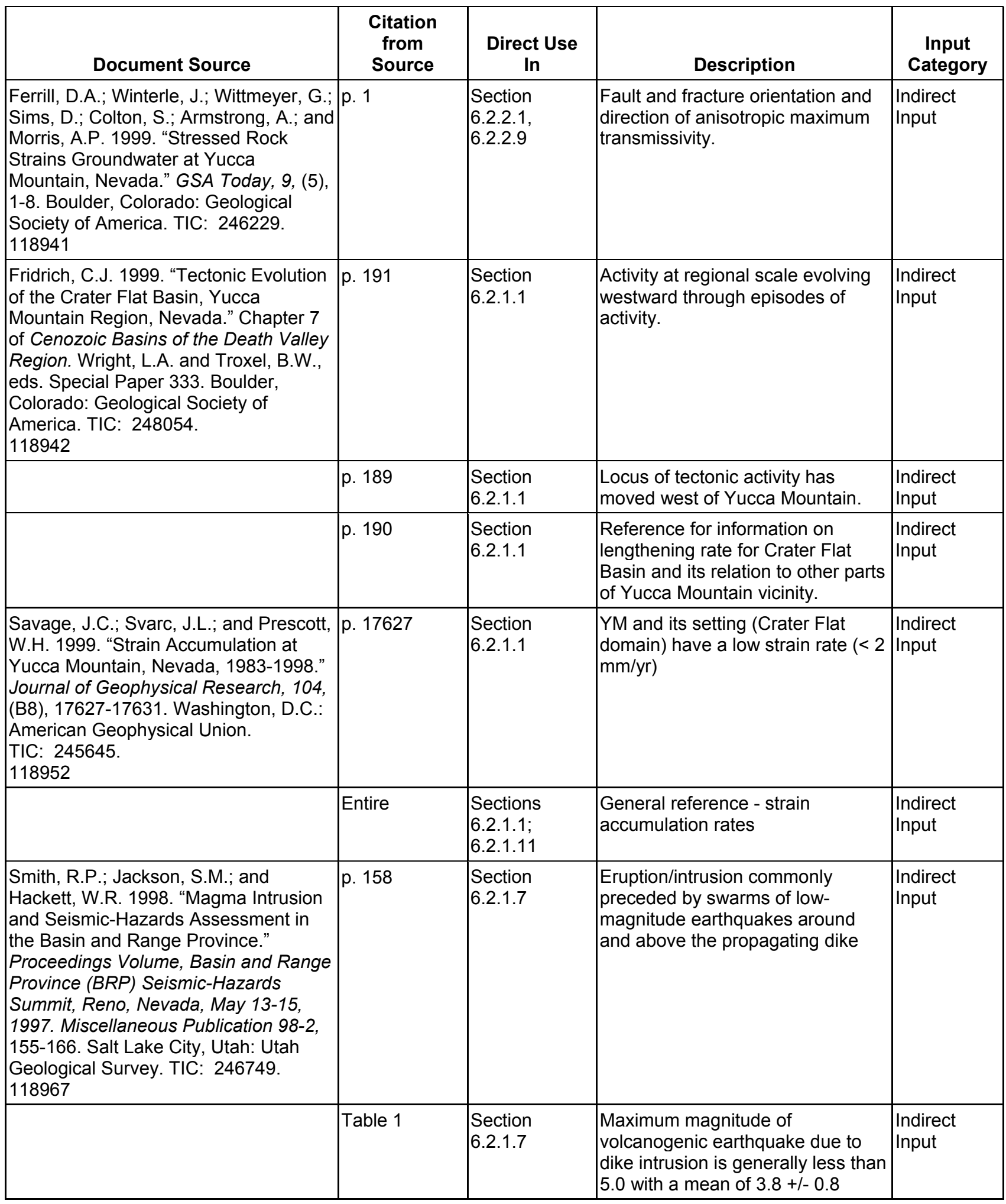


Table B-1. Table of Indirect Inputs for Included and Excluded Features, Events, and Processes (Continued)

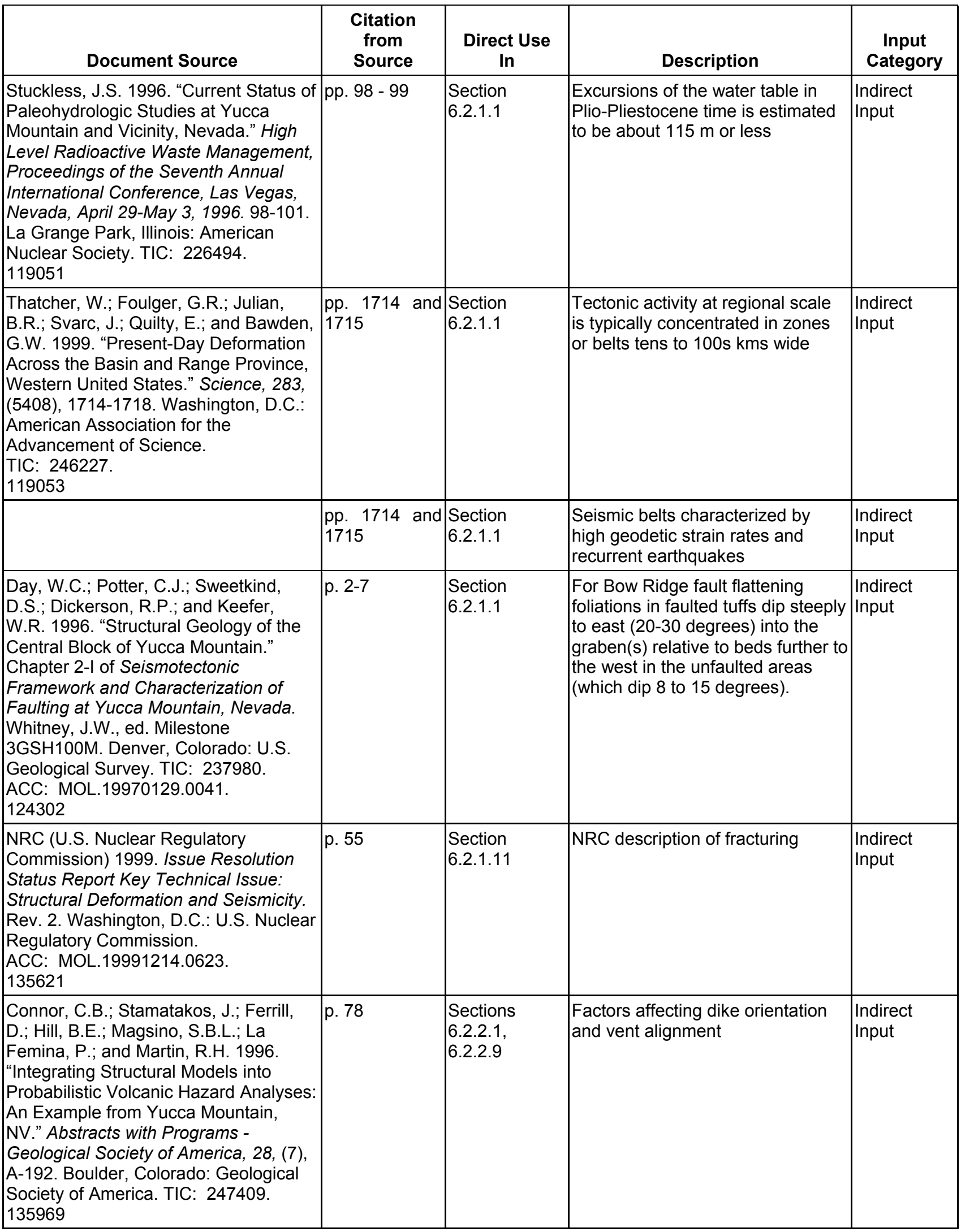


Table B-1. Table of Indirect Inputs for Included and Excluded Features, Events, and Processes (Continued)

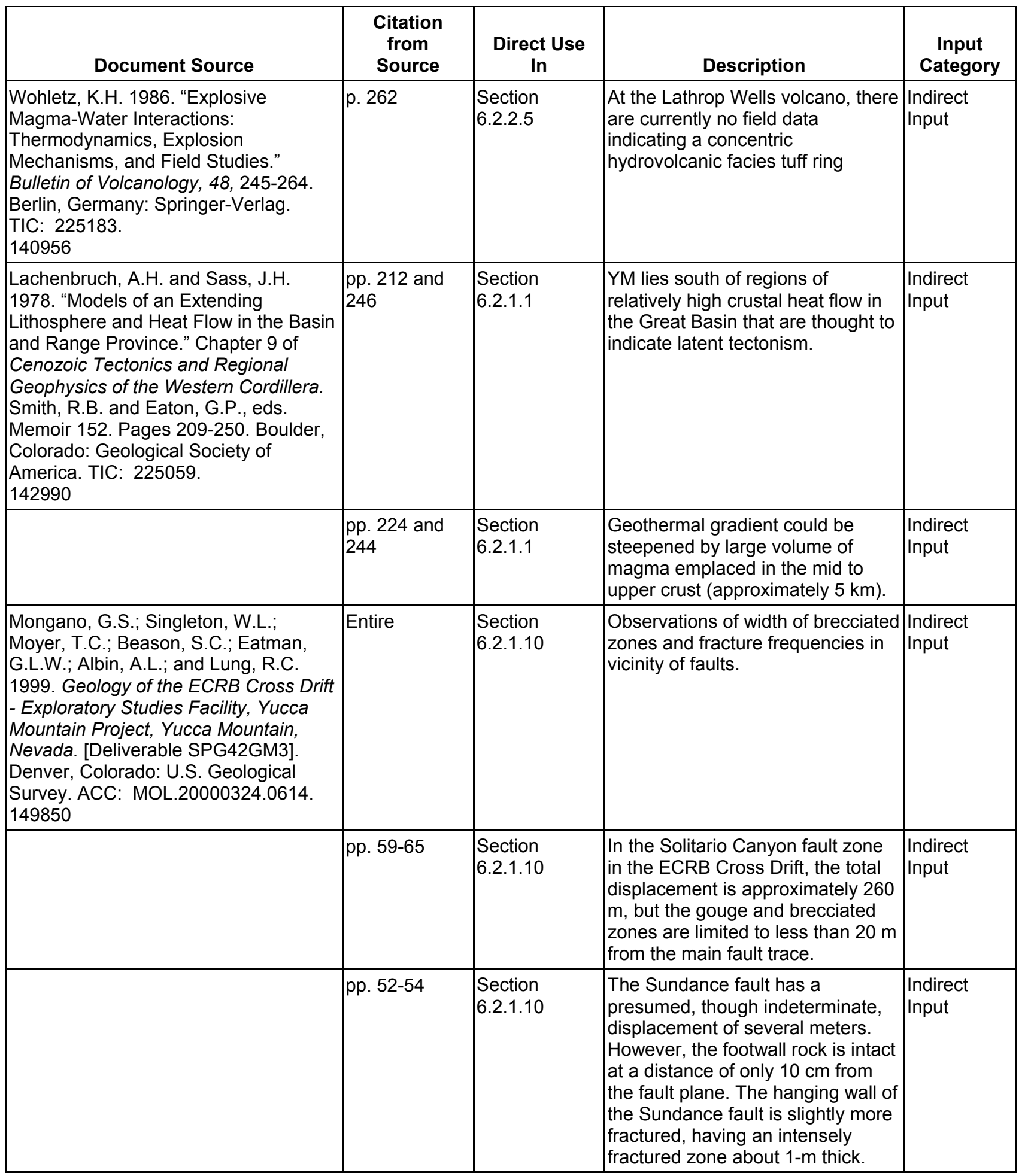


Table B-1. Table of Indirect Inputs for Included and Excluded Features, Events, and Processes (Continued)

\begin{tabular}{|c|c|c|c|c|}
\hline Document Source & $\begin{array}{l}\text { Citation } \\
\text { from } \\
\text { Source }\end{array}$ & $\begin{array}{c}\text { Direct Use } \\
\text { In }\end{array}$ & Description & $\begin{array}{c}\text { Input } \\
\text { Category }\end{array}$ \\
\hline $\begin{array}{l}\text { Wilson, S.F. and Cline, J.S. } 2001 . \\
\text { "Paragenesis, Temperature and Timing } \\
\text { of Secondary Minerals at Yucca } \\
\text { Mountain." "Back to the Future - } \\
\text { Managing the Back End of the Nuclear } \\
\text { Fuel Cycle to Create a More Secure } \\
\text { Energy Future," Proceedings of the 9th } \\
\text { International High-Level Radioactive } \\
\text { Waste Management Conference } \\
\text { (IHLRWM), Las Vegas, Nevada, April } \\
\text { 29-May 3, 2001. La Grange Park, } \\
\text { Illinois: American Nuclear Society. } \\
\text { TIC: 247873. } \\
\text { 155426 }\end{array}$ & Entire & $\begin{array}{l}\text { Section } \\
6.2 .1 .1\end{array}$ & $\begin{array}{l}\text { Results of a two-year study at } \\
\text { UNLV concluded that hydrothermal } \\
\text { water has not invaded Yucca } \\
\text { Mountain in the last } 2 \text { m.y }\end{array}$ & $\begin{array}{l}\text { Indirect } \\
\text { Input }\end{array}$ \\
\hline $\begin{array}{l}\text { DOE (U.S. Department of Energy) } \\
\text { 2002. Final Environmental Impact } \\
\text { Statement for a Geologic Repository for } \\
\text { the Disposal of Spent Nuclear Fuel and } \\
\text { High-Level Radioactive Waste at Yucca } \\
\text { Mountain, Nye County, Nevada. } \\
\text { DOE/EIS-0250. Washington, D.C.: U.S. } \\
\text { Department of Energy, Office of Civilian } \\
\text { Radioactive Waste Management. } \\
\text { ACC: MOL.20020524.0314; } \\
\text { MOL.20020524.0315; } \\
\text { MOL.20020524.0316; } \\
\text { MOL.20020524.0317; } \\
\text { MOL.20020524.0318; } \\
\text { MOL.20020524.0319; } \\
\text { MOL.20020524.0320. } \\
\text { 155970 } \\
\end{array}$ & p. 3-59 & $\begin{array}{l}\text { Sections } \\
6.2 .1 .8, \mathrm{C} 1.1\end{array}$ & $\begin{array}{l}\text { Results of National Research } \\
\text { Council consideration of seismic } \\
\text { pumping phenomenon }\end{array}$ & $\begin{array}{l}\text { Indirect } \\
\text { Input }\end{array}$ \\
\hline $\begin{array}{l}\text { Carter Krogh, K.E. and Valentine, G.A. } \\
\text { 1996. Structural Control on Basaltic } \\
\text { Dike and Sill Emplacement, Paiute } \\
\text { Ridge Mafic Intrusion Complex, } \\
\text { Southern Nevada. LA-13157-MS. Los } \\
\text { Alamos, New Mexico: Los Alamos } \\
\text { National Laboratories. } \\
\text { ACC: MOL.20030828.0138. } \\
160928\end{array}$ & pp. 7 and 8 & $\begin{array}{l}\text { Sections } \\
6.2 .2 .1 \\
6.2 .2 .4 \\
6.2 \cdot 2.9, \mathrm{C} 2.2\end{array}$ & $\begin{array}{l}\text { Description of dikes and dike } \\
\text { margins of the Paiute Ridge dike } \\
\text { complex. }\end{array}$ & $\begin{array}{l}\text { Indirect } \\
\text { Input }\end{array}$ \\
\hline $\begin{array}{l}\text { Williams, N.H. 2001. "Contract No. DE- } \\
\text { AC08-01RW12101 - KTI Deliverable to } \\
\text { NRC - October 2001." Letter from N.H. } \\
\text { Williams (BSC) to S.J. Brocoum } \\
\text { (DOE/YMSCO), October 16, 2001, } \\
\text { 1012010135, LTS:cdg, with enclosures. } \\
\text { ACC: MOL.20020206.0018. } \\
\text { 161728 }\end{array}$ & Entire & Section 6.1 .2 & $\begin{array}{l}\text { Statement of DOE intent to use } \\
\text { mean, rather than median values, } \\
\text { for DE FEP screening }\end{array}$ & $\begin{array}{l}\text { Indirect } \\
\text { Input }\end{array}$ \\
\hline $\begin{array}{l}\text { Fisher, R.V. and Schmincke, H.-U. } \\
\text { 1984. Pyroclastic Rocks. New York, } \\
\text { New York: Springer-Verlag. } \\
\text { TIC: } 223562 . \\
\text { 162806 }\end{array}$ & pp. 231-264 & $\begin{array}{l}\text { Section } \\
6.2 .2 .5\end{array}$ & $\begin{array}{l}\text { Description of a hydrovolcanic } \\
\text { event }\end{array}$ & $\begin{array}{l}\text { Indirect } \\
\text { Input }\end{array}$ \\
\hline
\end{tabular}


Table B-1. Table of Indirect Inputs for Included and Excluded Features, Events, and Processes (Continued)

\begin{tabular}{|c|c|c|c|c|}
\hline Document Source & $\begin{array}{l}\text { Citation } \\
\text { from } \\
\text { Source }\end{array}$ & $\begin{array}{l}\text { Direct Use } \\
\text { In }\end{array}$ & Description & $\begin{array}{l}\text { Input } \\
\text { Category }\end{array}$ \\
\hline \multirow{6}{*}{$\begin{array}{l}\text { NRC (U.S. Nuclear Regulatory } \\
\text { Commission) 2003. Yucca Mountain } \\
\text { Review Plan, Final Report. NUREG- } \\
1804 \text {, Rev. 2. Washington, D.C.: U.S. } \\
\text { Nuclear Regulatory Commission, Office } \\
\text { of Nuclear Material Safety and } \\
\text { Safeguards. TIC: } 254568 . \\
163274\end{array}$} & $\begin{array}{l}\text { Section } \\
2.2 .1 .2 .1 .3 \\
\text { criterion } 2\end{array}$ & Section 4.2 .3 & $\begin{array}{l}\text { Allows for exclusion of a FEP is the } \\
\text { process is specifically excluded by } \\
\text { the regulations. }\end{array}$ & $\begin{array}{l}\text { Indirect } \\
\text { Input }\end{array}$ \\
\hline & Glossary & Section 6.1 & Definitions used by FEPs analysis. & $\begin{array}{l}\text { Indirect } \\
\text { Input }\end{array}$ \\
\hline & Section 2.2.1 & Section 4.2 .3 & $\begin{array}{l}\text { Technical basis for simplified } \\
\text { approaches to a complex analysis. }\end{array}$ & $\begin{array}{l}\text { Indirect } \\
\text { Input }\end{array}$ \\
\hline & $\begin{array}{l}\text { Section } \\
2.2 .1 .2\end{array}$ & Section 4.2 .2 & $\begin{array}{l}\text { The basis of the NRC license } \\
\text { application review is given. }\end{array}$ & $\begin{array}{l}\text { Indirect } \\
\text { Input }\end{array}$ \\
\hline & $\begin{array}{l}\text { Sections } \\
2 \cdot 2 \cdot 1 \cdot 2 \cdot 1 \cdot 3 \\
\text { and } \\
2 \cdot 2 \cdot 1 \cdot 2 \cdot 2 \cdot 3\end{array}$ & $\begin{array}{l}\text { Sections } 4.2 \\
4.2 .1 ; \text { Table } 7- \\
2\end{array}$ & $\begin{array}{l}\text { Pertinent sections of NRC Yucca } \\
\text { Mountain Review Plan that pertain } \\
\text { to FEPs requirements as related to } \\
\text { scenario development and analysis }\end{array}$ & $\begin{array}{l}\text { Indirect } \\
\text { Input }\end{array}$ \\
\hline & $\begin{array}{l}\text { Section } \\
2.2 .1 .2 .1 .3 \text {, } \\
\text { criteria } 1 \text { and } \\
2 \text {; Section } \\
2.2 .1 .2 .2 .3, \\
\text { criteria 1, 2, } \\
\text { and 5 }\end{array}$ & $\begin{array}{l}\text { Tables } 4-2,4- \\
3 ; \text { Sections } \\
6.1 .1 ; 6.1 .2\end{array}$ & NRC acceptance criteria for FEPs & $\begin{array}{l}\text { Indirect } \\
\text { Input }\end{array}$ \\
\hline $\begin{array}{l}\text { Rojstaczer, S. 1991. "Elastic } \\
\text { Deformation as a Second Order } \\
\text { Influence on Groundwater Flow in } \\
\text { Areas of Crustal Unrest." Eos } \\
\text { Transactions (Supplement), 72, (17), } \\
\text { [N/A]. [Washington, D.C.]: American } \\
\text { Geophysical Union. TIC: } 216706 . \\
163416\end{array}$ & Abstract & $\begin{array}{l}\text { Section } \\
6.2 .2 .9\end{array}$ & $\begin{array}{l}\text { For a dike initially intruding into the } \\
\text { SZ, a possible rise in the water } \\
\text { table of only a few tens of meters } \\
\text { is indicated. }\end{array}$ & $\begin{array}{l}\text { Indirect } \\
\text { Input }\end{array}$ \\
\hline $\begin{array}{l}\text { Woods, A.W.; Sparks, S.; Bokhove, O.; } \\
\text { LeJeune, A-M.; Conner, C.B.; and Hill, } \\
\text { B.E. 2002. "Modeling Magma-Drift } \\
\text { Interaction at the Proposed High-Level } \\
\text { Radioactive Waste Repository at Yucca } \\
\text { Mountain, Nevada, USA." Geophysical } \\
\text { Research Letters, 29, (13), 19-1 } \\
\text { through 19-4. [Washington, D.C.]: } \\
\text { American Geophysical Union. } \\
\text { TIC: } 254467 . \\
163662\end{array}$ & Entire & $\begin{array}{l}\text { Sections } \\
6.2 .2 .6\end{array}$ & $\begin{array}{l}\text { Reference for the "dog-leg" } \\
\text { alternative conceptual model }\end{array}$ & $\begin{array}{l}\text { Indirect } \\
\text { Input }\end{array}$ \\
\hline $\begin{array}{l}\text { Bates, R.L. and Jackson, J.A., eds. } \\
\text { 1987. Glossary of Geology. 3rd Edition. } \\
\text { Alexandria, Virginia: American } \\
\text { Geological Institute. TIC: } 8832 . \\
164050\end{array}$ & p. 257 & $\begin{array}{l}\text { Section } \\
6.2 .1 .11\end{array}$ & Definition of "fracture" & $\begin{array}{l}\text { Indirect } \\
\text { Input }\end{array}$ \\
\hline
\end{tabular}


Table B-1. Table of Indirect Inputs for Included and Excluded Features, Events, and Processes (Continued)

\begin{tabular}{|c|c|c|c|c|}
\hline Document Source & $\begin{array}{l}\text { Citation } \\
\text { from } \\
\text { Source }\end{array}$ & $\begin{array}{l}\text { Direct Use } \\
\text { In }\end{array}$ & Description & $\begin{array}{l}\text { Input } \\
\text { Category }\end{array}$ \\
\hline \multirow{2}{*}{$\begin{array}{l}\text { Fridrich, C.J.; Whitney, J.W.; Hudson, } \\
\text { M.R.; and Crowe, B.M. 1998. Space- } \\
\text { Time Patterns of Late Cenozoic } \\
\text { Extension, Vertical-Axis Rotation, and } \\
\text { Volcanism in the Crater Flat Basin, } \\
\text { Southwest Nevada. Open-File Report } \\
\text { 98-461. Denver, Colorado: U.S. } \\
\text { Geological Survey. } \\
\text { ACC: MOL.19981014.0299. } \\
\text { 164051 }\end{array}$} & pp. 1 and 2 & $\begin{array}{l}\text { Section } \\
6.2 .1 .1\end{array}$ & $\begin{array}{l}\text { Rate of tectonism has decreased } \\
\text { greatly since late Miocene. }\end{array}$ & $\begin{array}{l}\text { Indirect } \\
\text { Input }\end{array}$ \\
\hline & $\begin{array}{l}\text { pp. 1, 2, 13, } \\
19,20\end{array}$ & $\begin{array}{l}\text { Section } \\
6.2 .1 .1\end{array}$ & Rates of extension through time. & $\begin{array}{l}\text { Indirect } \\
\text { Input }\end{array}$ \\
\hline \multirow{2}{*}{$\begin{array}{l}\text { Canori, G.F. and Leitner, M.M. } 2003 . \\
\text { Project Requirements Document. TER- } \\
\text { MGR-MD-000001 REV 02. Las Vegas, } \\
\text { Nevada: Bechtel SAIC Company. } \\
\text { ACC: DOC.20031222.0006. } \\
166275\end{array}$} & $\begin{array}{l}\text { PRD-002/ T- } \\
015 \text { and PRD- } \\
002 / T-034\end{array}$ & Table 4-2 & $\begin{array}{l}\text { Project requirements applicable to } \\
\text { FEPs screening and analysis }\end{array}$ & $\begin{array}{l}\text { Indirect } \\
\text { Input }\end{array}$ \\
\hline & Entire & $\begin{array}{l}\text { Sections } 4.2 \text {, } \\
4.2 .1\end{array}$ & $\begin{array}{l}\text { General reference to project } \\
\text { requirements document }\end{array}$ & $\begin{array}{l}\text { Indirect } \\
\text { Input }\end{array}$ \\
\hline \multirow{3}{*}{$\begin{array}{l}\text { BSC (Bechtel SAIC Company) } 2003 . \\
\text { Total System Performance } \\
\text { Assessment-License Application } \\
\text { Methods and Approach. TDR-WIS-PA- } \\
\text { 000006 REV 00 ICN 01. Las Vegas, } \\
\text { Nevada: Bechtel SAIC Company. } \\
\text { ACC: DOC.20031215.0001. } \\
\text { 166296 }\end{array}$} & Section 2.1 & $\begin{array}{l}\text { Section } \\
6.2 .2 .8\end{array}$ & $\begin{array}{l}\text { The ash redistribution calculations } \\
\text { for a probability weighted volcanic } \\
\text { event are performed within TSPA- } \\
\text { LA using the SoilExp_LA DLL. }\end{array}$ & $\begin{array}{l}\text { Indirect } \\
\text { Input }\end{array}$ \\
\hline & Section 8.1 .2 & $\begin{array}{l}\text { Sections } \\
6.2 .2 .2 \\
6.2 .2 .3 \\
6.2 .2 .6 \\
6.2 .2 .7 \\
6.2 .2 .8\end{array}$ & $\begin{array}{l}\text { Outline of TSPA-LA approach for } \\
\text { the igneous eruptive and } \\
\text { groundwater models }\end{array}$ & $\begin{array}{l}\text { Indirect } \\
\text { Input }\end{array}$ \\
\hline & Section 5.2 & $\begin{array}{l}\text { Section } \\
6.2 .2 .2\end{array}$ & $\begin{array}{l}\text { The manner in which the igneous } \\
\text { intrusion is incorporated into the } \\
\text { TSPA-LA igneous intrusion } \\
\text { groundwater transport modeling } \\
\text { case is discussed. }\end{array}$ & $\begin{array}{l}\text { Indirect } \\
\text { Input }\end{array}$ \\
\hline $\begin{array}{l}\text { BSC (Bechtel SAIC Company) } 2004 . \\
\text { Q-List. 000-30R-MGR0-00500-000-000 } \\
\text { REV 00. Las Vegas, Nevada: Bechtel } \\
\text { SAIC Company. } \\
\text { ACC: ENG.20040721.0007. } \\
\text { 168361 }\end{array}$ & Entire & Section 2 & $\begin{array}{l}\text { The disruptive events FEPs } \\
\text { documented in this report involve } \\
\text { the investigations of items or } \\
\text { barriers on the Q-list. }\end{array}$ & $\begin{array}{l}\text { Indirect } \\
\text { Input }\end{array}$ \\
\hline
\end{tabular}


Table B-1. Table of Indirect Inputs for Included and Excluded Features, Events, and Processes (Continued)

\begin{tabular}{|c|c|c|c|c|}
\hline Document Source & $\begin{array}{l}\text { Citation } \\
\text { from } \\
\text { Source }\end{array}$ & $\begin{array}{l}\text { Direct Use } \\
\text { In }\end{array}$ & Description & $\begin{array}{l}\text { Input } \\
\text { Category }\end{array}$ \\
\hline \multirow{7}{*}{$\begin{array}{l}\text { BSC (Bechtel SAIC Company) } 2004 . \\
\text { The Development of the Total System } \\
\text { Performance Assessment-License } \\
\text { Application Features, Events, and } \\
\text { Processes. TDR-WIS-MD-000003, } \\
\text { Rev. 01. Las Vegas, Nevada: Bechtel } \\
\text { SAIC Company. } \\
168706\end{array}$} & Entire & $\begin{array}{l}\text { Sections } 1.2 \\
6.1,6.1 .6,7\end{array}$ & $\begin{array}{l}\text { Describes the TSPA-LA FEP } \\
\text { identification and screening } \\
\text { process that led to the } \\
\text { development of the LA FEP list }\end{array}$ & $\begin{array}{l}\text { Indirect } \\
\text { Input }\end{array}$ \\
\hline & Section 3 & Section 6.1 .1 & $\begin{array}{l}\text { The TSPA-LA FEP identification } \\
\text { classification process is described. }\end{array}$ & $\begin{array}{l}\text { Indirect } \\
\text { Input }\end{array}$ \\
\hline & Section 4 & Section 6.1 .2 & $\begin{array}{l}\text { The TSPA-LA FEP screening } \\
\text { process is described. }\end{array}$ & $\begin{array}{l}\text { Indirect } \\
\text { Input }\end{array}$ \\
\hline & $\begin{array}{l}\text { Section } \\
4.1 .3 .3\end{array}$ & Section 4.1 & $\begin{array}{l}\text { Definitions and concepts (e.g., } \\
\mathrm{RMEl} \text { is located no closer than } 18 \\
\mathrm{~km} \text { to the south in the direction of } \\
\text { groundwater flow and over a } \\
\text { contaminated groundwater plume). }\end{array}$ & $\begin{array}{l}\text { Indirect } \\
\text { Input }\end{array}$ \\
\hline & $\begin{array}{l}\text { Section } \\
4.1 .3 .2\end{array}$ & Section 4.1 & $\begin{array}{l}\text { Requirements (e.g., the reference } \\
\text { biosphere must be consistent with } \\
\text { present knowledge of conditions in } \\
\text { the region, and changes in the } \\
\text { biosphere [other than climate] from } \\
\text { conditions at the time of license } \\
\text { application submittal should not be } \\
\text { projected. Also, the geologic } \\
\text { setting [geology, hydrology, and } \\
\text { climate] may evolve based upon } \\
\text { cautious but reasonable } \\
\text { assumptions, consistent with } \\
\text { present knowledge of factors that } \\
\text { could affect the system in the next } \\
10,000 \text { years). }\end{array}$ & $\begin{array}{l}\text { Indirect } \\
\text { Input }\end{array}$ \\
\hline & Section 4.1.3 & Section 4.1 & $\begin{array}{l}\text { Regulatory definitions and } \\
\text { elucidation of the regulatory } \\
\text { concepts pertaining to the } \\
\text { reference biosphere, geologic } \\
\text { setting, REMI, and human intrusion } \\
\text { are explained in detail. }\end{array}$ & $\begin{array}{l}\text { Indirect } \\
\text { Input }\end{array}$ \\
\hline & Table 6-2 & Section 4.1 & $\begin{array}{l}\text { Subsequent additions to or } \\
\text { changes from that FEP list } \\
\text { (numbers, names, or descriptions) } \\
\text { are reflected in Section } 6.2 \text { and } \\
\text { can be traced through the FEP } \\
\text { History File in the FEP database. } \\
\end{array}$ & $\begin{array}{l}\text { Indirect } \\
\text { Input }\end{array}$ \\
\hline \begin{tabular}{|l|} 
BSC (Bechtel SAIC Company) 2004. \\
Development of Seismic Inputs, \\
Preparation of Seismic Topical Reports, \\
and Evaluation of Disruptive Events \\
Features, Events, and Processes. \\
TWP-MGR-GS-000001 REV 03 ICN \\
01. Las Vegas, Nevada: Bechtel SAIC \\
Company. ACC: DOC.20040601.0001. \\
169886
\end{tabular} & Section 8.1 & $\begin{array}{l}\text { Section } 2, \\
\text { Section } 4.2\end{array}$ & $\begin{array}{l}\text { Applicable controls for the } \\
\text { electronic management of data }\end{array}$ & $\begin{array}{l}\text { Indirect } \\
\text { Input }\end{array}$ \\
\hline
\end{tabular}


Table B-1. Table of Indirect Inputs for Included and Excluded Features, Events, and Processes (Continued)

\begin{tabular}{|c|c|c|c|c|}
\hline Document Source & $\begin{array}{l}\text { Citation } \\
\text { from } \\
\text { Source }\end{array}$ & $\begin{array}{l}\text { Direct Use } \\
\text { In }\end{array}$ & Description & $\begin{array}{l}\text { Input } \\
\text { Category }\end{array}$ \\
\hline & Entire & Section 1.1 & $\begin{array}{l}\text { General reference to the } \\
\text { controlling planning document }\end{array}$ & $\begin{array}{l}\text { Indirect } \\
\text { Input }\end{array}$ \\
\hline & $\begin{array}{l}\text { Sections } 4.1 \\
8.1\end{array}$ & Section 2 & Applicable QA procedures & $\begin{array}{l}\text { Indirect } \\
\text { Input }\end{array}$ \\
\hline $\begin{array}{l}\text { BSC (Bechtel SAIC Company) } 2004 . \\
\text { Engineered Barrier System Features, } \\
\text { Events, and Processes. ANL-WIS-PA- } \\
\text { 000002, Rev. 03. Las Vegas, Nevada: } \\
\text { Bechtel SAIC Company. } \\
169898\end{array}$ & Entire & $\begin{array}{l}\text { Sections } \\
6.2 .1 .2 \\
6.2 .1 .3 \\
6.2 .1 .6\end{array}$ & $\begin{array}{l}\text { Fault displacement - shared FEP } \\
\text { seismic consequence fault } \\
\text { displacement and ground motion. }\end{array}$ & $\begin{array}{l}\text { Indirect } \\
\text { Input }\end{array}$ \\
\hline $\begin{array}{l}\text { BSC (Bechtel SAIC Company). } \\
\text { Qualification of Igneous Inputs to } \\
\text { Features, Events, and Processes: } \\
\text { Disruptive Events. TDR-WIS-PA- } \\
\text { 000013 REV 00. Las Vegas, Nevada: } \\
\text { Bechtel SAIC Company. } 171999\end{array}$ & Entire & Section 6.1 .4 & $\begin{array}{l}\text { Qualification of extent of volcanic } \\
\text { surge deposits. }\end{array}$ & $\begin{array}{l}\text { Indirect } \\
\text { Input }\end{array}$ \\
\hline
\end{tabular}




\section{INTENTIONALLY LEFT BLANK}


APPENDIX C

QUALIFICATION OF EXTERNAL SOURCES 


\section{APPENDIX C \\ QUALIFICATION OF EXTERNAL SOURCES}

Per AP-SIII.9Q, Scientific Analyses, this appendix documents the justification of the following reference identified as direct input in this report (see Appendix A, Table A-1). The National Research Council (1992 [DIRS 105162) is identified as unqualified data from an outside source. These data are qualified in this appendix for intended use per criteria in AP-SIII.9Q (Section 5.2.1 1).

\section{NATIONAL RESEARCH COUNCIL 1992}

Reference-National Research Council. 1992. Ground Water at Yucca Mountain, How High Can It Rise? Final Report of the Panel on Coupled Hydrologic/Tectonic/Hydrothermal Systems at Yucca Mountain. Washington, D.C.: National Academy Press. TIC: 204931. DIRS: 105162].

Description of Use-The National Research Council (1992 [DIRS 105162]) reference provides the basis for excluding the FEP related to potential water level rise due to seismic pumping. Alternative perspectives on seismic pumping and water-level changes are discussed in the Final Environmental Impact Statement (DOE 2002, p. 3-59 [DIRS 155970]), which cites the work by the National Research Council. The panel reviewed the alternative conceptual model and concluded that it was infeasible.

Extent to which the Data Demonstrate the Properties of Interest-Seismic pumping and water-level changes are discussed in a report prepared by the Panel on Coupled Hydrologic/Tectonic/Hydrothermal Systems at Yucca Mountain, commissioned by the National Research Council (NRC). The panel reviewed an alternative conceptual model that predicted large changes in water level, and concluded that it was infeasible. The panel went on to state that seismic pumping would at most elevate the water-levels a few tens of meters (Ground Water at Yucca Mountain: How High Can It Rise? Page 7).

Qualifications of Personnel or Organizations Generating Data-The project that is the subject of this report was approved by the Governing board of the National Research Council, whose members are drawn from the councils of the National Academy of Sciences, the National Academy of Engineering, and the Institute of Medicine. The members of the committee responsible for the report were chosen for their special competences and with regard for appropriate balance. This report has been reviewed by a group other than the authors according to procedures approved by a Report Review Committee consisting of members of the National Academy of Sciences, the National Academy of Engineering, and the Institute of Medicine.

\section{Panel On Coupled Processes At Yucca Mountain:}

C. Barry Raleigh, University Of Hawaii, Chairman

George A. Thompson, Stanford University, Vice-Chairman

William F. Brace, Massachusetts Institute Of Technology (Ret.)

Barry H. G. Brady, Dowell-Schlumberger

John D. Bredehoeft, U. S. Geological Survey

Raymond M. Burke, Humboldt State University 
Robert O. Fournier, U. S. Geological Survey

Sabodh K. Garg, S-Cubed

George M. Hornberger, University Of Virginia

Robin K. Mcguire, Risk Engineering, Inc.

Amos M. Nur, Stanford University

H. J. Ramey, Stanford University

Edwin W. Roedder, Harvard University

Douglas Rumble, Geophysical Laboratory, Carnegie Institution Of Washington

W. Geoffrey Spaulding, Dames \& Moore

Brian P. Wernicke, California Institute Of Technology

Mary Lou Zoback, U. S. Geological Survey

Reliability of Data Source-The report was published by the National Academies Press (NAP). The National Academies Press was created by the National Academies to publish the reports issued by the National Academy of Sciences, the National Academy of Engineering, the Institute of Medicine, and the National Research Council, all operating under a charter granted by the Congress of the United States. NAP publishes over 200 books a year on a wide range of topics in science, engineering, and health, capturing the most authoritative views on important issues in science and health policy. The institutions represented by NAP are unique because they attract the nation's leading experts in every field to serve on their blue ribbon panels and committees.

The National Academy of Sciences is a private, nonprofit, self-perpetuating society of distinguished scholars engaged in scientific and engineering research and dedicated to the furtherance of science and technology and to their use for the general welfare. Upon the authority of the charter granted to it by the Congress in 1863, the Academy has a mandate that requires it to advise the federal government on scientific and technical matters.

The National Research Council was organized by the National Academy of Sciences in 1916 to associate the broad community of science and technology with the Academy's purposes of furthering knowledge and of advising the federal government. Functioning in accordance with general policies determined by the Academy, the Council has become the principal operating agency of both the National Academy of Sciences and the National Academy of Engineering in providing services to the government, the public, and the scientific and engineering communities. The Council is administered jointly by both Academies and the Institute of Medicine. 


\section{APPENDIX D}

\section{GLOSSARY}




\section{APPENDIX D \\ GLOSSARY}

annual exceedance probability-The probability that a specified value (such as for ground motions or fault displacement) will be exceeded during one year.

aperture-The gap between two walls or faces of a fracture.

ash flow-A density current, generally a hot mixture of volcanic gases and tephra that travels across the ground surface. The solid materials contained in a typical ash flow are generally unsorted and ordinarily include volcanic dust, pumice, scoria, and blocks in addition to ash.

ash fall-Airborne ash that falls from an eruption cloud, and the resulting deposit.

asperity-A measure of the roughness of the area of contact between two surfaces of a fracture.

background earthquake-An earthquake that does not produce ground breakage, hence is not associated with a known fault. Such earthquakes are considered to be random in time and space. In the Great Basin, background earthquakes have magnitudes of less than 6.0.

basalt-A dark-colored, fine-grained volcanic or intrusive rock (dike or sill intrusion) consisting chiefly of calcic plagioclase, pyroxene, and olivine.

base level-The theoretical lowest level toward which erosion progresses, considered practically as the level below which a stream cannot erode its bed.

blind fault-A fault that dies out in bedrock and is not exposed at earth's surface.

block faulting-Segmentation of the crust into block-like masses by systematic normal faulting.

caldera complex-An assemblage of extrusive and intrusive rocks and associated structures generated by explosive and effusive volcanism that comprise a number of genetically related overlapping or adjacent or proximal calderas.

caliche-A calcareous soil component typically forming friable to hard, off-white, crudely layered to finely laminated intervals near the surface of stony desert soils; several $\mathrm{cm}$ or more thick. Old, thick caliche intervals (calcretes) have the texture and hardness of concrete aggregate.

colluvial slope-A hill slope mantled with loose, heterogeneous soil and rock fragments that are the result of weathering and accumulation by creep and unchanneled snow melt or runoff.

conduit-The vertical or subvertical, essentially cylindrical, tube that brings magmatic material to land surface. Conduit is the appropriate term regarding the subsurface, and PA conceptual models emphasize the interactions that occur at the intersection of a conduit with the repository.

Crater Flat tectonic domain-A tectonic domain is a block of the Earth's crust bounded by major faults or zones of complex shear and deformation. A domain features a history and styles 
of deformation that distinguish it from adjacent areas of the crust. The Crater Flat domain includes Yucca Mountain and is characterized by normal faulting into the Crater Flat basin which lies immediately to the west of Yucca Mountain.

debris flow-A moving mass of rock fragments and mud, comprised mostly of fragments larger than sand size; water-mobilized colluvium; also the deposit of such a flow.

detachment faulting-A style of normal faulting wherein large, extensional displacement occurs on a fault plane that dips less than $30^{\circ}$. In places, the lower plates (footwalls) of detachment faults have been uplifted from mid-crustal depths, implying that detachment is accompanied by significant isostatic uplift or uplift by magmatic inflation.

dike-A tabular intrusion of magma that is at a high angle to layering in the intruded strata (i.e., vertical or subvertical at Yucca Mountain).

dike system-One or more dikes that are closely related in space and time. Dike systems may include multiple dikes that share a common magmatic source with a single volcano. This definition does not preclude the possibility that a dike system may feed more than one volcano.

dip-slip faulting-Faulting in which the hanging wall moves down the dip of the fault plane. Normal faulting has slip directly along the dip normal to the strike of the fault; oblique faulting has a component of slip parallel to the fault strike (i.e., some lateral displacement).

disruptive FEP-An Included FEP that has a probability of occurrence during the period of performance less than 1.0 (but greater than the cutoff of $10^{-4} / 10^{4}$ year).

disruptive event scenario class-The scenario class, or set of related scenarios classes, that describes the behavior of the system if perturbed by disruptive events. The disruptive scenario classes contain all disruptive FEPs that have been retained for analysis.

eruptive event (with respect to repository performance)-The formation of a volcano that includes at least one subsurface conduit that intersects a drift containing waste packages.

event-A natural or human-caused phenomenon that has the potential to affect disposal-system performance and that occurs during an interval that is short compared to the period of performance.

Excluded FEP-A FEP that is identified by the FEP screening process as not requiring modeling in the quantitative TSPA.

expected FEP-An Included FEP that, for the purposes of the TSPA, is presumed to occur with a probability equal to 1.0 during the period of performance.

extrusive event (with respect to repository performance)-Synonymous with eruptive event.

faulting-Process of fracture and attendant slip along a fracture plane or recurrent slip along such a plane. 
fault strand-A fault segment expressed as a continuous intersection with the earth's surface, as indicated by a scarp, scarp line, or series of exposed displacement features, all having the same style of offset. A fault strand is generally taken to connote a relatively short fault segment or "splay" that is one of a series of many faults that together form the principal fault zone. The zone is usually not straight and well developed, and faults may bifurcate or anastomose or step over from one fault to another. Slip can be transferred across many strands.

feature-An object, structure, or condition that has a potential to affect disposal-system performance.

flowing interval-A fracture or fractured zone that transmits flow in the SZ.

folding-Bending in strata. Formation of folds expressed by geometric features that include fold limbs, fold axes, and axial planes. Large or systematic compressive and drag folds are results of tectonic activity.

fracture-A brittle crack in rock. Groups of fractures in more or less regular orientation and spacing are termed joints. Fractures form by bending (shear joints) or tension or principal stress reduction (extension joints). Cooling joints are formed by tension exerted by contraction as an intrusive or extrusive volcanic rock cools.

future-A single, deterministic representation of the future state of the system. An essentially infinite set of futures can be imagined for any system.

geodetic strain rate-Regional strain rate determined at the earth's surface by repeated measurement of displacements of precisely located landmarks (monuments) embedded in the deforming medium.

geologic setting-The geologic, hydrologic, and geochemical systems of the region in which a geologic repository is or may be located.

geothermal gradient-The rate of increase of temperature with depth in the earth

heat flow-The amount of heat energy leaving the earth's crust, measured in Heat Flow Units (HFU) or calories $/ \mathrm{m}^{2} / \mathrm{sec}$.

hydrovolcanic eruption-Very energetic explosive eruptions triggered by the rapid mixing of ground or surface water with rising magma eruptions. Rather than formation of scoria cones by ballistic deposition, tephra and lithic clasts are deposited as fallout and pyroclastic density currents leaving surge deposits and typically forming wide, shallow tuff rings.

igneous activity-Any process associated with the generation, movement, emplacement, or cooling of molten rock within the earth or on the earth's surface.

Included FEP-A FEP that is identified by the FEP screening process as requiring analysis in the quantitative TSPA. 
intrusive event (with respect to repository performance)-An igneous structure (such as a dike, dike system, or other magmatic body in the subsurface) that intersects the repository footprint at the repository elevation.

key block-Critical blocks formed in the rock mass surrounding an excavation (by the intersection of three or more planes of structural discontinuity). These blocks are capable of displacement so that they are likely to move into the drift opening unless restraint is provided.

lithophysae-A subrounded cavity from about one to several $\mathrm{cm}$ in diameter formed in silicic volcanic rocks (e.g., welded tuff) by gas bubbles evolved during cooling; lithophysae are typically lined or largely filled with finely crystalline or cryptocrystalline rinds of secondary, vapor-phase minerals.

maar-A low-relief, broad volcanic crater formed by shallow explosive eruptions. The explosions are usually caused by the heating and boiling of groundwater resulting from magma invading the groundwater table.

magma-Partially or completely molten rock within the earth's crust or mantle.

magmatic inflation-Uplift of the crust caused by intrusion of subjacent magma, which can occur due to large-volume batholithic melts, dike swarms, or lower crustal magmatic underplating.

mantle-The zone of the earth below the crust and above the core, typified by high seismic velocity and dense iron- and magnesium-rich silicate mineral components.

mantle plume-A large mass of molten mantle material rising up from the lower mantle into the base of the crust by the process of convection and buoyancy. Mantle plumes are typically hundreds of $\mathrm{km}$ in area.

Miocene-Epoch of the Tertiary Period between $24 \mathrm{Ma}$ and $5 \mathrm{Ma}$.

modeling case-A well-defined, connected sequence of FEPs that can be thought of as an outline of a future condition of the repository system. Modeling cases can be undisturbed, in which case the performance would be the expected, or nominal, behavior for the system. Modeling cases can also be disturbed, if altered by disruptive events such as human intrusion or natural phenomena such as volcanism, seismicity, or nuclear criticality.

nominal scenario class-The scenario class, or set of related scenarios classes, that describes the expected or nominal behavior of the system as perturbed only by the presence of the repository. The nominal scenario class contains all expected FEPs that have been retained for analysis.

nonwelded unit-A volcanic ash, or tuff, that is crumbly or easily excavated because the component glass shards did not weld together during compaction of relatively cool ash or ash having relatively sparse glass content.

paleoseismic slip-The amount of fault slip indicated by buried offset strata; individual paleoearthquakes are indicated by discrete amounts of offset. 
percolation flow-Flow of groundwater through small, interconnected rock or soil pores.

playa-A dried lake bed. Playas have, typically, a flat, salty surface that forms the low part of a confined desert basin.

Pleistocene-The epoch of the Quaternary Period from about 1.6 Ma to $10 \mathrm{Ka}$.

Plio-Pleistocene-Combined duration of the Pliocene and Pleistocene epochs of the Cenozoic era, from $10 \mathrm{Ka}$ to $5 \mathrm{Ma}$.

potentiometric surface-A notional surface representing the total head of groundwater as defined by the level at which such water stands in a well. The water table is a particular type of potentiometric surface pertaining to an unconfined aquifer in which the surface is in equilibrium with atmospheric pressure.

process - A natural or human-caused phenomenon that has the potential to affect disposal-system performance and that operates during all or a significant part of the period of performance.

pumice-Highly vesicular or frothy siliceous glass formed during volcanic eruption; typically a pale gray color.

pumiceous-Having observable pumice content.

pyroclastic-Pertaining to clastic rock material formed by volcanic explosion or aerial expulsion from a volcanic vent.

Quaternary-The period of the Cenozoic Era from 1.6 Ma to present includes the Pleistocene and Holocene Epochs.

reference biosphere-The description of the environment inhabited by the reasonably maximum exposed individual (RMEI). The reference biosphere comprises the set of specific biotic and abiotic characteristics of the environment, including but not necessarily limited to, climate, topography, soils, flora, fauna, and human activities.

regional slope-The surface defined by the elevations of resistant peaks in a given area; it approximates the surface formed by uplift prior to erosional incision.

regional subsidence-Broad depression of the earth's surface resulting from tectonic activity such as extension, crustal cooling, or deep crustal or mantle flow.

regional uplift-Broad elevation of the earth's surface resulting from tectonic activity such as compression or igneous intrusion.

rockburst-A sudden and often violent failure of masses of rocks in quarries, tunnels, or mines. It is an uncontrolled disruption of rock associated with a violent release of energy additional to that derived from falling rock fragments. 
scenario class $-A$ set of related modeling cases that share sufficient similarities that they can usefully be aggregated for the purposes of screening or analysis. The number and breadth of scenario classes depends on the resolution at which modeling cases have been defined. Coarsely defined modeling cases result in fewer, broad scenario classes, whereas narrowly defined modeling cases result in many narrow scenario classes. Scenario classes (and modeling cases) should be aggregated at the coarsest level at which a technically sound argument can be made, while still maintaining adequate detail for the purposes of analysis.

seismic activity-The recurrence and distribution of earthquakes associated with a specified seismic source.

seismicity-The capacity of a fault, group of faults, or region of the crust to generate earthquakes, as determined by instrumental or paleoseismic history; the relative rate at which earthquakes recur (syn. seismic activity).

springline-The imaginary line at which an arch, vault, or drift begins to curve; for circular cross-sections, this corresponds to the vertical mid-point along the drift wall.

strain rate-The rate at which a unit of length is shortened or lengthened under a stress load, usually given in terms of inverse seconds. Strain rate is often expressed in units of $\mathrm{mm} / \mathrm{yr}$ where an actual length difference rather than a ratio is calculated.

strand-See fault strand.

stream gradient-Angle between inclination of a stream channel bed and the horizontal measured in direction of flow (i.e., the "slope" of a stream).

subducting slab-A section of oceanic (basaltic) crust in process of being drawn down into the upper mantle by tectonic forces as crustal plates interact.

tectonic activity-The dynamic manifestation of stress loads generated within the earth's crust (e.g., igneous intrusion, earthquakes, uplift).

tectonic deformation-The suite of geological structures generated by body stresses exerted within the earth's crust; such structures range in scale from microscopic (e.g., mylonite fabric) to regional (e.g., overthrust belts). Also, the process by which such structures together is formed.

tectonic extension-Stretching or extension of the crust as a result of deep-seated tectonic stress, such as back-arc spreading.

tectonic process-The dynamic evolution of structure generated through the buildup and relaxation of regional stress.

tectonism-All movement of the crust produced by tectonic processes, including mountain building (orogeny), regional uplift and subsidence; the general expression of tectonic process through time and space. 
tephra-A collective term used for all pyroclastic material, regardless of size, shape, or origin, ejected during an explosive volcanic eruption. Originally applied exclusively to fallout ejecta, but now also applies to pyroclastic flow deposits.

terrain relief-For some defined area of the earth's surface, it is the measure of difference between the lowest local elevation and the highest local elevation.

topography-The physical features of a district or region, such as are represented on maps, taken collectively; especially the relief and contour of the land.

Type I fault-Faults or fault zones that are subject to displacement and are of sufficient length and location that they may affect repository design or performance.

vent-The intersection of a conduit with land surface. Volcanoes may have more than one vent.

violent strombolian eruption-volcanic eruptions with violent blasts that project voluminous showers of scoria and bombs to heights of hundreds or thousands of feet, accompanied by a dense black ash cloud. Violent strombolian eruptions are characterized by vertical eruption of a high-speed jet of a gas-clast mixture.

volcanic activity-The suite of events and processes associated with extrusion of molten rock, such as eruption, lava emission, or cone formation comprising the subaerial components of igneous activity.

volcanic event-The formation of a volcano (with one or more vents) resulting from the ascent of basaltic magma through the crust as a dike or system of dikes.

volcano-A geologic feature that includes an edifice of magmatic material erupted on the land surface, a conduit that feeds the eruption, and a dike that feeds the conduit.

water table-The surface of unconfined groundwater at which the pressure is equal to that of the atmosphere.

welded unit-A volcanic ash, or tuff, that is strongly indurated because hot glass shards were partially melted together (welded) during compaction of the ash bed while the ash was still hot. 


\section{INTENTIONALLY LEFT BLANK}


ILLEGIBILITY STATEMENT

The illegibility and/or cutoff information does nor impact the technical meaning or content of the record or create a condition adverse to quality.

$\frac{\text { Annal Gilman }}{\text { Denise Gibson }}$

$\frac{11 / 05 / 2004}{\text { Date }}$ 